\title{
Infrastructure implications of a Green Economy Transition in the Western Cape Province of South Africa: A system dynamics modelling approach
}

by

\author{
T. A. York
}

Thesis presented in partial fulfilment of the requirements for the degree of Master of Engineering in the Faculty of Engineering at Stellenbosch University

Department of Industrial Engineering, University of Stellenbosch,

Private Bag X1, Matieland 7602, South Africa.

Supervisor: Prof. A.C. Brent

Co-supervisor: Dr. J.K. Musango

December 2015 


\section{Declaration}

By submitting this thesis electronically, I declare that the entirety of the work contained therein is my own, original work, that I am the sole author thereof (save to the extent explicitly otherwise stated), that reproduction and publication thereof by Stellenbosch University will not infringe any third party rights and that I have not previously in its entirety or in part submitted it for obtaining any qualification.

Date:

Copyright (C) 2015 Stellenbosch University All rights reserved. 


\title{
Abstract
}

\section{Infrastructure implications of a Green Economy Transition in the Western Cape Province of South Africa: A system dynamics modelling approach}

\author{
T.A. York \\ Department of Industrial Engineering, \\ University of Stellenbosch, \\ Private Bag X1, Matieland 7602, South Africa. \\ Thesis: MEng (Industrial) \\ September 2015
}

This study investigated the infrastructure implications of a green economy transition in the Western Cape with particular focus on the transport sector. Within South African context, a green economy transition is recognised as one of the key pathways towards achieving an environmentally sustainable, resource efficient, low-carbon economy and just society. In response to the call of achieving a green economy transition, interdisciplinary, integrated approaches to the management and design of infrastructures across all sectors is required. This provided the backdrop in which the research took place and the reasons for this investigation being conducted.

With the examination of various literature relating to transition theories and management practices involved in such a problem, an understanding of the complex systems involved in such a transition enabled an appropriate method of analysis to be developed for the research problem. Utilising a system dynamics modelling approach, the research effort aimed to improve understanding, and develop the associated capacities, of how technical, economic, political, social and environmental factors interact, particularly in the context of the uncertainties encountered during this transition. A framework from which the processes and methods involved in the system dynamics technique was identified and described, including the manner in which the model was built and the theoretical grounds on which it stands. From this it was possible to illustrate the important relationships existing between various components of the system. The subsequent implications of the decisions to be made by managerial 
bodies with regards to the study were disclosed in the form of recommendations to the various stakeholders in order to aid the decision making process.

The use of System Dynamics Modelling for the investigation of the infrastructure implications of a green economy transition in the Western Cape provided a holistic manner in which to conceptualise and simulate the complexities of the problem. The ease of creation and its flexibility with regards to simulating dynamic behaviours made it a robust form of modelling. The key findings of the research indicated that through the investment into a better public transport system as well as shifting the movement of freight onto the rail network there would be long term positive effects environmentally, socially and economically. These included reduced truck and private vehicle numbers on the roads resulting in better road conditions, lower traffic densities, lower $\mathrm{CO}_{2}$ emissions and reduced diesel and petrol demand within the province. The combination of the two major intervention strategies of public transport and rail freight yielded a significant reduction in emissions from the transport sector, of up to $17.89 \%$ compared to the business as usual scenario. Through the aid of simulation, decision-making based on accurate representations of the future effects of strategies was made possible. It can be concluded that reaching a sustainable green economy in the Western Cape is possible and the implications of such a transition on transport infrastructure are manageable and achievable through strategic development. 


\title{
Uittreksel
}

\section{Die implikasies van 'n groen ekonomie oorgangsproses op die infrastruktuur van die Wes-Kaap Provinsie van Suid-Afrika : 'n stelsel dinamika benadering}

\author{
("Infrastructure implications of a Green Economy Transition in the Western Cape
} Province of South Africa: A system dynamics modelling approach")

\author{
T.A. York \\ Departement Bedryfsingenieurswese, \\ Universiteit van Stellenbosch, \\ Privaatsak X1, Matieland 7602, Suid Afrika. \\ Tesis: MIng (Bedryfs) \\ September 2015
}

Hierdie studie ondersoek die gevolge wat die oorgangsproses na 'n groen ekonomie sal inhou, met die klem spesifiek op die infrastruktuur van die Wes-Kaapse vervoersektor. So 'n groen oorsgangs proses word beskou as een van die belangrikste maniere waarop Suid-Afrika 'n samelewing sal kweek wat gestel is op omgewingsvolhoubaarheid, doeltreffende hulpbron gebruik, lae-koolstof ekonomiese aktiwiteite sowel as regverdigheid. Die oorgangsproses tot 'n groen ekonomie vereis 'n interdisiplinre en geintegreerde benadering tot die bestuur en ontwerp van infrasturktuur. Hierdie studie is uitgevoer met die oog om hierdie vereistes aan te spreek.

'n Ondersoek van akademiese literatuur rakende so 'n oorgangsproses en die bestuurs praktyke wat daarmee gepaard gaan, het gelei tot die begrip van die gekompliseerde stelsels in die oorgang tot 'n groen ekonomie. Dit het gelei tot die ontikkeling van 'n toepaslike analiseringsmetode vir die probleme wat geassosieer word met die oorgang. Stelsel dinamika modellering het gelei tot 'n beter begrip van die interaksie tussen tegniese, ekonomiese, politieke en ander sosio-ekologiese faktore wat met 'n groen ekonomie verband hou. Hierdie proses mik spesifiek om die onsekerhede tydens die oorgang na 'n goen ekonomie aan te spreek. 'n Raamwerk wat die prosesse en metodes van stelsel dinamika modellering beskryf is ondersoek waarby die wyse waarop die model gebou is en die teoretiese werking daarvan, ingesluit word. Belangrikke verwantskappe tussen verskillende komponente en daaropvolgende implikasies 
kon uitgewys word. Aanbevelings met betrekking tot ingeligte besluite wat uiteindelik deur die bestuursliggame en belanghebbendes gemaak moet word, word in die studie bekendgemaak.

Met behulp van die stelsel dinamika model kon die kompleksiteit van die inplikasies van 'n oorgang na 'n groen ekonomie op die infrastruktuur in die Wes-Kaap uitgewys word. 'n Vermindering in die hoeveelheid swaarvortuie sowel as privaat motors op paaie sal lei tot verbeterde padtoestande, laer verkeersdigtheid, verlaagte $\mathrm{CO}_{2}$ vrystelling en 'n verlaging in die brandstof aanvraag word hierby ingesluit. Dit is bewys dat die doelbewuste gebruik van publieke en spoor vervoer in plaas van privaat vervoer, uitlaatgasse met tot $17.89 \%$ kan verminder. Akkurate simulasies en modelle kan dus 'n groot effek he op besluitneming rakende toekomstige strategi. Dus kan die gevolgtrekking gemaak word dat met behulp van 'n strategiese ontwikkelings plan, die nodige infrastruktuur en bestuur daarvan, 'n groen ekonomie in die Wes-Kaap bereikbaar is. 


\section{Acknowledgements}

I would like to express my sincere gratitude to the following people and organisations ...

- Professor Alan C. Brent, my supervisor for his constant support and advice.

- Dr. Josephine K. Musango, my co-supervisor for her advice and help throughout the model building process.

- The National Research Fund (NRF), for providing the necessary funding for my research.

- My family, for their constant support and wisdom. 


\section{Dedications}

This thesis is dedicated to my family past and present who have so positively influenced my life. 


\section{Contents}

Declaration $\quad$ i

Abstract

Uittreksel iv

Acknowledgements $\quad$ vi

Dedications vii

Contents viii

List of Figures $\quad$ xi

List of Tables $\quad$ xiv

Nomenclature $\quad$ xv

List of Acronyms . . . . . . . . . . . . . . . . . . . xv

List of Variables . . . . . . . . . . . . . . . . . . . . . . xvi

1 Introduction $\quad 1$

1.1 Transition to a Green Economy . . . . . . . . . . . . . . . . 1

1.2 Sustainable Development in the Western Cape . . . . . . . . . . 2

1.3 Infrastructure Development globally and in the Western Cape . 3

1.4 Rationale for the research . . . . . . . . . . . . . . 4

1.5 Research problem statement and research objectives . . . . . . . 4

1.6 Research Approach . . . . . . . . . . . . . . . . . . 6 6

1.7 Conclusion . . . . . . . . . . . . . . . . 7

2 Literature Survey \& Analysis $\quad 8$

2.1 Literature Analysis Methodology . . . . . . . . . . . . . 8

2.2 Western Cape transport infrastructure networks . . . . . . . . . 9

2.3 Sustainable Transport Indicators for the Western Cape . . . . . 12

2.4 Understanding Complex Systems . . . . . . . . . . . . . 15

2.5 Understanding Sustainable Transition Theory . . . . . . . . . . 17 
2.6 Modelling and simulating infrastructure transitions . . . . . . . 21

2.7 Discussion and critique of modelling approaches . . . . . . . . 27

2.8 Conclusion ......................... 31

3 Methodology 32

3.1 System Dynamics Modelling process . . . . . . . . . . . . 32

3.2 Problem Structuring . . . . . . . . . . . . . . . . . . . . . . 34

3.3 Causal loop modelling . . . . . . . . . . . . . . . . . . 38

3.4 Dynamic Modelling . . . . . . . . . . . . . . . . . . . . . . . . . . . . 44

3.5 Model Validation and testing . . . . . . . . . . . . . . . . . 55

3.6 Scenario planning and modelling . . . . . . . . . . . . . . 66

3.7 Implementation and organisational learning . . . . . . . . . . . 68

3.8 Conclusion of Methodology chapter . . . . . . . . . . . . . . 69

4 Analysis of Baseline and Scenario Results $\quad 70$

4.1 Western Cape Road Infrastructure Network . . . . . . . . . . . 70

4.2 Live Vehicle Population sub-module . . . . . . . . . . . . . . 72

4.3 Cape Metrorail Network and system sub-module . . . . . . . . . 74

4.4 Rail Freight Transport Network sub-module . . . . . . . . . . . 76

4.5 Freight Transport sub-module in the Western Cape . . . . . . . 79

4.6 Bus Rapid Transit network and system sub-module . . . . . . . 80

$4.7 \quad \mathrm{CO}_{2}$ emissions from Transport sector . . . . . . . . . . . . 82

4.8 Other Important Indicators to selected sub-modules . . . . . . . . 83

4.9 Green Economy Transport Investment sub-module . . . . . . . 86

4.10 Conclusion of Results analysis . . . . . . . . . . . . . . 88

5 Conclusions and Recommendations $\quad 89$

5.1 Business as Usual $(B A U)$ scenario conclusions . . . . . . . . . . 89

5.2 Passenger Transport $(S 1)$ scenario conclusions . . . . . . . . . . 91

5.3 Freight Transport (S2) scenario conclusions . . . . . . . . . . 92

5.4 Passenger \& Freight Transport (S3) scenario conclusions . . . . 94

5.5 Recommendations to stakeholders . . . . . . . . . . . . . 96

5.6 Model Limitations . . . . . . . . . . . . . . . . . . . . . . 100

5.7 Appropriateness of System Dynamics Modelling . . . . . . . . . 101

5.8 Future Research . . . . . . . . . . . . . . . . . . . . . . . 104

5.9 Concluding remarks . . . . . . . . . . . . . . . . . . . 105

$\begin{array}{ll}\text { List of References } & 107\end{array}$

$\begin{array}{lr}\text { Appendices } & 115\end{array}$

A Tables and figures as discussed in text $\quad 116$

A.1 Model Boundary describing all parameters of certain sub-modules

. . . . . . . . . . . . . . . . 116

A.2 Historical data input parameters for model validation . . . . . . 116 
B Stock and flow descriptions of Sub-models $\quad 120$

B.1 Western Cape Road Infrastructure Network Module . . . . . . . 122

B.2 Live Vehicle Population sub-module . . . . . . . . . . . . . . . . 124

B.3 Cape Metrorail Network and System sub-module . . . . . . . 126

B.4 Passenger Transport sub-module . . . . . . . . . . . . . . . . . . 128

B.5 Mainline Rail Freight Transport Network sub-module . . . . . . 130

B.6 Branchline Rail Freight Transport Network sub-module . . . . . 132

B.7 Western Cape Freight Transport demand sub-module . . . . . . 134

B.8 Bus Rapid Transit sub-module . . . . . . . . . . . . . . . . . . 137

B.9 $\mathrm{CO}_{2}$ emissions from transport for the Western Cape sub-module 139

B.10 Fuel Demand sub-module for the Western Cape . . . . . . . . . 141

B.11 Total Road Accidents for the Western Cape sub-module . . . . . 143

B.12 Western Cape Population sub-module . . . . . . . . . . . . . . . 145

B.13 GDP sub-module for the Western Cape . . . . . . . . . . . . . . 147

B.14 Green Economy Transport Investment sub-module . . . . . . . 149

$\begin{array}{ll}\text { C SDM-Documentaion of model structure } & 150\end{array}$

D Model Results 152

D.1 Western Cape Road Infrastructure Network Module . . . . . . . 152

D.2 Live Vehicle Population sub-module . . . . . . . . . . . . . . . . 156

D.3 Cape Metrorail Network and System sub-module . . . . . . . . 158

D.4 Western Cape Rail Freight Transport Network sub-module . . . 161

D.5 Western Cape Freight Transport demand sub-module . . . . . . 164

D.6 Bus Rapid Transit sub-module . . . . . . . . . . . . . . . . . . 165

D.7 $\mathrm{CO}_{2}$ emissions from transport for the Western Cape sub-module 166

D.8 Passenger Transport in the Western Cape . . . . . . . . . . . . 167

D.9 Fuel Demand sub-module for the Western Cape . . . . . . . . . 168

D.10 Total Road Accidents for the Western Cape sub-module . . . . . 169

D.11 Western Cape Population sub-module . . . . . . . . . . . . . . . 170

D.12 GDP sub-module for the Western Cape . . . . . . . . . . . . . . 171 


\section{List of Figures}

2.1 Graphical representation of a unidirected (a), a directed (b), and a weighted unidirected (c) graph with $N=7$ nodes and $K=14$ links (Boccaletti et al., 2006) . . . . . . . . . . . . . . 23

2.2 Typical attributes of an Agent (Macal and North, 2009) . . . . . . 24

3.1 Phases of systems thinking and modelling methodology, adapted from Maani and Cavana (2012) . . . . . . . . . . . . . 34

3.2 Population example of causal loop conceptualisation . . . . . . . . . 39

3.3 Causal Loop Diagram for the Transport Infrastructure Network in the Western Cape . . . . . . . . . . . . . . . . . . . . . . 41

3.4 Causal Loop Diagram for Passenger Transport Infrastructure in the Western Cape . . . . . . . . . . . . . . . . . . . . . 42

3.5 Causal Loop Diagram for the Freight Transport Infrastructure in the Western Cape . . . . . . . . . . . . . . . . . . . . . . . 43

3.6 Selected Road Freight corridors to illustrate behavioural reproduction in the model . . . . . . . . . . . . . . . . 60

3.7 Selected Metro Rail corridors to illustrate behavioural reproduction in the model . . . . . . . . . . . . . . . . . . . . . . 61

3.8 Sensitivity Analysis: Elasticity of Road Maintenance and Traffic on road life ...................... . . . 63

3.9 Sensitivity analysis: Elasticity of inter-and-intra-provincial freight movements to GDP growth on rail network . . . . . . . . . . . 64

3.10 Sensitivity analysis of key input variables for GE scenario predictions on the GE Transport Infrastructure Investment stock . . . . . 65

4.1 Total Motor Vehicle on Western Cape Roads . . . . . . . . . . . . . 71

4.2 Total Motor Vehicle on Western Cape Roads . . . . . . . . . . . . . 73

4.3 Total Cape Metro rail Network . . . . . . . . . . . . . . . . . . . 74

4.4 Western Cape rail Branch-line network . . . . . . . . . . . . . 77

4.5 Cost of Freight Rail . . . . . . . . . . . . . . . . . . . . 78

4.6 Bus Rapid Transit fleet size . . . . . . . . . . . . . . . . . . . 81

4.7 Bus Rapid Transit Project Expenditure . . . . . . . . . . . . . . . 82

4.8 Total $\mathrm{CO}_{2}$ emissions resulting from the transport sector . . . . . . . 83

4.9 Total Western Cape Petrol Demand . . . . . . . . . . . . . . . 86 
4.10 Total Green Economy Investment . . . . . . . . . . . . . . 87

5.1 Harris Curve adapted by De Bod and Havenga (2010) . . . . . . . . 94

5.2 Green Economy Transport Infrastructure Investment . . . . . . . . 95

A.1 Model Boundary . . . . . . . . . . . . . . . . . . . 117

B.1 Western Cape Road Infrastructure Network . . . . . . . . . . . . . 122

B.2 Live Vehicle Population in the Western Cape . . . . . . . . . . . . . 124

B.3 Cape Metrorail Network and System . . . . . . . . . . . . . . . 126

B.4 Passenger Transport in the Western Cape . . . . . . . . . . . . . 128

B.5 Mainline Rail Freight Transport Network . . . . . . . . . . . . . 130

B.6 Branchline Rail Freight Transport Network . . . . . . . . . . . . . 132

B.7 Rail Freight Transport demand in the Western Cape . . . . . . . . 134

B.8 Road Freight Transport demand in the Western Cape . . . . . . . 135

B.9 BRT system and fleet . . . . . . . . . . . . . . . . 137

B.10 $\mathrm{CO}_{2}$ emissions from transport for the Western Cape sub-module . . 139

B.11 Fuel Demand module for the Western Cape . . . . . . . . . . . . . 141

B.12 Total Road Accidents for the Western Cape sub-module . . . . . . 143

B.13 Western Cape Population sub-module . . . . . . . . . . . . . . . . 145

B.14 GDP sub-module for the Western Cape . . . . . . . . . . . . . . 147

B.15 Green Economy Transport Investment sub-module . . . . . . . . . 149

D.1 Western Cape Roads Under Construction . . . . . . . . . . . . . . . 152

D.2 Western Cape Road Infrastructure Expenditure . . . . . . . . . . . 153

D.3 Western Cape Road Disruption . . . . . . . . . . . . . . . . . 153

D.4 Western Cape pavement network conditions . . . . . . . . . . 154

D.5 Live Vehicle population per subscript group excluding motor cars . 156

D.6 Total Trucks on Western Cape Roads . . . . . . . . . . . . . . . . 157

D.7 Cape Metrorail upgrades and maintenance requirements . . . . . . 158

D.8 Cape Metrorail total passengers carried annually . . . . . . . . . 159

D.9 Cape Metrorail total fleet stock . . . . . . . . . . . . . . . . . . 159

D.10 Cape Metrorail maintenance and renewal costs . . . . . . . . . . . . 160

D.11 Cape Town-Gauteng mainline rail Freight Transport . . . . . . . . 161

D.12 Cape Town-Gauteng mainline rail network . . . . . . . . . . . . . 161

D.13 Western Cape branch-line rail maintenance and renewal costs . . . 162

D.14 Western Cape main-line rail maintenance and renewal costs . . . . 162

D.15 Western Cape Road Freight Transport along specified corridors . . 164

D.16 Cape Town BRT annual passengers carried . . . . . . . . . . . 165

D.17 Cape Town BRT vehicle acquisition expenditure . . . . . . . . . . 165

D.18 Cumulative $\mathrm{CO}_{2}$ emissions from the transport sector . . . . . . . . 166

D.19 Western Cape passenger transport modes . . . . . . . . . . . . . . 167

D.20 Western Cape Diesel Demand . . . . . . . . . . . . . . . . . . . 168

D.21 Total Road Accidents occurring on Western Cape roads . . . . . . . 169

D.22 Fatal Road accidents occurring on Western Cape roads . . . . . . . 169 
D.23 Western Cape Population . . . . . . . . . . . . . . . . . . 170

D.24 Western Cape GDP . . . . . . . . . . . . . . . . . . . 171 


\section{List of Tables}

1.1 Research outline and summary of chapters . . . . . . . . . . 7

2.1 Literature Review search variations . . . . . . . . . . . . . . . . 9

2.2 Sustainable transport indicators for Cape Town (City of Cape Town,

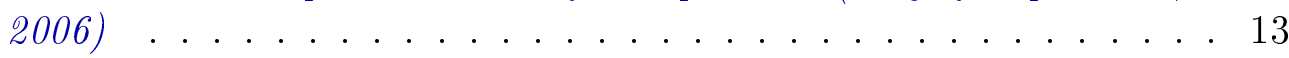

2.3 Benchmarking of different simulation techniques . . . . . . . . 30

3.1 The system dynamic modelling process across classic literature to current day, adapted from Luna-Reyes and Andersen (2003) . . . . 33

3.2 Western Cape Green Economy Strategies and Frameworks . . . . . 35

3.3 Information and Data sources used in the model . . . . . . . . . . . 37

3.4 Description of main parameters included in the aggregate CLD . . . 40

3.5 Summary of Model Settings . . . . . . . . . . . . . . . 45

3.6 System Dynamics 'core' confidence building tests (Maani and Cavana, 2012) \& (Forrester and Senge, 1980) . . . . . . . . . . 57

3.7 Description of scenarios for green economy infrastructure in the Western Cape . . . . . . . . . . . . . . . . 67

3.8 Key variables indicating the modal percentage changes required for a GE transition . . . . . . . . . . . . . . . . . . . 68

4.1 Western Cape pavement network conditions . . . . . . . . . . . 72

4.2 Cape Metrorail scheduled trains per service line . . . . . . . . . . . 75

4.3 Total Freight on Western Cape Branch-lines (tons/year) . . . . . . 76

4.4 Western Cape Road Freight Transport on specific corridors . . . . . 79

4.5 Modal splits of passenger transport modes . . . . . . . . . . . . 85

5.1 Green Economy Transport Infrastructure Investment . . . . . . . . 95 


\section{Nomenclature}

\section{List of Acronyms}

$\begin{array}{ll}\text { ABM } & \text { Agent Based Modelling } \\ \text { ACSA } & \text { Airports Company South Africa } \\ \text { BRT } & \text { Bus Rapid Transit } \\ \text { CAPEX } & \text { Capital Expenditure } \\ \text { CAS } & \text { Complex Adaptive System } \\ \text { CO } 2 & \text { Carbon Dioxide } \\ \text { CLD } & \text { Causal Loop Diagram } \\ \text { E80 } & \text { Equivalent heavy vehicle axle load } \\ \text { GE } & \text { Green Economy } \\ \text { GDP } & \text { Gross Domestic Product } \\ \text { GHG } & \text { Green House Gasses } \\ \text { IEA } & \text { International Energy Agency } \\ \text { IRT } & \text { Integrated Rapid Transit } \\ \text { LED } & \text { Local Economic Development } \\ \text { MLP } & \text { Multi-Level Perspective } \\ \text { NCCR } & \text { National Climate Change Response } \\ \text { NDP } & \text { National Development Plan } \\ \text { NMT } & \text { Non-Motorised Transport } \\ \text { OPEX } & \text { Operating Expenditure } \\ \text { SA } & \text { South Africa } \\ \text { SAGEM } & \text { South African Green Economy Model } \\ \text { SANRAL } & \text { South African National Roads Agency Limited } \\ \text { SD } & \text { System Dynamics } \\ \text { SDM } & \text { System Dynamics Modelling } \\ \text { SNM } & \text { Strategic Niche Management } \\ \text { TIS } & \text { Technological Innovations Systems } \\ \text { TM } & \text { Transition Management } \\ \text { UNEP } & \text { United Nation Environment Programme } \\ \text { WCED } & \text { World Commission on Environment and Development } \\ \text { WCG } & \text { Western Cape Government } \\ & \end{array}$




\section{List of Variables}

$\begin{array}{ll}R U C & \text { Roads Under Construction } \\ F R & \text { Functioning Roads } \\ L V & \text { Live Vehicle population of Western Cape } \\ R N & \text { Cape Metro Rail Network } \\ M F & \text { Cape Metro train fleet } \\ M L & \text { Cape Town - Gauteng Mainline network } \\ W C B L & \text { Western Cape Branch-line networks } \\ B R T & \text { Bus Rapid Transit fleet } \\ B R T_{E X P} & \text { BRT total expenditure } \\ C A E & \text { Cumulative Air Emissions } \\ G E I & \text { Green Economy Investment }\end{array}$




\section{Chapter 1}

\section{Introduction}

In the past decade, international recognition of the effects of climate change, environmental and ecological resource scarcities and increases in poverty have led to a growing consensus on the need for a transition towards a green economy. Identified as one of the key pathways towards achieving an environmentally sustainable, resource efficient, low-carbon economy and just society; the green economy transition has been recognised as a key development plan by the South African government. This transition requires trans-disciplinary, integrated approaches to the management and design of infrastructures across all sectors.

In order to meet future goals in reducing the resulting carbon emissions from municipal transport networks, a vast investment into the development of a more energy efficient and sustainable infrastructure is required. The frame work created by this model will provide realistic indicators of different strategies available to the municipality, including new innovations that are currently being developed. Included in this approach will be the important considerations of social, economic, political and technical issues that are critical to a more sustainable future.

\subsection{Transition to a Green Economy}

The United Nations Environmental Programme (UNEP) defines a green economy as one that results in improved human well-being and social equity, while significantly reducing environmental risks and ecological scarcities (UNEP, 2013). Put simply a green economy is one in which the growth in employment and income is governed by both private and public investments that aim to reduce carbon emissions and enhance energy and resource efficiency whilst protecting biodiversity and ecological services. With this, a green economy has the potential to address the pressing problems of unemployment, poverty, food and water security, energy sufficiency and environmental degradation. This 
provides an enticing incentive for developing countries to make such investments, however the capital required to do so, remains the crippling constraint governing the development of such endeavours. It is here that an integrated method of being able to predict outcomes including the costs and benefits of sustainable developments becomes important to the decision making processes involved both in private and public sector.

In response to the justified push towards a green economy transition, South Africa's Green Economy Accord recognised the potential to create sustainable and equitable jobs, agreeing to a goal of creating 300000 green jobs by 2020 (Economic Development Department, 2011). In response to this the Government set up the Green Economy Fund in 2012 with the allocation of 800 million Rand aiming to facilitate investments in green initiatives (Department of Environmental Affairs, 2012). These and many other policies and programmes attribute to a commitment by government to move towards a green economy, all that is required are incentivised and realistic initiatives that through accurate analysis have been proven to be attainable and equitable.

\subsection{Sustainable Development in the Western Cape}

The central emphasis of the transition to a Green Economy is the need to address climate change, the primary policy response to this is the National Climate Change Response (NCCR) White Paper (2011). The strategic priorities outlined in this document, provide the direction of action and responsibility for the different levels of government. Section 10.2.6 of the NCCR states that; "Each province will develop a climate response strategy, which evaluates provincial climate risks and impacts and seeks to give effect to the National Climate Change Response Policy at provincial level" (Department of Environmental Affairs, 2011). In response to this the Western Cape Government created the Western Cape Green Economy Strategy Framework with growth in green investments and market opportunities sitting at the core of the strategic framework.

Identified as a country leader in green initiatives, the Western Cape emphasises the need for their principle drivers to have the ability to deliver both economic activity and improved environmental performance (Western Cape Government, 2013). This framework aims to use the region's existing economic strengths to positively impact the lives of the poor and at the same time deliver results. Whilst this remains an attractive mode for transition, the responsibility falls onto municipalities that are required to plan and respond to climate change amidst the demanding challenges that the future holds. The 
South African LED Network (2010) identifies these challenges as being; limited skill development and capacity at a local level, persistent short-term needs diminishing already limited funds and the inability to predict with any certitude the necessary adaptions for future conditions. All of which form the setting of the emerging need to prepare municipalities towards a green economic transition, which is evidently one of great difficulty.

\subsection{Infrastructure Development globally and in the Western Cape}

Over the past decade a global emphasis on considerable change to reduce carbon emissions and improve economic efficiency in the transport sector has been made on many levels. This comes as no surprise as $22 \%$ of carbon emissions from fossil fuel combustion globally are derived from the transport sector (International Energy Agency, 2013). This in turn has led to Government emphasising the need to transform the current inefficient infrastructure system and invest in new innovations leading to more sustainable transportation. The Green Accord identifies the reduction of carbon-emissions on the roads as one of its key commitments, including large investments into improved mass transport systems and a shift to rail for freight transport (Economic Development Department, 2011). Thus the underlying need for more efficient infrastructure has been recognised by government on a national level; yet the area for tangible change remains at a smaller scale on a municipal basis; requiring not only policy development but also investment and implementation of sustainable measures.

The Western Cape Government through its green initiative has acknowledged a number of opportunities available for investment, such as; better transport planning, improved public transport as the crux, home-grown minibustaxi service innovations, efficiency in private transport, local development and adoption for cleaner energy for motor vehicles, and progressive infrastructure improvements for non-motorised transport (Western Cape Government, 2013). Additional developments including better design and maintenance of road infrastructure and improved land use planning would need to be acknowledged, stressing the importance of informal transport services meeting the needs of the urban poor in inaccessible areas at affordable prices (Figueroa et al., 2013). The demands on such services would require fuel subsidies and incentives for private vehicle owners to move towards more sustainable modes of transport. All of which are sound notions but still require a vast amount of insight into the complexity of the associations between these different initiatives on all levels. 


\subsection{Rationale for the research}

The rationale of this research relates to the development of the Western Cape Green Economy Strategy Framework and the green initiatives therein. One of the corner stones of this Framework is that of "Smart Mobility". This framework identifies that the transport sector of the Western Cape constitutes 10\% of the GDP and is a crucial enabler to the other sectors (Western Cape Government, 2013). However, due to the lack of efficiency with regards to cost, energy, emissions and lifestyle within the current transport configuration, a great need to develop a more sustainable system has risen. In this regard the ability to model the socio-economic, financial and technical implications of such drastic developments will greatly assist in the decision making processes of both private and public investment and implementation.

Analysis of this transition is a difficult progression, one that has to identify and dissect the complex relationships between social, economic, environmental and political counterparts. This has already been undertaken on a national basis in the modelling of the transition towards a green economy in South Africa. This analysis was carried out using an integrated model customised to South Africa, developed to investigate the contribution of technology policies to a green economy transition (Musango et al., 2010). The South African Green Economy Model (SAGEM) was primarily aimed at assessing the impacts of green investments across all sectors on a national basis. Studies have not yet been undertaken to critically analyse and assess the implications of green investments on a regional level, let alone with the focus on a specific sector. Therefore, together with the combined analysis of per sector investments, the critical assessment of the complex systems involved in the implementation of provincial strategic frameworks will provide a solid decision making platform for local government in the transition to a green economy.

\subsection{Research problem statement and research objectives}

In order to attain a environmentally sustainable and resource efficient economy, the green economy transition has been recognised as a key development plan by the South African government. This transition requires trans-disciplinary, integrated approaches to the management and design of infrastructures across all sectors. A clear understanding of the complex systems involved in the implementation of strategic frameworks is required to make informed decisions. Realistic indicators of these strategies are still yet to be developed, taking into consideration the social, economic, political and technical issues that are critical to a more sustainable future. Studies have not yet been undertaken to critically analyse and assess the implications of green investments on a regional 
level, let alone with the focus on a specific sector therefore creating an opening for the analysis of such infrastructure systems. The research undertaken in this study hopes to provide an accurate analysis of infrastructure implications of a green economy transition.

\subsubsection{Problem statement}

The transition to a low-carbon, resilient economy or the "green economy" will place an emphasis on the management of infrastructure, including the planning and design thereof. This requires trans-disciplinary, integrated approaches, since academic and industrial organisations still lack the expertise required for the management of the 'systems of systems' that constitute the current infrastructure system at a societal level. Improvements in understanding the interactions between technical, economic, political and other socio-ecological factors are necessary, particularly in the context of the great uncertainties that this transition will have. Little has been achieved in the search for a combined analysis of sectoral investments and the critical assessment of the complex systems involved in the implementation of provincial strategic frameworks that are essential to providing solid decision making platforms for local government in the transition to a green economy.

\subsubsection{Research objectives}

The objectives of the research to be undertaken in this study have emerged from the demands of the problem as mentioned above. Critical questions surrounding the different complexities and unknowns regarding the implications of understanding a green economic transition on a regional basis in South Africa were answered in the formulation of the following practical research objectives:

- To provide and contribute to the underlying knowledge base of analytical and theoretical methods to support effective infrastructure transformation in the Western Cape.

- To develop innovative methods that combine social, technical and economic factors using integrative frameworks that recognise the fundamentally broad and interdisciplinary nature of a green transition.

- To make progressive inroads into the development of comprehensive frameworks that will enable a broader and deeper understanding of transport infrastructure transformation in a green economy shift.

The research objectives as mentioned above pertain primarily to the answering of the research problem and aim, existing as the desired outcome of the research effort. These practical objectives act as the backdrop for the academic intentions of the process of investigation to be undertaken. This will 
require the following academic objectives to be met through out this research effort in order to address the aim of this thesis.

- To investigate the necessary literature on systems, complexities and transition theories in order to understand the problem at hand.

- To investigate and critically review previous studies in order to understand the transition taking place.

- To identify all of the applicable drivers constraints and contexts of the research topic.

- To develop a method of analysing the transition taking place and the implications felt across the infrastructure systems of the Western Cape.

- The gathering of relevant information and up to date data from different components of the infrastructure network applicable to the chosen method of analysis.

- To make critical assumptions pertaining to a relevant method of understanding the problem at hand to aid and enable conclusions to be drawn relating to the research aim.

The meeting of the above mentioned objectives will require methods able to asses the socio-economic, financial and technical implications of GE developments and will greatly assist in the decision making processes of both private and public investment and implementation. The capacity to span all facets of development will allow for only positive change and investment to be made. The benefits of which will be felt on all levels of government as well as society. Not only will the ability to foresee the implications that new policies and developments will have on the economy benefit the decision and policy-makers, but they will also add value to the people and environments in which they will come to affect.

\subsection{Research Approach}

The process of addressing the aim of this research effort is illustrated in table 1.1 and follows the order of the chapters comprised in the text. Chapter one introduces the aim and objectives of the study, providing the backdrop in which the research is taking place and the reasons for this investigation being conducted. Chapter two will examine the various literature relating to transition theories and management practices involved in such a problem. An understanding of complex systems and systems thinking will need to be developed in order to decide on an appropriate method of analysis for the research problem. This will involve the scrutiny of various modelling techniques through which a chosen method is envisioned to enable the realisation of the research aim. 
Table 1.1: Research outline and summary of chapters

\begin{tabular}{ll}
\hline \multicolumn{1}{c}{ Summary of Chapters } \\
\hline 1 & Introduction \\
2 & Literature Survey \& Analysis \\
3 & Model Methodology \\
4 & Discussion of Results \\
5 & Research Discussion and Conclusion \\
\hline
\end{tabular}

From the envisioned method identified from the literature, Chapter three will provide a framework from which the processes and methods involved in such a technique are identified and described. The manner in which the model is to be built and the theoretical grounds on which it stands will herein be discussed. Chapter four will give light to the results and outcomes of the investigation illustrating the important relationships existing between various components of the system. This will be followed by the final chapter in which the key discussion of the research outcomes is discussed including the limitations of the study as well as future recommendations relating to paper.

\subsection{Conclusion}

This Chapter introduced the research topic under investigation and provided the physical and conceptual background in which the research is taking place. The reasons for which this study is being conducted were discussed in the context of transport infrastructure in the Western Cape. This Chapter introduced the aims and objectives of the research effort as well as giving the overall approach towards the study as followed throughout this paper. Acting as the starting point for this study the following Chapter will follow on with the survey and analysis of the literature relating to the topic. 


\section{Chapter 2}

\section{Literature Survey \& Analysis}

The ever increasing effects of climate change occurring around the globe have led to a growing interest in sustainable development and a 'green' drive throughout the world, resulting in large amounts of research being undertaken in relation to these fields and ideas. The previous discussion over what the green economy transition is and how it relates to the South African context as well as the measures that the Western Cape is taking to promote sustainable developments now and in the future, forms the backdrop to investigating the different pathways to a more energy efficient, low carbon and sustainable infrastructure system. To better understand and assess this milieu, an understanding of the complexity of the different systems at work is required; relating to this is the assessment of transition theories that will influence the perceptions generated by decision and policy makers both in private and public sector.

\subsection{Literature Analysis Methodology}

The methodology used to the review the literature in this paper followed a traditional examination of a wider spectrum of literature and concepts providing an overview of the topic at hand. The research effort utilised many different sources from books to journal articles, government papers and distinguished websites. The nature of the topic required an array of search categories that were used for the respective sections of research. A traditional literature review typically involves the critique and summary of a body of literature that draws on conclusions made about the topic in question. This body of literature generally comprises relevant studies of knowledge that address the subject area and are typically selective in the material it uses (Cronin et al., 2008). Due to the ability to gather a comprehensive background understanding and develop conceptual and theoretical frameworks the traditional review method was used.

The literature study was broken into the following topical areas:

- Background to sustainable developments and green transitions 
- Systems Thinking and understanding Complex Systems

- Sustainable transition theory

- Complex systems modelling techniques

Table 2.1: Literature Review search variations

\begin{tabular}{|c|c|}
\hline Key Terms & Key word variations \\
\hline Sustainable Development & $\begin{array}{l}\text { Sustainable development }=\text { green economy } \\
=\text { South Africa }=\text { Western Cape }=\text { climate } \\
\text { change }\end{array}$ \\
\hline Systems Thinking & $\begin{array}{l}\text { Systems thinking }=\text { definition }=\text { methodol- } \\
\text { ogy }=\text { complex }\end{array}$ \\
\hline Complex Systems & $\begin{array}{l}\text { Complex systems }=\text { definition }=\text { complexity } \\
\text { theory }=\text { complex adaptive systems }\end{array}$ \\
\hline Transition Theory & $\begin{array}{l}\text { Transition theory }=\text { infrastructure }=\text { transi- } \\
\text { tion management }=\text { strategic niche }=\text { multi- } \\
\text { level perspective }=\text { technological innovative } \\
\text { systems = green economy }\end{array}$ \\
\hline Complex systems modelling & $\begin{array}{l}\text { Complex systems }=\text { modelling techniques }= \\
\text { empirical = agent-based approach }=\text { system } \\
\text { dynamics = economic theory based }\end{array}$ \\
\hline
\end{tabular}

Using these categories as a foundation, the review of the literature continued through the development of key words to create a search model as illustrated in table 2.1. The different search variations resulted in a multitude of sources and source types, from which actual reference were made based on reputation, peer review and relevance to topic. The use of E-databases resulted in easy access to journal articles, making sourcing and critiquing of literature easier for the researcher.

\subsection{Western Cape transport infrastructure networks}

Often referred to as the backbone of a nation an infrastructure system can be defined as a network of independent, man-made systems and processes that function in collaboration with one another to produce and distribute a continuous flow of essential goods and services (Ouyang, 2014). The transport infrastructure systems in the Western Cape comprise many different facets that can be broadly characterised into passenger transport and general freight transport. These networks generally comprise airports, ports and harbours, roads, public transport, and rail lines all of which comprise complex relationships 
between key developments in society, the economy and the environment. This section describes the different infrastructure networks of the Western Cape and identifies the many system complexities that exist within and between the networks in light of the above mentioned key development outlooks.

\subsubsection{Airports}

The Western Cape has two well-developed airports; the Cape Town International Airport and the regional George Airport, both of which serve the commercial air transport sector within the province. The George airport handles over 600,000 passengers each year due to the areas large tourist economy (Airports Company South Africa, 2014). It is also a national distribution hub for cargo such as flowers, fish, oysters, herbs and ferns all of which attribute to a growing dependence of the regions agricultural exports on the systems service performance. Cape Town International Airport is the third biggest airport in Africa serving a multitude of international flights and is expected to accommodate over 14 million people in the year 2015 according to ACSA. Forming a central hub to the tourism economy of the Western Cape the airport plays a central role in achieving the key development plans of the province. These networks in themselves have many complexities, but also exist as important sectors of the broader transport network of the Western Cape in which the relationships with other systems are paramount to the smooth running of all infrastructure services.

\subsubsection{Ports and harbours}

Approximately $96 \%$ of the country's exports being conveyed by sea through the eight major ports of South Africa, two of which are situated in Cape Town and Saldanha. Port expansion is heavily dependent on the national, regional and global economy as well as the ports competitiveness of pricing both locally and internationally (Palmer and Graham, 2013). The Western Cape infrastructure framework further describes that any development occurring in the Cape Town port area requires environmental approval for seaward expansion and improvements to back-of-port logistics networks. This legislature alone sheds light on the environmental impact that ports can have and the importance thereof to maintain a stringent control of future developments but also the necessity for more sustainable investments in these sectors.

Cape Town port is the second busiest container harbour in South Africa, in the 2011/2012 financial year the port handled 2775 vessels for a gross tonnage of 51 million GT (Hutson, 2014). With this the port remains as the largest exporter of fruit and has a busy fishing industry including many shipyards used by international companies for carrying out repairs. The Saldanha Bay Port is a key exporter of iron ore from the Sishen mine in the Northern Cape as well as 
steel and oil from the surrounding industries. Both ports exist as key strategic and economic assets for South Africa, placing importance on managing any transitions occurring within the ports with the upmost certainty.

\subsubsection{Roads and Public Transport}

The road infrastructure existing in the Western Cape consists of $6400 \mathrm{~km}$ of paved network and $10500 \mathrm{~km}$ of gravel network, this is testament to the substantial agricultural sector that exists within the province. Only $63 \%$ of the paved network is deemed to be in good condition according to the Western Cape infrastructure framework due to the increase in heavy freight traffic on the roads (Palmer and Graham, 2013). This problem results in an insurmountable maintenance backlog on all of the roads, coupled with a critical shortage in funding both provincial and municipal. One of the key factors in the deterioration of the roads is the increase in road freight traffic which is exceeding the design load capacities of even the national roads. This comes as a result of an inefficient rail service and a lack of confidence by industry to transport large volume goods by rail due to the inflexible nature of the service.

With a society that is generally reliant on either private automotive transport or public taxi/bus services the roads in the province play a vital role in the success of the economy. With the number of motorised trips projected to increase substantially in the near future, the demand for a reliable passenger transport service has become a top priority for future developments. Already the Bus Rapid Transit (BRT) is being progressively implemented in the Cape Town city area with notable success however as a proportion of total commuters, volumes remain fairly low (Attwell, 2012). There still remain large improvements to the public transport networks with respect to the key challenges of safety and security, dedicated and integrated passenger transport services, stakeholder and user participation, the minibus taxi industry, and bus services as identified by the Department of Economic Development and Tourism (Department of Economic Development and Tourism, 2005).

\subsubsection{Rail and Freight Transport}

The Western Cape Infrastructure Frame work of 2013 identifies the current split between road and rail freight transportation to be $14 \%$ rail and $86 \%$ road freight. This is a concerning fact as South Africa has the biggest rail network on the continent and yet is failing to utilise this important piece of infrastructure. This comprehensive spilt has been recognised as resulting from a lack of performance and market orientation within Spoornet operating in a rail monopoly type structure (Department of Economic Development and Tourism, 2005). The rail infrastructure has historically suffered from underinvestment resulting in the poor maintenance and growth of the vast network 
systems. It exists as a great opportunity for investment that will have far reaching benefits for broadening public transport, reducing carbon emissions and reducing road congestion.

The public transport transitions of the future will focus on increased passenger rail and Integrated Rapid Transit (IRT), with investments into nonmotorised transport in urban centres and shifts from road to rail freight traffic, all of which stand to benefit society, the economy and the environment. However each network in itself is a vastly complex system dependent on many external factors and relates to all other systems in many different ways. The nature of these interrelations make it very difficult to envisage the future outcomes of any investment or policy changes involved in such transitions.

\subsection{Sustainable Transport Indicators for the Western Cape}

It is clear that the Western Cape has an intricate transport network as previously discussed, but in order to investigate who or what the systems impact, requires the development of certain transport indicators. This leads to the discussion of sustainable transport which generally gives rise to the issues of emissions, energy use and safety, all of which impact society and the environment significantly. The structure of transport infrastructure especially in urban areas, fundamentally impacts its spatial form and quality of its environment (Kane, 2010). The complexity of each transportation system derives from the pluralism of its hardware, of the people and the organizations involved (Richardson, 2005). This interconnectivity of the infrastructure with vehicles, commuters and authorities gets multiplied by the existence of different transport modes and regulations.

Richardson (2005) goes further in identifying other influences such as "legislative bodies, service providers, builders, financing systems, technologies, landuse patterns and most importantly human behaviour". When considering the sustainability of the transport system both positive and negative consequences need to be accounted for, adding to the issues mentioned above, traffic congestion and access to transport need to be included as indicators. These aspects were investigated through the Trans:SIT project funded by the British High Commission for the City of Cape Town which looked at issues of sustainable development and assessment in transport related matters. This originally lead to the development and review of the sustainable transport indicators for the City of Cape Town, provided in Table 2.2. 
Table 2.2: Sustainable transport indicators for Cape Town (City of Cape Town, 2006)

\begin{tabular}{|c|c|}
\hline Indicator & Unit \\
\hline \multicolumn{2}{|l|}{ Environment } \\
\hline Energy use for transport & $\begin{array}{l}\text { Consumption of Non-renewable } \\
\text { resources }\end{array}$ \\
\hline Greenhouse Gas Emissions & $\begin{array}{l}\text { Total GHG emissions (Megatonnes of } \\
\mathrm{CO}_{2} \text { equiv.) }\end{array}$ \\
\hline Per Capita Expenditure on Roads & Rands/capita of Cape Town \\
\hline Commuters using NMT as Main Mode & Percentage \\
\hline $\begin{array}{l}\text { Population living within } 500 \mathrm{~m} \text { of nearest public } \\
\text { transport facility and service }\end{array}$ & Percentage \\
\hline $\begin{array}{l}\text { Public right of way ( }+ \text { public parking) per capita } \\
\text { Economic }\end{array}$ & Economic \\
\hline Average Total Journey Time & Time Unit \\
\hline $\begin{array}{l}\text { Job Opportunities, commercial services and } \\
\text { educational facilities within } 5 \mathrm{~km} \text { of residents }\end{array}$ & Number \\
\hline Modal split & NMT: mass transit: Private Transport \\
\hline \multicolumn{2}{|l|}{$\begin{array}{l}\text { Ratio of No. of Daily Passenger trips by public } \\
\text { transport: }\end{array}$} \\
\hline Public transport standee + seating capacity & Utilization: Capacity \\
\hline Generalized cost of Movement of goods and services & $\begin{array}{l}\text { Percentage of total cost of goods and } \\
\text { services to the customer }\end{array}$ \\
\hline Condition of transport infrastructure & Visual Condition Index of $70+$ \\
\hline \multicolumn{2}{|l|}{ Social } \\
\hline Portion of household income devoted to transport & Percentage \\
\hline $\begin{array}{l}\text { Per capita Accident Cost for Fatal and Serious } \\
\text { Accidents only }\end{array}$ & Rands/persons involved in accidents \\
\hline $\begin{array}{l}\text { Accessibility of infrastructure by mobility } \\
\text { disadvantaged, children, elderly }\end{array}$ & $\begin{array}{l}\text { Survey. During typical week day trip } \\
\text { on a typical journey, count the number } \\
\text { of inaccessible locations. Sum all and } \\
\text { determine average }\end{array}$ \\
\hline Car and bicycle ownership per 1,000 population & $\begin{array}{l}\text { Number of Cars and Bicycles per } 1,000 \\
\text { population }\end{array}$ \\
\hline Transport impacts on the Livability of Community & Survey: converted to a scoring unit \\
\hline Public participation & $\begin{array}{l}\text { Structured sessions with civil society } \\
\text { and other transport stakeholders }\end{array}$ \\
\hline
\end{tabular}

The rationale for many of the indicators was based on the current understanding of the meaning of sustainable transport at the time and as the process progressed the indicators evolved with it. This lead to a more succinct and robust set of indicators being developed to be as follows (City of Cape Town, 2009): 
- Transport Energy Use

- Emissions

- Full modal Split

- Public transport use

- Coverage, Quality and Security

- Congestion on Major freight routes

- Congestion on peak hour commuter routes

- Loss of life and livelihood

- Urban quality

With transport energy use in South African cities being estimated at more than $50 \%$ of total energy use, this provided good motivation for including this as a key indicator as described by Kane (2010). The calculation of energy use through urban petrol and diesel consumptions and trip-distance travelled data resulting in overall energy use, forms the main measure of this indicator. Emissions can be calculated using a fuel-emission relationship, with the use of emission factors of $\mathrm{CO}_{2}$ fo fossil fuels and electricity. Indicating the relationship in this manner allows for changes in emissions to mirror changes in the fuel indicator (Kane, 2010). Emissions and especially $\mathrm{CO}_{2}$ emissions have become the most widely used and accepted indicator for environmental impact and climate change, making it highly important for decision makers to consider it.

The Full modal split was included to monitor the relationship of NMT, private and public transport but it is also envisaged to include the model split of freight transportation in the broader scheme of the research. Coverage, Quality and Security are included more for the monitoring of government efforts towards a system that serves the needs of the travelling public and are often referred to as the issue most often resulting in society's reluctance to use public transport. Congestion on major freight and commuter routes attempts to capture the role that transport plays in the efficient operation of the macro-economy, particularly looking at activities surrounding the two major ports and also to capture the widely held view that excessive commuter congestion also impacts the economy (Kane, 2010). Finally the aspect of loss of life and livelihood and Urban Quality is included to bring attention the outcome of road-based fatality and injury and to humanise this often overlooked indicator.

These indicators aim to provide a form of scope and focus from which to look into the implications of a Green Economy transition on transport infrastructure within the Western Cape. Whilst many of them are significant to the City of Cape Town, they can still be applied to the broader scale of the province in order to fit the boundary of this study. 


\subsection{Understanding Complex Systems}

The nature of a green economy inherently means that a range of different systems need to interact in a cohesive way in order to create the most efficient and beneficial situation. For example; engineers were traditionally concerned about technological complexities, whilst both social and environmental planners focussed on social and bio-physical complexities respectively. The necessity for these skillsets to overlap is paramount to the success of a green economy and calls for change agents to be "heterogeneous engineers", able to work across material, physical and social boundaries in situations of dynamic emergent complexity (Kane, 2010). Therefore a thorough understanding of how complex systems work and interact is required in order to understand and create accurate models of meaningful analysis.

The concept of complex systems is difficult to define, there exist many different interpretations based on different principles relating to unique situations. However, an attempt to better understand complex systems requires the breakdown of the concept itself. The term systems can be defined as groups of interacting interdependent parts linked together by exchanges of energy, matter and information (Costanza et al., 1993). The definition is taken further by Costanza et al. (1993) explaining how "complex systems are characterised by strong (usually non-linear) interactions between these parts, complex feedback loops making it difficult to distinguish between cause and effect, and significant time and space lags, discontinuities, thresholds and limits".

The definition of a complex systems leads onto the theory that facilitates the use and understanding of the concept in its entirety, otherwise known as Complexity Theory. This interdisciplinary field provides the framework by which groups of connected components that influence each other can be analysed and assessed. Complexity theory involves the characterisation of the different features of complex systems as described by (Rotmans and Loorbach, 2009) to be the following:

- Complex Systems are open systems that are constantly interacting and evolving with their environment over time.

- Interactions between components in complex systems are generally nonlinear.

- Complex Systems have feedback loops being both negative (damping) and positive (amplifying).

- Complex systems have history, creating path dependence whereby current and future states depend on the path of previous states.

- Complex systems are nested on various organizational levels, having emergent properties, implying that higher level structures arise from interaction between lower level components. 
- Complex systems have multiple attractors being a preferred steady system's state set.

Complex systems can be further modified to have the capacity to react and change from learnt experience; in other words they are able respond and adapt to a dynamic environment. This type of system is called a Complex Adaptive system (CAS) and is defined as a dynamic system able to adapt in and evolve with a changing environment, emphasising that there is no separation between a system and its environment, in the idea that a system always adjusts to a changing environment (Chan, 2001). From this explanation, the nature of infrastructure networks and systems can be described as being complex systems, such that they are a compilation of many different components collaborating with one another yet still acting independently of each other, whilst being influenced by an ever changing environment.

This means that each system has to function effectively in order to uphold the integrity of another system, whilst still controlling and adapting to its own set of dynamic factors. Therefore the systems cannot be seen in isolation of each other or in fact the entire network, but rather as highly interdependent and connected structures. In relation to the implications on transport infrastructure in a green economy transition, the complexity lies in the manner in which the various modes and networks of transport interact and influence one another. It is thus important to look at this theme in terms of the understanding of complex systems and systems thinking.

\subsubsection{Systems Thinking}

Systems thinking is a field of knowledge that aims at understanding change and complexity within the collection of parts comprising the system itself and the relationship the system has with its environment. The underlying complexity of all systems is studied through the dynamic cause and effect over time (Maani and Cavana, 2012). This particular definition further identifies three distinct but related dimensions namely; paradigm, language and methodology. The paradigm of systems thinking is described as being the way of thinking about the world and relationships. Emphasis is put on the ability to see the big picture and how interrelated parts within the system interact in a dynamic non-linear manner with an understanding of the operations between the counterparts. The language and methodologies involved in systems thinking are tools used to understand and analyse the behaviour of the systems in the real world.

The ability of systems thinking to conceptualise real world complex scenarios has led to its popularity in many fields. The framework created by this results in a manner of problem solving that considers the problem in its 
entirety, involving pattern finding to enhance the understanding of and responsiveness to the problem at hand (Rubenstein-Montano et al., 2001). Further consideration is made to how the system is influenced by its environment and how this effects the solving of the problem. The emphasis on the relationships among the parts of the system rather than parts themselves makes systems thinking a powerful approach to problem solving (Schiuma et al., 2012). This combination of understanding the individual counter parts of the system as well as the inter-linkages and relationships between these parts adds to the benefits of applying such a thought process. For the case of investigating the implications of a green economy transition on transport infrastructure this way of thinking is paramount to the understanding and analysis of the various policy changes involved.

\subsection{Understanding Sustainable Transition Theory}

Having identified the necessity and desire for a transition to a more sustainable future by most governments and societies, the issue of how to promote and govern this transition toward sustainability arises. The complexities of the mechanics that drive the different systems involved in this change as aforementioned create an array of fundamental sustainability challenges faced by policy makers.

A transition can be defined as a gradual process of change whereby the structural character of a society or complex system transforms. Described as a set of connected changes which reinforce each other but take place in several different areas, transitions can involve a range of possible development paths whose scale, direction and speed can influence but never control government policy (Rotmans et al., 2001).

These sectors can be conceptualised as socio-technical systems consisting of actors and institutions interacting to provide specific services for society, leading on to socio-technical transitions involving changes along different dimensions. For example; the emergence of the transport system with the development of auto-mobiles required a complementary development of road infrastructure, fuel supply systems, traffic rules and services. All of which involved technological, material, organizational, institutional, political, economic and socio-cultural changes which form the basis of a socio-technical transition (Markard et al., 2012).

Such a transition has further far-reaching effects on societal domains, leading to the broader idea of sustainability transitions which Markard et al. (2012) 
goes further to define as "long-term, multi-dimensional and fundamental transformation processes through which established socio-technical systems shift to more sustainable modes of production and consumption". Furthermore, four frameworks have been realised in more theoretical terms, including; Transition Management, Strategic Niche Management, Multi-level Perspective, and Technological Innovation Systems for which a brief discussion on each will follow.

\subsubsection{Transition Management}

The challenges of mapping these transition structures arise with the difficulties in translating relatively abstract concepts into practical management frameworks without alleviating too much of the complexity of the situation. Emerged out of theoretical reasoning and practical observation; transition management aims to combine ideas on technical transitions with insights into complex systems theory. In other words it can be seen as an analytical lens to assess how societal actors handle complex societal issues at different levels, consequently resulting in the development and implementation of strategies to influence the 'natural' governance processes (Lorbach, 2010).

At the core of transition management lies the challenge of orienting longterm change in large socio-technical systems. The insights created about these transitions get combined into a management strategy for public decisionmakers and private actors. This approach is based on a more process-oriented philosophy that balances coherence with uncertainty and complexity as described by Rotmans et al. (2001). The authors go further in explaining the aim of transition management is not so much the realisation of a specific transition but more about "working towards a transition that offers collective benefits in an open, exploratory manner". The management of this approach requires the regular evaluation of the goals and instruments of change that were initially identified.

In theory, transition management has a modular structure with many components interrelating to produce the whole system. Meadowcroft (2009) identifies the key elements of transition management as being:

- The image of the transition dynamic, focussing on the movement from one equilibrium to another.

- The three level analytical hierarchy of 'niche', 'regime', and 'landscape'

- Future oriented visioning devices of; goals, visions, pathways and intermediate objectives.

- The practical focus for activities; arenas and experiments. 
- A broad philosophy of governance emphasising decision-making in terms of uncertainty and the gradual adjustment of existing development long term pathways.

The above mentioned elements of transition management form the structural backdrop for the implementation of the theory in real-world cases. The elements and the use thereof give this form of transition theory the ability to explore various options acting as guides for selection processes into more sustainable directions. Rotmans and Kemp (2008) wrote in a response letter that was later published, that transition management is a "cyclical process of envisioning, agenda building, instrumenting, experimenting, and learning rather than focusing on single available solutions". They go further to explain that this form of management is not about the implementation of a set blueprint but rather involves a forward-looking adaptive manner of exploration of various system innovations. This bottom-up approach allows for the empowerment of 'front-runners' in technology innovations over extended periods of time, leading to the key features of Transition Management being described by Meadowcroft (2009) as:

- Making the future more clearly manifest in current decisions through longer time frames and alternative trajectories

- Transforming established practices in critical societal subsystems, where before hand unsustainable practises existed.

- Developing interactive processes where networks of actors can come together to share and develop different perspectives to create practical solutions.

- Linking technological and social innovation, so that both can move forward together.

- The Development of experiments and novel practices and technologies through a "learn by doing" approach, in order to learn the potential and limits of each new pathway.

- The encouragement of a diversity of innovations('variation') and competition among different approaches ('selection') to fulfil the needs of society.

\subsubsection{Strategic Niche Management}

Originally introduced to trigger off regime shifts by the deliberate creation and support of different niches, strategic niche management has evolved to form the basis of most multi-level systems. These niches have been conceptualised as protected spaces, being specific markers or application domains, in which radical innovations can be developed without being influenced by regime pressures (Markard et al., 2012). On a different level with a 'greener' outlook, green niches have been defined as spaces where networks of actors experiment 
with and mutually adapt to greener organisational forms and more eco-friendly technologies (Smith, 2007). Thus these niches can be viewed as the building blocks of certain technologies, facilitating innovative journeys for broader societal changes towards sustainable development (Schot and Geels, 2008).

In creating these niches and protected spaces for new technologies, the chance is created for the exhibition of its actual use and viability as a new product. This process of actually using the new technology enables the building of a network around the product and for learning to surround the use of it. Yet, it is more than just an experiment of a new technology, instead it is aimed at making institutional connections and adaptations, that facilitate the development and ultimately the use of the new technology (Kemp et al., 1998).

\subsubsection{Multi-level Perspective}

As more consideration was given to sustainability transition studies, researchers were required to address the multi-dimensional (technological, political, sociocultural, and economic) nature of sustainable developments as well as the necessary structural changes to pre-existing systems and infrastructures. This led to the development of a particular approach namely, the multi-level perspective which explains technological transitions by the interaction of the forces at work on three different levels: niches, regimes, and landscapes (Markard et al., 2012). This analytical framework aims to conceptualise the overall dynamic patterns involved in socio-technical transitions by investigating the interplays between the three different levels (Geels, 2011). The term regime refers to the existing socio-technical structures put in place by scientific, political, social, cultural and economic systems. The landscape level forms the backdrop or the wider context that sustains society, but provides factors that pressurise the existing regimes thus creating opportunities for special niches to break through and effect change.

\subsubsection{Technological Innovative Systems}

The fourth field of transition studies is concerned with the emergence of innovative technologies and the institutional and organisational changes that are required to accommodate these new developments (Markard et al., 2012). Again the emphasis on interplay between systems comes to the fore, in that firms and actors of institutional infrastructures become the important drivers behind novel technologies and sustainable developments. Using the accepted definition of a system to be a group of components serving a common purpose, the components of an innovation system are the actors, networks and institutions contributing to the overall function of developing, diffusing and utilising new products (goods and services) and processes (Bergek et al., 2008). 
Therefore to fully understand the complex nature of a transition to a green economy, the above mentioned ideas and frameworks will become instrumental to the thought processes and approaches to the modelling and hypothesising of this investigation.

\subsection{Modelling and simulating infrastructure transitions}

The dependency on fast moving robust infrastructure systems and services has never before been so influential in society as it is today. With the speed at which information can now travel the physical world in moving goods and people is at a constant struggle in trying to keep pace. Johansson and Hassel (2010) who investigate the vulnerabilities of interdependent infrastructure systems, describes that "since today's society is very dynamic, including fast technological developments and new types of threats, it is increasingly important these risk management efforts are proactive". This 'pro-activity' refers to the importance of anticipating future problems and implications inherent in the systems. The author goes further in describing that in relation to this, when the dependencies between the various systems are of a higher order(i.e. do not interact in a linear manner), it is more difficult to make sense of their effects without explicit modelling and simulation. This calls for methods of analysis that enable decision makers to envisage the future and mitigate risks during times of transition and change.

In this light having identified different frameworks and strategies to help understand and contextualise the complexities of transition management, the next step to comprehending those changes is to formulate and develop models to analyse certain scenarios. There exist many different modelling techniques, of which the most pertinent to the research topic will hence forth be discussed, categorised into five approaches; empirical, complex network, agent based, economic theory based, and system dynamics. A brief introductory review on the different techniques associated with the topical case of infrastructure systems will be provided in order to develop a method of rationalising the implications of a green economy transition on transport infrastructure.

\subsubsection{Empirical Approaches}

The empirical approach analyses the interdependencies according to historical accident or disaster data and expert experience (Ouyang, 2014). This approach would therefore identify common significant failure patterns and be able to quantify the strength of associated interdependencies. This would enable informed decisions to be made in conjunction with an empirical based 
risk analysis and also provide alternative measure to mitigate those risks. Difficulties arise in identifying all interdependencies within these systems and capturing relevant and tangible historical data for analysis, as many sources originate from media driven outlets.

\subsubsection{Network Models}

The nature of transport infrastructure is inherently based on the interaction between the different transport networks. Networks like systems are all around us and exist in social, biological, technical and tangible objects existing in the world. In the past decade a growing interest in the study of complex networks has emerged and falls under the umbrella term of Network Modelling. Historically based on a branch of discrete mathematics know as graph theory, Network Models focus on the analysis of networks whose structure is irregular, complex and dynamically evolving over time making use of mathematical theorems and algorithms (Boccaletti et al., 2006). In essence a network model or graph is a set of nodes or points connected by edges where nodes represent entities (e.g. people, cities, infrastructure systems) with the edges being the relationship between those said entities (Balestrini-Robinson, 2009).

The field of complex networks focusses on three main aspects according to Weber and Porto (2007) as; measuring network topology, investigating the dynamics of networks, and examining the interplay between the dynamic processes on networks and the network topology. Here the terms topology and dynamics refer to the structure and behaviour respectively of complex systems and the understanding of the relationship between the two. This structure or topology of network modelling draws its definitions and notations from graph theory which is the framework for the exact mathematical representation of complex networks as graphs.

A Graph is described as an ordered pair of elements where the nodes represent the vertex set which are vertices of the graph itself and the edge set whose elements are the edges or connections between the vertices. Biggs (1993) goes further to define that the third element to graph theory is the incidence relation which is the subset of both the vertex and edge set respectively. An example of three types of graphs is illustrated in Figure 2.1, here Graph (a) represents an undirected graph in which the edges have no orientation or direction meaning that this graph does not consist of ordered pairs. A Directed Graph (b) on the other hand is considered an ordered pair which is represented by the directional arrows, here the edges are dependent on predecessor-successor relationships. Graph (c) is an example of a weighted graph where the intensity and capacity of the links are considered as represented by the thickness of the lines. 


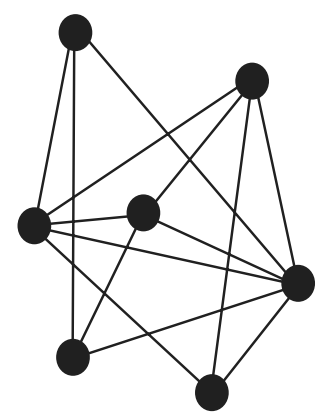

(a)

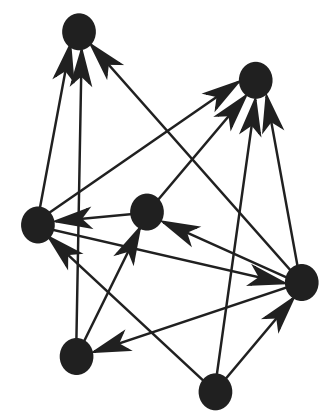

(b)

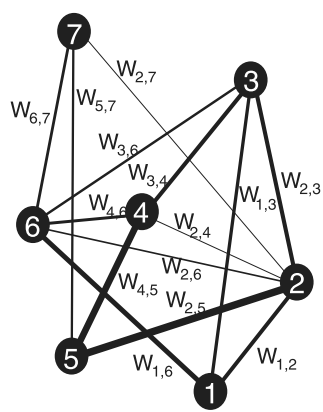

(c)

Figure 2.1: Graphical representation of a unidirected (a), a directed (b), and a weighted unidirected (c) graph with $N=7$ nodes and $K=14$ links (Boccaletti et al., 2006)

Network models aim to simplify systems to the maximum level possible yet still retain the essence of the system being studied (Balestrini-Robinson, 2009). Therefore making network modelling a compelling manner in which to help understand a systems behaviour and characteristics. However there do exist some limitations to this method, in that there is a heavy dependence on mathematical relationships between nodes and links as well as the inflexible nature of this technique to adapt throughout simulation.

\subsubsection{Agent Based Approaches}

An effective way of analysing the inherent complexity of infrastructure systems is the Agent-based approach, which adopts a bottom-up method assuming the complex behaviour emerging form many individual and relatively simple interactions of autonomous agents (Ouyang, 2014) . These agents interact with others as well as their environment based on a set of predetermined rules which reflect the manner in which that agent would react in the real world. An agent can be defined as a computer system situated in some environment that is capable of flexible autonomous action in order to meet a defined set of goals (Chappin and Dijkema, 2010).

There is however no universal agreement on the definition of the term 'agent' with regards to Agent-based modelling. Instead there are certain properties and attributes that agents should possess which are illustrated in Figure 2.2 as described by Macal and North (2009). In a basic sense for practical modelling purposes an agent should function independently in its environment and in its relationship with other agents. An agent should be self-contained and identifiable with its own set of characteristics and decision making capabilities with in its predefined boundary. Other key elements include an agents 
ability to interact with other agents and its environment in terms of its communications and information exchanges with these other entities as illustrated in Figure 2.2.

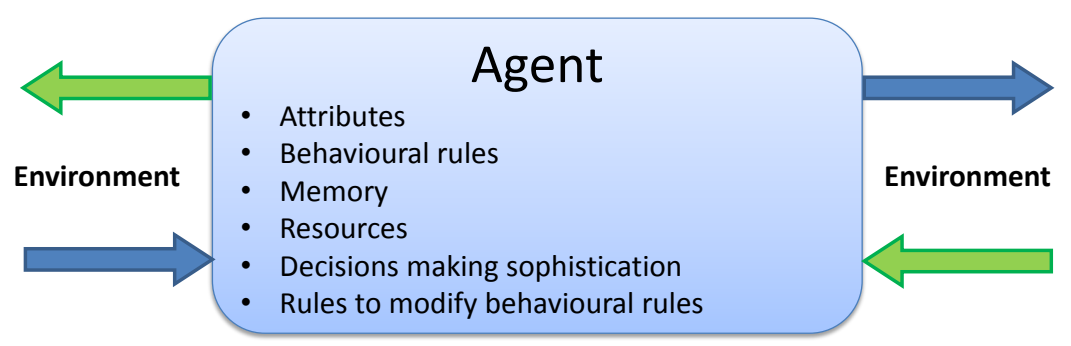

Figure 2.2: Typical attributes of an Agent (Macal and North, 2009)

Once the agents are defined, it then becomes necessary to form a basis for modelling the agent behaviour which is often initiated with a generic behavioural heuristic. The model then gets built around the different relationships that exist between the agents. It is through these interactions that the outcomes are represented with in the context of the complex system that is being modelled.

It was previously discussed that there exists an inherent complexity when it comes to infrastructure systems and the decision-making processes involved in the management thereof. This requires the understanding of the system's components and how they interact with one another and how the results can be more than the sum of the parts. Whilst this is normally attributed to political or economic situations within the social sciences, Agent-based modelling is well suited for transportation-related problems.

According to Axelrod and Tesfatsion (2006) Agent-based modelling is well suited for studying systems with the following properties; the system is comprised of interacting agents, and the system exhibits emergent properties (properties arising from the interactions of the agents that cannot be deduced simply through aggregation). Sanford Bernhardt and McNeil (2008) goes on to use these principles to justify the use of Agent-based modelling for transport and infrastructure related problems in that many such problems fall into those two categories including the domains of "traffic flow, travel demand and infrastructure management".

Agent-based modelling does however have some weaknesses, generally due to the quality of simulations often being dependent on the modellers assumptions and that calibrating the simulation parameters can be very difficult due 
to a lack of relevant data. It is also noted by Yazdani et al. that the most common negative aspect of Agent-based modelling arises in difficulties relating to the assessment of model outcomes. Grimm et al. (2006) goes further to explain the difficulties that arise in understanding models with regards to the transformation of the verbal description into explicit equations or rules. Consequentially in order to get a general idea of a certain model, it is necessary to read the entire model in great detail before an understanding of the general purpose or structure can be realised.

\subsubsection{Economic theory based or Econometric Models}

For a market economy there exist mainly two types of players, namely producers and households. These so called players interact in a continuous cycle, where households offer labour and capital to producers in exchange for payment. The producers also provide goods and services not only through labour and capital but various types of processed materials. Otherwise known as econometrics; this type of modelling measures the relationship between multiple variables by running analysis of historical data in order to find correlations to the specific variables (Bassi, 2014). The structure of the system runs on three stages; specification, estimation, and forecasting specified by a set of equations describing both physical and behavioural relations.

The general structure of Econometric models uses economic theory to develop mathematical statements relating different sets of variables and then introduces statistical assumptions to define and rationalise the model outcomes (Reiss and Wolak, 2007). This allows researchers to investigate how economic behaviour and institutions affect relationships between sets of variables with regards to their conditions and outcomes. The statistical aspect that is added allows for the researchers to rationalize why the economic theories introduced do not always accurately explain the data. The use and applicability of such models can differ yet the main components of econometric models as described further by Reiss and Wolak (2007) include:

- A description of the economic environment including:

- the extent of the market and its institutions

- the economic actors

- the information available to each actor

- A list of primitives, including; technologies, preferences and endowments

- Variables exogenous to agents and the economic environment, including:

- constraints on agents

- variables outside the model that alter the behaviour of economic agents 
- The decision variables, time horizons and objective functions of agents, such as:

- utility maximization by consumers and quantity demanded

- profit maximisation by firms and quantity supplied

- An equilibrium solution concept

The greatest limitations experienced with econometrics as described by Bassi (2013) are "related to the assumptions characterising the most commonly used economic theories: full rationality of human behaviour, availability of perfect information and market equilibrium". Again the downfalls of this framework also arise in the difficulties experienced in the calibration of production functions when data is limited.

\subsubsection{System Dynamic Modelling}

Used in a diverse collection of areas, System Dynamic (SD) models have become an important tool for analysing and making difficult normally complex managerial decisions. This approach makes use of a top down method to assess complex adaptive systems over long periods of time. The unique and beneficial attributes of this technique are the use of feedback loops and stock and flow elements to help understand non-linear systems.

Feedback loops identify the connection and direction of effects between the components of complex systems whereas stocks represent the quantities or states of the system, controlled over time by flow rates (Ouyang, 2014). In other words feedback loops permit information resulting from some action to travel through the system and return to its original point (System Dynamics Society, 2011), thus creating the ability to influence future actions. To capture the causal influence among the different variables of a system a causal-loop diagram is used in conjunction with a stock-and-flow diagram which describes the flow of information and products through the entire system.

The ability of this approach to be used in so many different scenarios, be it in a quantitative or qualitative system lies in the assumption that the behaviour of the system is to a great effect caused by its own structure (Pruyt, 2013). These system structures are comprised of physical and informational aspects important to the decision making process of a system and may also include other features such as policies, traditions, securities and strategies. Pruyt (2013) goes further to explain that in order to improve unwanted behaviours of the system, the structures governing the system must be changed. System Dynamics provides the framework required to identify and then test desirable changes to a system in a virtual setting. 
The functions attributed to this type of modelling would enable decision makers to determine the consequences of green investments into infrastructure in response to the green economy transition. This would include the expected disruptions to existing infrastructure and socio-political practices, as well as the exploration of the mechanisms behind the outcomes in order to evaluate certain risk mitigations. The ability to reflect the evolution of long-term effects of policy and technical changes would provide accurate investment recommendations as well as the ability to compare alternative infrastructure development strategies. This would in turn help to build a growing consensus between policy makers and potential stakeholders in green investments.

There do however remain some drawbacks to system dynamic approaches which often require the integration of other modelling approaches to provide a uniform analysis framework. These weaknesses include; the semi-quantitative nature of casual-loop diagrams as well as the many functions and parameters in the model that require calibration being data intensive. This leads to the greatest problem being the acquisition of relevant data resulting in only conceptual validation efforts, which can limit the model.

\subsection{Discussion and critique of modelling approaches}

The following section aims to build on previous discussions of modelling techniques in order to critique the various methods with the intention of coming to a conclusion on the best approach for the case of this study. The four main approaches identified are discussed with regards to a summary of both their strengths and weaknesses. In order to create a means to comparing these techniques the section will end with a benchmarking process in order to determine the most appropriate approach.

\subsubsection{Econometric Models}

As previously described econometric models are generally used to analyse large data intensive economic based problems with the aim of drawing conclusions with degrees of statistical certainty. The strength of this method lies within its ability to analyse large volumes of data and being able to predict the short term behaviour of the system that created it. The short sighted nature of this technique is one of the major drawbacks limiting the use of this method for the case of infrastructure implications in a green economy transition in the Western Cape. Based on the frameworks proposed initially by government as mentioned in Chapter 1, the policy simulation will need to span a long period 
of time.

Furthermore for the purpose of analysing complex systems Balestrini-Robinson (2009) proposes that econometric models "do not suffice because they cannot explicitly model the relationships between the parts and require the existence of large volumes of data that in many cases do not exist when evaluating revolutionary, or even conceptual, architectures". With regards to the research problem, this leads to one of the greatest shortfalls, as data acquisition is foreseen as one of the major limiting factors in this study as certain infrastructure systems are badly documented.

\subsubsection{Agent-Based Modelling}

The characteristics of the Agent-based modelling technique make it a viable option when considering the investigation of transport infrastructure implications in a green economy transition. One of the big advantages of this method is that it enables the analyst to study how various elements impact the macro behaviour of a system by only knowing and manipulating certain interactions between agents. This allows for the models to be built based on systems that have never been previously and entirely observed or understood.

There do however remain some critical limitations involved in this method of simulation. The principal detriment according to Balestrini-Robinson (2009) is the computational expense required to simulate using ABM, in that runtimes can become exceptionally demanding due to the model becoming overly complex. Furthermore as mentioned by the author is that in order to construct valid simulations, extensive efforts to firstly develop the model, verify and then valid it are required. In order to achieve an acceptable level of confidence in an Agent-based model, large amounts of historical data are required. On top of this, meaningful comparison between the historic outcome and simulated data is necessary, through performing stochastic analysis on the real-world system as alluded to by Champagne and Hill (2005).

\subsubsection{Network Models}

With the ability of Network Models to simplify real-world systems to the highest level possible they can therefore assist in understanding very complex system behaviours. These models are relatively simple to create provided that there exists adequate information and relationships of the real-world system to be simulated. However when compared to other techniques the ability to capture the complexity of the system is relatively week. The ability to provide insight into the macroscopic behaviour of the system is therefore not at the same level as other techniques. In order to achieve a certain level of complexity within the model, the analyst is thus required to have a vast knowledge of the 
entities at play thus making it difficult to build models where a high level of uncertainty exists about the system.

\subsubsection{System Dynamics}

The usefulness and appeal of system dynamics lies in the ability to analyse policy and managerial issues in real-world scenarios. Their ability to do so is due to the link created in the observable patterns of behaviour of systems to micro-level structure and decision making processes (Qudrat-Ullah, 2005). As previously discussed the crux of SD modelling is that single events and entities are made possible to be viewed at an aggregate level concerning policies (Borshchev and Filippov, 2004). This is all achieved through the simulating of systems behaviour through the flow and delay of information. This makes system dynamics a compelling technique for modelling transitions over long periods of time at levels of aggregation designed to enable policy development in managerial spheres.

There do however exist some drawbacks to this technique as further described by Borshchev and Filippov (2004) that "as long as the model works only with aggregates, the items in the same stock are indistinguishable, they do not have individuality". The authors go on to explain that SD modellers are required to think in terms of global structural dependencies, this means that accurate understanding and quantitative data is necessary to support this technique. Another factor is that model parameters are generally concerned with averages due to the level of aggregation to describe behaviours in large groups. This makes it difficult to model certain systems where aggregates are not easily determined prior to the modelling effort.

\subsubsection{Final critique and benchmarking of modelling techniques}

Due to the vast differences in the various modelling frameworks both mentioned and excluded it is very difficult to develop a way in which to characterise and compare the different techniques. Balestrini-Robinson (2009) attempts to provide a method of benchmarking the different simulation techniques based on their characteristics of complexity and ability to represent the real world behaviour of the systems. In this regard, certain benchmarking characteristics were used and adapted to form a baseline for the comparison of the various approaches discussed. Thus the following benchmarking criteria as adapted from Balestrini-Robinson (2009) are:

- Non-linearity: Ability to model disproportionate causes-to-effects

- Interactions: Ability to model the effects of interdependencies between entities 
- Flexibility: Ability to adapt and manipulate the model to incorporate various policy changes.

- Adaptation: Ability to model the capability to change of the individual entities

- Dynamic Behaviour: Ability to model time dependent effects and changes of state.

- Ease of creation: How much time and effort must be devoted to developing a model.

- Ease of validation: How much time and effort must be expended in validating the models.

These criteria help to form a level of comparison between the different approaches. In this regard three techniques were compared with the others excluded based on the previous critiques being deemed adequate to exclude the approaches from this stage of the comparison. Economic based modelling was already deemed to be inadequate for this study due to its inability to explicitly predict system behaviour and its over reliance on large volumes of data. This leaves the techniques of Network modelling, System Dynamics and Agent-based Modelling to be compared in Table 2.3.

Table 2.3: Benchmarking of different simulation techniques

\begin{tabular}{llll}
\hline & \multicolumn{3}{c}{ Methods } \\
\hline Evaluation Criteria & $\begin{array}{l}\text { Network } \\
\text { Models }\end{array}$ & $\begin{array}{l}\text { System } \\
\text { Dynamics }\end{array}$ & $\begin{array}{l}\text { Agent-Based } \\
\text { Models }\end{array}$ \\
\hline Non-linearity & Good & Very Good & Excellent \\
Interactions & Very Good & Poor & Very Good \\
Flexibility & Good & Excellent & Very Good \\
Adaptation & Very Poor & Good & Excellent \\
Dynamic Behaviour & Poor & Excellent & Very Good \\
Ease of Creation & Excellent & Very Good & Very Poor \\
Ease of Validation & Very Good & Good & Very Poor \\
\hline
\end{tabular}

The comparison created in Table 2.3 yields very close characteristics for the different modelling techniques. It is required that the understanding developed throughout the identification and discussion of these approaches and their relation to the research topic also be used in deciding on the most appropriate method. Evident from the table is that Agent-based modelling is a strong candidate, due to its ability to adapt and model systems of inherent non-linearity. However the telling drawback of its difficulty to develop even a basic model and be able to fully validate it is concerning. For this research effort the aim is not primarily aimed at being a modelling exercise, the focus is 
on the managerial implications of a green transition. This means that the ease of creation is an important factor and because of this moves this technique out of the scope of this study.

Network Models are easier to develop and validate when compared to ABM, they are able to model the interdependencies between entities very well and adequately simulate non-linear systems. However their ability to model the dynamic behaviour of the system and change or adapt to various pressures on the individual entities make it difficult to use when looking at infrastructure implications on a relatively aggregate level as in this study. This leaves System Dynamics, which although it struggles to model the effects of certain interdependencies between entities, it is very flexible and able to simulate the dynamic behaviour of systems. The conceptual methods of model building both mentally and computationally are relatively simple and easy to take up. This makes it possible to create simple yet robust models based on limited modelling experience and rather using real-world knowledge of the system for simulation. System Dynamics also allows for different policy scenarios to be easily introduced into the model for analysis which will be the crux of testing and investigating the different strategies involved in a green economy transition.

\subsection{Conclusion}

This chapter aimed to better understand and assess the green economy transition and how it relates to the Western Cape's promotion of sustainable developments now and in the future. The initial discussion of the various infrastructure networks existing in the province created a canvas on which to contextualise any further discussion. From this an understanding of the complexity of the different systems at work was investigated, relating to this was the assessment of transition theories influencing the perceptions generated by decision and policy makers. This resulted in some form of modelling or simulation required to analyse the future effects of current strategies which lead to the discussion on various modelling approaches. This discussion resulted in critical comparisons being made between the modelling techniques with the final outcome being that System Dynamics will be the most appropriate method to move forward with. This method will be discussed and built on in the context of the research topic in the following chapter. 


\section{Chapter 3}

\section{Methodology}

The knowledge gained through the study of various literature on the research topic provided a basis on which to move forward in conceptualising and then modelling the current transport paradigm existing in the Western Cape. This chapter aims to provide the stepwise thought processes and methodical actions undertaken in the model building process. This endeavour sheds light on the model boundary as conceptualised from the defined problem, it then describes the manner in which data was acquired and processed, followed by the dynamic understanding of causality within the system. From this, each sub-module was described and unravelled so as to create transparency in the model building thinking leading to the tests involved in the validation of the model. An important discussion of the policy changes incurred in the scenario analyses and description there in acted as a bridging medium towards understanding Chapter 4 in which the results of the simulation are discussed.

\subsection{System Dynamics Modelling process}

The basic methodology of modelling with a systems thinking framework can be applied to almost any complex problem and thus can be used as a useful tool in understanding the infrastructure implications involved as the crux of this investigation. Building on the argument of Chapter 2 with regards to System Dynamics being the most suitable for this study, it was then necessary to describe the methodology involved in building a system dynamics model. The process of which is eloquently described by Sterman (2001) as being: "To improve our ability to learn about and manage complex systems, we need tools capable of capturing the feedback processes stocks and flows time delays and other sources of dynamic complexity. The tools must enable us to understand how these structures create a system's dynamics and generate policy resistance. They must help us evaluate the consequences of new policies and structures we might design these tools include causal mapping and simulation modelling". 
Since the inception of System Dynamics by Jay Forrester in 1958, the process and approaches to SDM have evolved and adapted over the years. This has lead to many different takes on the modelling process throughout the literature but still the basic principals remain constant throughout. A breakdown of three different approaches from some of the most reputable SD thinkers is provided in Table 3.1. From this table the evolution of the modelling process is evident and whilst some of the steps are named differently, it is clear that the basic principals of SDM are similar.

Table 3.1: The system dynamic modelling process across classic literature to current day, adapted from Luna-Reyes and Andersen (2003)

\begin{tabular}{lll}
\hline (Randers, 1980) & (Richardson and Pugh, 1981) & (Sterman, 2000) \\
\hline Conceptualisation & Problem definition & Problem articulation \\
& System conceptualisation & Dynamic hypothesis \\
\hline Formulation & Model formulation & Formulation \\
\hline Testing & Analysis of model behaviour & Testing \\
& Model evaluation & \\
\hline Implementation & Policy Analysis & Policy formulation \\
& Model use & Evaluation \\
\hline
\end{tabular}

It is clear from these sources that the process of SDM begins with the identifying of the problem and subsequent articulation and conceptualisation thereof. This leads to the important matter of causal loop modelling which is a tool used to help better understand the dynamics and feedbacks occurring within the real system. Building on the mental model created it is then possible to create a formal model of the system with the aid of computer software. The model created needs to then be validated and tested accordingly so as to provide a level of confidence necessary to accept the outcomes resulting from the model simulation. Relating back to what the problem was defined as, certain policy measures or scenario tests must be implemented in order to address the critical questions identified to be answered.

The most recent and robust methodology of SDM is outlined by Maani and Cavana (2012) and builds on all of the previous approaches as illustrated in Table 3.1. The authors summarise the process into five phases of systems thinking and modelling as illustrated in Figure 3.1. However, through the knowledge gained from other literature it was decided that an extra phase of model validation and testing be added as an independent phase due to its importance within the SDM process as identified by Barlas (1996). 


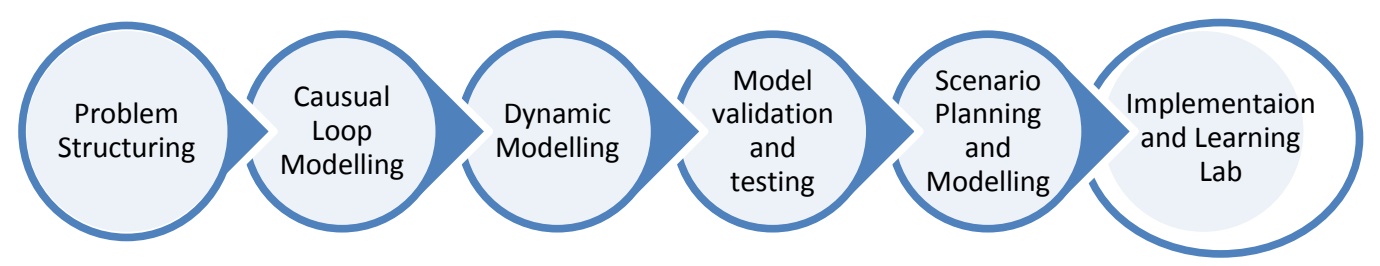

Figure 3.1: Phases of systems thinking and modelling methodology, adapted from Maani and Cavana (2012)

This method although briefly described here provides a rigorous way in which to visualise, share and communicate the evolution of complex organisations and issues over a dynamic time period. This framework further provides a solid platform on which to solve problems and create designs while mitigating unwanted surprises in the process. The following sections follow this framework giving the stepwise process to be followed as further defined by Maani and Cavana (2012).

\subsection{Problem Structuring}

Problem formulation involves the identification of a specific problem that is of greatest concern to the relevant stakeholders. This involves the identification of key variables to be considered as well as the time horizon of the problem itself and the analysis (Maani and Cavana, 2012). Other key aspects include the collection of information and data as well as organising group discussions with the relevant stakeholders concerned with the problem. This section describes the problem structuring aspects of the model in the context of these steps.

The identity of the problem to be modelled lies in the topic of investigating the transport infrastructure implications of a green economy in the Western Cape. For this the main stakeholders are policy and decision makers within government concerned with being able to envisage the long term effects of strategies being implemented today. In this regard the model includes drivers, such as: population growth and urbanization, international pressure for sustainable development, more stringent policies on carbon emissions, government policy and intervention, public demand for safe affordable public transport and socio-economic changes. Constraints, such as financial backing from government, increase of informal transport, lack of public support and private sector investment will all influence the outputs achieved by the model. All of these factors will be framed within the context of government intervention, stakeholder actions, social factors, and economic-political opportunities. 


\subsubsection{Model Boundary}

While the infrastructure network of the Western Cape Comprises many sectors, this model focuses on the existing functionality of the current road and rail networks and the detrimental effects of the current modal splits of freight and passenger transport. In terms of setting the physical and conceptual boundaries for the model, a link is created between the problem statement and research aim. In this regard, the physical boundary of the model is the Western Cape Province of South Africa, treated as an independent entity as if it were another country. The conceptual boundaries were formed by the various strategies and frameworks existing in the province as described in Table 3.2.

Table 3.2: Western Cape Green Economy Strategies and Frameworks

\begin{tabular}{ll}
\hline & Green \\
\hline Transport Planning & Western Cape Green Economy Strategy Framework \\
& Western Cape Infrastructure Framework \\
& Western Cape Provincial Land Transport Framework \\
& City of Cape Town Integrated Transport Plan \\
\hline Improved Public Transport as & Metro Rail \\
the crux & MyCiti BRT \\
& Subsidised Bus Services \\
& Minibus Taxis \\
\hline Efficiency in Private Transport & Electric cars \\
& Shorter car journeys \\
& Shift to Public transport \\
\hline Modal Shift in Freight & Shift freight on major corridors and branch lines back to \\
Transportation to rail & rail \\
\hline Non-Motorised Transport & Improve NMT infrastructure in urban areas \\
& Enable shorter walking times to public transport hubs \\
\hline
\end{tabular}

It was still however important to delimit the system and model boundaries as Pruyt (2013) describes: "All (potentially) important elements which influence other parts of the system and are also significantly influenced by elements of the system should be modelled as endogenous variables". On the contrary, all elements that could impact the system but that are not sufficiently influenced by the system thus become exogenous variables, with all other elements not fitting these characteristics being omitted. This process was carried out throughout the modelling journey, an example for the road network sub-module is provided in Appendix A.1.

\subsubsection{Time Horizon of Analysis}

The time horizon of a model eludes to the simulation period that the model will analyse as stipulated by the problem definition. Sterman (2000) describes that the time horizon should extend far enough back in history so as to grasp the 
emergent behaviour of the system and far enough into the future to capture the effects of potential policies. For this model the start year is 2001 ending in the year 2040, this is in conjunction with the Western Cape government's strategic framework for future infrastructure improvements. The reason for beginning in the year 2001 was to align the data validation period with statistical census information and data which was undertaken in the same year.

\subsubsection{Data Acquisition}

The collection of detailed information and data was an important step in the modelling process and was obtained from a range of sources including observations, meetings, company records, historical records, statistical publications, forums and reports. The collected information was used in the formulation and validation of initial values for stocks, parameter values for auxiliary variables, graphs and constants as described by Maani and Cavana (2012). A breakdown of the various data and sources of information according to specific variables is provided in Table 3.3. 
Table 3.3: Information and Data sources used in the model

\begin{tabular}{|c|c|}
\hline $\begin{array}{l}\text { Data/Information } \\
\text { Variables }\end{array}$ & Sources \\
\hline Population & Census data through Statistics South Africa (2013) \\
\hline Education & $\begin{array}{l}\text { Annual Reports: Western Cape Government, Department of } \\
\text { Education (2013/2014) }\end{array}$ \\
\hline \multirow[t]{2}{*}{ GDP } & WC Economic Growth Surveys: Attwell (2012) \\
\hline & $\begin{array}{l}\text { Provincial Economic Review and Outlook: Statistics South } \\
\text { Africa (2014b) }\end{array}$ \\
\hline \multicolumn{2}{|l|}{ Vehicle Parc } \\
\hline Fuel Demand Statistics & SAPIA Future Fuels Working Group (2008) \\
\hline Live Vehicle Population & Live vehicle statistics available through $e N a T i S$ (2014) \\
\hline Access to Vehicles & National Household surveys: Statistics South Africa (2014a) \\
\hline Motor Vehicle sales & NAAMSA available throughQuantec (2015) \\
\hline \multicolumn{2}{|l|}{ Road Infrastructure } \\
\hline $\begin{array}{l}\text { Road Infrastructure } \\
\text { expenditure }\end{array}$ & $\begin{array}{l}\text { Provincial Budget Statements Western Cape Department of } \\
\text { Transport and Public Works (2010) }\end{array}$ \\
\hline Functioning Roads & $\begin{array}{l}\text { Western Cape Provincial Land Transport Framework Western } \\
\text { Cape Government, Department of Transport and Public Works } \\
\text { (2013) }\end{array}$ \\
\hline Condition of paved network & Integrated Transport Plan: City of Cape Town (2006) \\
\hline \multicolumn{2}{|l|}{ Passenger Transport } \\
\hline BRT and MyCiTi & MyCiTi Business plans: City of Cape Town (2010) \\
\hline & $\begin{array}{l}\text { IRT Progress and status Reports Martheze and Grimbeek } \\
\text { (2012) }\end{array}$ \\
\hline Cape Metro Rail Network & $\begin{array}{l}\text { Integrated transport Plan 2013-2018: City of Cape Town } \\
\text { (2015b) }\end{array}$ \\
\hline Cape Metro Rail Fleet & Rail Census Reports: Asakhe Consulting Engineers (2007) \\
\hline Rail Passenger Journeys & $\begin{array}{l}\text { Annual Reports: Passenger Rail Agency South Africa and } \\
\text { South African Rail Commuter Corp. Ltd (2002) }\end{array}$ \\
\hline Road Accidents & Integrated Transport Plan: City of Cape Town (2015b) \\
\hline \multicolumn{2}{|l|}{ Freight Transport } \\
\hline Provincial Rail network & Tracks across the veld: Boonzaaier (2008) \\
\hline Road Freight movements & Obtained from Zane Simpson at GAIN \\
\hline Rail Energy Consumption & $\begin{array}{l}\text { Railway handbook: International Energy Agency and } \\
\text { International Union of Railways (2012) }\end{array}$ \\
\hline Rail Freight movements & Western Cape Freight Data Bank: Jorgensen (2005) \\
\hline $\mathrm{CO}_{2}$ Emissions & $\begin{array}{l}\text { U.S. Environmental Protection Agency (2008), Indalo Yethu } \\
\text { (2014), International Energy Agency and International Union } \\
\text { of Railways (2012), Carbon Fund (2014), International Energy } \\
\text { Agency (2013) }\end{array}$ \\
\hline
\end{tabular}

The data and information described in Table 3.3 for this model was acquired through many different sources. Both private and public organisations were willing to provide limited data which was then calibrated to fit the structure required for the model. It should be noted that in some cases data or information was based on the assumptions of industry experts, a good example of which are the road freight movements in the Western Cape. The Data provided by GAIN Group a transport and logistics company, was collected based on the process followed by Havenga and Pienaar (2012) which uses traffic counts from SANRAL to estimate the road freight flows throughout the 
province on the major traffic routes. A full account of the Historical Data input parameters is provided in Appendix A.2 correlating to the data sources as defined in Table 3.3.

\subsection{Causal loop modelling}

The conceptualisation or dynamic hypothesis formulation involves the investigation of current theories of the problematic behaviour. The dynamic hypothesis aims to explain the dynamics as endogenous consequences of the feedback structure (Maani, Cavana 2007). The mapping of the available data and gathered information is developed through causal loop diagrams (CLD) or system archetypes. These diagrams are based on the initial dynamic hypothesis, key variables, reference modes and available historical data.

Causal Loop Diagrams (CLD's) are used to determine the nature and direction of the relationships within the system between the key variables that are identified. A causal diagram consists of variables connected by arrows denoting the causal influences among variables identifying the important feedback loops of the system (Sterman, 2000). From the CLD, stock and flow diagrams can be created from which the modelling process can begin. In defining the causality of the problem scenario, there exist different types of feedback loops which are important in understanding the problem. These include reinforcing loops which are positive feedback systems often representing growing or declining actions. On the contrary, balancing loops seek to stabilise or return to control, aiming for a specific target. In all CLD's the nature of the feedback loops are identified and indicated in order to better conceptualise the problem.

An easy example to illustrate the nature of the CLD feedback loops is that of population. In Figure 3.2 there exist two feedback loops, one being reinforcing (births) and one balancing (deaths). The understanding of the causality of the reinforcing loop can be described as the more births there are the more the population will be and the more the population is, the more births there will be. This is an example of a growing reinforcing loop for which the plus signs indicate a positive move of each variable in the same causal direction. The balancing (deaths) loop can be described as the more the population, the more deaths there will be, but the more deaths there are, the less the population will be. In this regard the specific terminology is used in order to show the relationship and direction of influence between the variables. The positive and negative signs indicate the way in which one variable moves or changes direction in relation to another, with $(+)$ being movement in the 'same direction' and (-) being movement in the 'opposite direction'. 


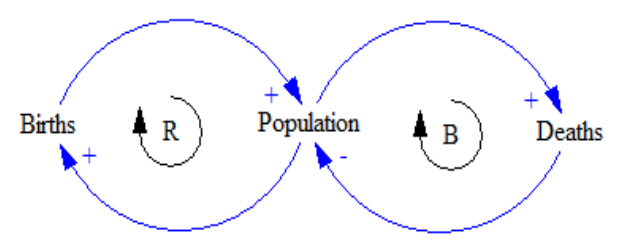

Figure 3.2: Population example of causal loop conceptualisation

The dynamics of the transport infrastructure problem coupled with the green economy investment initiatives are mainly dependent on the functionality of the roads and the GDP related expenditure on transport infrastructure. The various loops illustrated in figure 3.3 indicate the different balancing and reinforcing loops existing in the model. The variables included in this CLD represent the problem scenario on an aggregate level aimed at conceptualising the interdependencies existing in the real world case. The various feedback loops existing in this conceptual model are discussed according to the understanding created through the problem structuring phase. The most important parameters identified through the problem structuring phase are described in table 3.4 and form the basis from which the conceptualisation of the real world system is made. 
Table 3.4: Description of main parameters included in the aggregate CLD

\begin{tabular}{|c|c|}
\hline Parameter & Parameter Description \\
\hline Public Transport & $\begin{array}{l}\text {-Refers to the key focus areas of public transport } \\
\text { identified for investment by various strategies (Bus, } \\
\text { BRT, Passenger Rail, Minibus Taxi, NMT) }\end{array}$ \\
\hline Population & -Refers to the Population of the Western Cape \\
\hline Desired Vehicle & -A factor based on Economic stability (GDP/Capita) \\
\hline Ownership & $\begin{array}{l}\text { and access to public transport effecting vehicle } \\
\text { ownership }\end{array}$ \\
\hline GDP per Capita & $\begin{array}{l}\text {-Is the relative amount of Gross Domestic Product } \\
\text { divided by the current population }\end{array}$ \\
\hline Live Vehicles & $\begin{array}{l}\text {-Refers to the various modes of transport utilising the } \\
\text { road network (Motor vehicles, LDV's, minibus taxis, } \\
\text { Buses, Trucks) }\end{array}$ \\
\hline Private Transport & $\begin{array}{l}\text { - Linked to Live Vehicles, refers to the modes of private } \\
\text { transport utilising the road network }\end{array}$ \\
\hline Functioning Roads & $\begin{array}{l}\text {-Refers to the paved road network in the Western Cape } \\
\text { as a whole initialised at } 6348 \mathrm{~km}\end{array}$ \\
\hline Road Freight & $\begin{array}{l}\text {-Refers to the freight moved by road within the } \\
\text { province (Metro, Rural, N1,N2, N7) }\end{array}$ \\
\hline Rail Freight & $\begin{array}{l}\text {-Refers to the freight moved by rail within the province } \\
\text { (CT-Gauteng mainline, WC Branch-lines) }\end{array}$ \\
\hline Rail Network & $\begin{array}{l}\text {-Refers to the rail infrastructure in existing in the } \\
\text { province in terms of kilometres of track }\end{array}$ \\
\hline Freight Demand & $\begin{array}{l}\text {-Refers to the commodities demand both inter and } \\
\text { intra provincial based on economic growth and other } \\
\text { factors }\end{array}$ \\
\hline Fuel Demand & $\begin{array}{l}\text {-Refers to the Fuel demand from all transport modes } \\
\text { across the sectors, split between diesel and petrol }\end{array}$ \\
\hline $\mathrm{CO}_{2}$ emissions & $\begin{array}{l}\text {-Refers to all } \mathrm{CO}_{2} \text { emissions coming from the transport } \\
\text { sector }\end{array}$ \\
\hline GDP & -Gross Domestic Product, economic growth indicator \\
\hline Roads under & -Refers to all roads under construction in the province \\
\hline \multicolumn{2}{|l|}{ Construction } \\
\hline Government & - Budged government expenditure on transport \\
\hline Expenditure & infrastructure \\
\hline GE investment & $\begin{array}{l}\text {-All GE investments or costs incurred through new } \\
\text { infrastructure strategies }\end{array}$ \\
\hline
\end{tabular}

Figure 3.3 illustrates the aggregate CLD for the Western Cape transport infrastructure problem as defined. One of the key variables pertaining to the conceptual model is that of Green economy investment into infrastructure par- 
ticularly related to transport. This parameter acts as a driver for many of the policy or strategy changes occurring within the model but is increased by the perception of increased $\mathrm{CO}_{2}$ emissions and resulting climate change pressures. As illustrated by the balancing loop $B 1$ this parameter will increase public transport, an increase in access to public transport leads to desired vehicle ownership per capita going down which in turn results in less live vehicles utilising the road network. The fewer live vehicles there are the lower carbon emission should be and thus in the eventual case of climate change perception, if $\mathrm{CO}_{2}$ emissions are seen to have dropped substantially GE investments may decrease due to a lack of public interest.

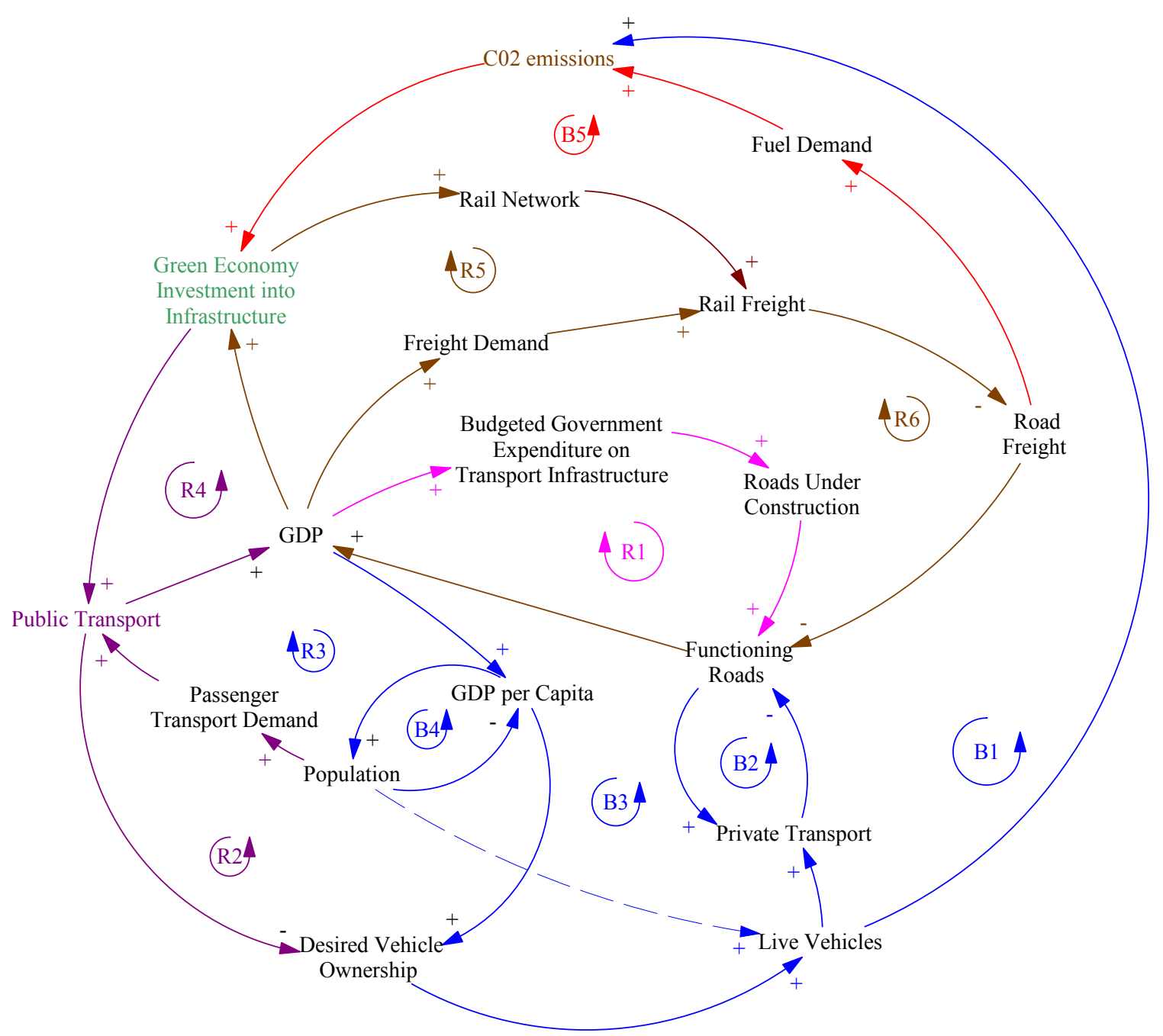

Figure 3.3: Causal Loop Diagram for the Transport Infrastructure Network in the Western Cape 
The other important loop from the aggregate CLD is that of $R 4$ which illustrates the simple relationship of an increase in green economy investments leading to better public transport which will in turn benefit the economy $(G D P)$ both directly and indirectly. With the two spheres of focus being identified as passenger and freight transport respectively for this problem, they are discussed independently in more detail. Figure 3.4 focusses on the dynamics of passenger transport, loop $B 3$ describes the balancing nature of a growing economy $(G D P)$ leading to a greater GDP per capita resulting in an increase in desired vehicle ownership, with this there will be more live vehicles on the roads resulting in increased private transport. The more the populace uses private transport as a primary means of travel the larger the impact on functioning roads will be due to the pure volume of traffic and the more the functioning road infrastructure is effected the greater the impact on the economy $(G D P)$ will be. Another interesting loop in this regard is that of $B 2$ illustrating the counteractive nature between private transport use and functioning roads whereby the better the conditions of the roads are, the more they will be used but this in turn deteriorates the road structure.

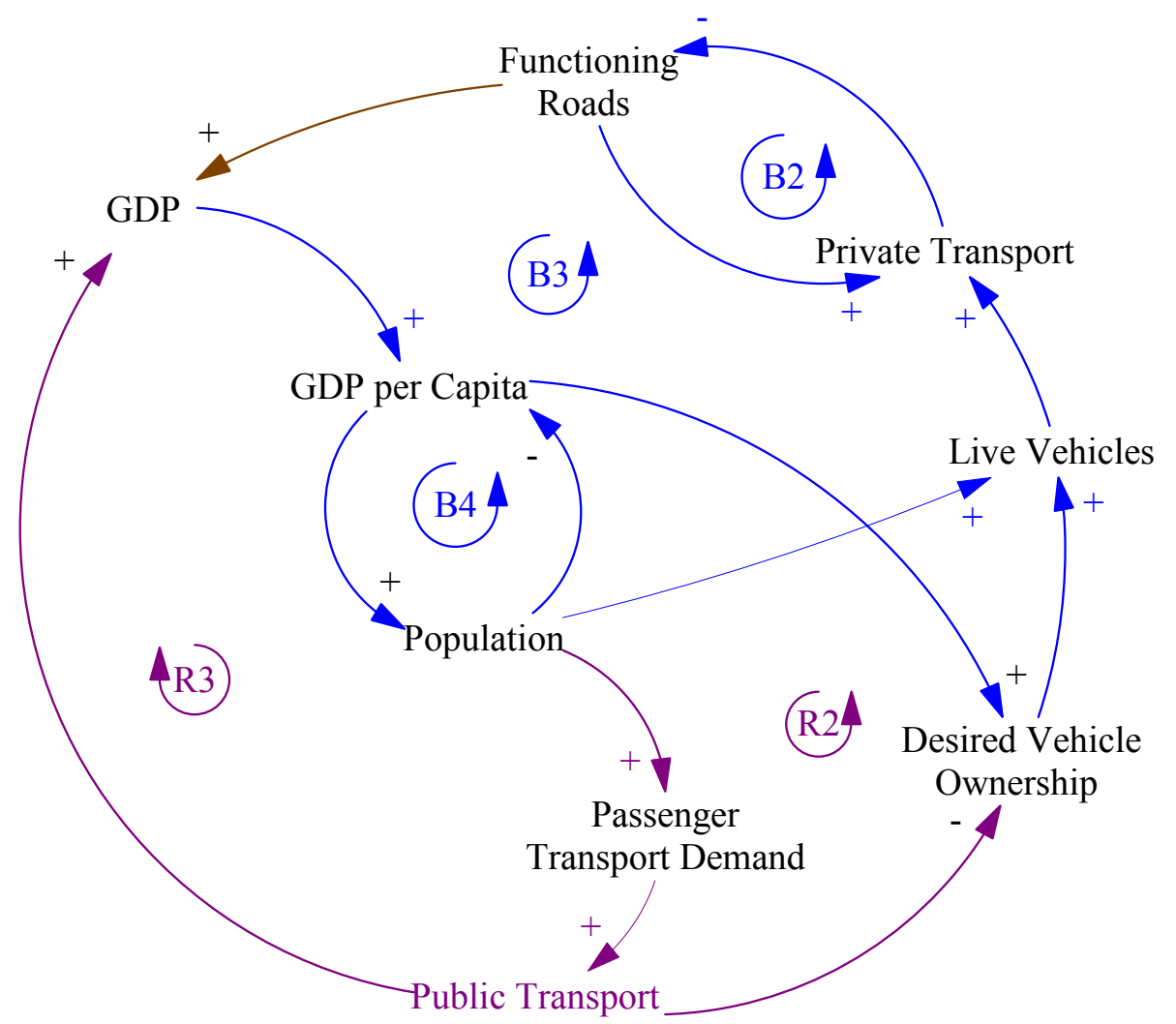

Figure 3.4: Causal Loop Diagram for Passenger Transport Infrastructure in the Western Cape 
A similar feedback loop to $B 3$ is that of $R 2$ whereby the parameters of population and the resulting increase in passenger transport demand leads to an increase in public transport, this in turn results in a decrease in desired vehicle ownership which then follows the same behaviour as loop B3. Loop $R 3$ is described by similar behaviour as $R 4$ with the added parameters of GDP per capita and population increasing passenger transport demand and thus public transport usage. This behaviour is aided by the balancing dynamics of GDP per Capita and population illustrated by loop B4. With the Economy in the Western Cape and also South Africa being largely dependent on road infrastructure both for freight and passenger movements this parameter to a great extent acts as the link between the two spheres of passenger and freight transport. Figure 3.5 thus illustrates the upper half of the aggregate CLD (Figure 3.3) with focus on the freight demand, functioning roads and the rail network.

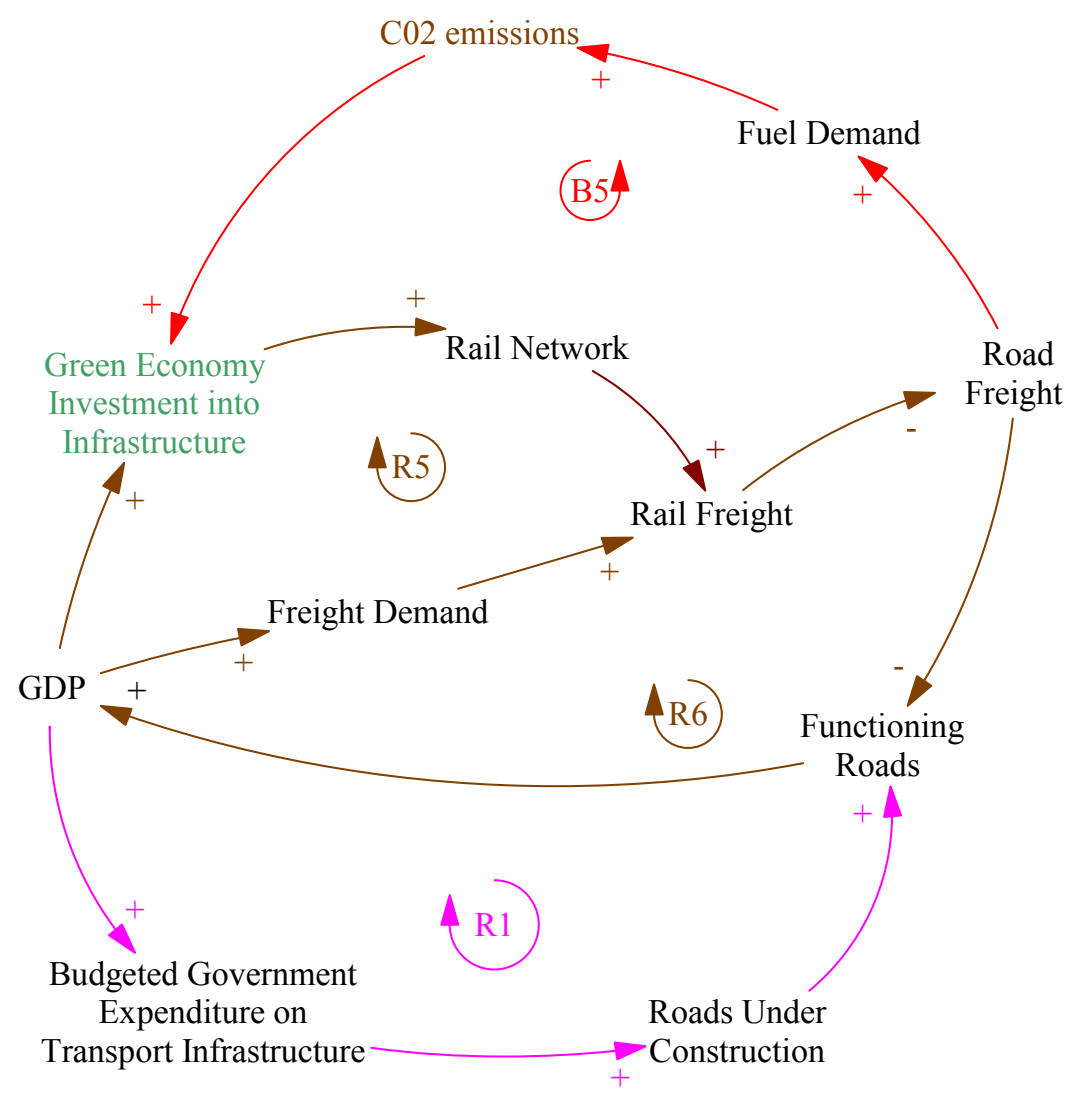

Figure 3.5: Causal Loop Diagram for the Freight Transport Infrastructure in the Western Cape

The reinforcing loop $R 1$ describes the growing nature between economic growth $(G D P)$ and functioning roads. This reinforcing process is described by 
and increase in GDP resulting in a greater budget for government expenditure on transport infrastructure which leads to more road construction projects being made possible, this in turn betters the condition of the road network which as previously discussed is a crucial enabler of economic growth. With any economic growth being realised, it is expected that freight demand will increase as a result, this in turn should increase the freight being transported by rail which in an ideal world would bring down the amount of freight being hauled by road. Road freight transport i.e. truck haulage has a large impact on the pavement lifespan of a road and thus is described as decreasing the parameter of functioning roads. The dynamic behaviour for this process is characterised by loop $R 6$.

Relating to the feedback process involved with freight demand and the relationship between road and rail freight movements is that of the green economy investments into infrastructure and the effects of the various strategies and policy changes there in. It is envisaged that through a GE transition more investment will be made into the rail network both in terms of rail infrastructure and the Transnet train fleet. The results of this investment lead to more freight being transported by rail, thus decreasing road freight haulage leading to less impact on the road network as described by loop $R 5$. The environmental aspects of this strategy are also accounted for in loop $B 5$ by including the variables of fuel demand and $\mathrm{CO}_{2}$ emissions. In this regard the strategy to improve the rail systems resulting in a decrease in road freight will in turn mean that fuel demand will decrease based on the fact that transporting freight by rail is more fuel efficient than by truck. A decrease in fuel demand will also result in less fuel being burned meaning that $\mathrm{CO}_{2}$ emissions will decrease. In the long term however, if $\mathrm{CO}_{2}$ emissions are perceived to have decreased or levelled off substantially there is a possible risk of investments into sustainable strategies also decreasing. From this conceptual model it is now possible to dynamically model the problem based on the behavioural patterns defined and discussed.

\subsection{Dynamic Modelling}

The phase of Dynamic Modelling involves the development of the high level map or systems diagram consisting of the relevant stocks and flows following from the conceptualisation phase and causal loop models (Maani and Cavana, 2012). In this phase the construction of the computer simulation model occurs based on the identification of the main variables and collected data and information. Through the use of specialised computer packages such as Vensim, STELLA, iThink and others, the mathematical and structural relationships between variables is made possible. The model must be simulated over the predefined time horizon from which graphical and tabular outputs are pro- 
duced. This section describes the processes involved in the dynamic modelling of the research problem.

\subsubsection{Model Settings}

The modelling effort utilised the Vensim DSS (Ventana Systems Inc., 2013) package due to its availability and familiarity to the developer when compared to other software. Vensim DSS also has a substantial amount of on-line help and tutorials readily available and easy to follow making it a desirable software to use. The model utilised a time step of 0.625 in order to maintain integration accuracy without compromising computational time allowing for a more accurate analysis of the dynamic elements existing in the different sub-models. The Euler method was selected for numerical integration purposes: the level of data uncertainty, speed requirements and lack of specificity-requirements warranted selecting Euler over Runge-Kutta (Musango et al., 2015). Table 3.5 provides a summary of the model settings as defined in the software in alignment with the predefined time horizon.

Table 3.5: Summary of Model Settings

\begin{tabular}{ll}
\hline Software & Vensim DSS \\
Initial Time $\left(t_{0}\right)$ & 2001 \\
Final Time $\left(t_{f}\right)$ & 2040 \\
Time Step & 0.625 \\
Time Units & Years \\
Integration Type & Euler \\
\hline
\end{tabular}

\subsubsection{Description of sub-models}

With the understanding of the causal dynamics as discussed in the previous section, the development of a working model based on theoretical and practical relationships between variables becomes possible. The model created in Vensim DSS consisted of eleven interconnected sub-modules in which the key variables and indicators are calculated endogenously in order to facilitate the investigation into the implications of a GE transition on transport infrastructure. This section describes the sub-modules comprising the model, focusing on the stocks and flows involved and the most important variables acting within. The discussion will also shed light on the thought processes involved along with the assumptions made, based on various sources of information and understanding. 


\subsubsection{Road Infrastructure sub-module}

The two main stocks in the road network sub-model are roads under construction $(R U C)$ and functioning roads $(F R)$. The stock of roads under construction (defined by equation 3.4.1) is increased through road construction starting $\left(r_{r c s}\right)$, which is in turn influenced by the average road cost per kilometre and the budget provided through government expenditure for road construction. The budget for road construction is the difference between the road maintenance cost and the roads infrastructure expenditure over the average budget time. The road maintenance cost is the product of the kilometres of functioning roads. The cost of road maintenance is modelled as a stock which grows over time, based on a $2 \%$ increase per year. The road infrastructure expenditure is determined based on historical data provided by the provincial budget and is then projected over time (Western Cape Department of Transport and Public Works, 2010). The rate of road completion $\left(r_{r c}\right)$ is then simply the flow of roads under construction and the average time it takes to complete a road which was assumed to be 5 years based on industry norms.

$$
\begin{gathered}
R U C(t)=R U C\left(t_{0}\right)+\int_{t_{0}}^{t_{n}}\left[r_{r c s}-r_{r c}\right] \mathrm{d} t \\
F R(t)=F R\left(t_{0}\right)+\int_{t_{0}}^{t_{n}}\left[r_{r c}-r_{r d}\right] \mathrm{d} t
\end{gathered}
$$

With the flow of road completion increasing the stock of functioning roads, road disruption $\left(r_{d}\right)$ acts as the outflow and is influenced by the effect of maintenance on road life, the average road life without maintenance and the effects that motor vehicles and trucks have on pavement life. Determining the effects of increased motor vehicles and truck numbers on the roads is a difficult prospect and would require a detailed calculation of the number of equivalent axle loads on the roads (E80's) and how they relate to the original design life categories for each road. This process is specific to each road and section when construction is completed, it is thus out of the scope of this study and instead a simple percentage increase on road effects calibrated with data was assumed in a lookup table to portray the effects of increased traffic numbers.

An important variable in this sub-model is that of the condition of paved network, this auxiliary is influenced by the total kilometres of functioning roads and the initial break down of the system into standardised categories. These categories range from being very good, good, fair, poor and very poor and were compared with data accrued through road condition surveys conducted over the years. This variable is directly effected by the stock of functioning roads, importantly that of increased traffic on road conditions based on the growing number of live vehicles is included. The structure of the road infrastructure is illustrated in Appendix B.1. 


\subsubsection{Live Vehicle sub-module}

This sub-module represents the live motor vehicles existing and operating in the Western Cape (Appendix B.2). The Motor Vehicles stock $(M V)$ is the accumulation of privately used vehicles that has been broken into the following subscript actors:

- Motor cars and Motor cycles

- Minibusses

- Busses

- LDV's and Light load vehicles

- Trucks

- Other vehicles

The Motor Vehicles stock is increased by vehicle sales $\left(r_{v s}\right)$ and decreased by vehicle disposal $\left(r_{v d}\right)$. Vehicle sales is directly influenced by the desired amount of vehicles. This desired amount is influenced by the population of the province and the desired vehicle ownership per capita which was initially taking as the product of the percentage of population with access to vehicles and the relative real GDP. Vehicle disposal $\left(r_{v d}\right)$ is managed through the average life span of each vehicle group which is disclosed in the study completed by Letshwiti et al. (2003), through the analysis of vehicle ownership trends in South Africa. The Motor Vehicles (equation 3.4.3) was then calibrated against data collected from the provincial live vehicle population statistics from 2007 to 2014 (eNaTiS, 2014).

$$
M V(t)=M V\left(t_{0}\right)+\int_{t_{0}}^{t_{n}}\left[r_{v s}-r_{v d}\right] \mathrm{d} t
$$

The various green economy investments into different modes of passenger transport were included as percentage decreases on the desired vehicle stock and thus when introduced, it is expected to reduce the growth of private motor vehicle ownership. The percentage decreases for the different investments were obtained from the infrastructure strategic framework of the Western Cape and the various desired modal splits that are envisioned by the government (Palmer and Graham, 2013).

\subsubsection{Rail Infrastructure Network sub-module}

The rail infrastructure network for the Western Cape was modelled with the focus on three main systems including the Cape Town-Gauteng mainline, the collection of intra-provincial Branch-lines and the Cape Metro rail lines. The following subsections aim to discuss the thought process involved in the building of these sub-modules. 


\section{Cape Metrorail network}

In the modelling of the Cape Metrorail network operating in and around the Cape Town Municipality (Appendix B.3) two main stocks were realised, that being the rail tracks named as the Cape Metro Network $(C M N)$ and the Metro Fleet(running train sets) $(M F)$, represented in the equations 3.4.4 and 3.4 .5 respectively. The metro train fleet made up of available functioning train sets defined by the different train types is increased through fleet maintenance $\left(r_{f m}\right)$ and the new Prasa roll-out strategy $\left(r_{p r}\right)$ beginning in the year 2016 . The stock is depleted by through fleet deterioration $\left(r_{f d}\right)$ which is directly influenced by the design life of each of the different train sets and the metro fleet.

$$
\begin{aligned}
& C M N(t)=C M N\left(t_{0}\right)+\int_{t_{0}}^{t_{n}}\left[r_{r m r}-r_{m d}\right] \mathrm{d} t \\
& M F(t)=M F\left(t_{0}\right)+\int_{t_{0}}^{t_{n}}\left[r_{f m}+r_{p r}-r_{f d}\right] \mathrm{d} t
\end{aligned}
$$

The total metro fleet in operation influences the scheduling of the train sets per service line where a balance is met between passenger demands and available trains resulting in the actual train trips scheduled. The effect of increased traffic on the rail lines is then factored in to represent the metrorail track deterioration $\left(r_{m d}\right)$ of the rail network stock $(C M N)$. This stock is equally increased by the rail upgrades required to maintain service line tracks through the rate of rail maintenance and renewal $\left(r_{r m r}\right)$.

The costs incurred in the maintenance and renewal of the service lines are accumulated in the stock of rail maintenance and renewal which considers the different types of maintenance measures and the relating costs. The costs of the Prasa roll-out strategy are equally accrued over time in another stock, both of these are then introduced into the Green Economy Investment sub-model.

\section{Cape Town-Gauteng Mainline}

The freight rail network for the Western Cape was modelled with the focus on two stocks, namely the Cape Town-Gauteng mainline $(C T M L)$ and the network of Western Cape Branchlines $(W C B L)$ existing in the province. The Saldanha-Sishen Orex line was excluded from the model as it operates almost entirely as an individual entity with only one main commodity being transported (iron ore). It was due to the independent nature of operation that the system was excluded from the model as it would fall out of the scope of being effected by a Green Economy transition in the Western Cape. 
The Cape Town-Gauteng mainline network is made up of the Western Cape's portion of the rail tracks measured in kilometres (Appendix B.5). The stock is increased by rail line upgrades $\left(r_{r l u}\right)$ and decreased by rail line disruption $\left(r_{r l d}\right)$ as illustrated in Equation 3.4.6. The rail upgrades undertaken on the line are determined by the mainline upgrades required which is determined by the existing gap of the mainline stock with its initial value. This is required because of the holistic nature of a rail line, in that if one section of the line is out of operation the whole line is effected. Rail disruption $\left(r_{r l d}\right)$ is a function of the Ct-Gauteng mainline stock and the rail line life time which is determined by the amount of freight traffic occurring on the line. A relationship was determined between rail life and freight traffic through the use of a lookup of the effects of freight on mainline rail life. The freight transported on the line was broken into intra-provincial and inter-provincial goods, based on economic growth.

$$
C T M L(t)=C T M L\left(t_{0}\right)+\int_{t_{0}}^{t_{n}}\left[r_{r l u}-r_{r l d}\right] \mathrm{d} t
$$

Data for freight being transported in the Western Cape was very limited for a substantial period falling between 2001-2014. Data was obtained through the Freight Transport Data Bank for the Western Cape created by Jorgensen (2005) and obtained through the Western Cape department of transport and public works. This data bank provided specific statistics for each rail line in the western cape, allowing for the modelling of the network however because no data was available for any periods after this, the validation process for these stocks was limited.

\section{Western Cape Branchlines}

In a similar manner to the modelling of the mainline the network of branchlines existing in the Western Cape was undertaken (Appendix B.6). The stock of branchlines $(W C B L)$ was modelled as subscript, influenced in much the same way as that of the mainline. $(W C B L)$ as indicated in Equation 3.4.7 is increased by Branchline upgrades $\left(r_{b u}\right)$ and decreased by Branchline disruption $\left(r_{b d}\right)$. The following branchlines were identified in the Western Cape:

- Overberg line (Eersterivier-Bredasdorp)

- Paarl-Franschoek line

- Cape Town - Bitterfontein line

- Kalbaskraal - Saldanha line

- Worcester - Voorbaain line

- Wolseley - Ceres - Hamlet line

- Mosselbaai - Oudshoorn - Toorwater line

- Hermon - Porterville line 
- George - Knysna line

For both networks the cost of rail renewal and maintenance was accrued annually based on the rate of upgrades achieved for each stock. Two main maintenance measures were identified (Ballast screening and Turnout Replacements) along with the costs of fully renewing sections of the track.

$$
W C B L(t)=W C B L\left(t_{0}\right)+\int_{t_{0}}^{t_{n}}\left[r_{b u}-r_{b d}\right] \mathrm{d} t
$$

Another important variable necessary for discussion was that of the freight allocated to rail based on a green economy transition. With the simulation of the GE transitions for freight transport, the modal split between road and rail freight transport was altered based on strategic frameworks. With road freight being characterised by different corridors, the freight that would then shift onto rail was required to be linked ot the correct branchline. For Example, the freight being moved on the N1 corridor to Gauteng by road is in direct competition with freight being transported on the CT-GAU mainline by rail, thus a link was created and the correct allocation of freight movements were added into the rail network.

\subsubsection{Freight Transport sub-module}

The Freight transport sub-model represents the movement of freight in tonnage, in the Western Cape for road and rail (Appendix B.7). The reason for this being, that the strategies included in a green economy transition are primarily focused around these specific sectors. The other transport infrastructure areas such as airports and harbours have strategic importance more on a national planning level and inherently have specific strategies and frameworks for any future developments. It is for this reason that the scope for modelling freight demand and transport was limited within the boundaries of road and rail.

Modelling freight demand is challenging and in many cases, techniques used can differ significantly. A major determining factor in how a specific freight system is modelled is the level of aggregation to which the scenario is investigated. "Traditionally, the relationship between economic activity and freight transport was used to make forecasts of future aggregate freight flows and volumes" as described by Akiva et al. (2013) ${ }^{1}$. Akiva et al. (2013) go further to explain that although Gross Domestic Product (GDP) is the main indicator of economic activity on a regional or country level, it is too general to be used in most aggregate freight models. The reason being that it consists for a large part of value added generated in the services sector. The authors suggest that

\footnotetext{
${ }^{1}$ Chapter two of book composed by Akiva et al. (2013) but written by Meersman and Van de Voorde (2013)
} 
the use of more relevant indicators which can differ for example by country, by goods category and by mode, additionally the inclusion of indicators which capture the reasons for the changing of transport intensity would be ideal.

The factors affecting the movements of goods are wide ranging and often specific to the value chain and again the scope of aggregation. Ortúzar S. (1994) identifies many of these factors as being; locational, physical, operational, geographical, dynamic and price orientated. Due to the high level of aggregation of this model, freight demand was still dependent on economic activity, however variables such as agricultural production growth and the functionality of the road network were introduced from other sub-models in order to diversify the effects there on. The geographic and locational factors were characterised by the splitting of freight transport into subscripts, for example road freight consisted of:

- Rural

- Metropolitan

- N1 Corridor

- N7 Corridor

- N2 Corridor

This in conjunction with various elasticities used to correlate the model with historical data allowed for relatively accurate predictions of freight flows along these corridors. Once accumulated to provide the provincial freight movements the indicators such as fuel/energy demand and $\mathrm{CO}_{2}$ emissions could be determined as discussed in Section 3.4.2.6.

\subsubsection{Passenger Transport Sub-module}

The Passenger transport sub-module represents the BRT or MyCiti bus service in Cape Town and was modelled based on information obtained from various progress reports and business plans made available through the following sources; Cape Town City Council (2012) and City of Cape Town (2015a). Focus was made only on the BRT fleet $(B R T F)$ which is described in equation 3.4.8, this stock reflects the vehicle fleet growth throughout the MyCiti project phase cycle. Growth is realised through the BRT fleet investment $\left(r_{\text {BRTinv }}\right)$ which basically represents vehicle acquisition and is decreased by BRT bus disruption $\left(r_{B R T d}\right)$.

$$
B R T F(t)=B R T F\left(t_{0}\right)+\int_{t_{0}}^{t_{n}}\left[r_{B R T F i n v}-r_{B R T F d}\right] \mathrm{d} t
$$

Although it would be more realistic to model the various infrastructural aspects of the entire MyCiti project, plans and strategies already exist for this and are entirely project specific. This is the reason for only simulating 
the BRT fleet and not the accompanying stations and infrastructure. Due to the aggregate scope of this model it was more important to investigate the effects on total road infrastructure that would have been developed over the simulated period. It is however important to realise the costs incurred in this project as indicated in equation 3.4.9, this stock $\left(B R T_{E X P}\right)$ reflects the total capital, operational, government funding and generated revenue over the life cycle of the project. The rates of capital, operational, government expenditure increase the stock with the revenue created decreasing the stock of total BRT expenditure.

$$
B R T_{E X P}(t)=B R T_{E X P}\left(t_{0}\right)+\int_{t_{0}}^{t_{n}}\left[r_{C A P E X}+r_{O P E X}+r_{G o v O P E X}-r_{R E V}\right] \mathrm{d} t
$$

From this stock the annual capital expenditure on vehicle acquisition is determined and gets translated into the fleet investment rate as afore mentioned. The total project expenditure becomes an important input into the Green Economy Investment sub-module yet to be described.

It can also be noted that the conventional approach to transport infrastructure modelling includes the estimation of vehicle distance travelled. In conventional transport models this involves the estimation what travel mode should be used to satisfy the required vehicle distance travelled. Whilst this was recognised, the modelling approach in this case was slightly different, for example; variables such as Rail Passengers journeys demand and passengers carried per year both lead to the variable Annual Modal Passenger Travel Distance which goes onto to effect fuel demand and carbon emissions. This did not quite follow the traditional manner whereby an over-arching passenger demand was realised subsequently estimating which modes should represent required vehicle distance travelled. Instead, based on the nature of the information and data acquired for the various transport modes, the model was constructed in the above mentioned manner. This still incorporated the various important aspects of travel distance and passenger demand, but all according to the specific modes which were included as subscripts in the model structure. Again the nature of the level of scope of the research topic being on a provincial level, resulted in focus being put on the overall volume of traffic on the different infrastructure systems which then had influencing factors on their life cycles.

\subsubsection{Emissions sub-module}

This sub-model represents the $\mathrm{CO}_{2}$ emissions resulting from transport activities in the Western Cape which were investigated within the following categories:

- $\mathrm{CO}_{2}$ emissions from road freight 
- $\mathrm{CO}_{2}$ emissions from all road passenger transport

- $\mathrm{CO}_{2}$ emissions from rail freight

The annual emissions from the different transport modes were accumulated as the input rate for the stock of Air Emissions $(A E)$ for the Western Cape. This stock is decreased by the annual natural decomposition rate of atmospheric $\mathrm{CO}_{2}$ as illustrated in equation 3.4.10.(Appendix B.9)

$$
A E(t)=A E\left(t_{1}\right)+\int_{t_{0}}^{t_{n}}\left[r_{A E a}-r_{A E d}\right] \mathrm{d} t
$$

It is important to note the manner in which the emission factors were calculated for the different transport modes, as there is surprisingly little data on actual air emission measurements for these sectors on a provincial scale. Instead in many cases the data were merely estimations based on other driving factors. In this regard the most practised process for determining air emissions was realised and then utilised with respect to the available variables in the model. In this regard the example of passenger transport can be used; whereby annual travel distances based on passenger demand and road functionality result in the total fuel demand per transport mode determined by the average fuel consumption per vehicle type. The $\mathrm{CO}_{2}$ emissions factors obtained from sources such as Indalo Yethu (2014) and U.S. Environmental Protection Agency (2008) were then used to calculate the kilograms of $\mathrm{CO}_{2}$ based on the annual fuel demands per travel mode.

For rail and road freight there exists factors in studies undertaken by the Carbon Fund (2014) organisation resulting in the kilograms of $\mathrm{CO}_{2}$ per tonkilometre travelled annually. The aspect of passenger rail was undertaken slightly differently as the system is predominantly electrified, the carbon footprint results in the electricity generation sphere and thus factors for emissions per power output unit were utilised.

\subsubsection{Other Important Indicators to selected sub-modules}

There are other sub-modules in the model that are not governed necessarily by stocks and flows yet are important indicators to the general modelling problem. A brief discussion is included below to describe the dynamics involved in the various sub-models.

\section{Population of the Western Cape}

The population of the Western Cape is an important driver in the whole transport paradigm, as it directly effects both freight and passenger transport demand and influences the economic activity of the region. Whilst this sub-module is used in the modelling of the transport infrastructure scenario 
it was developed as a collective research effort in modelling a green economy transition in the Western Cape across all sectors ${ }^{2}$. The sub-module is included in Appendix B.12 and for a detailed description of the dynamics involved as elaborated in Musango et al. (2015).

\section{Western Cape Gross Domestic Product}

The GDP sub-model estimates the growth in the provincial GDP over time (Appendix B.13). Due to a lack in data and model outputs the GDP uses the baseline GDP of South Africa as determined in $\mathrm{SAGEM}^{3}$ and is factored down and calibrated to fit the existing GDP recordings. This sub-module also acts as an important driver in the green economy transport model, although it is a rather crude manner for modelling this activity, it remained the only way based on the scope of the problem.

This aspect exists as one of the limitations of this particular model, however the structuring of the model was designed in such a way to be incorporated in a model that focuses on the cross sectoral nature of the GE transition in the Western Cape. The GDP sub-module would then ideally have important feedbacks from all sectors creating the dynamics of the problem occurring endogenously in the model. The aspects that would effect the transport module specifically, would be predominantly felt from the agricultural sector, whereby the interaction between functioning infrastructure and various shifts in agrigoods transportation would be of interest. It would be important to incorporate the total productivity of the transport sector which would have a direct influence on the GDP of the province thus by inclusion creating the necessary feedback for the sectoral sub-module.

Referring to the above discussion involving the sectoral nature of the model. It must be highlighted however that GDP was not fully and independently used as the key driver in many cases. An effort was made to incorporate other key drivers such as population agricultural production for example where possible, to drive certain aspects of the model, such as Freight Transport. Again as mentioned above and in the text, it is difficult to move away from GDP as being a key driver, especially when it comes to large infrastructure investments, as it is often the key influencing factor for such aspects.

\section{Total Road Accidents}

The dynamics of road accidents is something that is very difficult to model, the nature of an accident implies that it is an unforeseeable event. However,

\footnotetext{
${ }^{2}$ Paper presented at the 33rd International Conference of the System Dynamics Society, Cambridge, Massachusetts, USA by Musango et al. (2015)

${ }^{3}$ SAGEM- South African Green Economy Model, A national system dynamics modelling investigating the implications of a green economy transition in South Africa (Musango et al., 2010)
} 
it does remain possible to assume with relative certainty that aspects such as increasing road traffic and poor road conditions will play a significant role in the amount of road accidents. The two variables here mentioned are produced through the model dynamics and thus the relationship of the two in conjunction with elasticities calibrated with available data result in and indication of road accidents in the province. (Appendix B.11)

\section{Fuel Demand}

The importance of the fuel demand sub-model relates to other models in the greater research effort specifically that of bio-fuel production in the Western Cape. This sub-model combines the various fuel demand variable across the sector and sums them into two main variables namely the total petrol demand and the total diesel demand as illustrated in Appendix B.10.

\subsubsection{Green Economy Transport Investment sub-module}

This sub-module lies at the crux of the model problem as it records the expenditure and costs required to meet the transition to a green economy in the transport sector. The stock of green economy investment $(G E I)$ is increased by both operational budgets for green investments $\left(r_{\text {GEopex }}\right)$ and capital investments at certain times thorughout the simulation period $\left(r_{\text {GEcapex }}\right)$. It is evident from equation 3.4.11 that there exists no outflow for this stock, this is due to the nature of the sub-module only acting as an accumulation of the costs to be incurred in a green economy transition.

$$
G E I(t)=G E I\left(t_{0}\right)+\int_{t_{0}}^{t_{n}}\left[r_{\text {GEopex }}+r_{\text {GEcapex }}\right] \mathrm{d} t
$$

\subsection{Model Validation and testing}

With the identification and description of the different sub-modules acting within the model, an understanding of the systems at work and how they were conceptualised is created. This in itself is however not sufficient enough in building confidence within the model. Before any model can be used in some form of policy analysis or problem simulation a significant amount of confidence or 'soundness' must be realised (Maani and Cavana, 2012). From the early days of System Dynamic Modelling Forrester and Senge (1980) had already concluded that no single test which serves to 'validate' a model exists, instead "confidence in a system dynamics model accumulates gradually as the model passes more tests and as new points of correspondence between the model and empirical reality are identified".

This process by which confidence is generated in the model has become known as 'validation'. Coyle (1983) outlines the main test criteria that should 
be used in the validation process, further described by Maani and Cavana (2012) as being:

1. Verification tests - concerned with verifying that the structure and parameters or operating mechanisms in the real system have been correctly transcribed into the model.

2. Validation tests - concerned with demonstrating that the model generates the same behavioural patterns that would be expected in the real system.

3. Legitimisation tests - applied to determine that the model follows the laws of system structure or any other generally accepted rules.

The general purpose for applying these tests is to show that the model is fully representative of the real system in that there is nothing in the model that is not in the real system and visa versa.

There exist many different validation and verification methods aimed at ensuring that the model simulation that has been created is accurate and truly representative. Validation can include comparison testing to the reference mode in order to check the adequacy of the models representation of the problem (Maani and Cavana, 2012). The model can also be put under extreme conditions by manipulating variables to investigate if they react in a realistic manner. Sensitivity analyses can be undertaken to determine the behaviour of the model given uncertainty in parameters and initial conditions. Verification of the model can be achieved through comparative analysis of the model outcomes and historical data for certain time periods. Table 3.6 describes some of the tests as identified by Forrester and Senge (1980) and further refined by Maani and Cavana (2012) 
Table 3.6: System Dynamics 'core' confidence building tests (Maani and Cavana, 2012) \& (Forrester and Senge, 1980)

\begin{tabular}{|c|c|}
\hline \multicolumn{2}{|r|}{ Tests for model structure } \\
\hline Structure verification & $\begin{array}{l}\text { Is the model structure comparable with the } \\
\text { structure of the real system? }\end{array}$ \\
\hline $\begin{array}{l}\text { Parameter } \\
\text { verifications }\end{array}$ & $\begin{array}{l}\text { Do model parameters correspond conceptually } \\
\text { and numerically to the real system? }\end{array}$ \\
\hline Extreme Conditions & $\begin{array}{l}\text { Are the rate(policy) equations plausible if } \\
\text { maximum and minimum values are applied to } \\
\text { different variables? }\end{array}$ \\
\hline Boundary adequacy & Is the level of model aggregation appropriate? \\
\hline $\begin{array}{l}\text { Dimensional } \\
\text { consistency }\end{array}$ & $\begin{array}{l}\text { Are the rate equations dimensionally consistent } \\
\text { and do they have real-life meaning? }\end{array}$ \\
\hline \multicolumn{2}{|r|}{ Tests of model behaviour } \\
\hline $\begin{array}{l}\text { Behaviour } \\
\text { reproduction }\end{array}$ & $\begin{array}{l}\text { How well does the model-generated behaviour } \\
\text { represent the observed behaviour of the real } \\
\text { system? }\end{array}$ \\
\hline Behaviour anomaly & $\begin{array}{l}\text { Can a model assumption be defended if } \\
\text { implausible model behaviour occurs if the } \\
\text { assumption is altered? }\end{array}$ \\
\hline Behaviour sensitivity & $\begin{array}{l}\text { Can plausible shifts in model parameters cause a } \\
\text { model to fail model behaviour tests previously } \\
\text { passed? }\end{array}$ \\
\hline \multicolumn{2}{|r|}{ Tests of policy implications } \\
\hline $\begin{array}{l}\text { Changed behaviour } \\
\text { prediction }\end{array}$ & $\begin{array}{l}\text { Does the model correctly predict how the model } \\
\text { behaviour of the system will change if a } \\
\text { governing policy is changed? }\end{array}$ \\
\hline Policy sensitivity & $\begin{array}{l}\text { To what extent are policy recommendations } \\
\text { altered by plausible changes to parameter values? }\end{array}$ \\
\hline
\end{tabular}

The validation of the Western Cape Green Economy Transport Infrastructure model was an iterative process followed throughout the model building endeavour. This process is discussed with specific reference to the three core confidences areas of model testing as illustrated in Table 3.6.

\subsubsection{Validation of model structure}

The first step in verifying a model is to build confidence in the structure and parameters acting within the model itself. Barlas (1996) distinguishes between two types of structure tests that can be implemented in the model validation 
process: direct structure tests and structure-oriented behaviour tests. Direct structure tests aim to compare the model structure with knowledge about the real system, this involves looking into the mathematical or logical relationships individually and comparing them with available information concerning the real system. Structure-orientated behaviour tests asses the validity of the structure indirectly, through the application of certain behaviour tests on model-generated behaviour patterns (Barlas, 1996). With this in mind the model was put under a basic structural test for certain key variables and observing the outputs of the model and whether they represented the conditional change.

The Vensim software program (Ventana Systems Inc., 2013) utilises two measures of built-in model structure validation, namely a model check and a units check used as a dimension test for the model. The model check feature runs through all equations within the model and highlights any inconsistencies or fundamental errors in the equations. This process is undertaken throughout the model building stages and is necessary in order to run any simulation. The units check feature ascertains whether the model is dimensionally valid, in that the dimensions or units of measurement for the left-hand side of the equation is able to be converted to units on the right-hand side within each variable. In both tests the model in question displayed $100 \%$ validity.

The nature of the System Dynamics approach aims to inherently communicate scientific or hypothetical theories about the real world. Underlying this aspect is that of model transparency as described by Martinez-Moyano (2012) as being an important attribute of useful models because "it enables users to identify and understand the assumptions, relationships and data used in the model". In response to the transparency necessity and requirement for the enhanced documentation of models, The System Dynamics Model Documentation and Assessment Tool (SDM-Doc) ${ }^{4}$ was designed to provide a practical HTML-based model documentation and assessment tool to modellers. This tool provides a robust measure of the structural integrity of the model acting as an important means to building confidence, sections of the output run are included in Appendix C.

Martinez-Moyano (2012) provides a brief description of the various outputs resulting from the SDM-Doc assessment. One of which being the warnings section reporting on the number of equations that fail a set of documentation and formulation tests. The following warnings are included in the output:

- Undocumented Equations

\footnotetext{
${ }^{4}$ created at Argonne (Argonne National Laboratory and the University of Chicago, IL, USA) and hosted at the System Dynamics Society Web pages (http://tools.systemdynamics.org/sdm-doc/)
} 
- Equations with Embedded Data

- Equations with unit errors or warnings

- Variables not in any view

- Incompletely Defined Subscripted Variables

- Non-monotonic Lookup Functions

- Cascading Chained Lookup Functions

- Equations with IF...THEN...ELSE

- Equations with MIN or MAX

The warnings provided a good indication of the weak areas within the model structure. Firstly the undocumented equations warning revealed a high number of variables, which for a 'free-standing' model would normally reduce confidence in the model validity. However, because an in depth discussion is provided in the accompanying text of each sub-module this was not seen as detracting from the model transparency.

Martinez-Moyano (2012) describes that embedded data (equations in which numeric data is found) result in the model being obscured and often suspect of hiding information. Instead additional variables should be created to hold numeric values. In this case 48 variables indicated the warning of embedded data, yet 25 of those were level $^{5}$ variables where the inherent zero value gets identified as an embedded numeric value, which does not detract from any model validity. The remaining variables were investigated individually and either changed so as not to have embedded values or deemed satisfactory due to the use of unit or zero values within MIN/MAX and IF...THEN...ELSE functions or modal percentage changes also using unit values. The reason for these equations being satisfactory is that the values are used not for their numeric value but rather as binary functions. Other warnings such as Equations with unit errors or warnings, Variables not in any view, Cascading Chained Lookup Functions all indicated zero variables.

Another output of the SDM-Doc assessment is that of potential omissions which reports on the number of unused, supplementary, overly-complex and used supplementary variables occurring in the model. Of interest in this regard is the warning of overly complex variable formulations not adhering to the Richardson rule which states that; "in order to maximise the level of transparency of equation formulation, an equation should have a maximum of three variables as input". The threshold for this rule can be dependent on the modellers preference but as Martinez-Moyano (2012) explains; there exists a tension between achieving "model parsimony and equation simplicity" within the model. The results yielded 37 variables failing a threshold of 3,20 of

\footnotetext{
${ }^{5}$ Levels or stocks are accumulated quantities within the system, existing to describe the condition of the system (Maani and Cavana, 2012)
} 
which failed at a threshold of 4 and 11 failing at a threshold of 5 , these results were deemed sufficient as the majority of variables only just failed to meet the stringent threshold.

\subsubsection{Validation of model behaviour}

Obtaining real world data and measuring the inputs and outputs of the real system and the attributes of the intermediate variables is the first step in validating a model according to (Kleijnen, 1995). This was undertaken in many of the stocks within the model and comparison to the real data revealed adequate similarities between the model outputs and historical data. It is important to mention at this point as does Barlas (1996) that the emphasis is on pattern prediction rather than point or event prediction when it comes to reproducing behavioural patterns exhibited in the real system. A good example of model behaviour matching the behaviour of the real system is that of road freight transportation along various corridors as illustrated in Figure 3.6.

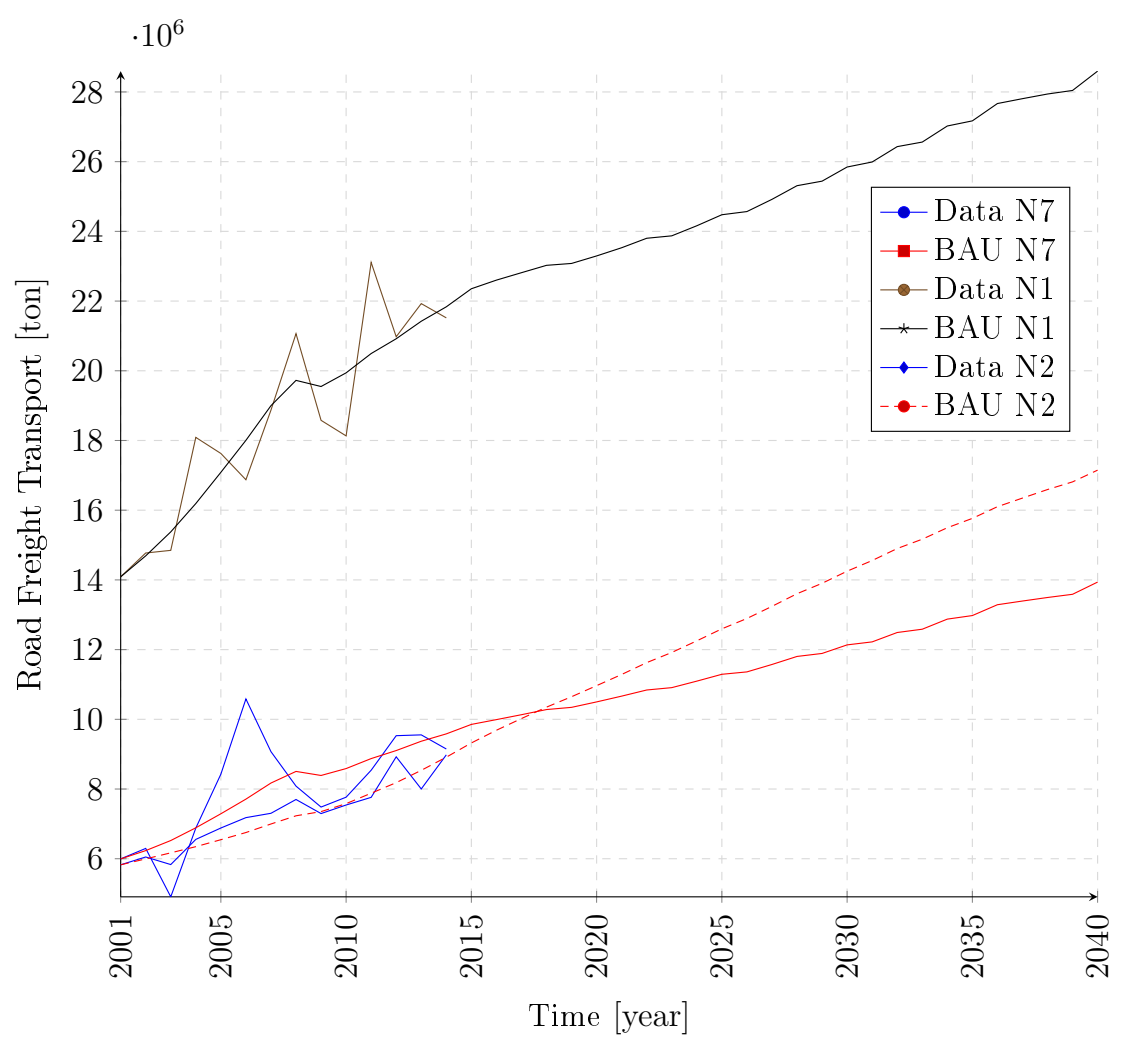

Figure 3.6: Selected Road Freight corridors to illustrate behavioural reproduction in the model 
It is evident that the real system behaviour fluctuates substantially as a result of the highly variable commodity drivers existing in road freight transport. However, the model manages to maintain an adequate behavioural match with regards to the pattern of growth over the extended model simulation period. Whilst there are many cases of adequate behavioural reproduction there are also variables that do not match the real system based on the data provided. As illustrated in Figure 3.7 the limited data points do not always match the model behaviour, but still provide enough of an indication as to the general system behaviour to still validate and provide confidence in the model outputs. This example in particular illustrates the difficulty in model building with limited information, but also describes the ability of System Dynamics to realise a certain level of robustness with this limitation.

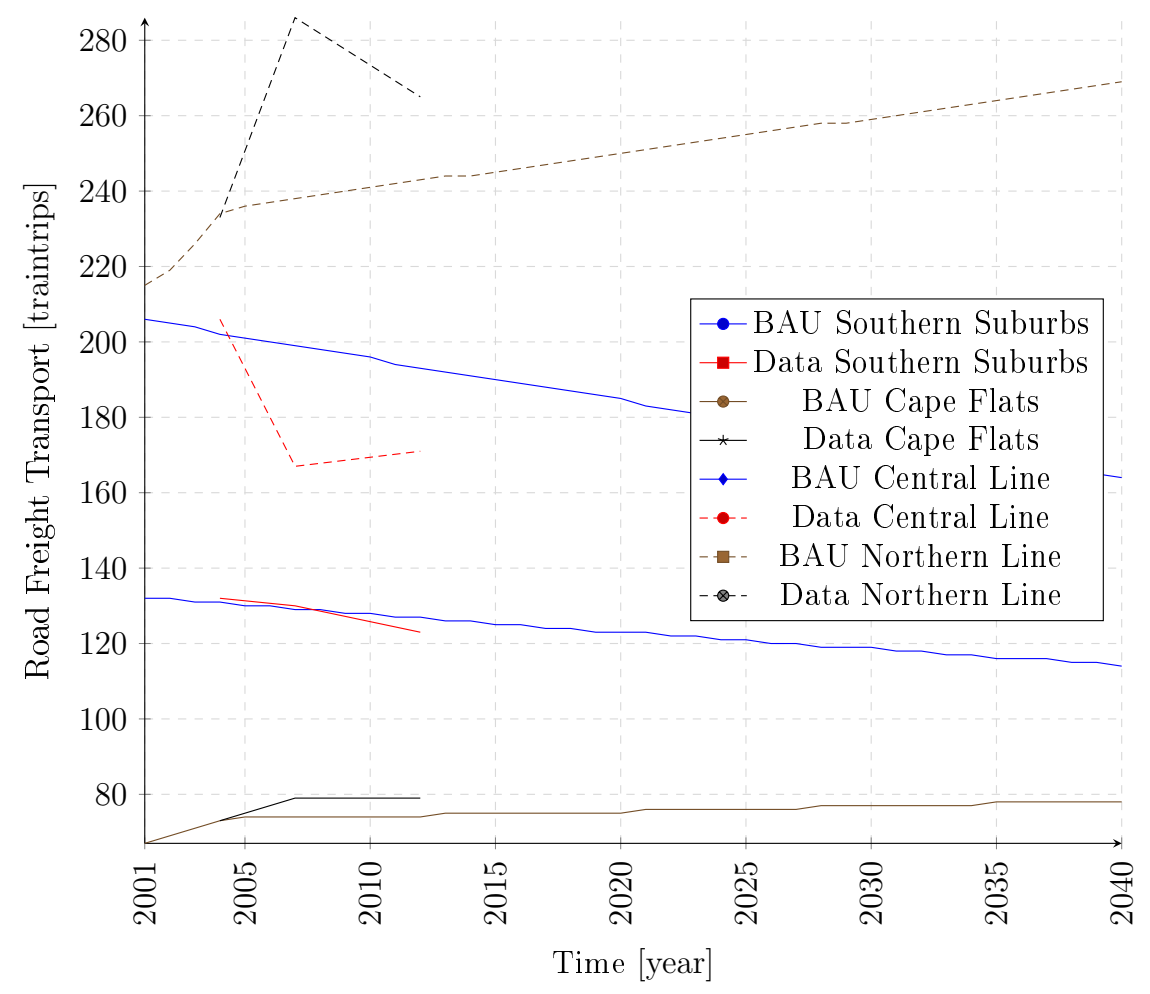

Figure 3.7: Selected Metro Rail corridors to illustrate behavioural reproduction in the model

During the model building phase more often than not the initial conditions, parameter values and structural relationships or equations are based on estimation or assumption. Because of this, confidence in the model can be reduced thus making it important to understand the behaviour of the model when subjected to variations in these parameters over a reasonable range. This process 
is called sensitivity analysis, the purpose of which as described by Maani and Cavana (2012) "is to see how much the system's quantitative (numerical) and qualitative (graphical) behaviour changes if the uncertain parameter values are altered". For the sensitivity analyses conducted in the model the Monte Carlo method was used with a random uniform distribution for a number of 300 simulation runs.

A good example of this involves the stock and flow of Functioning Roads and Road Disruption respectively which are both influenced by the exogenous variable of Elasticity of Road Maintenance and Traffic on Road Life. The sensitivity or confidence intervals ranging from $50 \%, 75 \%, 95 \%, 100 \%$ as illustrated by the various colour bands in Figure 3.8. From the graphics it is evident that the rate of Road Disruption (Figure 3.8a) is substantially sensitive to this parameter, which is to be expected as the variable is directly involved in the flow rate relationship. On the other hand this sensitivity is immediately diminished when comparing to the stock of Functioning Roads (Figure 3.8b) which is also expected, as the stock is not only influenced by the one flow rate. A certain amount of confidence can be taken from this as the stock is the most important variable and indicates a robust level of sensitivity illustrated by the narrow confidence bands in the graphic. 


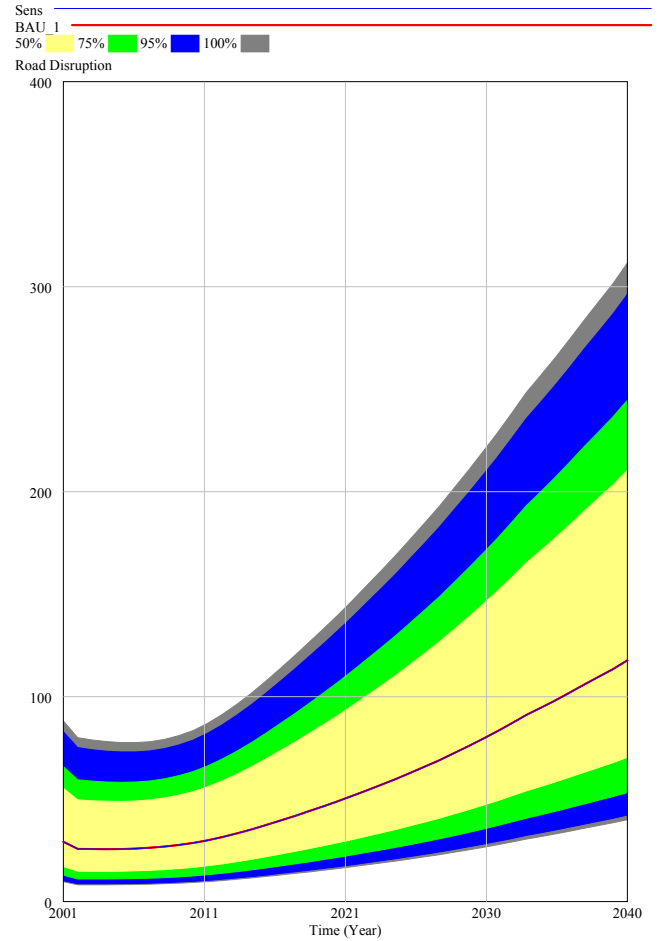

(a) Road Disruption

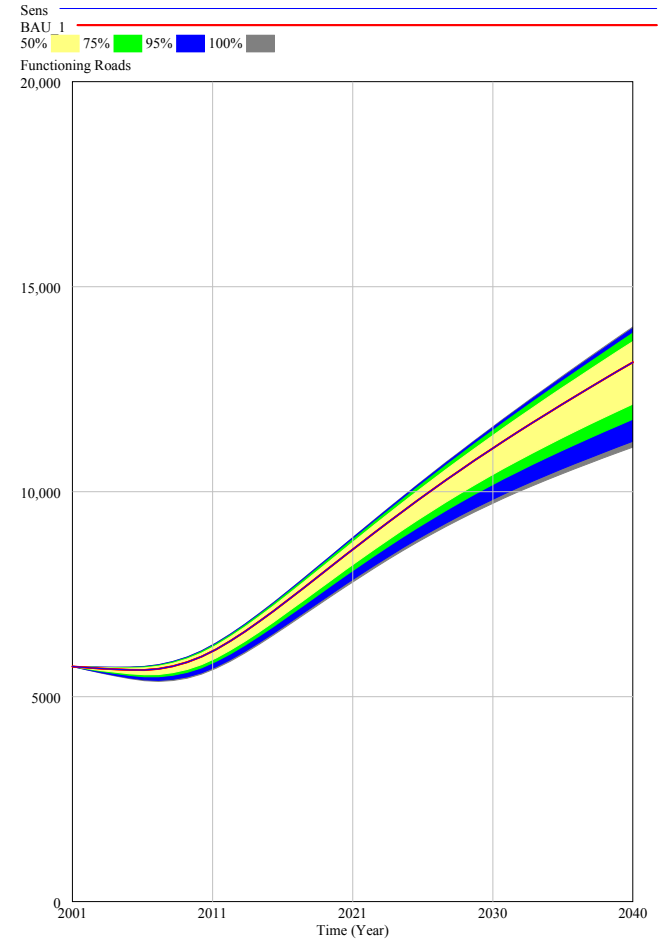

(b) Functioning Roads

Figure 3.8: Sensitivity Analysis: Elasticity of Road Maintenance and Traffic on road life

Another important sensitivity analysis conducted in the model validation process was that of the effects that the elasticity of inter-and-intra-provincial freight movements to GDP growth has on the entire rail network. In the case of the Cape Town-Gauteng mainline, the effects of both elasticities were tested within a $10 \%$ certainty range of $0-0.2$ with the parameter values being 0.1 respectively. The results of the tests (Figure 3.9) illustrate that mainline functioning track is not very sensitive to these exogenous variables. However, the costs incurred due to mainline maintenance and renewal are very sensitive. This comes as a result of rail upgrades and maintenance being directly influenced by annual rail disruptions. Again with the importance that the stock of rail track holds indicating a low sensitivity to exogenous variables, a relative sense of confidence can be realised in this section of the model. 


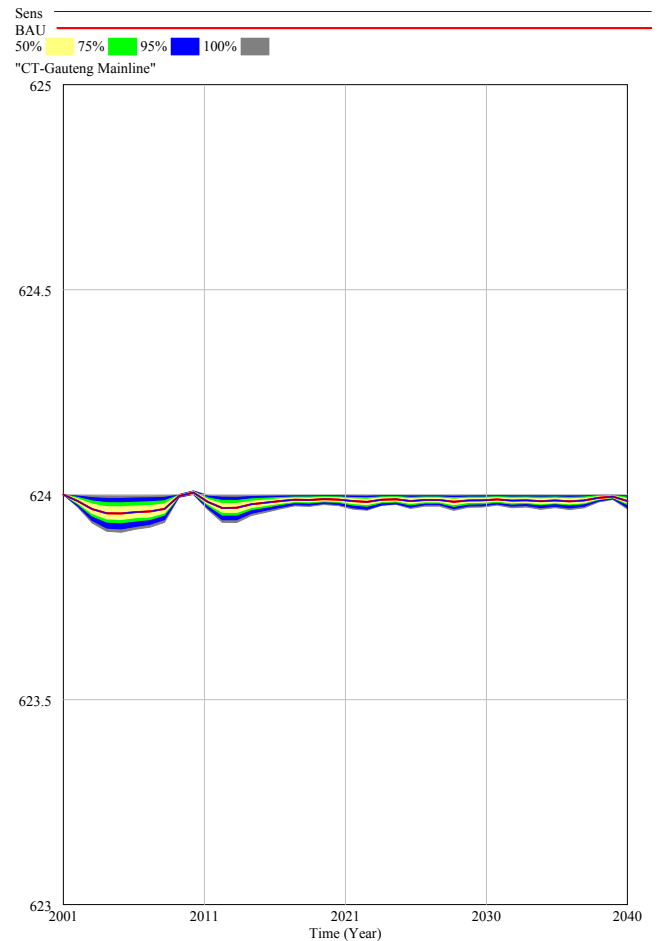

(a) Cape Town-Gauteng mainline

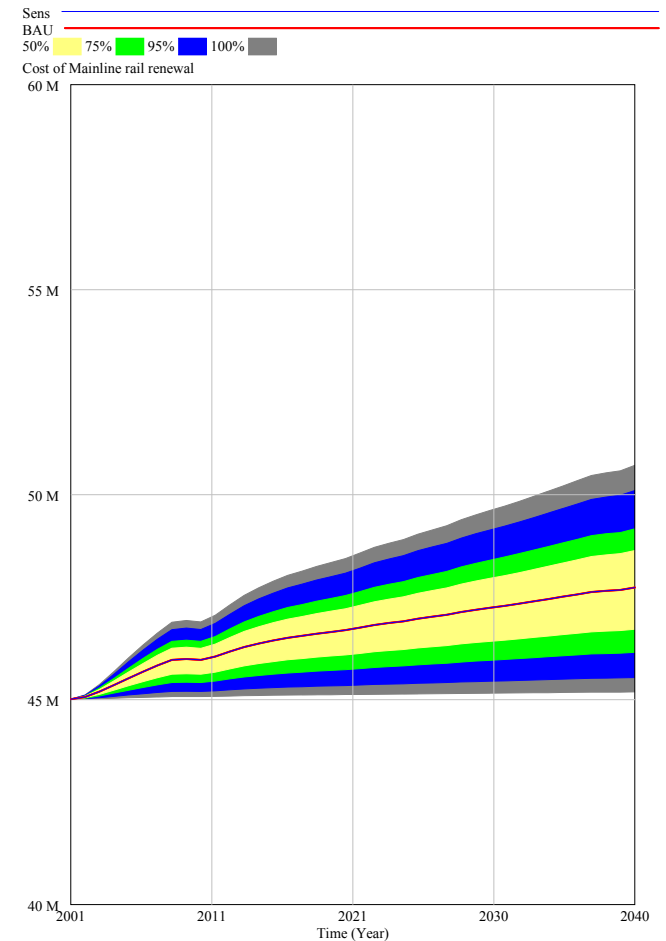

(b) Mainline renewal \& maintenance costs

Figure 3.9: Sensitivity analysis: Elasticity of inter-and-intra-provincial freight movements to GDP growth on rail network

The sensitivity analyses carried out in the model building process are carried out to find the key points or parameters in the system that cause considerable behaviour changes to model outcomes. As expected many of the variables acting as elasticities indicated a high level of induced sensitivity to other model parameters. This was to be expected and exists as a limitation to the model, however these variables were managed and mitigated as best a possible.

\subsubsection{Validation of policy implications}

The implications of changes in policy or in this case various scenario analyses requires a more conceptual assessment for model validation. In this regard the outputs obtained through the scenario runs were assessed on the expected outcomes of the policy changes and whether the behaviour predicts what is expected in the real situation. This process was undertaken in an iterative manner with more discussion following in Chapter 4, about the expected and achieved outcomes of the various scenarios. One of the key stocks however that is influenced by all scenario changes is the stock of Green Economy Transport Infrastructure Investment and is thus analysed with regards to the sensitivity 
to policy change.

The sensitivity analysis followed the same process as mentioned before but aims to check the extent to which the changes in certain parameter changes have on the scenario outputs. The parameters included for the GE passenger transport scenario was: Annual Operating subsidy for Bus services, Elasticity of BRT Expenditure on vehicle acquisition, and Predicted Prasa train-set rollout. The Parameters included for the GE rail freight scenario was: Expected Expenditure on Freight Rail.

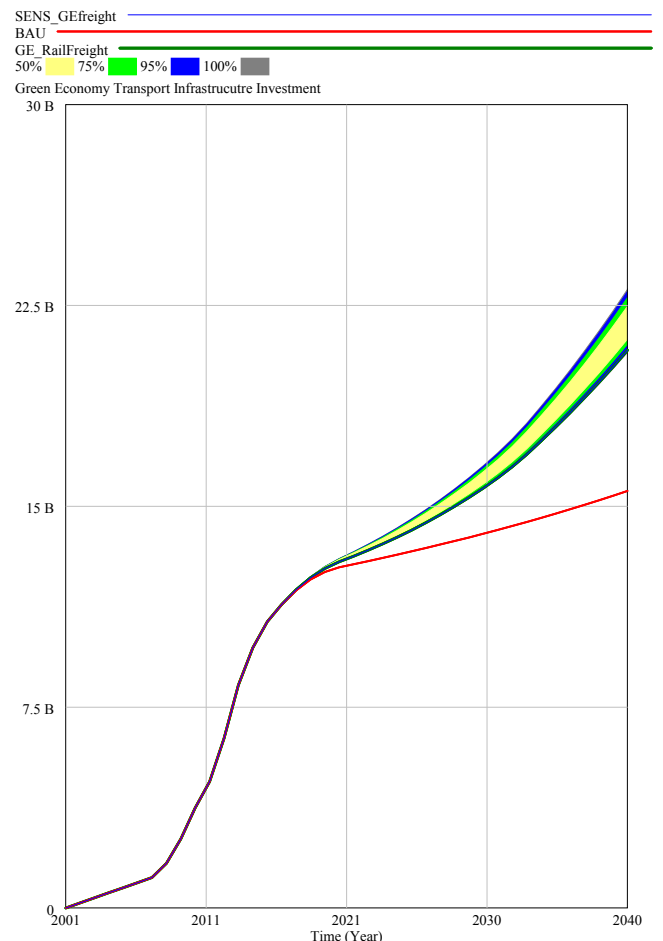

(a) GE investment into Rail Freight

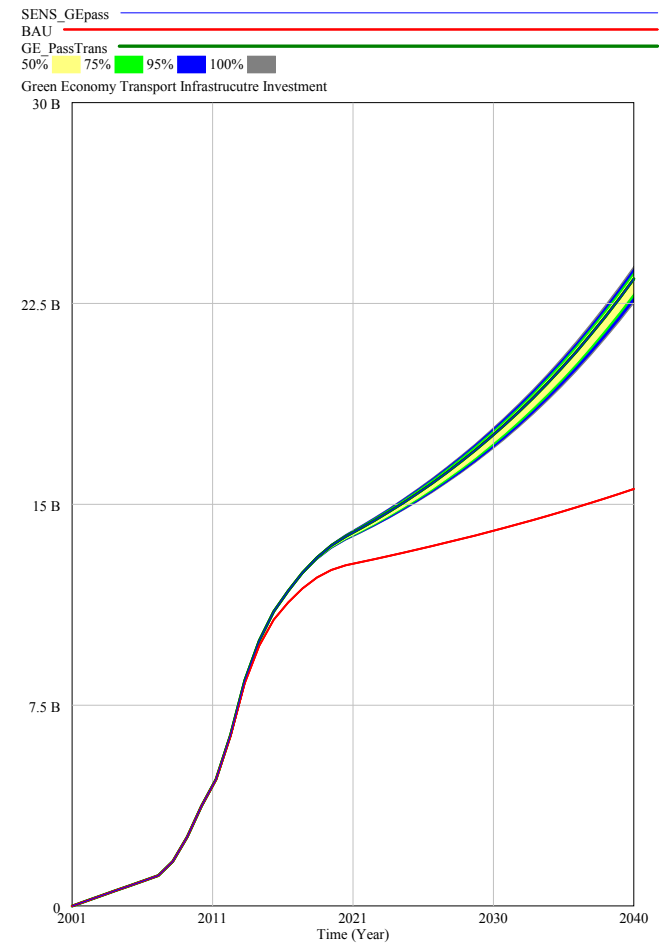

(b) GE investment into Public Transport

Figure 3.10: Sensitivity analysis of key input variables for GE scenario predictions on the GE Transport Infrastructure Investment stock

Both sensitivity analyses indicated adequate confidence bands in the effects that the input variables mentioned would have on the overall stock of Green Economy Transport investment. In both cases the business as usual scenario is included to provide a reference point as to the costs incurred due to Green Economy investments into transport infrastructure. 


\subsection{Scenario planning and modelling}

In this phase, various policies and strategies are formulated and tested where 'policy' refers to the changing of a single variable in the model and analysing the outcome of that change (Maani and Cavana, 2012). The reference to 'strategy' is the combination of a set of policies and, as such deals with internal or controllable changes according to Maani and Cavana (2012). When these strategies are tested under varying external conditions all aspects of scenario modelling are realised. It is important during this phase to envelop the general scope of the problem aims, to identify key drivers of change and to estimate the performance of the policies and strategies for each scenario.

The different scenarios were chosen in line with the Western Cape Infrastructure strategic framework and were used to create an indication of the implications involved in a GE transition on the transport sector. The effects of the various scenarios were compared to the Business as usual (BAU) scenario which aimed to illustrate the effects with no extra investment on the current infrastructure networks. The different policy changes implemented in the scenarios were based on initiatives that were already earmarked as future investment options through the green is smart strategy and others as indicated in Table 3.2. 
Table 3.7: Description of scenarios for green economy infrastructure in the Western Cape

\begin{tabular}{|c|c|c|}
\hline Scenarios & Description & Expected outcome \\
\hline $\begin{array}{l}\text { BAU-Business } \\
\text { As Usual }\end{array}$ & $\begin{array}{l}\text { - No investment into green } \\
\text { economy initiatives } \\
\text { - Influence of truck and mo- } \\
\text { tor vehicles fully impact } \\
\text { on road life }\end{array}$ & $\begin{array}{l}\text { - Decreased number of } \\
\text { Functioning roads } \\
\text { - Increase in } \mathrm{CO}_{2} \text { emissions } \\
\text { - Increase in private motor } \\
\text { vehicles }\end{array}$ \\
\hline $\begin{array}{l}\text { S1-Investment } \\
\text { into public } \\
\text { passenger } \\
\text { transport }\end{array}$ & $\begin{array}{l}\text { - Investment into inte- } \\
\text { grated minibus taxi } \\
\text { services } \\
\text { - Investment into Conven- } \\
\text { tional Bus transport } \\
\text { - Investment into bus IRT } \\
\text { (MyCiTi busses) } \\
\text { - Investment into Metrorail } \\
\text { fleet and network }\end{array}$ & $\begin{array}{l}\text { - Decrease in } \mathrm{CO}_{2} \text { emis- } \\
\text { sions } \\
\text { - Decrease in private vehi- } \\
\text { cle use }\end{array}$ \\
\hline $\begin{array}{l}\text { S2-Investment } \\
\text { into Freight } \\
\text { Rail System }\end{array}$ & $\begin{array}{l}\text { - Change in the modal split } \\
\text { of freight transportation } \\
\text { through investment } \\
\text { - Increase investment into } \\
\text { rail network }\end{array}$ & 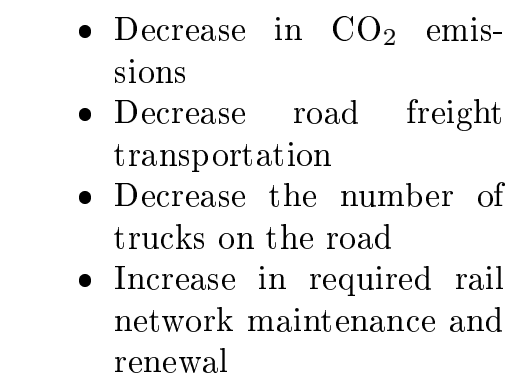 \\
\hline $\begin{array}{l}\text { S3-Investment } \\
\text { into both public } \\
\text { passenger } \\
\text { transport and } \\
\text { freight rail } \\
\text { system }\end{array}$ & $\begin{array}{l}\text { - Change the modal splits } \\
\text { for both effects as men- } \\
\text { tioned above }\end{array}$ & $\begin{array}{l}\text { - Similar effects as above } \\
\text { but with a greater de- } \\
\text { crease in } \mathrm{C} 02 \text { and road life } \\
\text { effect }\end{array}$ \\
\hline
\end{tabular}

The BAU scenario illustrates how a growth in population and thus transport demand will influence the road and rail networks based on current and expected levels of expenditure. The policy changes within the scenarios as defined in Table 3.7 indicate the variables that were changed over time in accordance with specific transition strategies. The potential policy changes or strategies as defined in the Western Cape Infrastructure Framework (Palmer and Graham, 2013) were realised and included as percentage changes over the simulation period as indicated in Table 3.8. 
Table 3.8: Key variables indicating the modal percentage changes required for a GE transition

\begin{tabular}{lrrrr}
\hline \multicolumn{5}{c}{ Percentage changes through simulation period } \\
\hline Public Passenger Modal Changes & 2000 & 2020 & 2030 & 2040 \\
\hline Passenger Rail Investment Change & 0 & 0.1 & 0.2 & 0.3 \\
IRT Investment Change & 0 & 0.016667 & 0.033333 & 0.05 \\
Bus transport Investment Change & 0 & 0.016667 & 0.033333 & 0.05 \\
Minbus Taxi Investment Change & 0 & 0.016667 & 0.033333 & 0.05 \\
NMT Investment Change & 0 & 0.013333 & 0.026667 & 0.04 \\
\hline Freight Modal Split from road to rail & 2000 & 2020 & 2030 & 2040 \\
\hline Freight Modal Split & 0 & 0.05 & 0.1 & 0.2 \\
\hline
\end{tabular}

The values characterised in Table 3.8 indicate percentage changes over time. For passenger transport, this entails shifts in the live vehicles between modes. In its simplest form for example, a percentage shift for passenger rail would mean more people using the rail system and thus not requiring to use private transport. It would ultimately be expected that the desired vehicle ownership would resultantly decrease over time because of this modal shift. The same would apply for all modes of public transport based on the indicated modal changes. The modal shift between road and rail was assumed to be $20 \%$ which was conservatively assumed based on estimations made in the Western Cape Infrastructure Framework. The modal shift results in a transfer of freight being transported by road onto the corresponding rail corridors or lines and factored according to the current utilisation of each specific rail line. The effects of this shift on the rail networks and systems can then be observed, both on an infrastructure and cost basis.

\subsection{Implementation and organisational learning}

This phase of the SDM process is geared more to specific modelling projects but involves the reporting and communication of the results and insights of the study to the relevant stakeholders. In the case of this study this phase falls into the greater scope of the research effort and thus is not highlighted as part of the methodology but rather as the final chapters of the study itself, discussing the results and conclusions of the model outcomes. In this regard the insights developed through the study will be communicated based on certain recommendations to the various stakeholders that have been identified and also shed light on the challenges and lessons learnt throughout the study. 


\subsection{Conclusion of Methodology chapter}

This chapter provided the step-by-step thought processes and methodical actions undertaken in the model building process. Utilising this modelling approach, the research effort aimed to improve understanding, and develop the associated capacities, of how technical, economic, political and other socioecological factors interact, particularly in the context of the infrastructure uncertainties encountered during a green economy transition. Similar to the approach taken in the SAGEM model Musango et al. (2014), this simulation aimed to identify the possible options and opportunities to achieving targets based on planned expenditures and/or costs of interventions.

The model boundary as conceptualised from the defined problem was described along with the manner in which data was acquired and processed. The dynamic understanding of causality within the system and various causal loops were discussed and provided the level of aggregation involved in the model. From this each sub-module was described and unravelled so as to create transparency in the model building thinking leading to the tests involved in the validation of the model. An important discussion of the policy changes and scenario analyses described the way in which the crucial questions to be asked were included in the model as input parameters. This enabled a level of understanding to be formed so as to bridge across to Chapter 4 which discusses the results of the simulation. 


\section{Chapter 4}

\section{Analysis of Baseline and Scenario Results}

The Problem Scenarios as discussed in Chapter 3.6 were simulated through the model to reveal the results to be discussed in the following sections. The scenarios were created to indicate the various policy changes in response to a Green Economy transition in the transport sector. The implications for which are characterised by the four output scenarios: Business As Usual $(B A U)$, Investment into Passenger Transport( $S 1)$, Investment into a modal Freight $\operatorname{shift}($ S2) and a combination of both $(S 3)$. The important stocks and key indicating variables of the various sub-modules are discussed with regards to the defined simulation outputs.

\subsection{Western Cape Road Infrastructure Network}

The results obtained for the key stock of the Western Cape paved road network interestingly characterised by the 'S'-shaped graph illustrated in Figure 4.1. The trend here relates to the kilometres of paved network initially decreasing due to a lack of road infrastructure expenditure (Figure D.2). As the budget for road construction (Figure D.1) increases in response to the state of the roads, more projects are able to reach their completion date and thus add to the stock of functioning roads. However with this acceleration comes the inevitable plateau effect as expenditure becomes more stable and roads begin to reach the end of their design lives. 


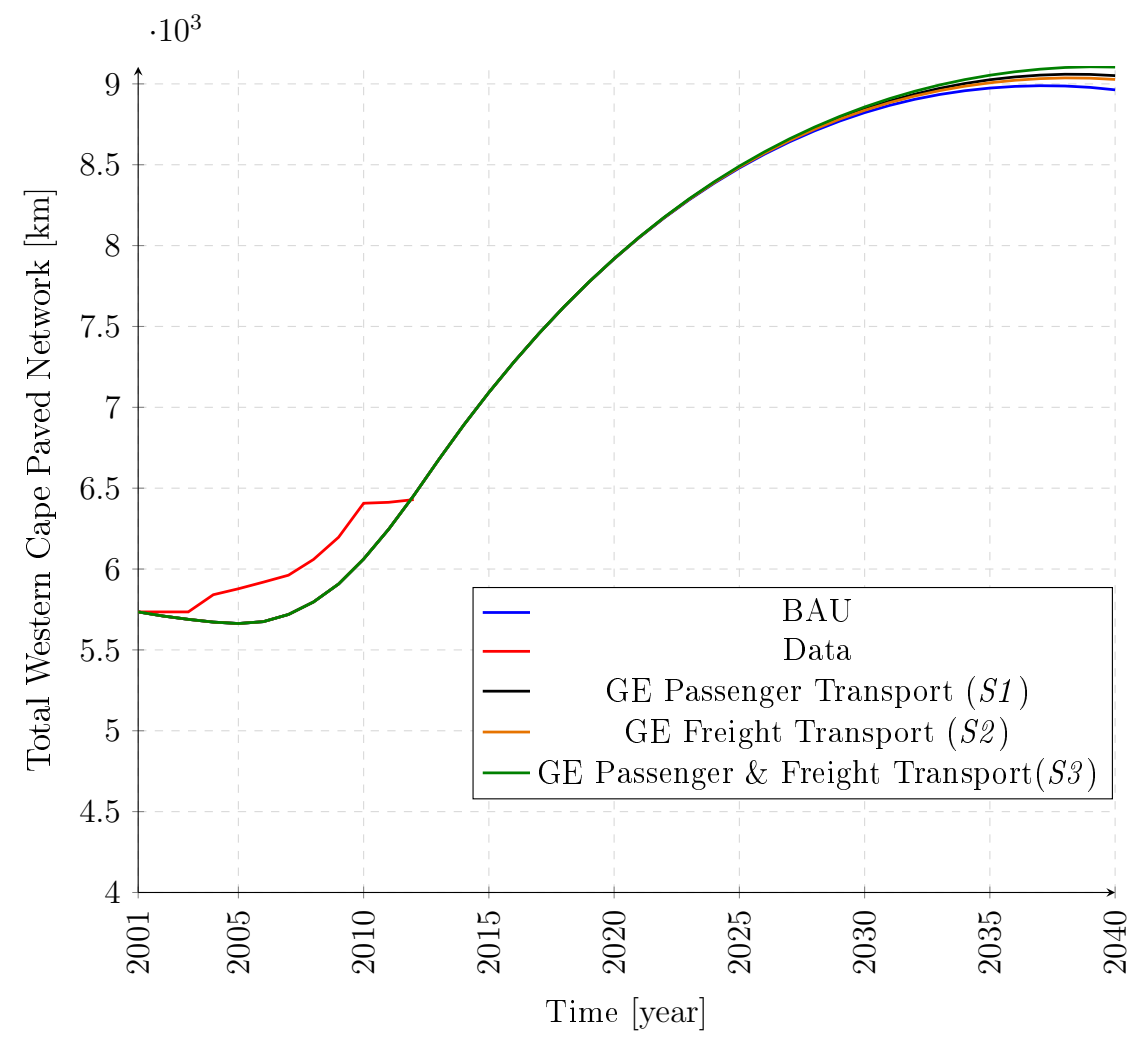

Figure 4.1: Total Motor Vehicle on Western Cape Roads

The scenario outputs illustrate how the process of road disruption (Figure D.3) is slowly decreased as the various policy interventions begin taking effect. The most beneficial scenario to functioning roads is expectedly that of $S 3$ interventions involving a shift in both freight and passenger transport to rail and public modes respectively. Interestingly, the least effective scenario is that of an S2 modal freight transport shift. This would lead to the conclusion that passenger transport in fact has a greater effect on the road design life and that a shift towards public transportation in the Province is of great importance to the survival of the road network. 
Table 4.1: Western Cape pavement network conditions

\begin{tabular}{lllllc}
\hline & \multicolumn{5}{c}{ Time Intervals } \\
& 2001 & 2015 & 2030 & 2040 & \% change \\
\hline BAU & & & & & \\
Very Good & 1238 & 1422 & 1585 & 1527 & 23 \\
Good & 2186 & 2510 & 2799 & 2697 & 23 \\
Poor & 521 & 693 & 962 & 1031 & 98 \\
GE Passenger Transport(S1) & & & & & \\
Very Good & 1238 & 1422 & 1628 & 1598 & 28 \\
Good & 2186 & 2511 & 2875 & 2822 & 28 \\
Poor & 521 & 693 & 941 & 1004 & 93 \\
GE Rail Freight (S2) & & & & & \\
Very Good & 1238 & 1422 & 1610 & 1588 & 29 \\
Good & 2186 & 2510 & 2842 & 2805 & 29 \\
Poor & 521 & 693 & 951 & 1005 & 93 \\
GE Passenger \& Freight(S3) & & & & & \\
Very Good & 1238 & 1422 & 1654 & 1664 & 34 \\
Good & 2186 & 2511 & 2921 & 2938 & 34 \\
Poor & 521 & 693 & 929 & 976 & 87 \\
\hline
\end{tabular}

Related to the stock of functioning roads is that of road condition (Figure D.4) which is realised through road surveys conducted throughout the province. The results for three of the five existing road condition levels (very Good, Good, and Poor) defined in Table 4.1 indicated an increase in good and very good road conditions over time in response to the scenario strategies with $S 3$ having the greatest effect, whilst a slight decrease on poor roads was also realised. The percentage change of pavement conditions for the the three mentioned condition levels from the start of the simulation period to the end, indicate that an $11 \%$ increase in Very Good and Good pavement conditions will be realised in the $S 3$ scenario compared to the $B A U$ case. This outcome is also coupled with a drop from $98 \%$ to $87 \%$ from the $B A U$ to $S 3$ scenarios for the poor pavement condition, resulting in the combination of both passenger and freight transport being the best case of road conditions.

\subsection{Live Vehicle Population sub-module}

The results of the live vehicle population indicate substantial growth by the year 2040 in the BAU scenario. The trend of the historical data evident in Figure 4.2 supports the business as usual case and would mean that by the year 2040 the total live vehicles would have more than doubled in capacity. The strategies involved in mitigating the live vehicles however result in a $55 \%$ 
decrease in live vehicle numbers by the year 2040 when compared to the $B A U$ scenario. Interestingly, the difference between scenarios $S 1$ and $S 3$ is slight, this comes as a result of the minuscule decrease in truck numbers realised in S2 when compared with the total motor vehicles in the Province. The live vehicles for all subscript ranges also indicate substantial growth across the various vehicle categories as illustrated in Figure D.5.

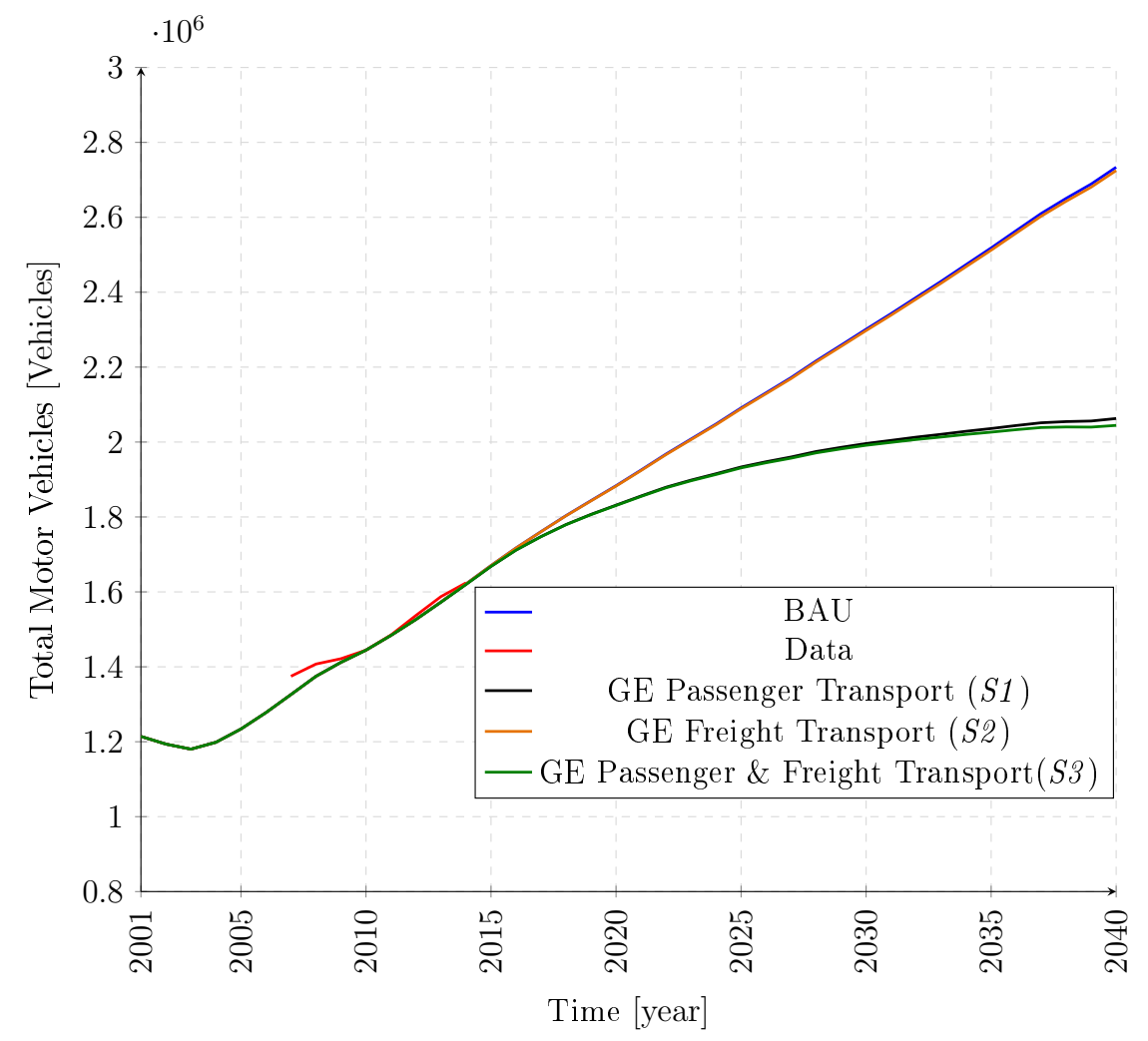

Figure 4.2: Total Motor Vehicle on Western Cape Roads

An important indicator exists in the variable of trucks utilising Western Cape roads as this parameter forms part of an import Green Economy transitions with regards to a shift of freight transport onto rail. Here again the influence of the policy changes in the various scenarios is evidently significant after taking effect (Figure D.6). A decrease in heavy vehicle traffic of up to $15 \%$ can be realised through the policy changes in $S 2$ and $S 3$ of aiming for a $20 \%$ shift of freight to rail by 2040 as discussed in Table 3.8 describing the various model scenarios. 


\subsection{Cape Metrorail Network and system sub-module}

The Cape Metrorail network compromising of the four main services lines, namely the; Southern suburbs, Cape Flats, Northern and Central Lines is totalled in Figure 4.3 to illustrate the general health of the network in its entirety. This variable gives an indication of the stock of relative functioning kilometres of rail track for the system which is inherently decreasing over time. The $B A U$ scenario does how ever suggest a slight resolve in the system as the maintenance and renewal measures undertaken proliferate the life of the rail track. The deficit between the original total kilometres of rail track and the functioning track over time can be understood as the constant rail renewal and maintenance backlog that exists in the real system (Figure D.7). This deficit is significantly exasperated through the GE scenario simulations however when the numbers are compared, scenario $S 1$ results in a deficit of $4.8 \mathrm{~km}$ which is only $1 \%$ of the entire network. This is interpreted as resulting from the increased train scheduling incurred through the Prasa Roll-out Strategy in effect from 2016.

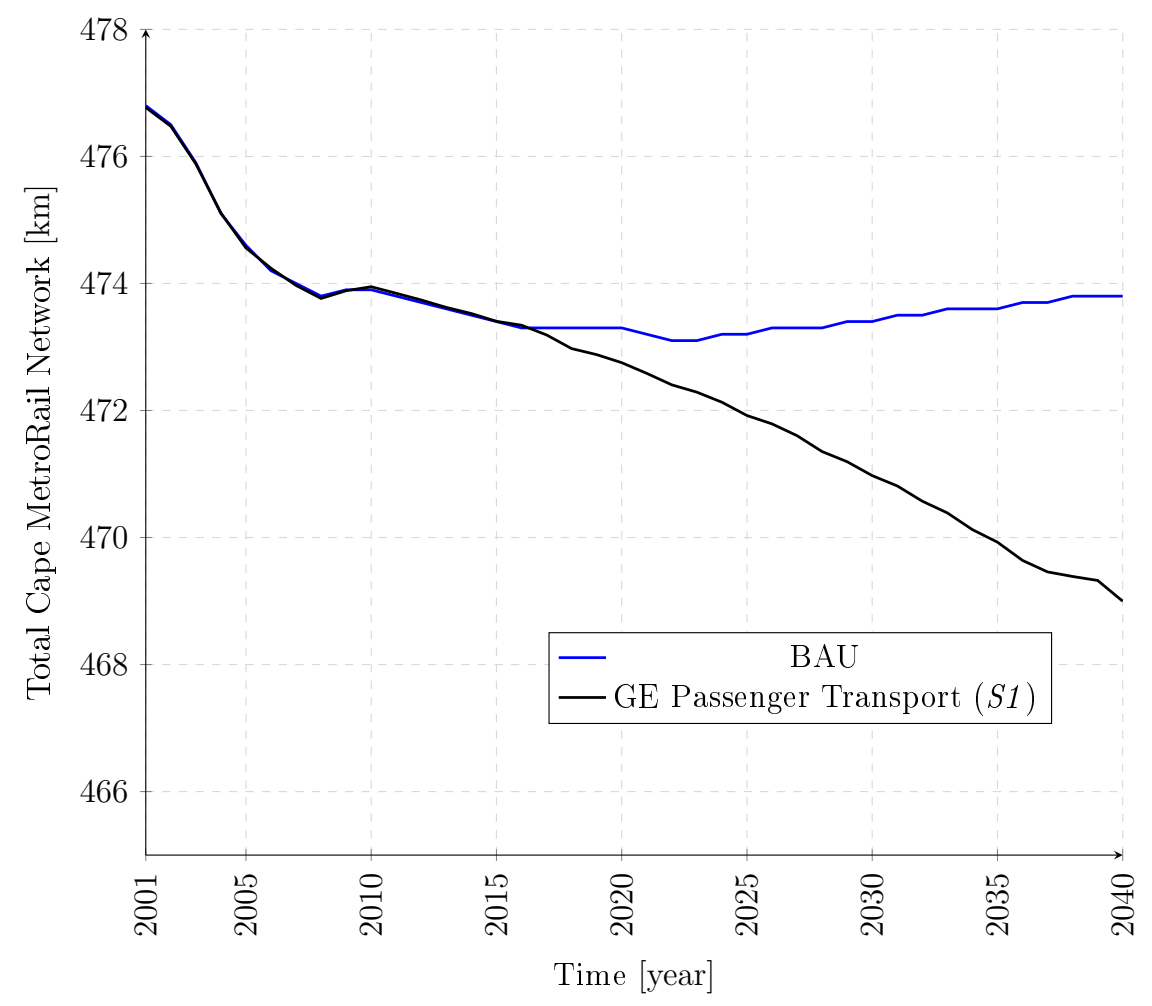

Figure 4.3: Total Cape Metro rail Network

The number of trains scheduled each year for a specific service line is re- 
alised through a balance of passenger journey demands (Figure D.8) and the availability of working trains sets (Figure D.9). The ever increasing rail passenger demand resulting from a growing populace puts pressure on the required scheduling of trains which in the $B A U$ scenario is characterised by an ageing train fleet. Only when the scenario case based on the envisioned roll-out strategy comes into effect, is it possible to schedule more trains per line as indicated in Table 4.2 .

Table 4.2: Cape Metrorail scheduled trains per service line

\begin{tabular}{lrrrrc}
\hline & \multicolumn{5}{c}{ Time Intervals } \\
\hline & 2001 & 2012 & 2030 & 2040 & \% change \\
Data & & & & & \\
Southern Suburbs Line & - & 123 & - & - & - \\
Cape Flats Line & - & 79 & - & - & - \\
Central Line & - & 171 & - & - & - \\
Northern Line & - & 265 & - & - & - \\
BAU & & & & & \\
Southern Suburbs Line & 121 & 127 & 122 & 119 & -2.02 \\
Cape Flats Line & 67 & 78 & 75 & 73 & 8.80 \\
Central Line & 178 & 197 & 189 & 185 & 3.64 \\
Northern Line & 187 & 237 & 254 & 249 & 32.85 \\
GE Passenger Transport (S1) & & & \\
Southern Suburbs Line & 121 & 127 & 161 & 187 & 54.0 \\
Cape Flats Line & 67 & 78 & 98 & 106 & 57.7 \\
Central Line & 178 & 197 & 251 & 281 & 57.7 \\
Northern Line & 187 & 237 & 274 & 295 & 57.7 \\
\hline
\end{tabular}

The greatest increase in train scheduling can be expected to occur on the Central and Southern Lines indicated by a percentage change of $54.06 \%$ and $56.02 \%$ respectively from the $B A U$ to $S 1$ scenarios. According to these results this would imply that a substantial passenger demand exists for these lines. Whilst this roll-out strategy will be beneficial in meeting the demand of the public, it cannot be seen in isolation from the implications it will have on the rail system itself. It was made clear in Figure 4.3 that the rail network will deteriorate due to an increased load of more trains operating in the system, thus the cost of maintenance and renewal of the network is included in Figure D.10. The rail maintenance and renewal costs which for the $B A U$ scenario stabilised at an annual cost of about R70 million, escalated to R88 million in the results obtained from scenario $S 1$. 


\subsection{Rail Freight Transport Network sub-module}

As described in earlier chapters the Provincial rail networks in operation by Transnet were conceptualised into two systems; the Cape Town-Gauteng mainline and existing Provincial branch-lines. For both systems the driving influence on the existing rail network stocks is that of freight movements on those lines effecting the rail life of the track and ultimately depleting the stock. Table 4.3 provides the simulation results for both the $B A U$ and $S 2$ cases for the existing branch-lines, indicating a substantial growth in freight movements across the province for the $S 2$ scenario. The same is apparent for the freight being moved on the mainline (FigureD.11), which illustrates a substantial increased in freight transport resulting from the allocation of freight onto rail based on $S 2$ strategies.

Table 4.3: Total Freight on Western Cape Branch-lines (tons/year)

\begin{tabular}{|c|c|c|c|c|c|}
\hline & \multicolumn{5}{|c|}{ Time Intervals } \\
\hline & 2001 & 2015 & 2030 & 2040 & $\%$ change \\
\hline \multicolumn{6}{|l|}{ BAU } \\
\hline Overberg Line & 745679 & 786969 & 809837 & 824063 & 10 \\
\hline Paarl-Franschoek & 0 & 0 & 0 & 0 & 0 \\
\hline CT-Bitterfontein & 2191867 & 2313235 & 2380454 & 2422270 & 10 \\
\hline Kalbaskraal-Saldanha & 0 & 0 & 0 & 0 & 0 \\
\hline Wellington-Worcester & 0 & 0 & 0 & 0 & 0 \\
\hline Worcester-Voorbaai & 0 & 0 & 0 & 0 & 0 \\
\hline Wolseley-Ceres-Hamlet & 0 & 0 & 0 & 0 & 0 \\
\hline Mosselbaai-Toorwater & 512811 & 541206 & 556933 & 566716 & 10 \\
\hline Hermon-Porterville & 252618 & 266606 & 274353 & 279173 & 10 \\
\hline George-Knysna & 19726 & 20818 & 21423 & 21800 & 10 \\
\hline \multicolumn{6}{|c|}{ GE Rail Freight Investment (S2) } \\
\hline Overberg Line & 745679 & 786969 & 1336894 & 1971746 & 164 \\
\hline Paarl-Franschoek & 0 & 0 & 27270 & 59380 & 118 \\
\hline CT-Bitterfontein & 2191867 & 2313235 & 5190618 & 8773135 & 300 \\
\hline Kalbaskraal-Saldanha & 0 & 0 & 8983666 & 19982068 & 122 \\
\hline Wellington-Worcester & 0 & 0 & 0 & 0 & 0 \\
\hline Worcester-Voorbaai & 0 & 0 & 532236 & 1166948 & 119 \\
\hline Wolseley-Ceres-Hamlet & 0 & 0 & 27270 & 59380 & 118 \\
\hline Mosselbaai-Toorwater & 512811 & 541206 & 2196682 & 4197419 & 718 \\
\hline Hermon-Porterville & 252618 & 266606 & 452907 & 667979 & 164 \\
\hline George-Knysna & 19726 & 20818 & 35366 & 52160 & 164 \\
\hline
\end{tabular}


The possible freight movements that can be realised with the $S 2$ strategies involving a modal shift of freight to rail are all over $100 \%$ meaning that its is possible to more than double the freight being transported by rail within the Province. Firstly, this illustrates the underutilisation of the system currently as well as the benefits and implications of a shift of freight back onto these networks in the future. In this regard, the effect of increasing freight traffic on the rail networks, results in a substantial amount of rail track disruption occurring based on the relationships between rail life to freight traffic. However, the $B A U$ scenario for both the mainline and branch-line networks, illustrates very little rail disruption occurring, which is due to the under-utilisation of the rail system.

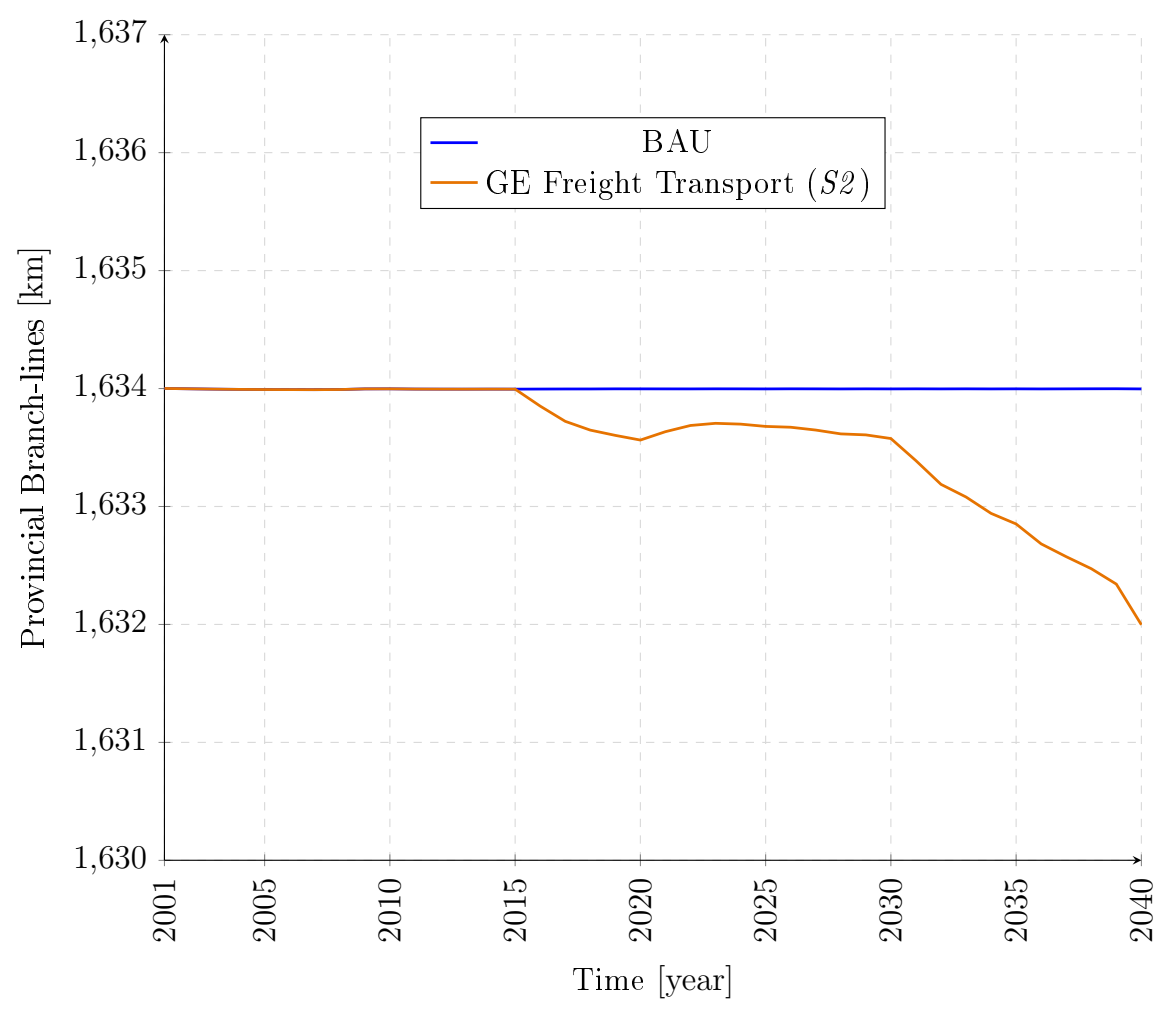

Figure 4.4: Western Cape rail Branch-line network

The rail disruption that is realised in the Green Economy Scenario analysis occurs in a similar manner as that of the Metrorail lines, in that the decreasing rail stock indicates the maintenance and rail renewal backlog existing in the real system. Figure $4.4 \&$ D.12 highlight the implications of experiencing escalations on the rail system. Although on closer inspection of the graphics, it must be noted that the disruptions to the stocks are minuscule when compared to the length of the entire network. This bodes well for the rail freight sector 
but the costs incurred in maintaining these lines cannot be excluded and in reality are substantially significant as indicated in Figures D.13 \& D.14.

The increasing freight traffic on the rail network also brings about a shift in the economies of density with regards to the costs of rail freight transportation. This anomaly originally hypothesised by Harris (1977), identified that significant economies of traffic density exist in the rail industry and are thus of critical importance with respect to public investment. It is important to note here that economies of density and not scale are used as further described by Harris (1977) "we want to know what happens to the average cost as output increases, holding the route system or miles of rail line constant". The curve generated through empirical relationships from historical data was further studied by De Bod and Havenga (2010) and developed for use within in Sub-Saharan African countries.

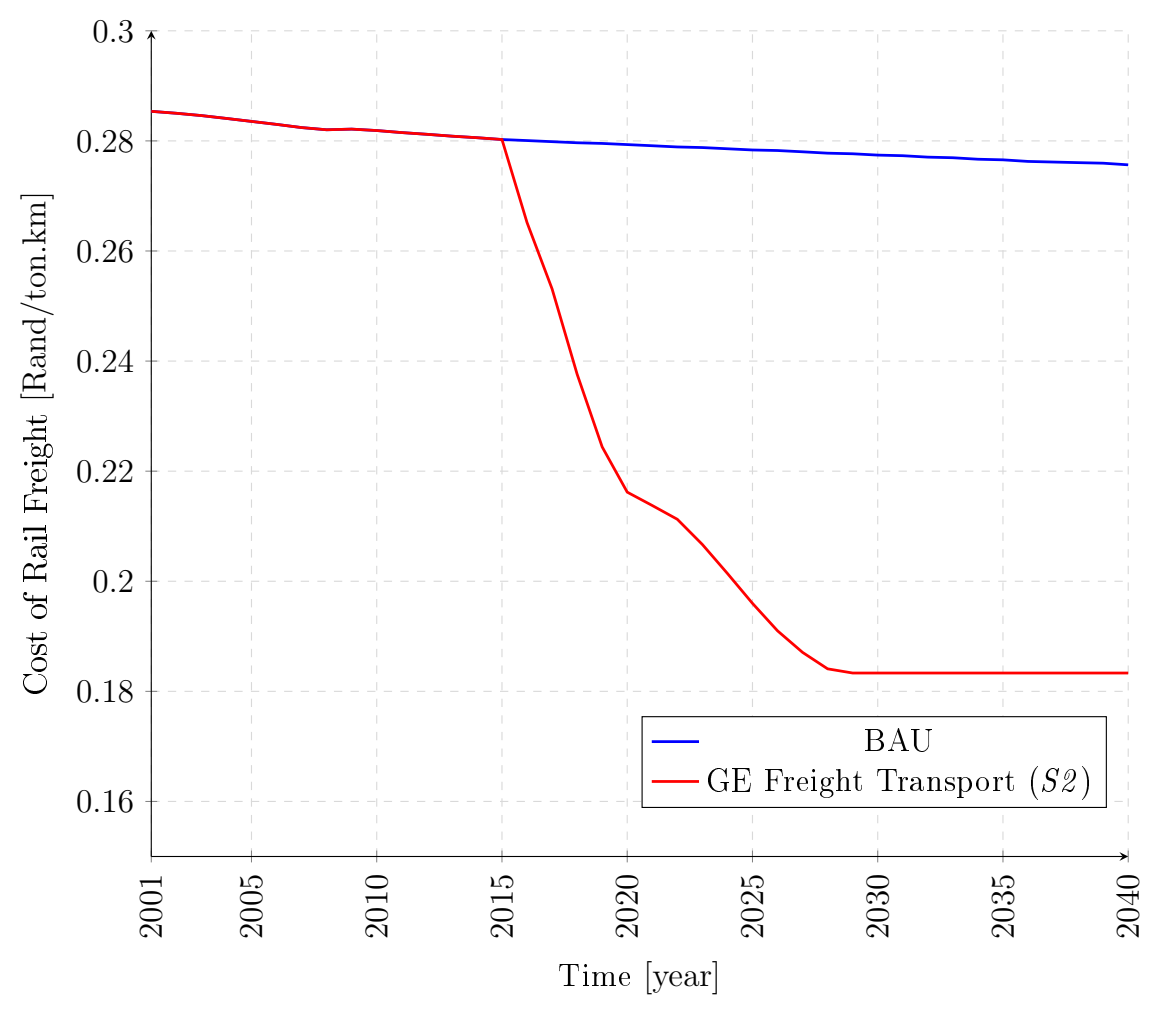

Figure 4.5: Cost of Freight Rail

Further discussion on this will take place in Chapter 5.3, but the results of relating the Harris Curve to freight movements on the Western Cape Mainline are provided in Figure 4.5. From the simulation it is evident that the increase in freight traffic on the rail network will decrease the cost of rail, implying that the cost(Rands) per ton.kilometre of the rail-line will decrease with each 
additional ton.kilometre of activity per unit length of track. This cost in the BAU scenario is expected to be R0.28 or 28 cents per (ton. $\mathrm{km} /$ route. $\mathrm{km}$ ) but with the increase in freight traffic, this drops to about R0.18 or 18 cents per (ton. $\mathrm{km} /$ route. $\mathrm{km}$ )

\subsection{Freight Transport sub-module in the Western Cape}

The stagnation of the rail freight industry over the past few decades has ultimately lead to the road network having to carry the load of freight movements throughout the Province. Further discussion on what the reason for this may be, is discussed in Chapter 5. The five corridors for road freight movements identified as being; Metro, Rural, N1, N2 and N7 with the resulting freight movements are illustrated in Figure D.15. Here it becomes evident in the BAU scenario that freight traffic on the roads will invariably increase over time with the growing demand from the populace. This trend is however mitigated through the policy changes in $52 \& S 3$ as a result of the modal shift from road back to rail freight transportation.

Table 4.4: Western Cape Road Freight Transport on specific corridors

\begin{tabular}{lrrrrc}
\hline & \multicolumn{5}{c}{ Time Intervals } \\
& 2001 & 2015 & 2030 & 2040 & \% change \\
\hline BAU (million tons) & & & & & \\
\hline Western Cape Metro & 90.11 & 128.82 & 158.09 & 175.70 & 95 \\
Western Cape Rural & 19.16 & 24.81 & 27.29 & 29.80 & 55 \\
Western Cape N7 & 5.99 & 9.85 & 12.613 & 14.91 & 149 \\
Western Cape N1 & 14.09 & 22.35 & 27.76 & 32.39 & 130 \\
Western Cape N2 & 5.83 & 9.33 & 12.76 & 14.16 & 143 \\
\hline Green Economy Freight Transport Investment (S2) & \\
\hline Western Cape Metro & 90.11 & 128.82 & 142.36 & 140.84 & 56 \\
Western Cape Rural & 19.16 & 24.81 & 24.51 & 23.65 & 23 \\
Western Cape N7 & 5.99 & 9.85 & 11.35 & 11.91 & 99 \\
Western Cape N1 & 14.09 & 22.35 & 24.98 & 25.85 & 84 \\
Western Cape N2 & 5.83 & 9.33 & 11.50 & 11.37 & 95 \\
\hline
\end{tabular}

With the historic dissatisfaction of industry and the resulting under-utilisation of the rail system, a decoupling of freight transport occurred between road and rail freight. Table 4.4 elaborates this trend by showing the growth in road freight movements at specific time intervals throughout the simulation. With 
the intervention of the Green Economy strategies the inherent link between the freight being moved between road and rail is rejuvenated and the results of which indicate a substantial decrease in freight being moved by road transport. This trend is indicated in the percentage changes realised between the start and end years of the simulation period between the two scenarios whereby $S 2$ results in far lower changes than $B A U$.

\subsection{Bus Rapid Transit network and system sub-module}

The bus rapid transit system existing and being developed in the Cape Town Municipality is seen to service a maximum of 6.8 million passengers annually by the year 2040, the results for the year 2012 match the statistics provided by the Provincial Land Transport Framework (Western Cape Government, Department of Transport and Public Works, 2013) at around 3.5 million passengers for the year (Figure D.16), indicating substantial growth in the system. The determining parameter in the amount of passengers carried annually is that of the available operating bus stock existing in the system (Figure 4.6) this stock is shown to increase substantially as the project aims to reach its predetermined goals. 


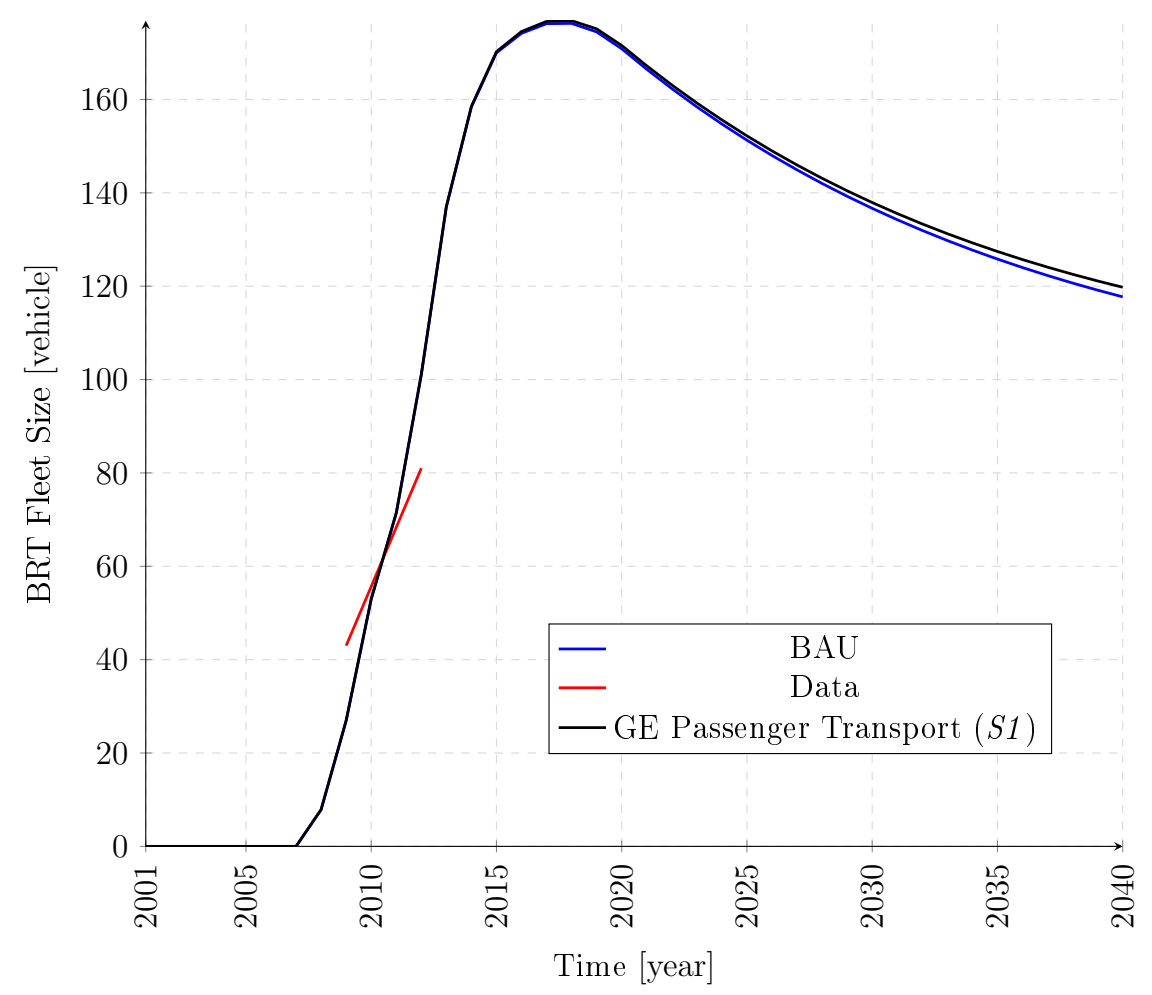

Figure 4.6: Bus Rapid Transit fleet size

It does however become evident that a cap is reached in the BRT fleet size at nearly 180 vehicles by the year 2020 and based on the expected budget for vehicle acquisition (Figure D.17) the stock slightly deteriorates over time if no further investment is realised. The same trend applies to that of the total BRT project expenditure as illustrated in Figure 4.7 whereby, as targets are met throughout the project duration the expenditure naturally decreases over time after reaching a crescendo in the year 2020 . 


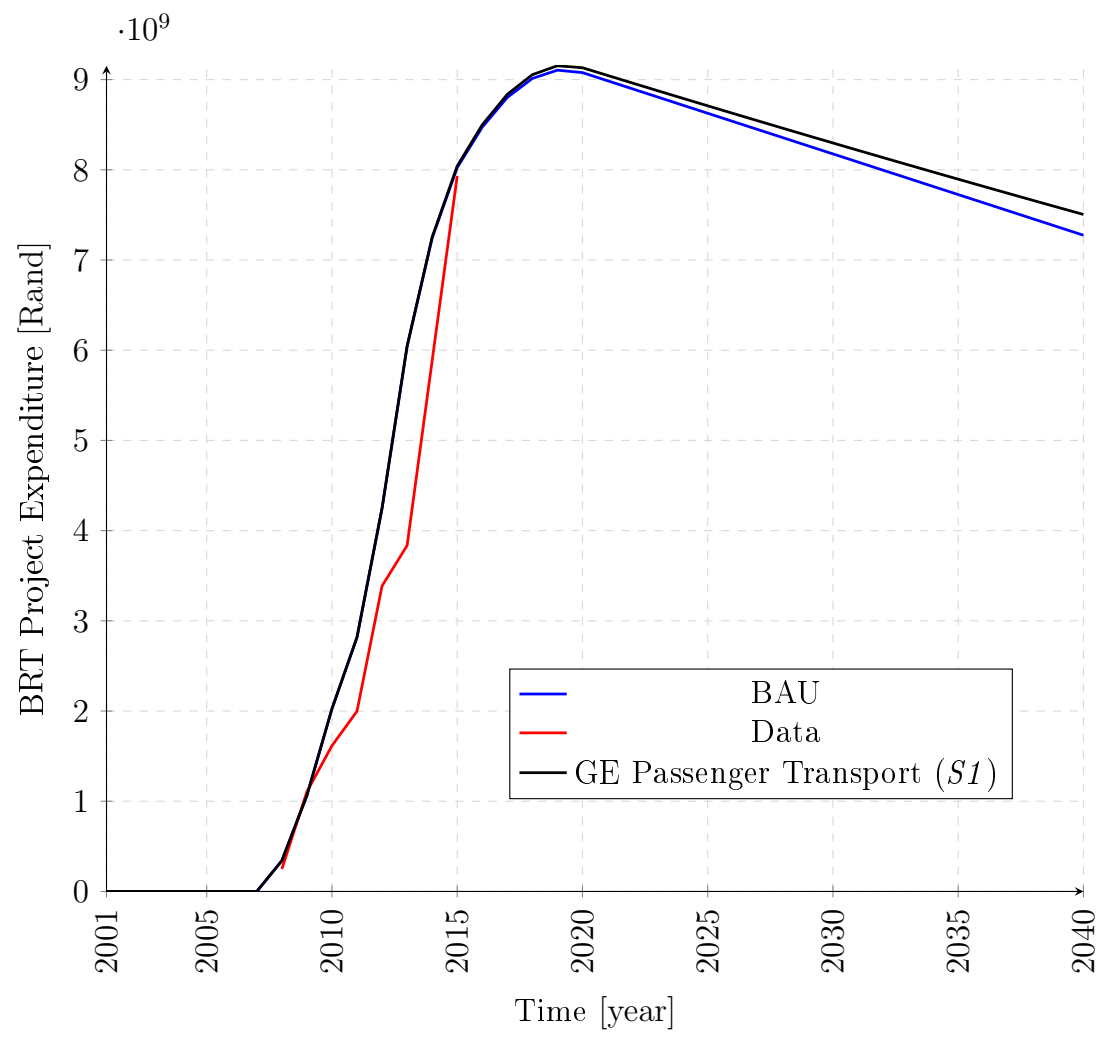

Figure 4.7: Bus Rapid Transit Project Expenditure

\section{7 $\quad \mathrm{CO}_{2}$ emissions from Transport sector}

Identified as one of the key indicators of reaching a green economy transition, consequential $\mathrm{CO}_{2}$ emissions from the transport sector are of significant importance in meeting the demands of climate change policies. Pressure from both local and international organisations have resulted in the mitigation of $\mathrm{CO}_{2}$ emissions through various policy interventions in the transport industry. The emissions resulting from all means of transport included in this model are quantified in Figure 4.8 with the results expressing rather alarming quantities of $\mathrm{CO}_{2}$ being emitted in the $B A U$ scenario. 


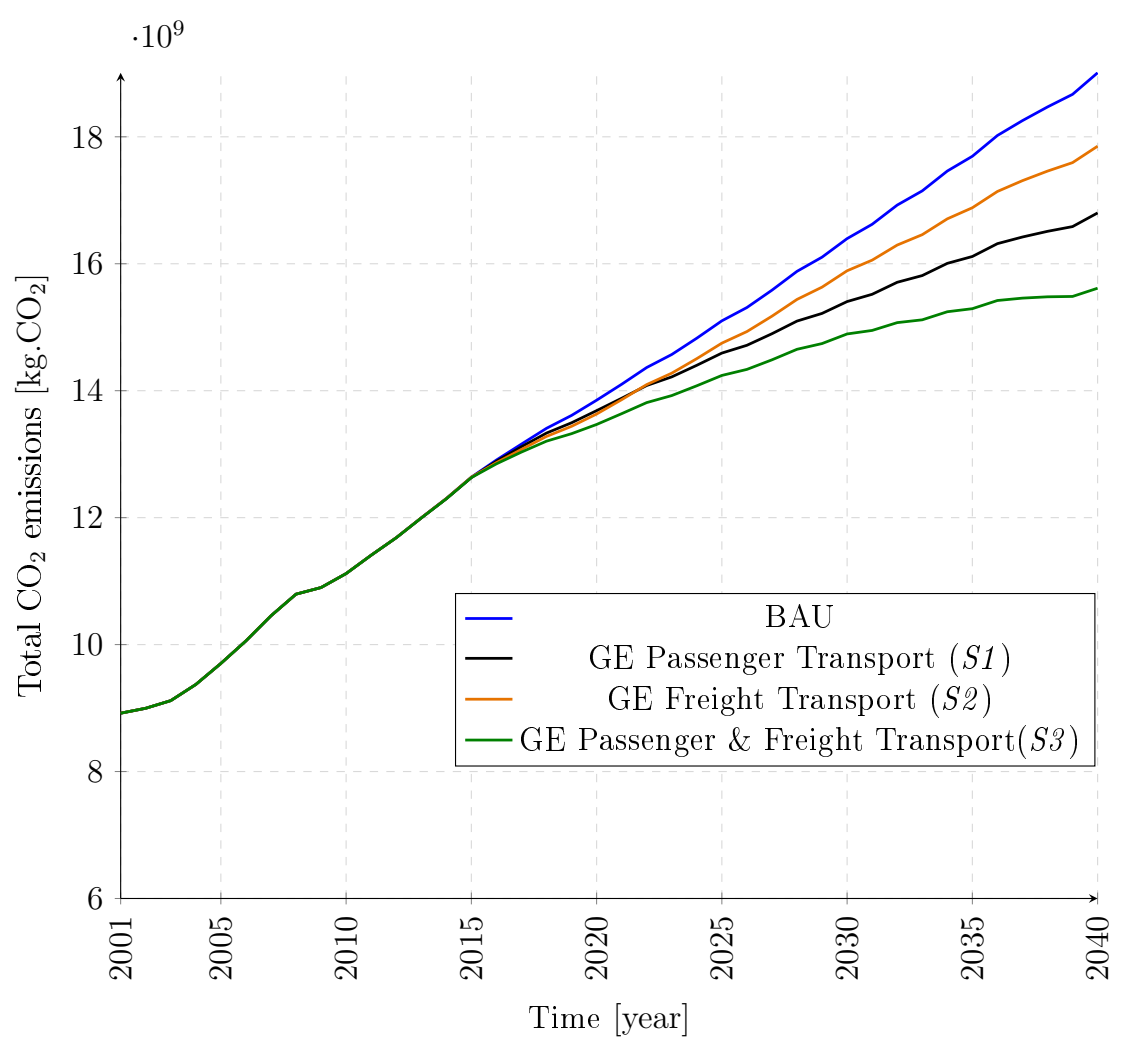

Figure 4.8: Total $\mathrm{CO}_{2}$ emissions resulting from the transport sector

The policy scenarios however shed a positive light on the matter whereby there are significant reductions in $\mathrm{CO}_{2}$ emissions in response to the various interventions undertaken in the GE transition. Interestingly the $S 1$ case of public transport investments has a greater mitigating effect on emissions when compared to the S2 case including the modal shift of freight transport. The $S 1$ scenario saw a drop in $\mathrm{CO}_{2}$ emissions of $11.63 \%$ over the simulation period with the S2 scenario involving a freight modal shift resulted in a $6.1 \%$ decrease in emissions. The obvious result of $S 3$ being the combination of both intervention strategies yields a significant reduction in emissions from the transport sector, of up to $17.89 \%$.

\subsection{Other Important Indicators to selected sub-modules}

The results for the sub-modules existing in the model as supporting matter providing necessary parameter information for key indicating variables and stocks are included in Appendix D. The following discussion of the results 
obtained in these sub-modules aims to provide an indication of the causes and effects in trends within the previously disclosed results.

\subsubsection{Population of the Western Cape}

The baseline results obtained through the simulation of the model revealed a consistent growth pattern of the Western Cape population (Figure D.23). The baseline was accurate in terms of matching the data from the population statistics of the province from 2000 to 2011 and indicated a similar growth pattern for the remainder of the analysis period. The reason for there being no influence in population to the scenario analyses is that it was included as an exogenous system acting only as a driver to other sub-modules.

\subsubsection{Western Cape Gross Domestic Product}

The next most important baseline required was the GDP of the province (Figure D.24) as this was often used as a driving parameter in other sub-modules used in the model. As discussed earlier the GDP sub-model was very simple and based on historical data following the SAGEM model outputs. Whilst this may be considered a rather crude form of projection, for the scope of this study it revealed a substantially accurate representation of a fluctuating GDP growth in the province and since it was used primarily as an exogenous parameter, there were no effects due to scenario changes.

\subsubsection{Passenger Transport in the Western Cape}

An important indicator for decision and policy makers is that of the private:public modal split for passenger transport. The various modes of passenger transport existing in the Province are illustrated in Figure D.19 in terms of the persons utilising each mode annually. The percentage share for the various modes is provided in Table 4.5, evidently the policy changes implemented in a Green Economy transition $(S 1)$ results in a rise in public transport modes and a subsequent decline in the use of private motor vehicles. 
Table 4.5: Modal splits of passenger transport modes

\begin{tabular}{lrrrr}
\hline & \multicolumn{4}{c}{ Time Intervals } \\
& 2005 & 2015 & 2030 & 2040 \\
\hline BAU & & & & \\
\hline Bus Rapid Transport & 0.0 & 0.7 & 0.4 & 0.3 \\
Minibus taxi & 18.8 & 13.1 & 11.1 & 10.0 \\
Metered Bus & 4.4 & 4.5 & 5.1 & 5.4 \\
Private motor vehicles & 56.7 & 62.8 & 68.6 & 71.5 \\
Metered Taxi & 0.1 & 0.2 & 0.3 & 0.4 \\
Rail & 20.0 & 18.6 & 14.5 & 12.4 \\
\hline Ge Passenger Transport $(\boldsymbol{S 1})$ & & \\
\hline Bus Rapid Transport & 0.0 & 0.7 & 0.5 & 0.4 \\
Minibus taxi & 18.8 & 13.2 & 12.1 & 12.1 \\
Metered Bus & 4.4 & 4.6 & 5.6 & 6.6 \\
Private motor vehicles & 56.7 & 62.7 & 62.5 & 60.5 \\
Metered Taxi & 0.1 & 0.2 & 0.4 & 0.6 \\
Rail & 20.0 & 18.6 & 18.9 & 19.8 \\
\hline
\end{tabular}

\subsubsection{Total Road Accidents}

Relating to the shift in passenger transport on the road network is the key indicator of road accidents occurring on Western Cape Roads. With the availability of accurate data for this variable the analysis through the different scenario simulations was completed with relative accuracy. The results for total road accidents (Figure D.21) indicate a substantial increase in the $B A U$ scenario in relation to the ever increasing live vehicle numbers on the roads and subsequently poorer road conditions. However with the development and enhancement of the public transport sector and the resulting decline in private vehicle use, the amount of road accidents was substantially reduced. Linked to the total road accident parameter is the factored statistic of accidents in which fatalities occurred provided in Figure D.22, indicating a similar behaviour.

\subsubsection{Fuel Demand}

In the modelling of the transport activities taking place in the province the assumption was made that there would be no limiting influence of fuel supply, consequently the fuel demand parameters provide an indication of just how much fuel will be required over the simulation period. Again a steady incline is evident in the petrol demand (Figure 4.9) throughout the $B A U$ scenario but with the limiting effects that interventions into public transport have on the live vehicle numbers, the fuel demand becomes more stable over time 
decreasing by $10 \%$ in the $S 2$ and $S 3$ scenarios by the year 2040 . In a similar manner the diesel demand (Figure D.20) shows a slight decline based on the interventions involving the shift in freight transport towards rail. In the case of total diesel demand the most notable change in demand is realised in the $S 3$ scenario, with a decrease of $14.4 \%$ when compared to $B A U$ outputs.

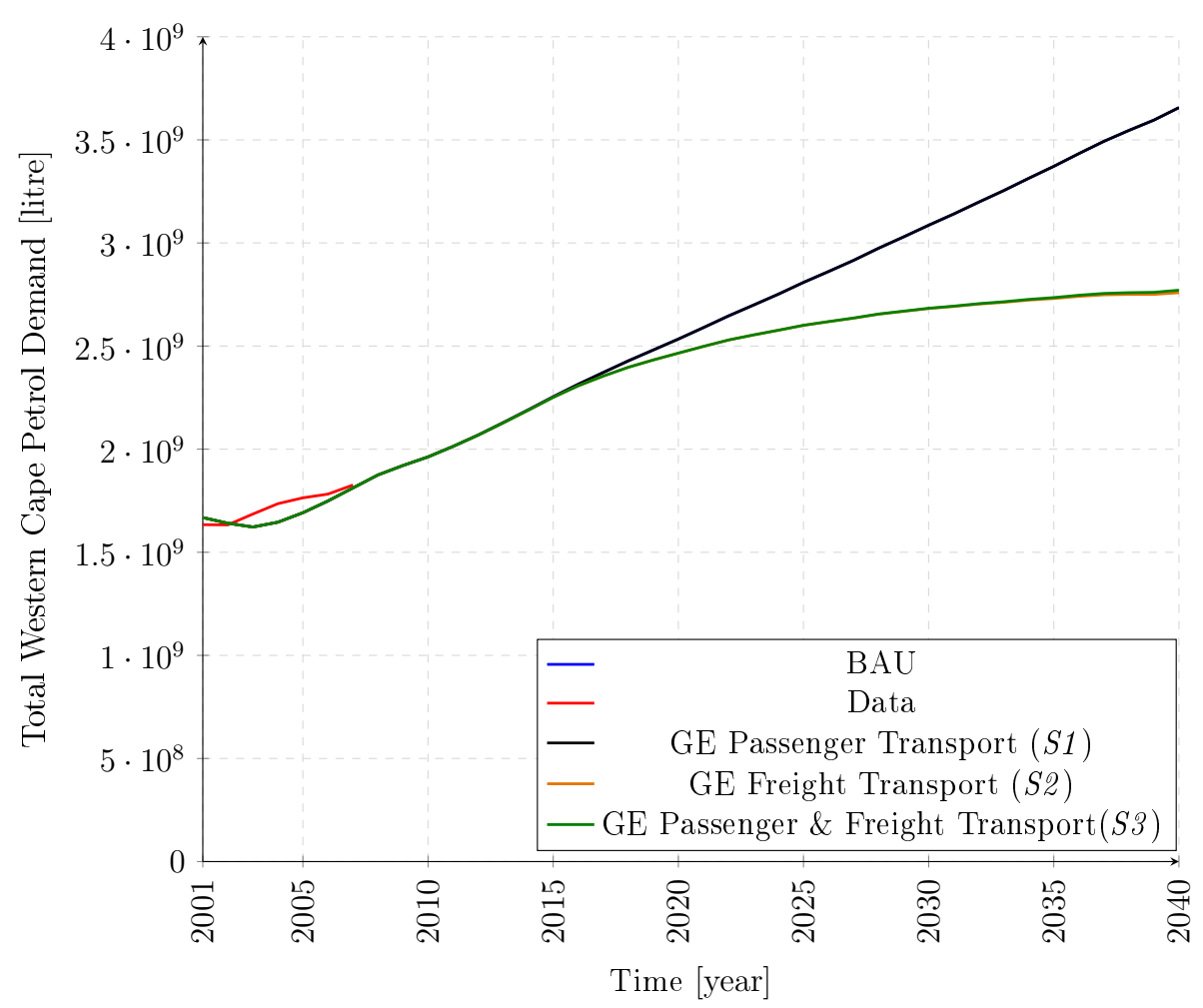

Figure 4.9: Total Western Cape Petrol Demand

\subsection{Green Economy Transport Investment sub-module}

All interventions and policy changes involved in the Green Economy transition and the corresponding costs incurred throughout the analysis were accumulated in the stock of Green Economy Investment illustrated in Figure 4.10. Representing all capital and operational expenditures across all initiatives, this stock provides an indication of the total expenditure required to meet the policy changes tested in the various scenarios. The trends illustrate a steep incline in expenditure from the year 2007 to 2020, with the $B A U$ case showing the least amount of expenditure from 2020 onwards. The reason for all trends illustrating the same growth until 2015 comes as a result of the BRT MyCiti project that began in 2007 and is envisioned to reach project completion by 
the year 2020. The scenario involving investment into public transport systems $(S 1)$ presents an initial growth continuation post 2015 followed by a more gradual development when compared to the (S2) scenario involving a shift in freight transportation.

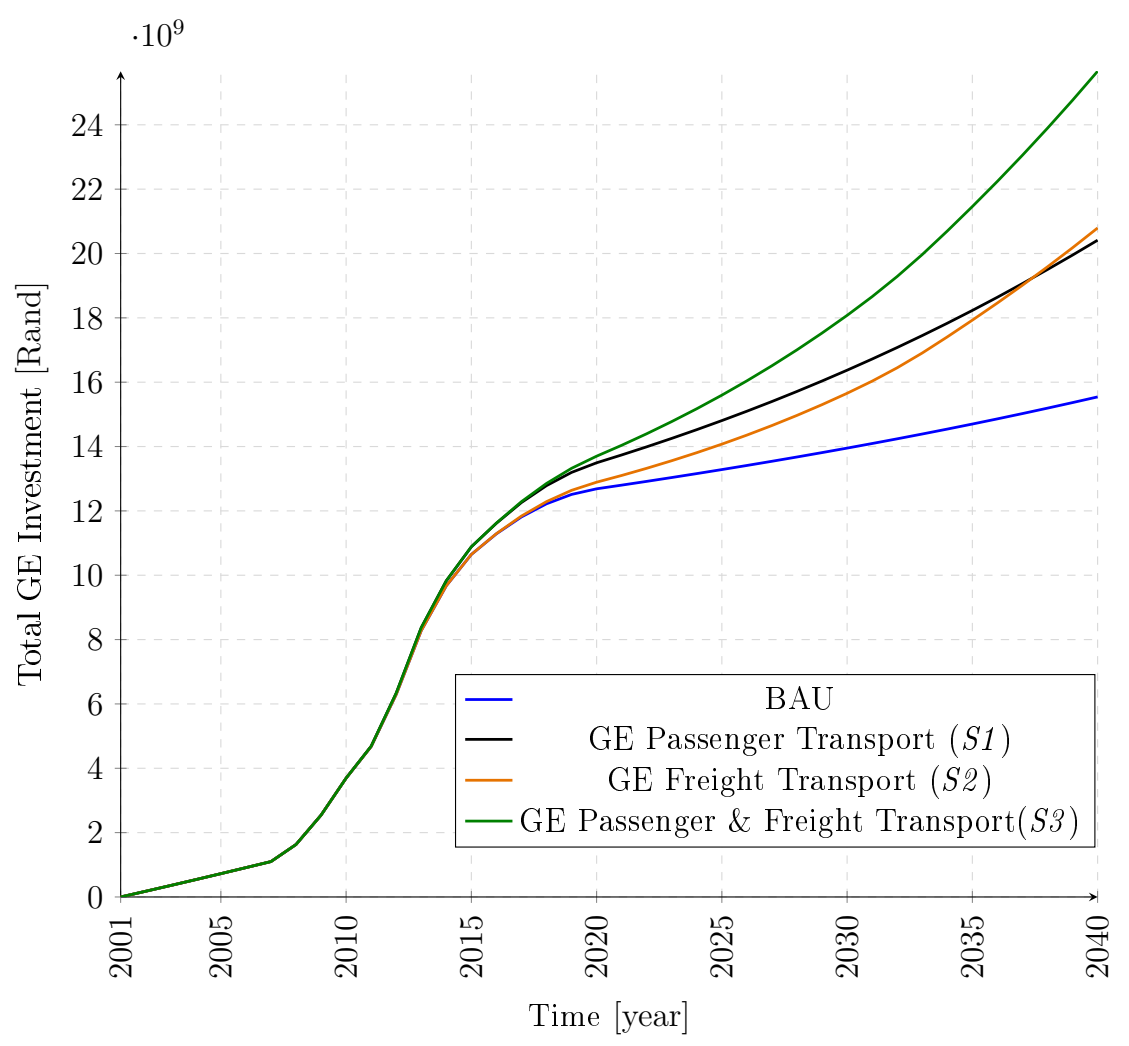

Figure 4.10: Total Green Economy Investment

Scenario (S3) combining both investment strategies indicates a greater incline in expenditure required to meet the goals set by the various frameworks. The total investment expenditure required to meet the goals for each scenario after the completion of the simulation period are as follows:

- $B A U:$ R15.6 billion

- $S 1$ : R20.2 billion

- S2: R20.8 billion

- S3: R25.5 billion

The optimal scenario $S 3$ is R10 billion more then the eventual $B A U$ baseline expenditure envisaged to be accumulated regardless of a Green Economy transition. In retrospect this amount is not as high as originally expected and 
is in fact an attainable measure when compared to the benefits expected across the sector.

\subsection{Conclusion of Results analysis}

The Problem Scenarios as discussed in Chapter 3.6 were simulated through the model to reveal the results as discussed in the preceding sections. The implications for which were characterised by the four output scenarios: Business as usual $(B A U)$, Investment into Passenger Transport (S1), Investment into a modal Freight $\operatorname{shift}(S 2)$ and a combination of both $(S 3)$. The results were discussed in terms of the important stocks and key indicating variables of the various sub-modules with regards to the defined simulation outputs. This chapter aimed to bridge the model and simulation results with the concluding discussions in response to the policy development and management outcomes being put forward. 


\section{Chapter 5}

\section{Conclusions and Recommendations}

The results obtained through the model simulation as discussed in Chapter 4 were disclosed according to the outputs in relation to the various sub-modules existing in the model. The following conclusions to be drawn from the results will aim to build on deductions on a holistic level regarding each specific scenario. With the results and corresponding conclusions drawn from the discussion of the different scenarios, recommendations to the various stakeholders identified at the beginning of the study will be made. The subsequent implications of the decisions to be made by managerial bodies with regards to the study will be disclosed by these recommendations in order to aid the decision making process of the management entities. The limitations of both the study and the model itself will also be discussed and will lead onto recommendations of future research taking this topic further. The Chapter will be closed by the final concluding remarks with regards to the research effort and the important outcomes of the study.

\subsection{Business as Usual $(B \boldsymbol{A} U)$ scenario conclusions}

The Business as Usual case gives the baseline from which all other scenarios are compared to. This scenario identifies the dynamics of the current situation in the real system being modelled and aims to simulate the trends relating to historical data provided in the model parameters. The important stocks in this regard include the paved road and rail networks of the Western Cape as well as the traffic densities on these networks currently and predicted over the simulation period.

The paved road network consisting of the stock Functioning Roads as described in Figure 4.1 indicates that in the BAU case the stock of roads is 
deemed to increase over time based on a constant budget provided by government. It must be noted that the budget for road expenditure varies significantly on an annual basis and that the model output is based on an average relation to GDP growth hence limiting the effects of unexpected expenditure. Budget gaps and lack of expenditure which are bound to occur in the future based on the economic stability of the country are thus impossible to include in the model and may give a false representation of the paved network over time. For example the BAU scenario for the paved road network may in fact not experience such growth in reality, it does however provide a good account of the system if a certain budget is aimed for and achieved.

The BAU scenario for the existing rail networks however is not as positive and instead shows a gradual decline in all rail systems based on current expenditure. This should raise concerns within the management structures of the operating organisations. Based on expected freight movements and traffic on the Cape Town-Gauteng mainline the relative kilometres of functioning rail track is predicted to decrease slightly, but will remain in adequate working condition at the current under utilisation of the line. The same is apparent in the branch-line network which is expected to remain constant due to the lack of traffic on the lines. It must be noted here that other components of the system such as signalling and power distribution lines and many others not included in the model are expected to deteriorate over time, independent rail traffic.

The Cape Metrorail network reflects a more substantial decrease in functioning rail track over the simulation period of up to 3 kilometres in annual servicing backlog. Such behaviour is not entirely unexpected as this system when compared to the freight lines is being used more regularly and with much greater traffic demands resulting in more rail maintenance and renewal being required. Relating to this is the constant balance of required train scheduling based on the current working train fleet and the demand for public transport from a growing populace.

Of greatest concern in the BAU scenario must be the steady increase in live vehicles on the roads which is expected to more than double by the year 2040. This as mentioned in various sections of Chapter 4 has many negative connotations with regards to road safety, $\mathrm{CO}_{2}$ emissions, fuel demand and pavement conditions, which all act as important drivers in transgressing to a Green Economy. In its most general form the BAU scenario which describes the real system if it were to carry on following its existing trends, alludes to a transport sector that will ultimately become far too skewed towards road based private transportation which is not socially, economically and environmentally sustainable. 


\subsection{Passenger Transport $(S 1)$ scenario conclusions}

With the baseline set it was then possible to introduce the policy changes and shifts within certain variables in an attempt to simulate the various strategies outlined in the corresponding Green Economy Frameworks. The changes implemented in scenario $S 1$ involved an increase to all public transport modes as outlined by Palmer and Graham (2013) and discussed in Chapter 3.6. The results for this scenario were conclusive in outlining the implications of an improvement in public transport within the province.

With respect to the condition of the paved network, the percentage of Very Good and Good roads increased by more than $4.6 \%$ respectively with the percentage of Poor roads reducing by $2.6 \%$. This comes as little surprise due to the significant decrease in live vehicles of 670000 vehicles by the year 2040 when compared to the BAU scenario, due to the increased availability of public transport services. This decline in vehicle numbers when compared to the BAU case occurs predominantly within the private motor vehicle mode. This comes as a result of the inter-leading parameter of desired vehicle ownership acting as the major contributor to the rate of vehicle sales, whereby the change in perception of public transport is the major factor within the real system.

The implications however of increasing the service of public transport within the rail system are far greater on the infrastructure networks than that of the road system. The desired roll-out of train sets from the year 2016 as identified by Prasa will allow for the system to meet the demands of passenger transport in respect to the amount of scheduled trains operating per line annually. This however will put a great deal of pressure on an already ageing and deteriorating rail network. The stock of functioning rail track can be expected to decrease by up to $7.8 \mathrm{~km}$ due to the increase in traffic on the various service lines which would amount to a required $\mathrm{R} 28.94$ million increase in rail maintenance and renewal by the year 2040. This amount will still not manage to bring the rail stock up to $100 \%$ functionality, it is expected that substantial rail upgrades will be required to do so. This is not to mention the necessary improvements to the signalling systems and other system components required to provide a modern rail service.

The BRT system developed in and around the Cape Town CBD indicated the majority of its growth relating to the years of project execution ending in the year 2020. From this year forward it is envisioned the no more capital expenditure will be required besides that of vehicle acquisition, instead it is hoped that the revenue generated will in fact outweigh the operational costs of the system. The requirements of a Green Economy implementation would 
result in maintaining and expanding where possible this system that is already in successful operation and creating the link between the various other modes of transport especially the rail network.

The best indicator for the health of the public transport system is evident in the modal splits of passenger transport as discussed in Chapter 4.8.3. The results identified in Table 4.5 indicate that the modal spit between private and public transport will reach the mark of a 60:40 ratio by 2040. Whilst this is still not the desired 50:50 split envisioned by various frameworks, the outcomes of the model were based on more conservative assumptions. What this does however mean for government is that more emphasis is required on public transport to meet this goal in conjunction with more aggressive strategies and interventions. When compared to what the BAU scenario predicts by the year 2040 with a ratio of $72: 28$ private to public transport, the results of scenario $S 1$ are put into context and reveal that achieving a modal split of 60:40 is in fact a considerable accomplishment.

\subsection{Freight Transport (S2) scenario conclusions}

The underlying aim of scenario S2 was to enforce a shift of freight movements onto the rail network and then investigate the various implications this transition would have on both road and rail infrastructures. With a $20 \%$ shift of freight movements onto the rail system a substantial impact on the already ageing rail infrastructure occurred. This shift resulted in a $2 \mathrm{~km}$ annual backlog in functioning rail track on the branch-line resulting in a R71.6 million increase in normal rail maintenance and renewal measures required by the year 2040 . Whilst this value seems a considerable amount the trend however indicates that costs start to incline almost exponentially only from the year 2030, which comes as a result of the cumulative effects of the ageing rail track. What this means for management is that there is a brief window period between now and 2030 where strategic rail infrastructure investment can be undertaken in order to reign in the maintenance costs before they escalate beyond a point of no-repair. This will entail across the board system upgrades along with substantial track renewal, signalling and power distribution improvements.

Similar behaviour is apparent on the Cape Town-Gauteng mainline and in this case the expenditure on maintenance and rail renewal is able to bring the track back to $100 \%$ functionality. This is most likely due to the simplicity of the system when compared to the branch-line network, as only one line of track is the point of focus instead of many different branches. Again the costs incurred in order to reach $100 \%$ functionality are substantial but in this case 
a plateau is reached in the last 5 years of the simulation period representing the time when the rail track is fully functional. The same conclusion however applies to this network as it did for the branch-line network, in that system upgrades and track renewal beginning as soon as possible will mitigate the costs expected in the future, instead of attempting to salvage a system at the end of its design life.

This scenario does however have some positive outcomes in that the reduced truck numbers on the roads result in better road conditions, lower traffic densities, lower $\mathrm{CO}_{2}$ emissions and a reduced diesel demand within the province. These are the positive spin-offs that apply to reaching the goals of the social and environmental aspects of a sustainable transition towards a Green Economy.

This scenario does also indicate positive economic potential as is specified by the cost of rail transport reducing as discussed in Chapter 4.4 where a potential reduction of 10 cents per ton. $\mathrm{km} /$ route. $\mathrm{km}$ is realised. In order to understand what exactly this means De Bod and Havenga (2010) describe that the "cent per ton-km cost of a rail-road will decrease with each additional ton$\mathrm{km}$ activity over the same track length". The subsequent curve was fashioned from the original developed by Harris (1977) illustrating the preportional relationships of decreasing costs to increase freight traffic dnesities (Figure 5.1). The nature of this curve comes as result of rail having a high level of fixed costs due to the permanent nature of the infrastructure, consequentially the average cost per ton-kilometre and profitability are directly related to the degree of traffic density i.e. the volume of traffic per kilometre of rail-road. 


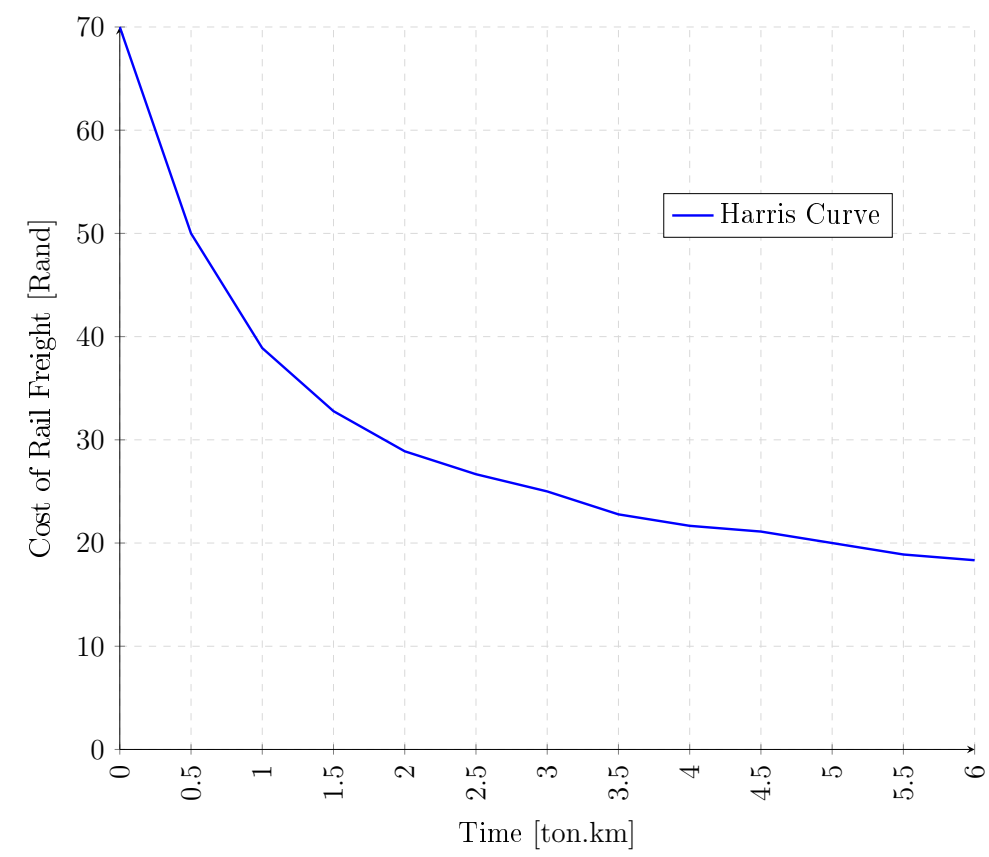

Figure 5.1: Harris Curve adapted by De Bod and Havenga (2010)

\subsection{Passenger \& Freight Transport (S3) scenario conclusions}

The combination of a transition in both passenger and freight transport was investigated in Scenario 3 in order to provide something of a best case simulation from the different strategies. Whilst many of the key indicating variables remain the same for this scenario as they did for the outcomes of the respective passenger and freight scenarios, it was apparent that in some cases the benefits of implementing both strategies were far reaching. For example the outputs for the freight rail networks in $S 3$ were almost identical to those in 52 due to the insignificant passenger traffic occurring on these lines. The greatest impacts were realised on the road infrastructure network where a reduction in both passenger and freight movements on the system enhanced the various outputs obtained in $S 1$ and S2. These included; reduced truck and private vehicle numbers on the roads resulting in better road conditions, lower traffic densities, lower $\mathrm{CO}_{2}$ emissions and reduced diesel and petrol demand within the province. Again aspects such as access to public transport and road safety were also improved based on the alleviation of the pressure on the road network. 


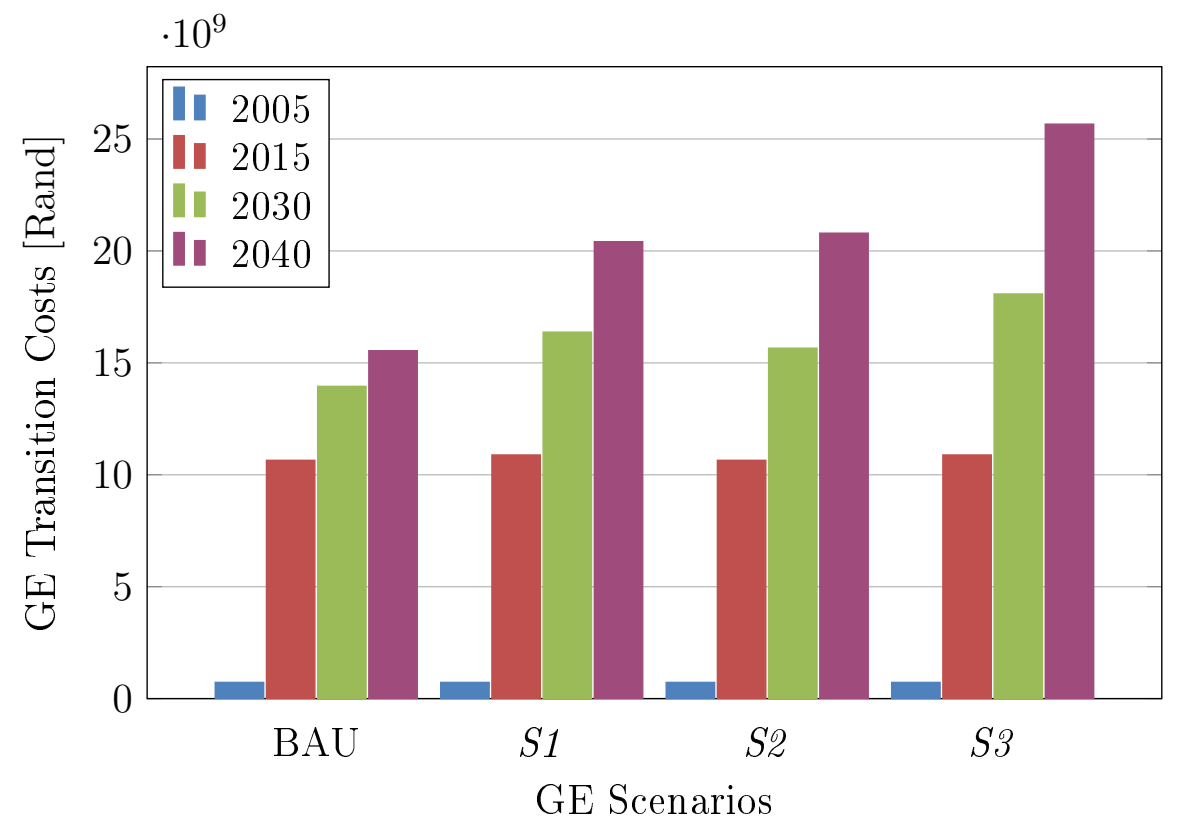

Figure 5.2: Green Economy Transport Infrastructure Investment

Arguably the most discerning implication to be considered in a Green Economy transition is that of the costs incurred and investments required in order to reach the goals set out by the various strategies. Figure 5.2 illustrates the costs involved in the transition for specific years within the simulation period according to each scenario. From the comparisons that can be drawn from this, it is possible to weigh up the cost-benefits of implementing the various policy changes. For example the cost-to-system for both scenario $S 1$ and $S 2$ are very similar with the investment into a modal shift in freight transport just topping an increase in public transport by the year 2040. The actual values relating to the representation in the figure as defined in Table 5.1 indicate that the implementation of scenario $S 3$ results in a R5 billion increase in what would be expected from either scenario $S 1$ or $S 2$. This when put into the greater perspective of what is trying to be achieved through this transition is not entirely a huge sum of money.

Table 5.1: Green Economy Transport Infrastructure Investment

\begin{tabular}{lrrrr}
\hline Time Intervals & 2005 & 2015 & 2030 & 2040 \\
\hline & \multicolumn{5}{c}{ (billions } & of Rand) \\
BAU & 0.75 & 10.7 & 14 & 15.6 \\
GE Passenger Transport $(\boldsymbol{S 1})$ & 0.75 & 10.9 & 16.3 & 20.2 \\
GE Rail Freight (S2) & 0.75 & 10.7 & 15.7 & 20.8 \\
GE Pass \& Freight $(\boldsymbol{S 3})$ & 0.75 & 10.9 & 18 & 25.5 \\
\hline
\end{tabular}




\subsection{Recommendations to stakeholders}

In order to attempt a transition to a Green Economy within the transport sector of the Western Cape, a shift in policy and investment will be required from both government and private enterprises. The results as described in Chapter 4 and the preceding sections of Chapter 5 focus on the costs and implications relating to the respective changes implemented within the different scenarios. With the picture that is created giving insight into how these changes may play out over a simulated time, it is possible to envisage the subsequent implications of the decisions to be made by managerial bodies. Giving rise to this are the recommendations put forward and explained in the following sections aimed at aiding the decision making process of management entities.

\subsubsection{Recommendations to stakeholders concerning Public Transport}

Identified as a key focus area in public transport is the bettering of the rail network within the province and the service provided to society. On a national scale the Passenger Rail Agency of South Africa(Prasa) is ultimately responsible for the funding and management of the commuter rail system across the board and including the Western Cape. The challenges resulting from the past decades of underinvestment identified by Prasa (2014) include:

- Railway infrastructure is at the end of its design life

- High costs of maintenance

- Limited access to rural and urban poorer areas

- An ageing train set and accompanying system technology

- Poor level of reliability

These challenges lead to the strategic turnaround plan which included firstly stabilising the existing commuter rail system followed by the modernisation of the asset base over the next 40 to 50 years. This process will include the acquisition of new commuter train sets, long distance locomotives, new electronic interlocking signalling systems, new generation stations as well as an improved communication control network (Prasa, 2014). This attempt to modernise the rail system needs to be carefully planned and managed over the next few years.

As the analysis of the results from this model simulation suggest, the rollout strategy of new train sets envisioned cannot be enforced without the upgrading of the network itself. Simply introducing new modern train-sets onto post-design-life infrastructure operating in conjunction with an ageing train fleet will result in service bottle necks and further degradation of the existing rail track. Whilst the new train fleet will be able to travel faster and possibly 
carry more passengers, the nature of rail lines only allows for the system to operate as fast as its slowest component. Thus the full benefits of integrating new train sets will not be fully realised if simply introduced onto the whole system. Instead focus should be made on upgrading specific service-lines in terms of the rail infrastructure and operating train-sets on an iterative basis, whilst still maintaining the existing system in order to service the current needs of the public. In this way the complete modernisation of the system can be met albeit over a longer period of time instead of attempting to combine a new system with an already out-dated network which evidently will only result in substantial maintenance costs and the ultimate demise of the infrastructure itself.

The integrated bus rapid transit system currently in operation within the City of Cape Town municipality denoted as MyCiti refers to the new generation of high-quality public transport envisioned in the city. Currently this name refers only to the Bus Rapid Transit (BRT) system and related nonmotorised services falling directly under the City or a future municipal entity (City of Cape Town, 2010). Based on current estimations of further project development and capital expenditure this system is expected to reach a vehicle cap of around 180 buses. The simulation reveals that without constant funding further growth of the system will be limited.

There is however a positive result in that the difference in revenue begins to outweigh the operational expenditure of the system by the year 2020 allowing for further input into the system being possible. This project has been deemed a success by many and is being implemented in other cities within the province such as George with the Go George program. Further efforts now need to be made in creating a seamless link between the different transport modes in an effort to provide feeder routes that service all areas towards the trunk routes bringing the necessary populace into the commercial zones.

This leads to the crucial enablers existing in the modes of non-motorisedtransport, minibus taxi and metered bus services operating as independent entities requiring a link into the publicly run services. This has already been achieved in the Golden Arrow and Sibanye bus services operating under government subsides within the Cape Metro area. The minibus taxi organisations operating throughout the province, service the majority of the rural populace and in many districts there exists an over supply of minibus taxis which often leads to the poor state of the vehicles (Western Cape Government, Department of Transport and Public Works, 2013).

In this regard the simulation did reveal a significant decline in registered minibus taxis within the live vehicle parc of the Western Cape. It is thus recommended that efforts should be made to formalise the service provided by 
this mode before it becomes obsolete, providing a means for public transport to reach all areas of both rural and urban developments. This would entail providing the necessary infrastructure to support this service, in the form of upgrading and construction of taxi ranks, developing designated operating routes and investigating a system that links all modes of public transport. The standardising of public transport in terms of the service provided and the manner of payment and operation would ultimately lead to a safer more efficient system.

\subsubsection{Recommendations to stakeholders concerning Freight Transport}

Historically in South Africa the transportation of freight both on road and rail networks was heavily regulated by government, consequentiality an adequate balance in the use of the infrastructure maintained the condition of the networks. From 1986 however, the market for transporting goods was deregulated due to international and internal commercial pressures resulting in an unprecedented shift to road freight haulage. Within the new free market road freight haulage offered a more flexible and versatile service with the ability to move goods from door-to-door with more accessibility, security, speed and frequency (Stander and Pienaar, 2002). This coupled with the disproportionately low taxation of trucks when compared to motor cars created a system that was more commercially attractive from both the freight movers and industry clients.

The model results for the $B A U$ scenario accurately portray the underutilisation of the rail network complemented by the high levels of freight transported by road. When compared to the simulations involving the shifts of freight onto rail, the implications of ignoring this transition are significantly apparent on the road network and environmentally regarding harmful emissions. The analysis of the effects incurred on the rail system however concluded that careful consideration of the infrastructure needs to be undertaken before drastic increases in freight movements can be realised.

The first recommendation with regards to freight transport would be to caution South Africa's national railway management in considering the further closing of branch-lines due to profitability pressures. Simpson and Havenga (2010) present supporting research which concludes that there does exist considerable volume opportunities on branch-lines if captured correctly, that will significantly reduce direct transport costs and external charges for the economy. Further savings can be realised if road axle limits are reduced or other pressures are placed through possible government regulation on certain mining commodities being forced to utilise rail transportation (Simpson and Havenga, 
2010). Again the consideration of these recommendations cannot be seen in isolation of the infrastructure implications on the rail networks where it should be noted that significant investment will be required for the upgrading and maintenance of the rail track and accompanying components.

Further research conducted by Havenga (2013) discusses how the monetary advantages of rail as a mode of transport comes as a result of the intrinsic technologies of rail itself namely bearing, guiding and coupling. Bearing refers to the axle-load and therefore volumes that can be carried by rail while guiding indicates the speed of movement made possible by the wheel-on-track differentials inherent in rail locomotives. Both of these factors are brought together by coupling, meaning that a combination of high volumes and long distance solutions can be met with relative speed. The strength of these technologies support four freight rail market spaces as defined by Van der Meulen and Möller (2007) and further described by Havenga (2013):

- General Freight: Combines the strengths of all technologies making it possible to attain often higher capacities than autonomous vehicles. This market space has been proven to be competitive for rail over almost any distance provided that sufficient volumes of commodities with similar cargo-handling requirements exist.

- Heavy Haul: This freight is typically pit-to-plant/port bulk commodities with sufficient density to allow a heavy, competitive axle load. This market competes in the $1000 \mathrm{~km}$ range but requires easy gradients to limit coupler forces in heavy trains.

- Heavy Fast-Moving Consumer Goods (FMCG): This market operates normally over short to medium distances with fast moving, light loads and is generally characterised by bimodal road-rail solutions. Focus is made on the high throughput of high value finished products, often palletised, and competes in the $200-500 \mathrm{~km}$ space.

- Heavy Inter-modal (double-stacked containers): This market is similar to heavy FMCG, but focusses on longer distance heavier axle loads preferably high-volume container movements requiring substantial vertical clearance and competes in the $300-2000 \mathrm{~km}$ space.

With regards to the Western Cape rail network these market spaces exist and are possible to tap into, provided adequate regard to the rail infrastructure is adhered. With the strong agricultural sector and an extensive branch-line network existing in the Province, the market space for general freight primarily referring to bulk agricultural produce is possible. Again for produce of a more perishable nature such as fruits and vegetables as opposed to grains, 
faster moving bimodal solutions will be required, whether movements are destined for export or intra provincial consumption. The market space of Heavy haul is already in successful operation on the Saldanha to Sishen line and as previously discussed in the study fell out of the scope for this model. The most pertinent market space is that of heavy inter-modal container transport predominantly on the Cape Town-Gauteng mainline. The vast majority of freight being moved on this corridor is container based and destined for the major city of Johannesburg. This means that inter-modal solutions are possible and arguably the most sustainable way of moving freight over this distance as indicated by the costs involved and reduction in $\mathrm{CO}_{2}$ emissions indicated by the results from the simulation.

\subsection{Model Limitations}

As with all research endeavours, there exist certain limitations and assumptions that are made out of necessity that prevent a perfect realisation of the study aim. This section describes the limitations resulting from the conceptualisation and building of the model that have been realised throughout the research effort and what could have been done differently in hind sight. In this regard however, it must be noted that the study was not focused on the building of a conceptual model as the crux, but instead created and used a model as a decision making tool to aid the answering of the pertinent engineering management questions related to the problem.

In this light it is was difficult to capture all of the essential aspects relating to the implications on infrastructure in a green economy transition within the model. The limitation of acquiring relevant data and information relating to the study often dictated the manner in which the model was built. Often data was required to be manipulated in order to fit the model structure and although it was done to the highest level of accuracy possible, in many cases the gaps were too big and thus influenced the modelling approach for that specific variable. Linking to the availability of data and information, the model used various elasticities to create more cohesion between the model behaviour and historical data. Although this is an accepted practice in SDM to an extent, it can create doubt in the relationship between the model and the real world system.

There were some specific areas within the model that also required assumptions to be made based on the modellers knowledge of the topic. There remains the difficult task of swaying the perceptions of both the public and policy-makers, this intangible sentiment is something that cannot be assumed or modelled and yet lies at the basis of all decisions. Making assumptions forms part of the SD process and is acceptable practice but it does allow for 
uncertainty of whether the assumptions made are in fact representative of the behaviour to be modelled. In this regard aspects such as the link between desired vehicle stock within the model and the effects of increased public transport was simplified by using percentage increases or decreases and not actual mathematical relationships which do not exist. A similar limitation lies in the effects of vehicle traffic on road life.

Due to the aggregate scope at which the road network was modelled in the Western Cape it was impossible to model the traffic volumes on each specific road. In order to accurately determine the effects of traffic volumes on road life it is required to compare the traffic densities for which a specific road was designed for with the actual densities resulting from the model and using this relationship to determine the deterioration rate of the road itself. The fact that each road is built at different times and designed for different traffic volumes and even types of vehicles, it was impossible to model these effects based on the level of aggregation in the model and thus simple measures were assumed as best as possible to represent these impacts. The same limitation existed for the modelling of the rail infrastructure networks were simplified tables of freight densities to rail life were created based on the best available information.

The greatest drawback of the model with regards to both the conceptualisation and representation of the real world was that of accurately modelling the GDP of the Province. As described in Chapter 3 the GDP sub-model runs as an exogenous entity, independent of any other sub-models within the model. This is the one area where the link between the conceptual model and the dynamic model was not fully realised. The reason for this being that the GDP of the Province is influenced by all sectors of the economy and thus without the dynamic modelling of all sectors it is impossible to model its behaviour. As a result of this the feedback from the various stocks within the transport sector back to the GDP was not possible and thus created the greatest shortfall of the model. To mitigate this limitation, the model adapted the best possible representation of GDP growth throughout the simulation period from the SAGEM model (Musango et al., 2010) and scaled down to the Western Cape. In relation to the limitations of the model realised throughout the modelling process, it is possible to discuss whether the SDM technique was in fact the most appropriate simulation method for the scope of this particular problem.

\subsection{Appropriateness of System Dynamics Modelling}

The use of System Dynamics Modelling for the investigation of the infrastructure implications of a green economy transition in the Western Cape provided 
a holistic manner in which to conceptualise and simulate the complexities of the problem. The ability of SDM to adapt and test various strategies and policy changes allowed for the meaningful analysis of the various frameworks identified in the problem, aimed at aiding the making of important decisions. There were however some difficulties and challenges that emerged throughout the research process, raising the question of whether SDM was the most appropriate modelling technique for the study. This section discusses the various advantages and limitations of using SDM as a suitable tool for investigating a green economy transition.

Firstly, the ease of model building and the use of Vensim software was relatively straight forward to initially grasp and within in a short period of time enough confidence was developed to undertake the process of model building. In this regard SDM when compared to other modelling approaches provided a combination of the most adequate technical modelling capabilities with an ease of development so as not to draw away from the scope of the study, turning it into a modelling exercise. The manner in which the real world system is conceptualised through the SD process also aided the breaking down of various system complexities, providing a robust way in which to identify the key drivers of the problem and initialise the behavioural patterns to be realised in the model.

The ability of SD to analyse policy changes and managerial issues of realworld scenarios is one of its major attributes, for the research problem this allowed for various changes to be included in the model and run as different scenarios. The ease at which SDM was able to compare these simulations was of great benefit for this study as it was possible to draw meaningful conclusions with relative speed and accuracy. Related to this, is the aptitude of SDM to model transitions over long periods of time at levels of aggregation to enable policy development. This characteristic however, in many cases was detrimental to the modelling effort as for certain parameters or variables accuracy was lost due to the scope of the model being too aggregate.

The greatest argument against the use of SDM for this problem lies in the question of whether Agent-based modelling was a more suitable method. With the ability of ABM to study the impact of various elements on the macro behaviour of the system by only knowing and manipulating certain interactions, it fits well into the topic of infrastructure and the implications of a green economy transition thereof. This means models can be built with limited understanding of the system interactions, provided adequate accuracy of defining the agents themselves is possible. Herein lies the drawback for this technique, due to the limited data and information available for this problem, ABM would not have been able to accurately simulate the system. In this regard, SDM was in fact more robust and because it lies heavily on macro behaviours, the 
information gaps were filled through the understanding of the system and the relationships therein.

The other down fall of using SD for this study is the fact that other mainstream transport mobility models differ in their application and design, thus limiting the ability to make comparisions between different models. For example the Mobility Model developed by the International Energy Agency (also known as MoMo) is a global transport spread sheet model that has been developed since 2003. It contains detailed by-mode, by-fuel and by-region historical data and projections for the transport sector and its energy and greenhouse gas implications looking forward to $2050^{1}$. The mobility model focuses more on vehicle/fuel costs and emissions to do with fuel type and mobility mode, which are simulated as a spread sheet model. Whilst such a model is limited by the lack of accounting for the dynamics that can be captured in a SD model, it does provide accurate projections of various indicators over time. Ideally, the use of the two models in conjunction with one another, focussing on the same problem with similar key indicating variables would allow for valuable comparisons to be made as well as for validation purposes.

With the greater research aim influencing the decision to use System Dynamics as it was collectively concluded to be the most suitable methodology for analysis, this sway the argument for the use of this technique. This may have resulted in the transport infrastructure model being modelled in a slightly unorthodox manner, but still being robust enough to meet the requirements of the study. In an ideal situation, the use of a System Dynamics model in conjunction with another mobility model for the Western Cape as mentioned above would be beneficial, whereby outputs could be calibrated and compared for more meaningful discussion

In its entirety SDM was deemed as the most suitable method in creating a tool for aiding decision-makers in managerial policy/strategy development. The ease of creation and its flexibility with regards to simulating dynamic behaviours made it a robust form of modelling. Although there were many limitations and challenges faced throughout the modelling process, as would have been for any technique, SDM proved an appropriate way in which to analyse and investigate the different strategies involved in a green economy transition in the context of transport infrastructure in the Western Cape. With the mentioning of these challenges the discussion leads to the recommendations of future research surrounding this topic.

${ }^{1}$ Information available at: www.iea.org/topics/transport/subtopics/mobilitymodelpartnership/ 


\subsection{Future Research}

The research involved in this study forms part of a greater effort aimed at providing a Green Economy Model for the Western Cape, investigating the implications across all sectors of a green economy transition in the Province. Relating to this, future research efforts should aim to incorporate the various models for each sector into one dynamic model able to accurately simulate the economy of the Western Cape and implement policy changes and strategies to each sector, enabling the holistic view of the entire system. Throughout the research endeavour and modelling process it became apparent that more accuracy could be realised if the boundaries of the model were stretched to that of the country. Whilst this has been achieved in the SAGEM model (Musango et al., 2010) for the South African economy from a more aggregate countrywide level, an ideal situation would arise in the creation of models for each province in the country, interacting to represent in the most accurate manner the economy of South Africa.

Such an endeavour would require interdisciplinary skill sets and a substantial knowledge-base of socio-economic, environmental issues critical to a more sustainable future. It would also be necessary to include the political and technical aspects affecting different spheres of the economy which would require a support base from stakeholders to enable and aid the collection of information and strategic frameworks identified for future development. With the connection being made to each province and the combination of the sectors for each of the economies the critical limitation that was realised in this study of the feedback from the sector back to the economy can be realised and thus more accurately modelled. Thus, in terms of future research, this study and the supporting endeavours within the different sectors of the Western Cape aimed to form a baseline from which to better and extend the decision making tool in the form of a System Dynamics model.

On a smaller scale in terms of the Western Cape infrastructure model created in this study more accuracy can be realised through the extension of the model to incorporate all other modes of transport. With more support in terms of stakeholder interaction and accessibility to information, the various infrastructure networks as defined in this model can be extended to more holistically depict the whole system. The scope which in this study was confined to passenger and freight transport relating the the Green Economy Framework of the Western Cape and the strategies therein can be stretched across the sector. This would include pipelines, ports, airports, links to the energy and water sector and the accompanying infrastructure as well as waste management and human settlement. As mentioned these aspects would require substantial amounts of stakeholder interaction and government support to gain the necessary information required in such an endeavour. 


\subsection{Concluding remarks}

This study investigated the infrastructure implications of a green economy transition in the Western Cape with particular focus on the transport sector. In response to the call of achieving an environmentally sustainable, resource efficient, low-carbon economy, a green economy transition requires interdisciplinary, integrated approaches to the management and design of infrastructures across all sectors. This provided the backdrop in which the research took place and the reasons for this investigation being conducted. With the examination of various literature relating to transition theories and management practices involved in such a problem, an understanding of complex systems involved in such a transition enabled an appropriate method of analysis to be developed for the research problem. This involved the critical analysis of various modelling techniques through which the method of system dynamics was chosen to enable the realisation of the research aim.

A framework from which the processes and methods involved in the system dynamics technique were identified and described, including the manner in which the model was built and the theoretical grounds on which it stands. The results and outcomes of the investigation were discussed in terms of the important stocks and key indicating variables of the various sub-modules with regards to the defined simulation outputs. From this it was possible to illustrate the important relationships existing between various components of the system. The subsequent implications of the decisions to be made by managerial bodies with regards to the study were then disclosed in the form of recommendations to the various stakeholders in order to aid the decision making process. Final discussion of the research outcomes including the limitations of the study as well as future recommendations relating to study were made.

The key findings of the research indicate that through the investment into a better public transport system as well as shifting the movement of freight onto the rail network there would be long term positive effects environmentally, socially and economically. It was recommended that efforts should be made in investigating a system that links all modes of public transport, standardising the service provided and the manner of payment and operation, ultimately leading to a safer more efficient system. With regards to freight, it was recommended that inter-modal solutions are arguably the most sustainable way of moving freight throughout the Province as indicated by the costs involved and reduction in $\mathrm{CO}_{2}$ emissions specified by the results from the simulation. The benefits herein lie with the reduction of trucks using the road network resulting in better pavement conditions and safety. In total to reach these goals, the costs of the infrastructure implications amounted to R25.5 billion over the simulation period ending in 2040. Through the aid of simulation, decision-making based on accurate representations of the future effects of strategies was made 
possible. It can be concluded that reaching a sustainable green economy in the Western Cape is possible and the implications of such a transition on transport infrastructure are manageable and achievable through strategic development. 


\section{List of References}

Airports Company South Africa (2014). George airport.

Available at: http://www.acsa.co.za/home.asp?pid=233

Akiva, M.B., Meersman, H. and Van De Voorde, E. (2013). Freight transport modelling. Emerald Group Publishing.

Asakhe Consulting Engineers (2007). 2007 rail census report: Western cape.

Attwell, W. (2012). City of cape town - economic growth stratergy.

Available at: http://www.capetown.gov.za/en/PublicParticipation/ Documents/FullDraftEGSpublicpart.pdf

Axelrod, R. and Tesfatsion, L. (2006). Appendix aa guide for newcomers to agentbased modeling in the social sciences. Handbook of computational economics, vol. 2, pp. $1647-1659$.

Balestrini-Robinson, S. (2009). A modeling process to understand complex system architectures. Ph.D. thesis, Scool of Aerospace Engineering, Georgia Institute of Technology.

Barlas, Y. (1996). Formal aspects of model validity and validation in system dynamics. System Dynamics Review, vol. 12, no. 3, pp. 183-210.

Bassi, A.M. (2013). Using models for green economy policy making. UNEP, KnowlEdge Srl.

Available at: http://www.unep.org/greeneconomy/Portals/88/Conferences/ GE $\% 20$ Week $\% 202013 / \mathrm{A} \% 20$ practitioners $\% 20$ guide $\% 20$ to $\% 20 \mathrm{GE} \% 20$ modeling $\%$ 20tools_20130723.pdf

Bassi, A.M. (2014). Using simulation models for green economy policy making: A comparative assessment. Review of Business and Economics Studies, vol. 2, no. 1, p. 88 .

Bergek, A., Jacobsson, S., Carlsson, B., Lindmark, S. and Rickne, A. (2008 4). Analyzing the functional dynamics of technological innovation systems: A scheme of analysis. Research Policy, vol. 37, no. 3, pp. 407-429.

Biggs, N. (1993). Algebraic graph theory. 2nd edn. Cambridge university press. 
Boccaletti, S., Latora, V., Moreno, Y., Chavez, M. and Hwang, D.-U. (2006). Complex networks: Structure and dynamics. Physics Reports, vol. 424, no. 45, pp. 175 - 308. ISSN 0370-1573.

Available at: http://www.sciencedirect.com/science/article/pii/ S037015730500462X

Boonzaaier, B. (2008). Tracks across the veld: a Southern African rail safari. JNC Boonzaaier, Warmbad/Bela Bela.

Borshchev, A. and Filippov, A. (2004). From system dynamics and discrete event to practical agent based modeling: reasons, techniques, tools. In: Proceedings of the 22nd international conference of the system dynamics society, vol. 22.

Cape Town City Council (2012). Myciti business plan.

Available at: http://myciti.org.za/en/about/management-reports/ business-plan/

Carbon Fund (2014). How we calculate.

Available at: http://www. carbonf und.org/how-we-calculate

Champagne, L.E. and Hill, R.R. (2005). Simulation validation with historic outcomes. In: Simulation Conference, 2005 Proceedings of the Winter, pp. 10-pp. IEEE.

Chan, S. (2001 31 October 2001). Complex adaptive systems . Tech. Rep..

Chappin, E.J. and Dijkema, G.P. (2010). Agent-based modelling of energy infrastructure transitions. International journal of critical infrastructures, vol. 6, no. 2, pp. 106-130.

City of Cape Town (2006). Integrated transport plan for the city of cape town: Draft for public consultation. Tech. Rep., City of Cape Town.

City of Cape Town (2009). Integrated transport plan for the city of cape town: 2006-2011. review and update october 2009.

Available at: https://www. capetown.gov.za/en/IDP/

City of Cape Town (2010 July). Business plan for phase 1a of the myciti integrated rapid transit project.

Available at: http://www. capetown.gov.za/en/irt/Documents/ MyCityBusinessPlan(6_043)101027a.pdf

City of Cape Town (2015 June a). Integrated rapid transit monthly project reports. Available at: http://www. capetown.gov.za/en/irt/Pages/ MonthlyProjectReports.aspx

City of Cape Town $(2015 b)$. Integrated transport plan for the city of cape town: Draft.

Available at: http://www.capetown.gov.za/en/PublicParticipation/ Documents/HYS_Transport_ITP_Final_Draft.pdf 
Costanza, R., Wainger, L., Folke, C. and Maler, K. (1993 September). Modeling complex ecological economic systems. BiosScience, vol. 43, no. 8, pp. 545-555. Published by: Oxford University Press on behalf of the American Institute of Biological Sciences.

Available at: http://www.jstor.org/stable/1311949

Coyle, R.G. (1983). The technical elements of the system dynamics approach. European Journal of Operational Research, vol. 14, no. 4, pp. 359-370.

Cronin, P., Ryan, F. and Coughlan, M. (2008). Undertaking a literature review: a step-by-step approach. British Journal of Nursing, vol. 17, no. 1, p. 1.

De Bod, A. and Havenga, J.H. (2010). Sub-saharan africa's rail freight transport system: potential impact of densification on cost.

Department of Economic Development and Tourism (2005). The scope of the transport industry in the western cape. Tech. Rep., Western Cape Department of Economic Development and Tourism, Cape Town.

Department of Environmental Affairs (2011). National climate change response white paper.

Available at: https://www.environment.gov.za/legislation/whitepapers;

Department of Environmental Affairs (2012). About the green fund.

Available at: http://www.sagreenfund.org.za/Pages/About.aspx

Economic Development Department (2011). New growth path: Accord 4 green economy accord. Tech. Rep..

Available at: http://www.economic.gov.za/communications/publications/ green-economy-accord;

eNaTiS (2014). Live vehicle population as per the national traffic information system.

Available at: http://www.enatis.com/index.php/statistics/ 13-live-vehicle-population?start $=20$

Figueroa, M.J., Fulton, L. and Tiwari, G. (2013 6). Avoiding, transforming, transitioning: pathways to sustainable low carbon passenger transport in developing countries. Current Opinion in Environmental Sustainability, vol. 5, no. 2, pp. $184-190$.

Forrester, J.W. and Senge, P.M. (1980). Tests for building confidence in system dynamics models. System dynamics, TIMS studies in management sciences, vol. 14, pp. 209-228.

Geels, F.W. (2011 6). The multi-level perspective on sustainability transitions: Responses to seven criticisms. Environmental Innovation and Societal Transitions, vol. 1 , no. 1 , pp. $24-40$. 
Grimm, V., Berger, U., Bastiansen, F., Eliassen, S., Ginot, V., Giske, J., GossCustard, J., Grand, T., Heinz, S.K., Huse, G. et al. (2006). A standard protocol for describing individual-based and agent-based models. Ecological modelling, vol. 198, no. 1, pp. $115-126$.

Harris, R.G. (1977). Economies of traffic density in the rail freight industry. The Bell Journal of Economics, pp. 556-564.

Havenga, J.H. (2013). Rail renaissance based on strategic market segmentation principles. Southern African Business Review, vol. 16, no. 1, pp. 1-21.

Havenga, J.H. and Pienaar, W.J. (2012). The creation and application of a national freight flow model for south africa: technical paper. Journal of the South African Institution of Civil Engineering= Joernaal van die Suid-Afrikaanse Instituut van Siviele Ingenieurswese, vol. 54, no. 1, pp. 2-13.

Hutson, T. (2014). Port of cape town.

Available at: http://ports.co.za/cape-town.php

Indalo Yethu, P.. (2014). Carbon calculator development.

Available at: http://www. $90 \times 2030$. org.za/view.asp?pg=calculator\&ccsub= assumptions

International Energy Agency (2013). CO2 Emissions from fuel combustion, Highlights. International Energy Agency.

International Energy Agency and International Union of Railways (2012). Railway handbook 2012: Energy consumption and co2 emissions.

Available at: http://www.uic.org/com/IMG/pdf/iea-uic_2012final-lr.pdf

Johansson, J. and Hassel, H. (2010). An approach for modelling interdependent infrastructures in the context of vulnerability analysis. Reliability Engineering \&3 System Safety, vol. 95, no. 12, pp. 1335 - 1344. ISSN 0951-8320. 19th European Safety and Reliability Conference.

Available at: http://www.sciencedirect.com/science/article/pii/ S0951832010001444

Jorgensen, A. (2005). Western cape freight transport data bank.

Available at: http://www.allenjorgensen.com/UserFiles/W\%20Cape $\% 20 \mathrm{DB} \%$ 20 to $\% 20$ ws , $\% 202014-05-31$.pdf

Kane, L. (2010). Sustainable transport indicators for cape town, south africa: Advocacy, negotiation and partnership in transport planning practice. Natural Resources Forum, vol. 34, no. 4, pp. 289-302.

Kemp, R., Schot, J. and Hoogma, R. (1998). Regime shifts to sustainability through processes of niche formation: the approach of strategic niche management. Technology Analysis \& Strategic Management, vol. 10, no. 2, pp. 175-198.

Kleijnen, J.P.C. (1995 4/6). Verification and validation of simulation models. European Journal of Operational Research, vol. 82, no. 1, pp. 145-162. 
Letshwiti, V., Stanway, R. and Mokonyama, M. (2003). Strategic overview and analysis of vehicle ownership trends in south africa with emphasis on light passenger vehicles. SATC 2003.

Lorbach, D. (2010). Transition management for sustainable development: A prescriptive, complexity-based governance framework. Governance, vol. 23, no. 1, pp. $161-183$.

Luna-Reyes, L.F. and Andersen, D.L. (2003). Collecting and analyzing qualitative data for system dynamics: methods and models. System Dynamics Review, , no. 19 , pp. $271-296$.

Maani, K.E. and Cavana, R.Y. (2012). Systems Thinking, System Dynamics: Managing Change and Complexity. 2nd edn. Pearson, Auckland, New Zealand. ISBN 9781877371035 .

Macal, C.M. and North, M.J. (2009). Agent-based modeling and simulation. In: Winter simulation conference, pp. 86-98. Winter Simulation Conference.

Markard, J., Raven, R. and Truffer, B. (2012 7). Sustainability transitions: An emerging field of research and its prospects. Research Policy, vol. 41, no. 6, pp. 955-967.

Martheze, J. and Grimbeek, J. (2012). Integrated rapid transit project progress report no.33. Tech. Rep., MyCiTi/IRT Project Team.

Martinez-Moyano, I.J. (2012). Documentation for model transparency. System Dynamics Review, vol. 28, no. 2, pp. 199-208.

Meadowcroft, J. (2009). What about the politics? sustainable development, transition management, and long term energy transitions. Policy Sciences, vol. 42, no. 4 , pp. $323-340$.

Meersman, H. and Van de Voorde, E. (2013). The relationship between economic activity and freight transport. Freight transport modelling. Bingley, Emerald, pp. $17-43$.

Musango, J.K., Brent, A.C. and Bassi, A.M. (2010). Modelling the transition towards a green economy in south africa. Technological Forecasting and Social Change.

Musango, J.K., Brent, A.C. and Bassi, A.M. (2014 9). Modelling the transition towards a green economy in south africa. Technological Forecasting and Social Change, vol. 87, no. 0, pp. 257-273.

Musango, J.K., Brent, A.C., van Niekerk, J.B.S., Jonker, W.D., Pienaar, A.P., York, T.A., Oosthuizen, J., Duminy, L. and de Kock, I.H. (2015). A system dynamics approach to understand the implications of a green economy transition in the western cape province of south africa. The 33rd International Conference of the System Dynamics Society, Cambridge, Massachusetts, USA. 
Ortúzar S., Juan de Dios., W.L.G. (1994). Modelling transport. Wiley, Chichester; New York.

Ouyang, M. (2014 1). Review on modeling and simulation of interdependent critical infrastructure systems. Reliability Engineering $\&$ System Safety, vol. 121, no. 0, pp. $43-60$.

Palmer, I. and Graham, N. (2013). Western cape infrastructure framework. Tech. Rep., Western Cape Government, Kenilworth, Cape Town.

Passenger Rail Agency South Africa and South African Rail Commuter Corp. Ltd (2002). Annual report 2002.

Prasa (2014 September). Prasa : Corporate plan 2014/15 presentation to portfolio committee on transport.

Available at: http://pmg-assets.s3-website-eu-west-1.amazonaws.com/ 140902prasa.pdf

Pruyt, E. (2013). Small System Dynamics Models for Big Issues: Triple Jump towards Real-World Complexity. 1st edn. TU Delft Library, Delft, The Netherlands. ISBN 978-94-6186-195-5.

Quantec (2015). Easy data: Naamsa regional vehicle sales.

Available at: http://www.easydata.co.za/data/dimensionnode/NMS-TREE_ E10/

Qudrat-Ullah, H. (2005). Structural validation of system dynamics and agent-based simulation models. In: 19th European Conference on Modelling and Simulation, Riga, Latvia, vol. 94.

Randers, J. (1980). Guidelines for model conceptualization in elements of the system dynamics method. j. randers, ed.

Reiss, P.C. and Wolak, F.A. (2007). Structural econometric modeling: Rationales and examples from industrial organization. Handbook of econometrics, vol. 6, pp. $4277-4415$.

Richardson, B.C. (2005). Sustainable transport: analysis frameworks. Journal of Transport Geography, vol. 13, no. 1, pp. 29 - 39. ISSN 0966-6923. Sustainability and the Interaction Between External Effects of Transport (Part Special Issue, pp. 23-99).

Available at: http://www.sciencedirect.com/science/article/pii/ S0966692304000857

Richardson, G. and Pugh, A. (1981). Introduction to system dynamics modeling with dynamo. Tech. Rep., Productivity Press, Cambridge, MA.

Rotmans, J. and Kemp, R. (2008). Detour ahead: a response to shove and walker about the perilous road of transition management. Environment and Planning A: international journal of urban and regional research, vol. 40, no. 4, pp. 1006-1012. 
Rotmans, J., Kemp, R. and Van Asselt, M. (2001). More evolution than revolution: transition management in public policy. foresight, vol. 3, no. 1, pp. 15-31.

Rotmans, J. and Loorbach, D. (2009). Complexity and transition management. Journal of Industrial Ecology, vol. 13, no. 2, pp. 184-196.

Rubenstein-Montano, B., Liebowitz, J., Buchwalter, J., McCaw, D., Newman, B. and Rebeck, K. (2001 5). A systems thinking framework for knowledge management. Decision Support Systems, vol. 31, no. 1, pp. 5-16.

Sanford Bernhardt, K. and McNeil, S. (2008). Agent-based modeling: Approach for improving infrastructure management. Journal of Infrastructure Systems, vol. 14, no. 3, pp. 253-261.

SAPIA Future Fuels Working Group (2008 November). Petrol and diesel in south africa and the impact on air quality.

Available at: http://www.sapia.co.za/publications/special-interest.html

Schiuma, G., Carlucci, D. and Sole, F. (2012 7). Applying a systems thinking framework to assess knowledge assets dynamics for business performance improvement. Expert Systems with Applications, vol. 39, no. 9, pp. 8044-8050.

Schot, J. and Geels, F.W. (2008). Strategic niche management and sustainable innovation journeys: theory, findings, research agenda, and policy. Technology Analysis \& Strategic Management, vol. 20, no. 5, pp. 537-554.

Simpson, Z. and Havenga, J.H. (2010). Revitalisation of branch lines in south africa: A long-term view for sustainability.

Smith, A. (2007 07/01; 2014/04). Translating sustainabilities between green niches and socio-technical regimes. Technology Analysis 83 Strategic Management, vol. 19, no. 4, pp. 427-450. Doi: 10.1080/09537320701403334; M3: doi: 10.1080/09537320701403334; 03.

Available at: http://dx.doi.org/10.1080/09537320701403334

South African LED Network (2010). Topic: Green economy.

Stander, H. and Pienaar, W. (2002). Perspectives on freight movement by road and rail in south africa. SATC 2002.

Statistics South Africa (2013). Gross domestic product: annual estimates 2003-2012, third quarter 2013: P044. Pretoria.

Statistics South Africa (2014 Junea). Nhts provincial report western cape profile. Available at: http://www.statssa.gov.za/publications/Report-03-20-02/ Report-03-20-022014.pdf

Statistics South Africa (2014b). Statistical release p0302: Mid-year population estimates 2014. Statistics SA, Pretoria. 
Sterman, J.D. (2000). Business dynamics: systems thinking and modeling for a complex world, vol. 19. Irwin/McGraw-Hill Boston.

Sterman, J.D. (2001). System dynamics modeling. California management review, vol. 43 , no. 4 , pp. $8-25$.

System Dynamics Society (2011). The field of system dynamics.

Available at: http://www.systemdynamics.org/whatissystemdynamics.html

UNEP (2013). What is GEI?

Available at: http://unep.org/greeneconomy/AboutGEI/WhatisGEI/tabid/ 29784/Default.aspx

U.S. Environmental Protection Agency (2008). Average annual emissions and fuel consumption for gasoline-fueled passenger cars and light trucks.

Available at: http://www.epa.gov/otaq/consumer/420f08024.pdf

Van der Meulen, R. and Möller, L. (2007). Some global touchstones in railway adaptation. In: Proc. 26th Southern African Transport Conference [CD-ROM], Pretoria, South Africa.

Ventana Systems Inc. (2013). Vensim dss for windows version 6.3 (x32).

Weber, S. and Porto, M. (2007). Generation of arbitrarily two-point-correlated random networks. Physical Review E, vol. 76, no. 4, p. 046111.

Western Cape Department of Transport and Public Works (2010). Budget statement number 2, vote number 10. Tech. Rep., Western Cape Government.

Western Cape Government (2013). Green is smart: Western cape green economy strategy framework.

Available at: http://led.co.za/topic/green-economy

Western Cape Government, Department of Education (2013/2014). Annual reports. Available at: http://www.wcpp.gov.za/sites/default/files/Annual\% 20Report $\% 20$ - \%20WCED $\% 202014 \% 20$-\%20Vote $\% 205$.pdf

Western Cape Government, Department of Transport and Public Works (2013 September). Western cape provincial land transport framework.

Yazdani, S., Yusof, M.J.M., Azizi, M.M. and Ali, A.A.A. (). An agent-based framework to improve coordination in the process of urban infrastructure provision in iran. 
Appendices 


\title{
Appendix A
}

\section{Tables and figures as discussed in text}

\author{
A.1 Model Boundary describing all parameters \\ of certain sub-modules
}

A.2 Historical data input parameters for model validation 


\begin{tabular}{|c|c|c|c|c|}
\hline \multicolumn{3}{|c|}{ Endogenous } & \multirow{2}{*}{$\begin{array}{l}\text { Exogenous } \\
\text { Parameters }\end{array}$} & \multirow{2}{*}{$\begin{array}{l}\text { Excluded } \\
\text { Excluded }\end{array}$} \\
\hline Stocks & Flows & Auxiliaries & & \\
\hline \multicolumn{5}{|l|}{ Road Network } \\
\hline $\begin{array}{l}\text { Roads under } \\
\text { Construction }\end{array}$ & $\begin{array}{l}\text { Road } \\
\text { construction } \\
\text { starts } \\
\text { Road } \\
\text { completion }\end{array}$ & $\begin{array}{l}\text { Average Road cost per km } \\
\text { Budget for Road construction } \\
\text { Road Maintenance cost } \\
\text { Time to Complete Road } \\
\text { Relative km of Road }\end{array}$ & $\begin{array}{l}\text { Initial Road Cost } \\
\text { per km } \\
\text { Average Budget } \\
\text { Time } \\
\text { Initial km of Road }\end{array}$ & $\begin{array}{l}\text { Elasticity of Road } \\
\text { Density }\end{array}$ \\
\hline $\begin{array}{l}\text { Functioning } \\
\text { Roads }\end{array}$ & $\begin{array}{l}\text { Road } \\
\text { completion } \\
\text { Road } \\
\text { disruption }\end{array}$ & $\begin{array}{l}\text { Average Road Life without } \\
\text { maintenance } \\
\text { Effect of Maintenance on } \\
\text { road life } \\
\text { Effect of increased truck } \\
\text { haulage on roads } \\
\text { Motor vehicles effect on } \\
\text { roads } \\
\text { Fraction of road maintenance } \\
\text { achieved }\end{array}$ & $\begin{array}{l}\text { Initial Road } \\
\text { network } \\
\text { Effect of } \\
\text { maintenance on } \\
\text { road life } \\
\text { Truck haul effect } \\
\text { Motor vehicle } \\
\text { disruption effect }\end{array}$ & $\begin{array}{l}\text { Road Design Life } \\
\text { comparison } \\
\text { Equivalent E80s for } \\
\text { vehicle growth } \\
\text { Road category }\end{array}$ \\
\hline $\begin{array}{l}\text { Roads } \\
\text { Infrastructure } \\
\text { Expenditure }\end{array}$ & $\begin{array}{l}\text { Yearly } \\
\text { Expenditure }\end{array}$ & time & $\begin{array}{l}\text { Initial transport } \\
\text { infrastructure } \\
\text { expenditure } \\
\text { Government } \\
\text { Expenditure on } \\
\text { Road Infrastructure }\end{array}$ & GDP deflation \\
\hline $\begin{array}{l}\text { Cost of Road } \\
\text { Maintenance }\end{array}$ & $\begin{array}{l}\text { Changes in } \\
\text { Road } \\
\text { maintenance } \\
\text { cost }\end{array}$ & $\begin{array}{l}\text { Cost of road maintenance } \\
\text { growth rate }\end{array}$ & $\begin{array}{l}\text { Initial road } \\
\text { maintenance cost } \\
\text { per km }\end{array}$ & \\
\hline \multicolumn{5}{|l|}{ Population } \\
\hline $\begin{array}{l}\text { Population of } \\
\text { Western Cape }\end{array}$ & $\begin{array}{l}\text { Births } \\
\text { Deaths } \\
\text { Domestic } \\
\text { migration in } \\
\text { Domestic } \\
\text { migration out }\end{array}$ & $\begin{array}{l}\text { Death Rate } \\
\text { Birth Rate }\end{array}$ & $\begin{array}{l}\text { Estimated } \\
\text { migration In stream } \\
\text { table } \\
\text { Estimated } \\
\text { migration Out } \\
\text { stream }\end{array}$ & $\begin{array}{l}\text { International } \\
\text { migration } \\
\text { South African } \\
\text { population relation }\end{array}$ \\
\hline \multicolumn{5}{|l|}{ Transport } \\
\hline $\begin{array}{l}\text { Motor } \\
\text { Vehicles }\end{array}$ & $\begin{array}{l}\text { Vehicle sales } \\
\text { Vehicle } \\
\text { disposal }\end{array}$ & $\begin{array}{l}\text { Desired vehicle stock } \\
\text { Desired vehicle ownership per } \\
\text { capita } \\
\text { Relative motor vehicles } \\
\text { C02 emissions }\end{array}$ & $\begin{array}{l}\text { Average vehicle life } \\
\text { span } \\
\text { Access to vehicles } \\
\text { Percentage } \\
\text { increases of other } \\
\text { passenger } \\
\text { transport modes } \\
\text { Average C02 } \\
\text { emissions per } \\
\text { vehicle } \\
\text { Average C02 } \\
\text { emissions per Truck } \\
\text { load }\end{array}$ & $\begin{array}{l}\text { Trips taken } \\
\text { Passenger trips } \\
\text { increase }\end{array}$ \\
\hline
\end{tabular}

Figure A.1: Model Boundary 


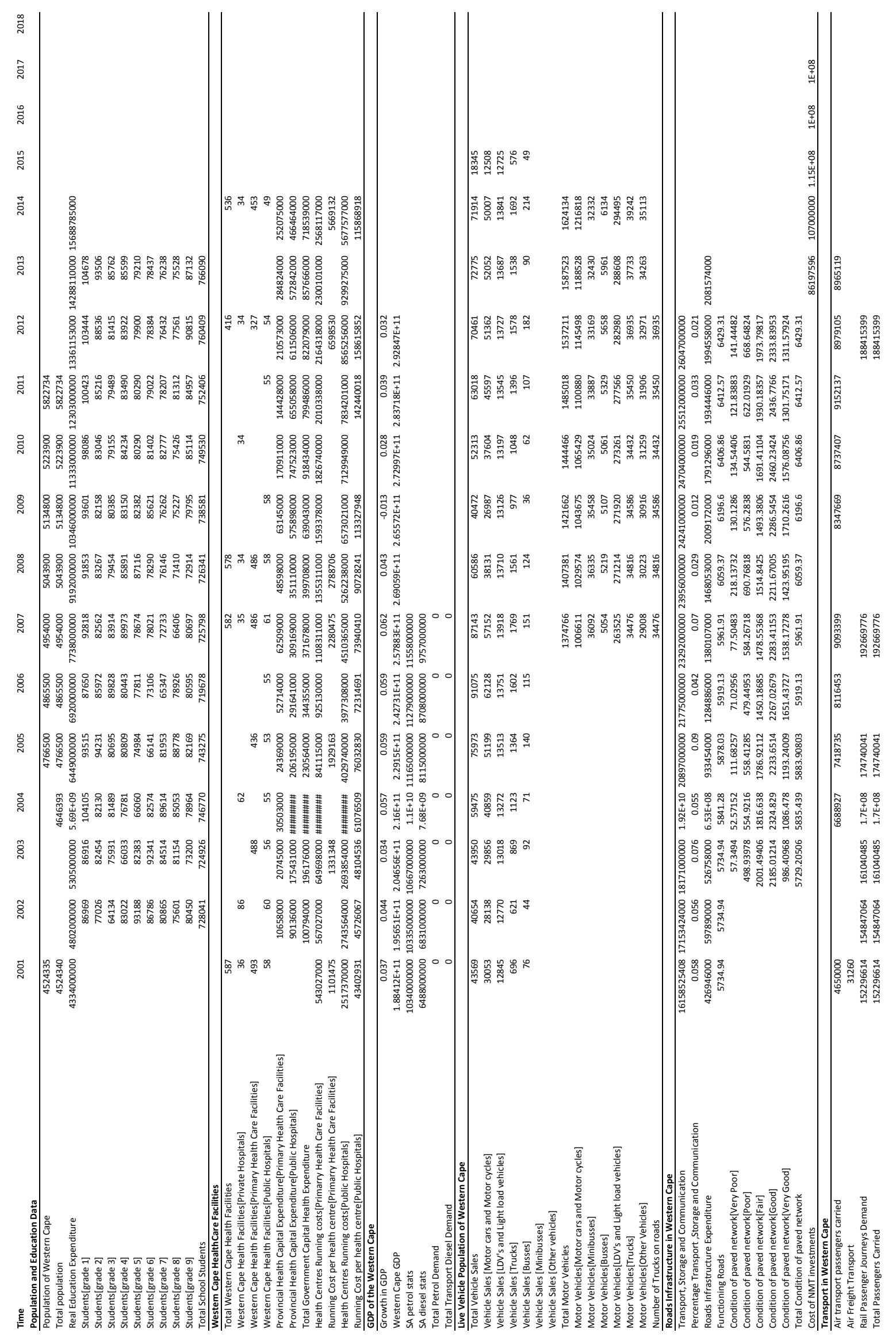




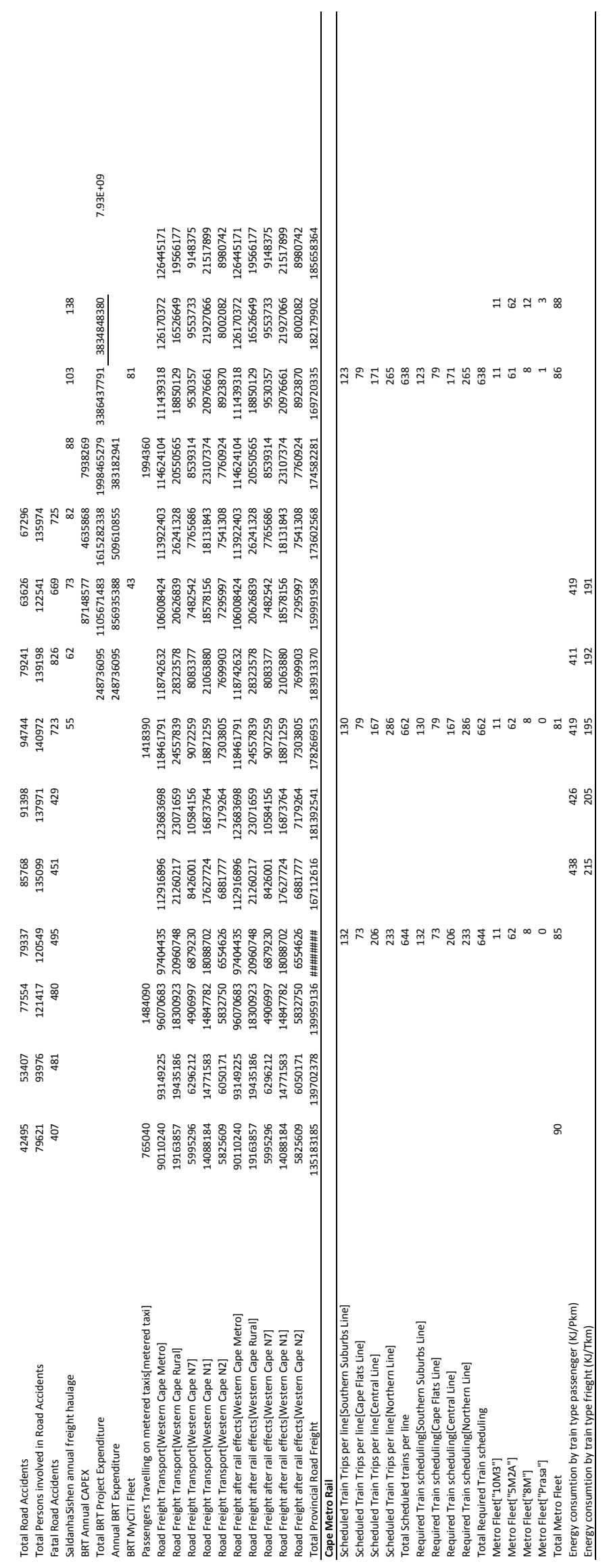




\section{Appendix B \\ Stock and flow descriptions of Sub-models}


APPENDIX B. STOCK AND FLOW DESCRIPTIONS OF SUB-MODELS 121 


\section{B.1 Western Cape Road Infrastructure Network Module}

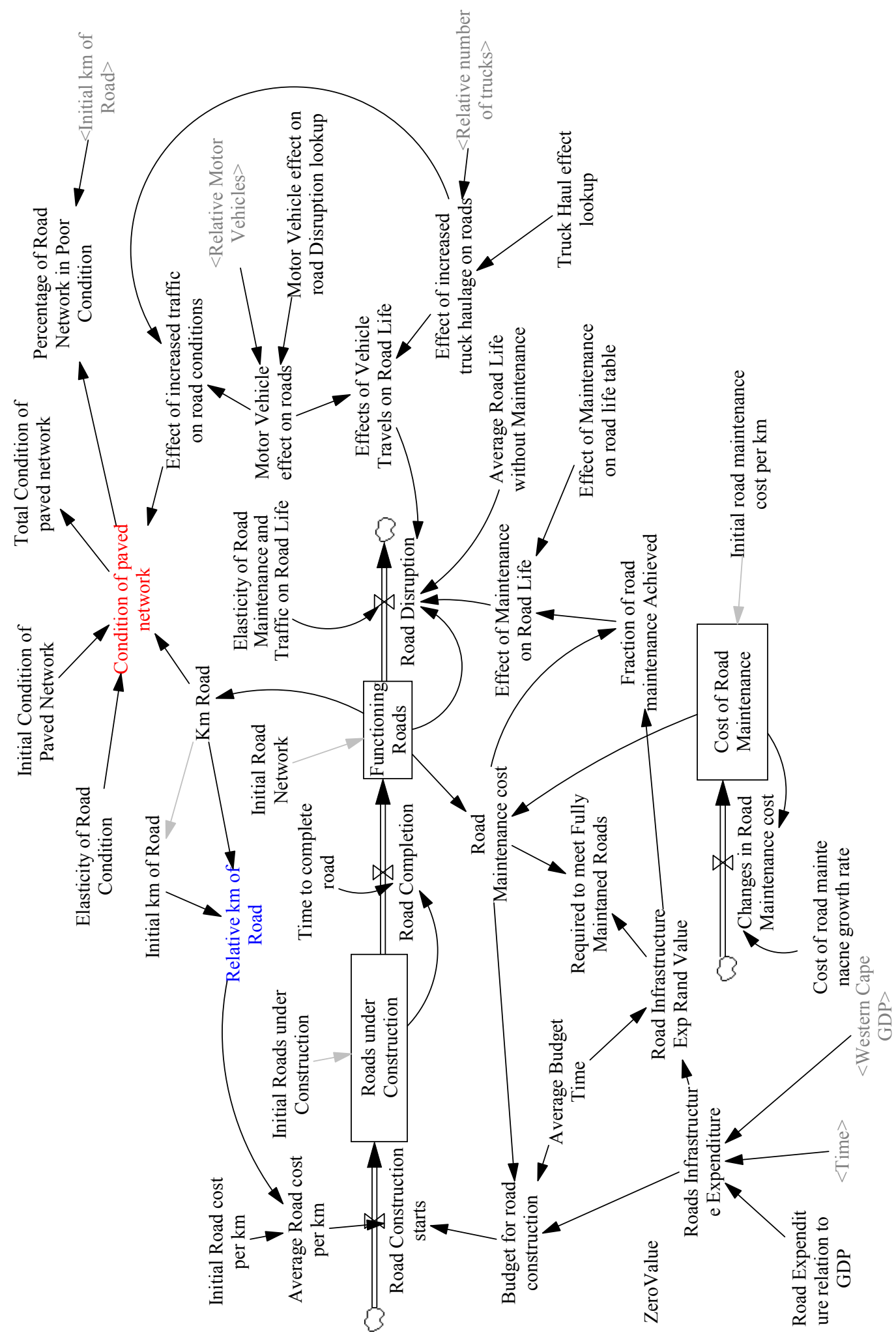

Figure B.1: Western Cape Road Infrastructure Network 
APPENDIX B. STOCK AND FLOW DESCRIPTIONS OF SUB-MODELS 123 


\section{B.2 Live Vehicle Population sub-module}

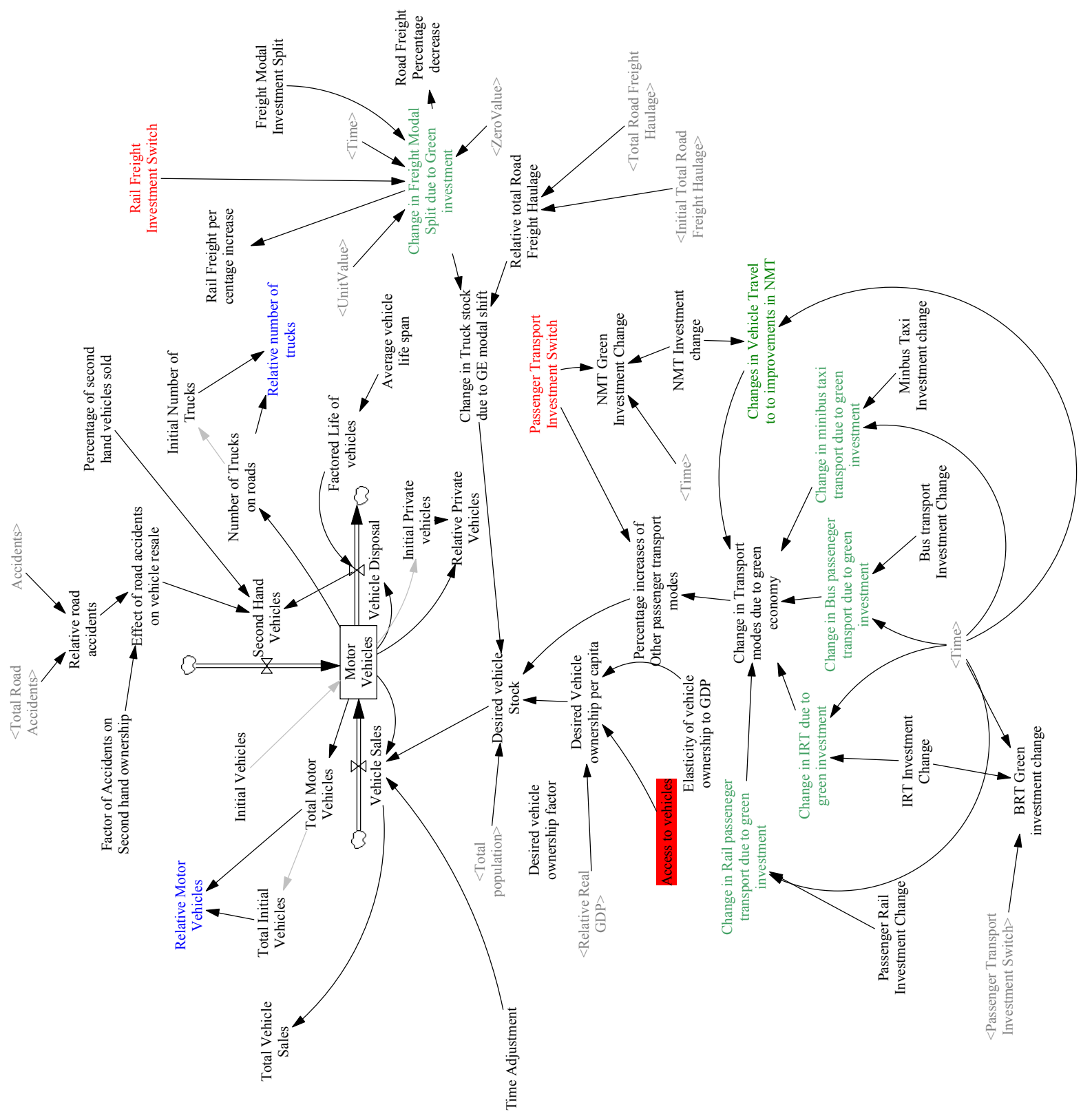


APPENDIX B. STOCK AND FLOW DESCRIPTIONS OF SUB-MODELS 125 


\section{B.3 Cape Metrorail Network and System sub-module}

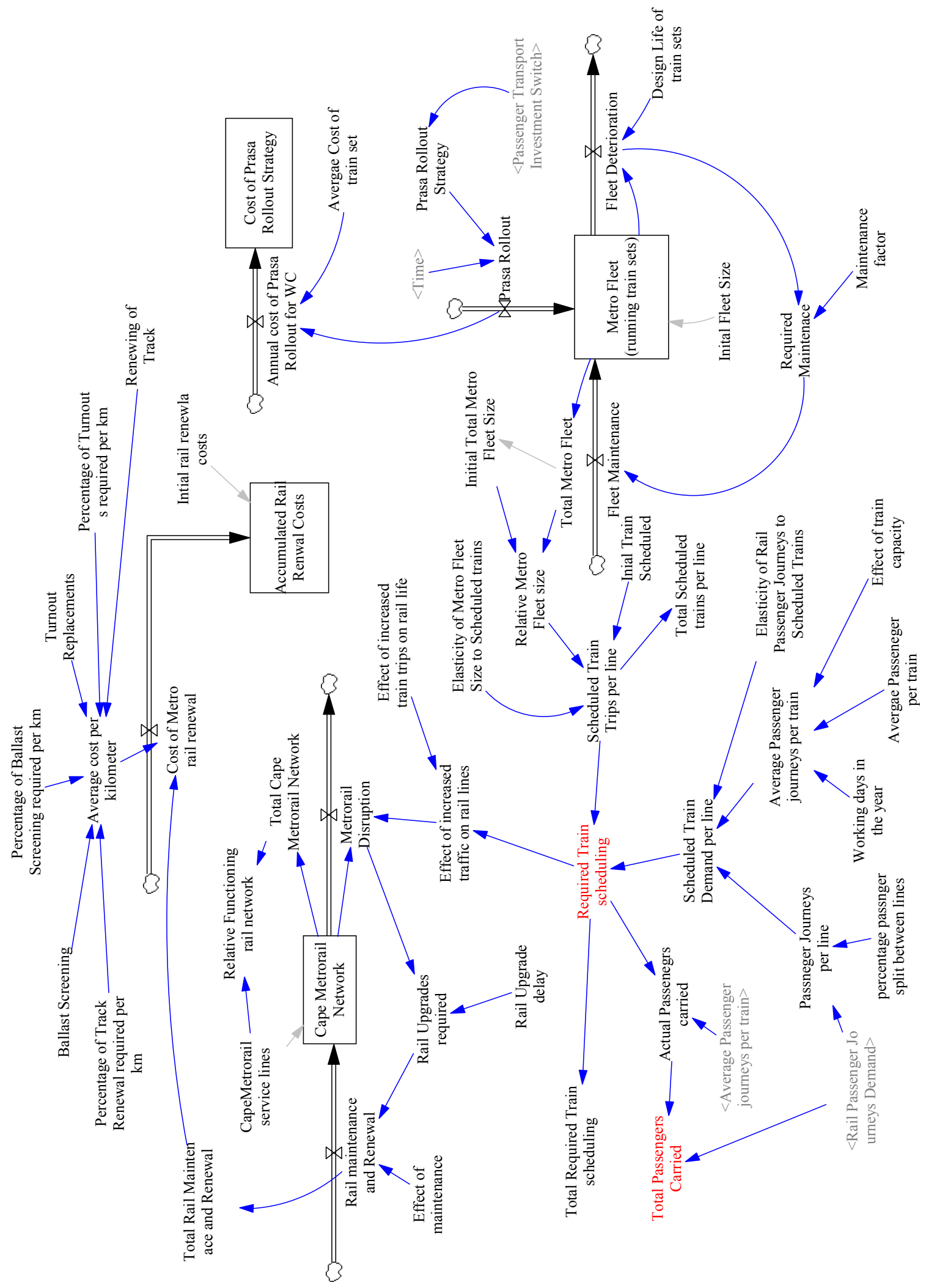

Figure B.3: Cape Metrorail Network and System 
APPENDIX B. STOCK AND FLOW DESCRIPTIONS OF SUB-MODELS 127 


\section{B.4 Passenger Transport sub-module}

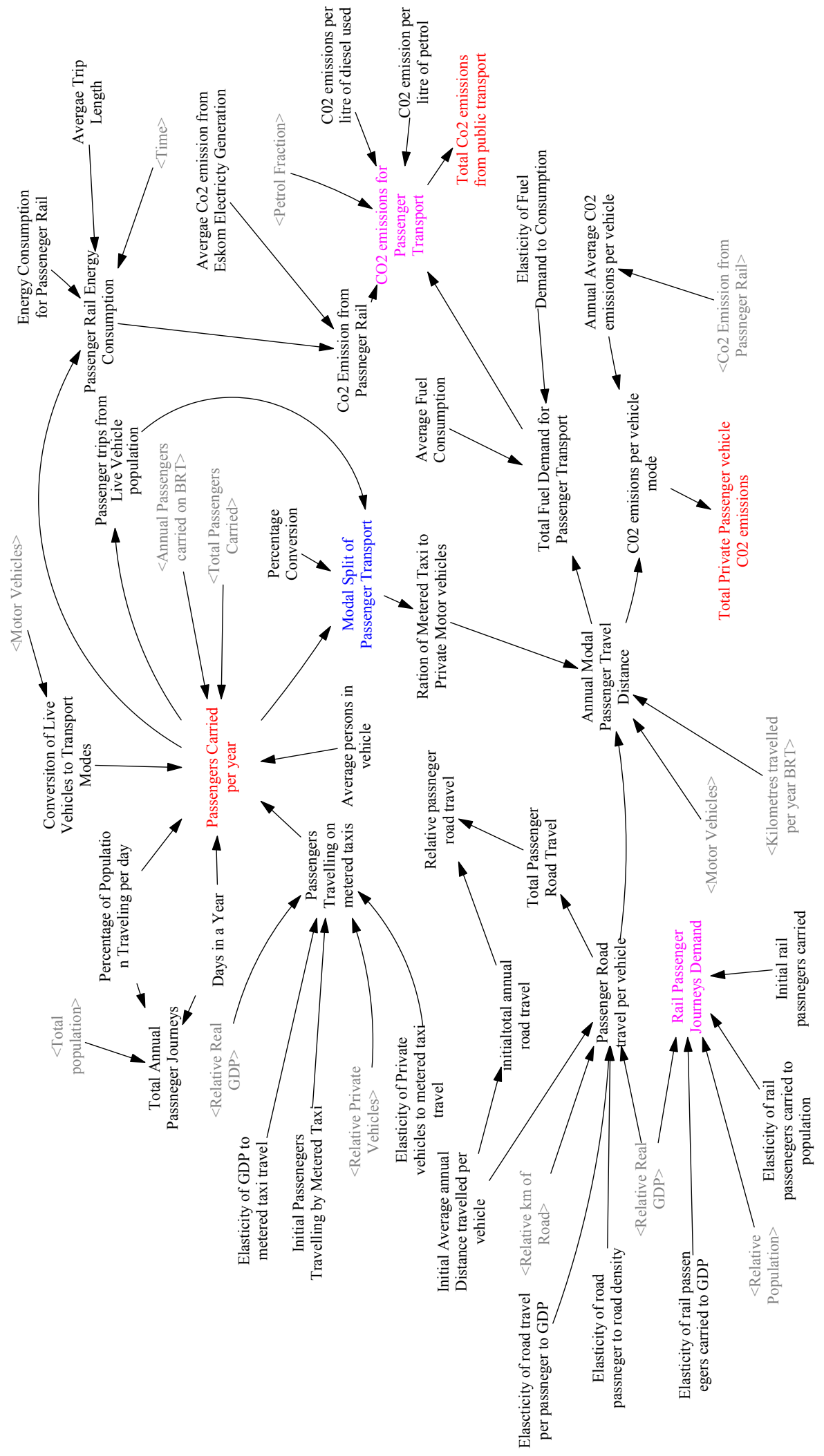

Figure B.4: Passenger Transport in the Western Cape 
APPENDIX B. STOCK AND FLOW DESCRIPTIONS OF SUB-MODELS 129 


\section{B.5 Mainline Rail Freight Transport Network sub-module}

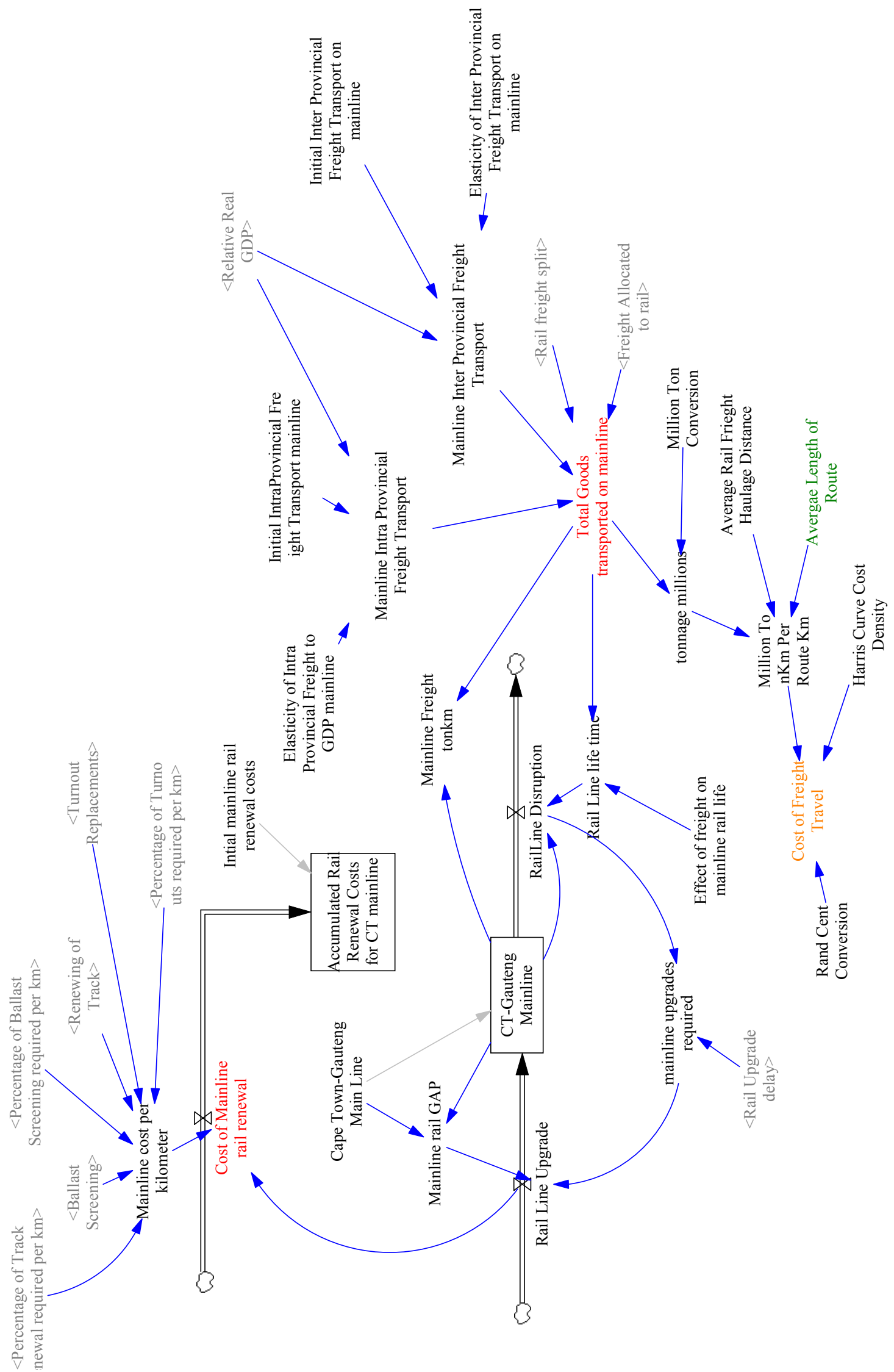

Figure B.5: Mainline Rail Freight Transport Network 
APPENDIX B. STOCK AND FLOW DESCRIPTIONS OF SUB-MODELS 131 


\section{B.6 Branchline Rail Freight Transport Network sub-module}

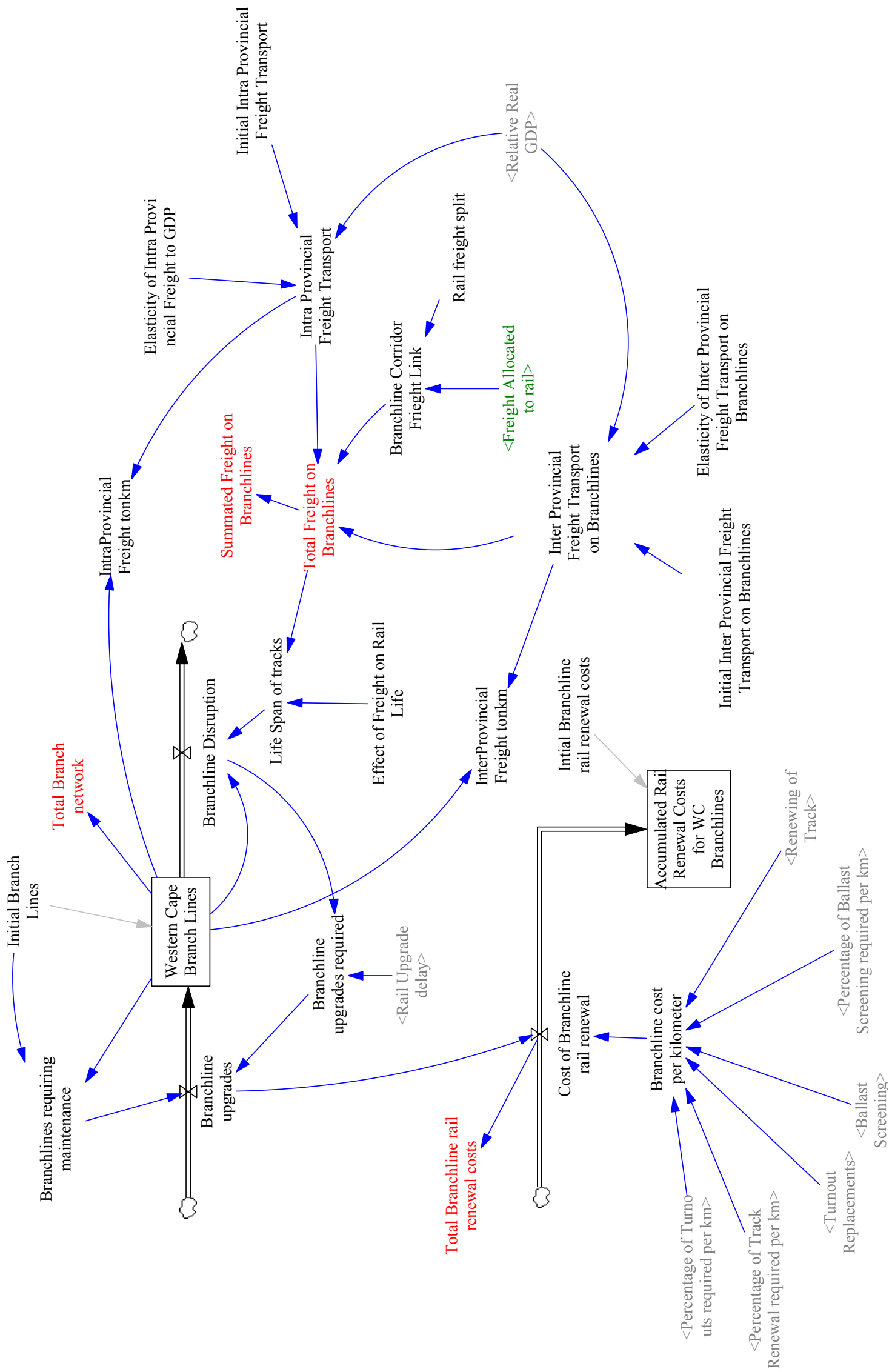

Figure B.6: Branchline Rail Freight Transport Network 
APPENDIX B. STOCK AND FLOW DESCRIPTIONS OF SUB-MODELS 133 


\section{B.7 Western Cape Freight Transport demand sub-module}

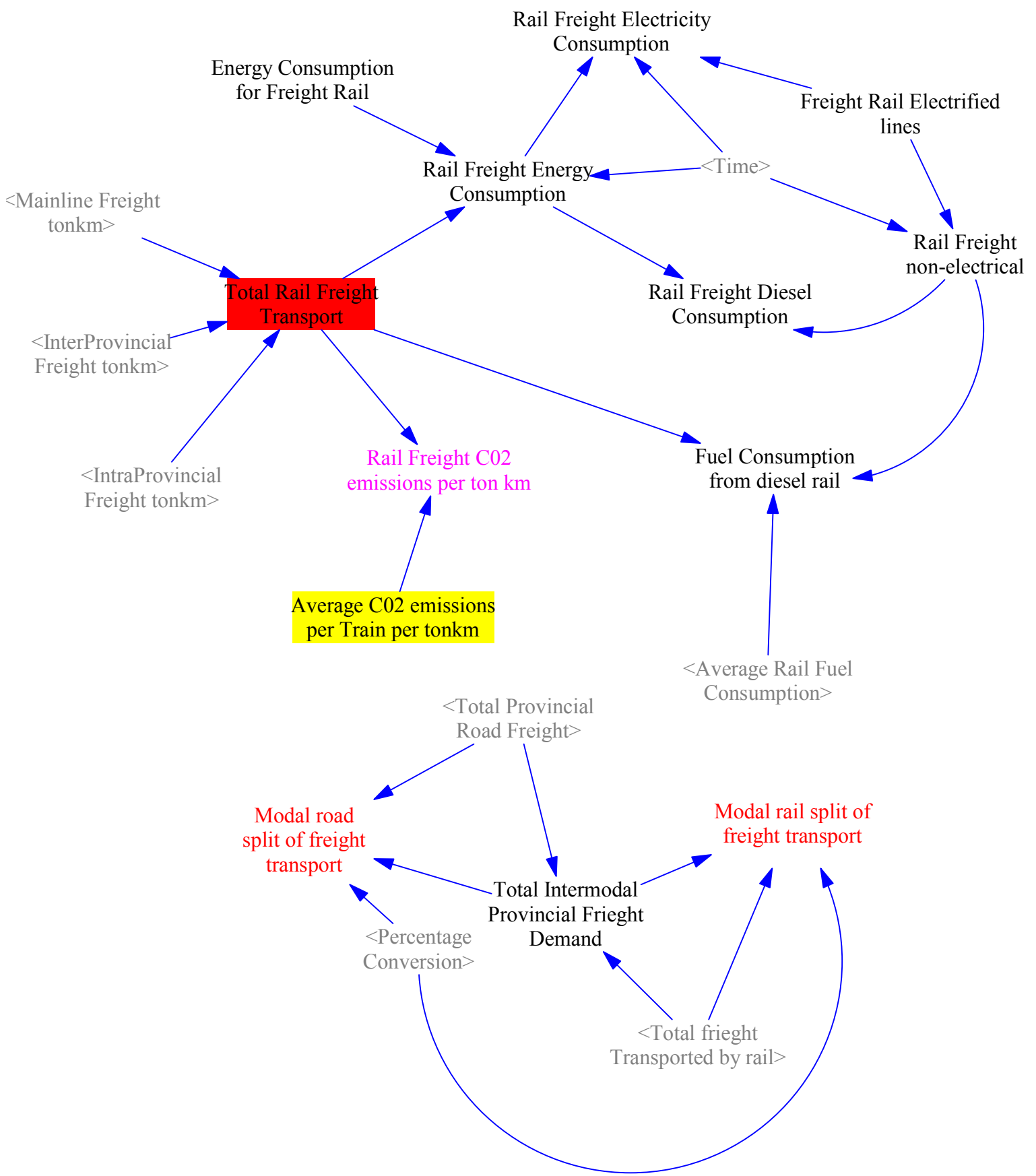

Figure B.7: Rail Freight Transport demand in the Western Cape 


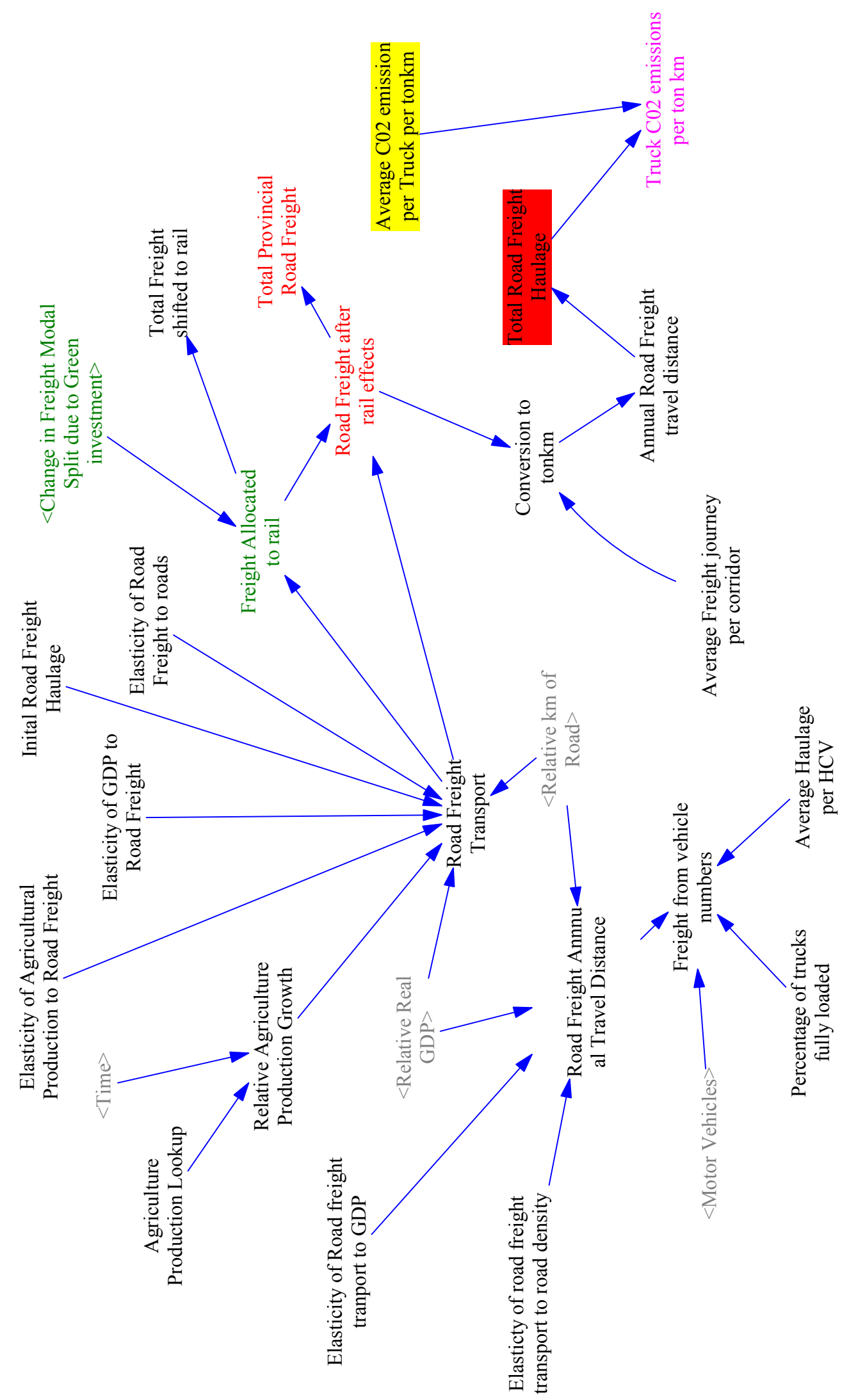

Figure B.8: Road Freight Transport demand in the Western Cape 
APPENDIX B. STOCK AND FLOW DESCRIPTIONS OF SUB-MODELS 136 


\section{B.8 Bus Rapid Transit sub-module}

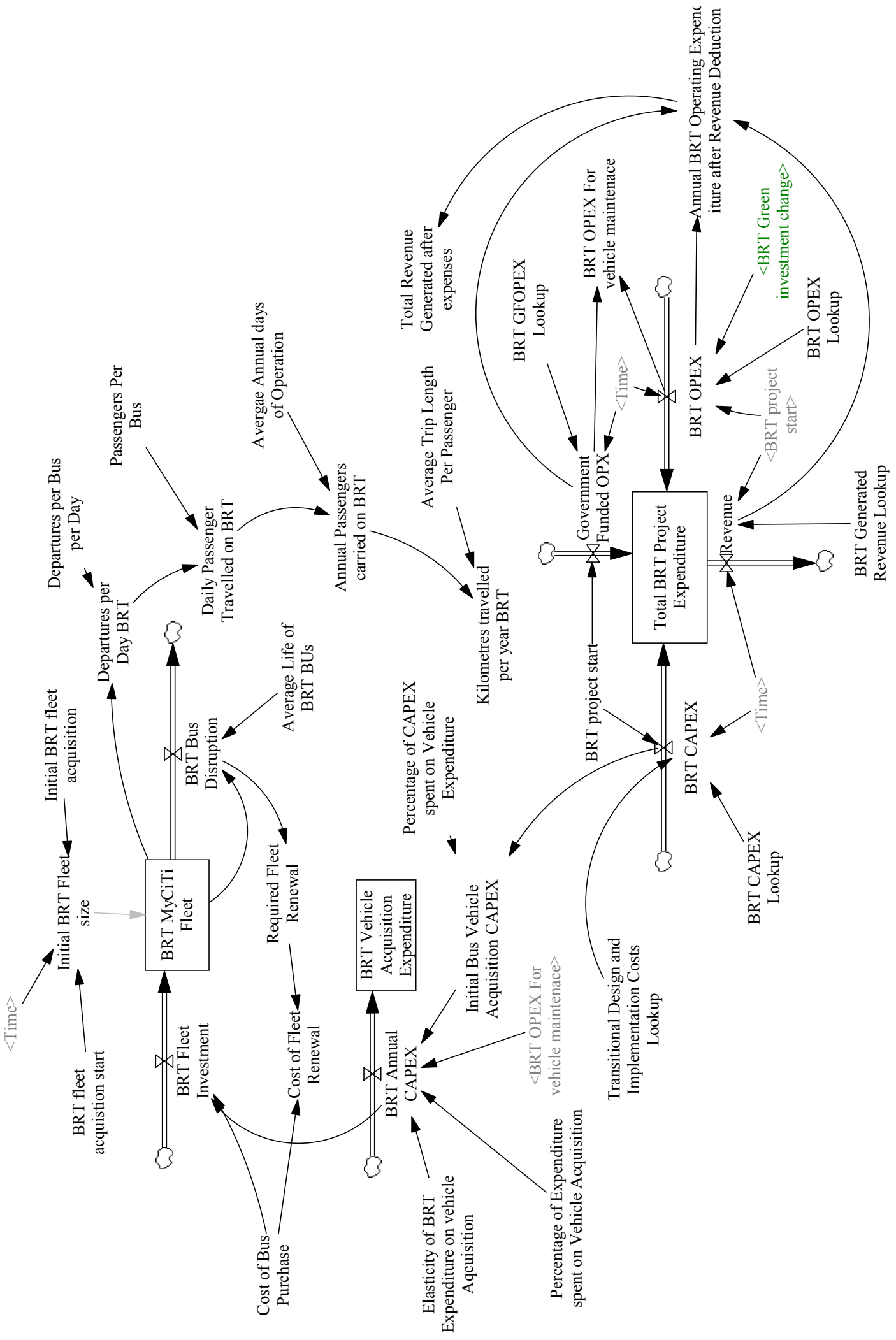

Figure B.9: BRT system and fleet 
APPENDIX B. STOCK AND FLOW DESCRIPTIONS OF SUB-MODELS 138 


\section{B.9 $\mathrm{CO}_{2}$ emissions from transport for the Western Cape sub-module}

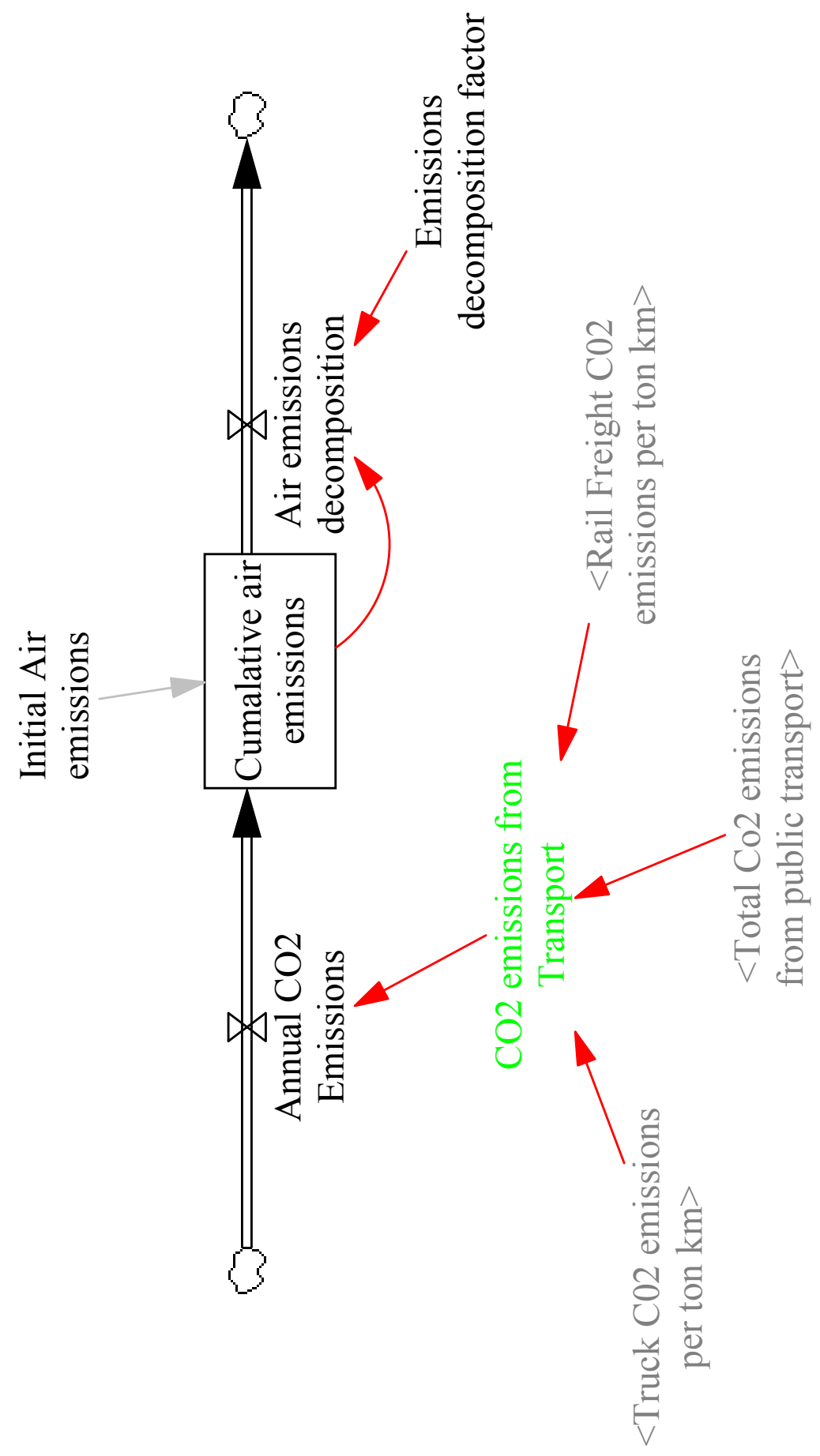

Figure B.10: $\mathrm{CO}_{2}$ emissions from transport for the Western Cape sub-module 
APPENDIX B. STOCK AND FLOW DESCRIPTIONS OF SUB-MODELS 140 
APPENDIX B. STOCK AND FLOW DESCRIPTIONS OF SUB-MODELS 141

\section{B.10 Fuel Demand sub-module for the Western Cape}

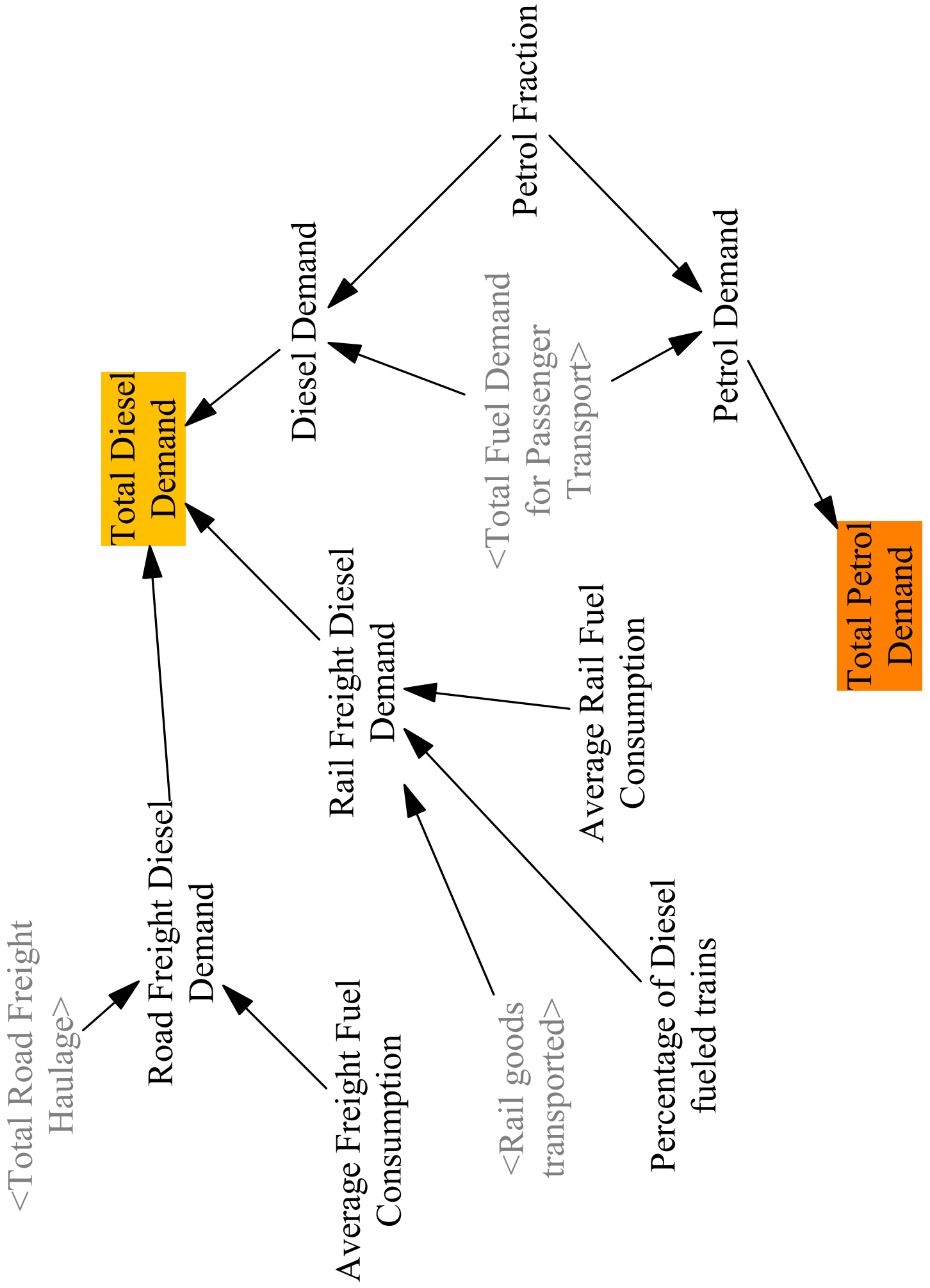

Figure B.11: Fuel Demand module for the Western Cape 
APPENDIX B. STOCK AND FLOW DESCRIPTIONS OF SUB-MODELS 142 


\section{B.11 Total Road Accidents for the Western Cape sub-module}

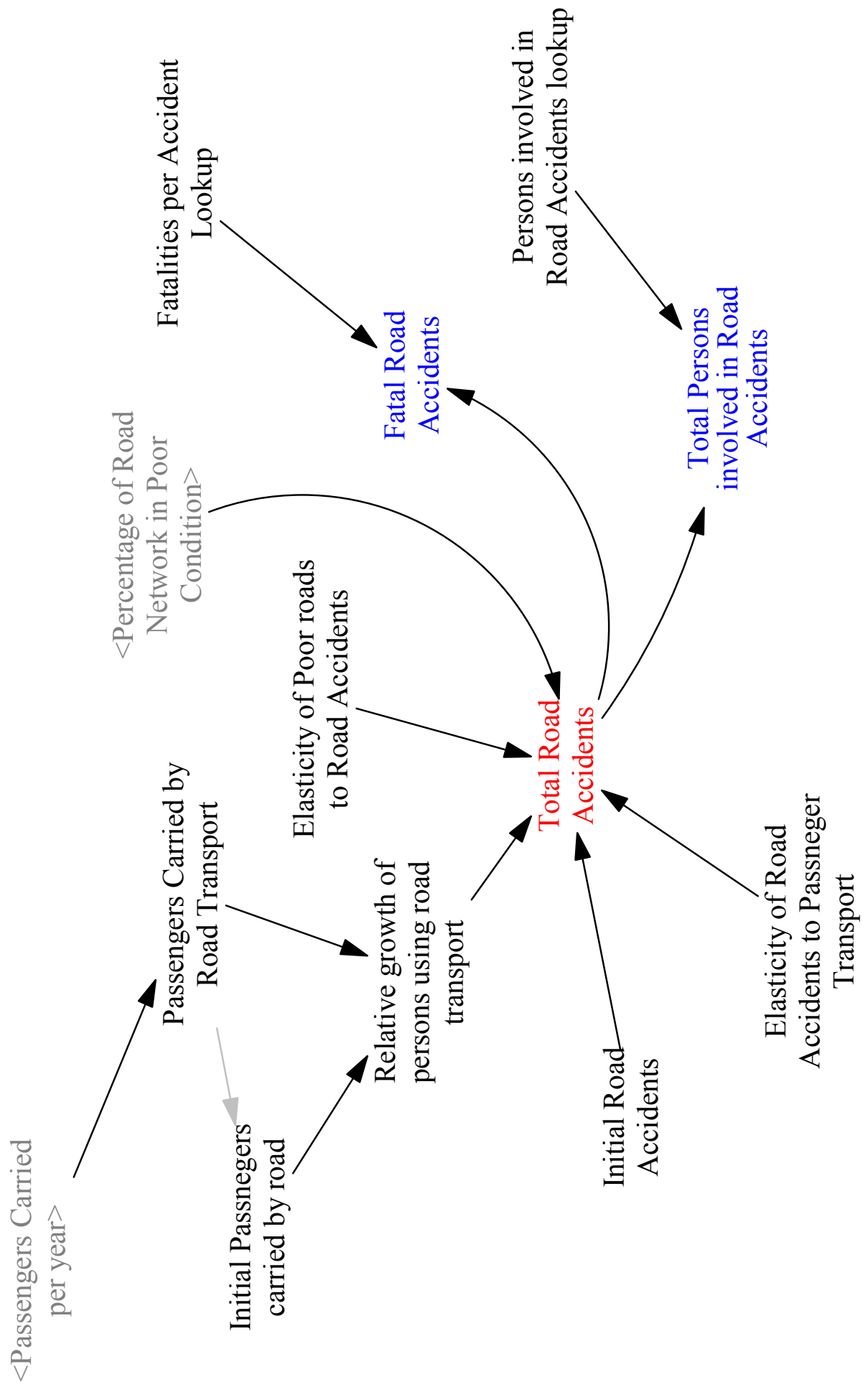

Figure B.12: Total Road Accidents for the Western Cape sub-module 
APPENDIX B. STOCK AND FLOW DESCRIPTIONS OF SUB-MODELS 144 


\section{B.12 Western Cape Population sub-module}

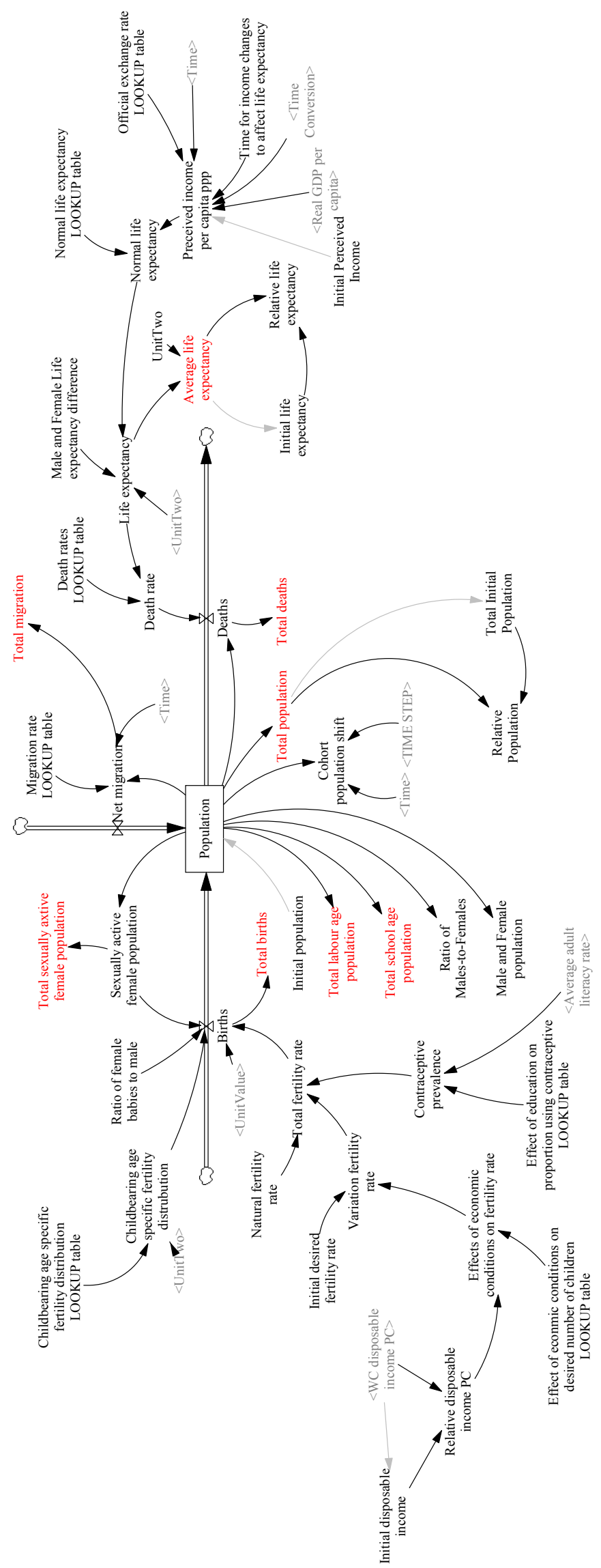

Figure B.13: Western Cape Population sub-module 
APPENDIX B. STOCK AND FLOW DESCRIPTIONS OF SUB-MODELS 146 


\section{B.13 GDP sub-module for the Western Cape}

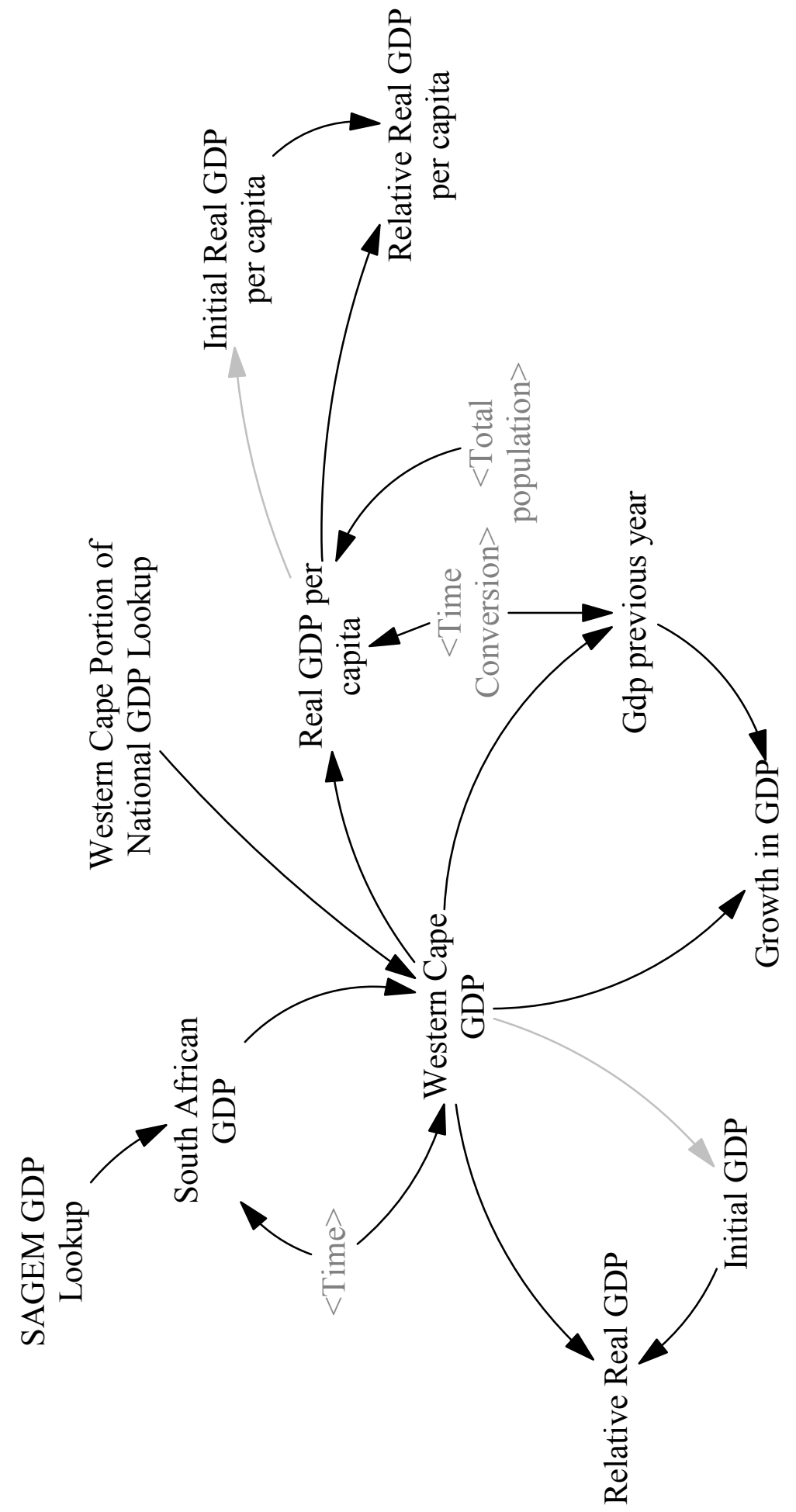

Figure B.14: GDP sub-module for the Western Cape 
APPENDIX B. STOCK AND FLOW DESCRIPTIONS OF SUB-MODELS 148 


\section{B.14 Green Economy Transport Investment sub-module}

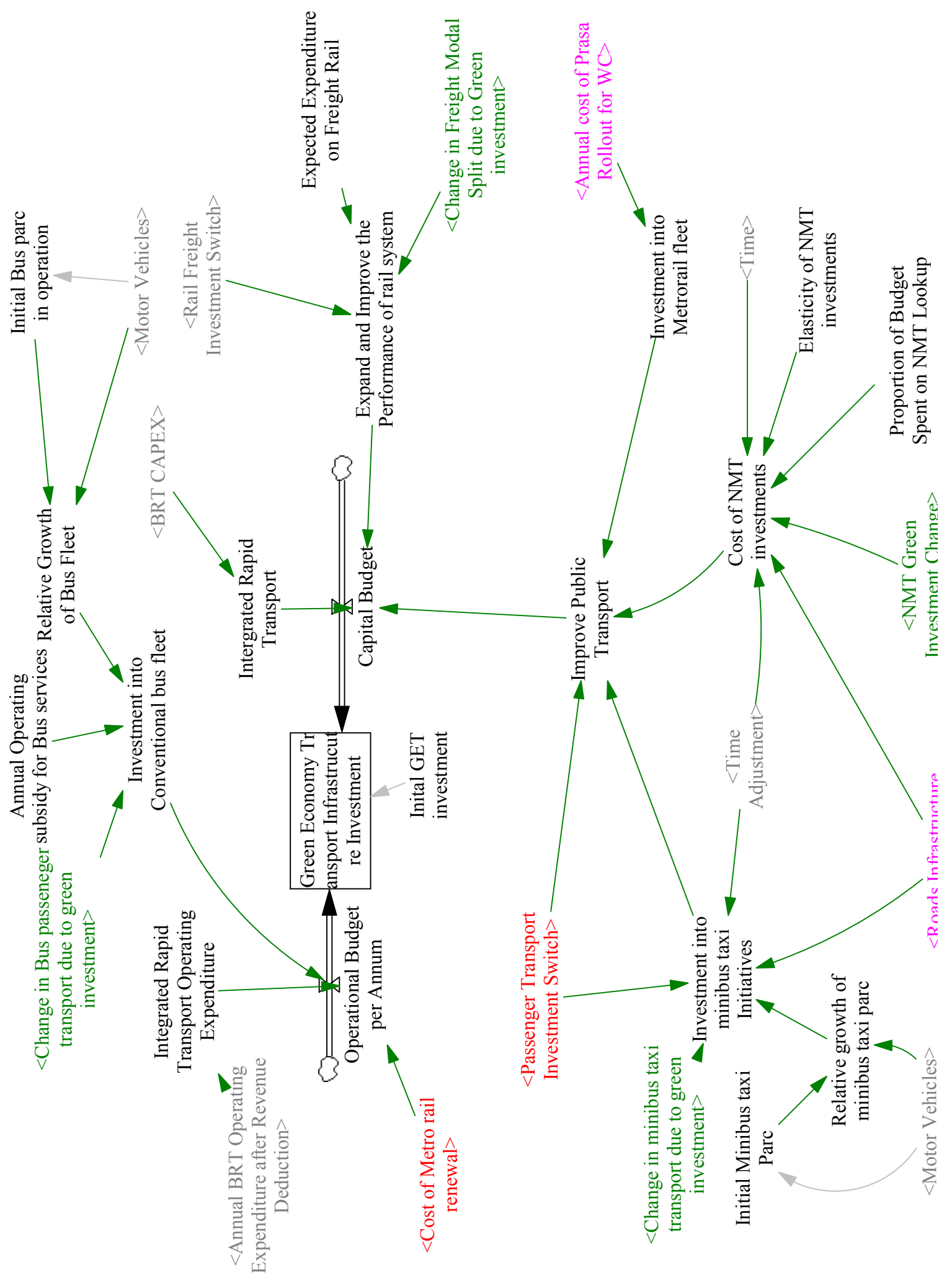

Figure B.15: Green Economy Transport Investment sub-module 


\section{Appendix C \\ SDM-Documentaion of model structure}


Documentation of WC_Infrastructure_FINAL_3

View the 590 variables sorted by type, module, group, variable name, module/group/name, Level Structure, or in a view summary.

Model Assessment Results

Model Information

Total Number of Variables

Total Number of State Variables (Level+Smooth+Delay Variables)

Total Number of Stocks (Stocks in Level+Smooth+Delay Variables)

Total Number of Macros

Function Sensitivity Parameters

Variables with Source Information

Data Lookup Tables

Time Unit

\begin{tabular}{|r|r} 
Year & Yea \\
\hline
\end{tabular}

\begin{tabular}{r|r}
2001 \\
\hline
\end{tabular}

Final Time

Reported Time Interva

Time Step

Model Is Fully Formulated

Modeler-Defined Groups

VPM File Available

\begin{tabular}{|l|c|}
\multicolumn{1}{c|}{ Warnings } & Number \\
Undocumented Equations & 502 \\
\hline Equations with Embedded Data & 48 \\
\hline Equations With Unit Errors or Warnings & Unavailable \\
\hline Variables Not in Any View & 0 \\
\hline Incompletely Defined Subscripted Variables & 2 \\
\hline Nonmonotonic Lookup Functions & 21 \\
\hline Cascading (Chained) Lookup Functions & 0 \\
\hline Equations with IF...THEN...ELSE & 18 \\
\hline Equations with MIN or MAX & 8 \\
\hline
\end{tabular}

Equations with MIN or MAX

Potential Omissions

Number

Unused Variables

Supplementary Variables

Supplementary Variables Being Used

Complex Variable Formulations (Richardson's Rule $=3$ )

Complex Stock Formulations

Types: VAl : : Level $(24 / 68)$

Constant (176)

\begin{tabular}{|l|l}
\hline 龠 SM : Smooth $(3 / 3)$ * & DE : Delay $(6 / 20)$ *
\end{tabular}

居F : Flow (44) 㨢A : Auxiliary (287)

Ä: : Initial (16)

" $"$ " : Game (0)

哭-T : Lookup $(48 / 89)$ t十

* (state variables / total stocks)

† Total stocks do not include fixed delay variables.

†† (lookup variables / lookup tables).

\begin{tabular}{|c|c|c|c|c|c|}
\hline Groups: & \begin{tabular}{|l|} 
Control (4) \\
Simulation Control Parameters
\end{tabular} & $\begin{array}{l}\text { WC Infrastructure FINAL } 3 \\
\text { (586) } \\
\text { (Default) }\end{array}$ & & & \\
\hline Modules: & Default (590) & & & & \\
\hline \multirow{3}{*}{ Views: } & 1. Population (64) & 2. GDP (16) & 3. Education (64) & 4. Healthcare (46) & 5. Live Vehicles (66) \\
\hline & 6. Road Infrastructure (48) & 7. PassengerTransport (155) & $\begin{array}{l}\text { 8. Rail Infrastructure network } \\
142)\end{array}$ & 9. Frieght Transport (68) & 10. Fuel demand (15) \\
\hline & 11. Emissions (21) & $\begin{array}{l}\text { 12. Green economy } \\
\text { investment (Transport) (48) }\end{array}$ & $\underline{\text { Causal Loop (0) }}$ & & \\
\hline
\end{tabular}

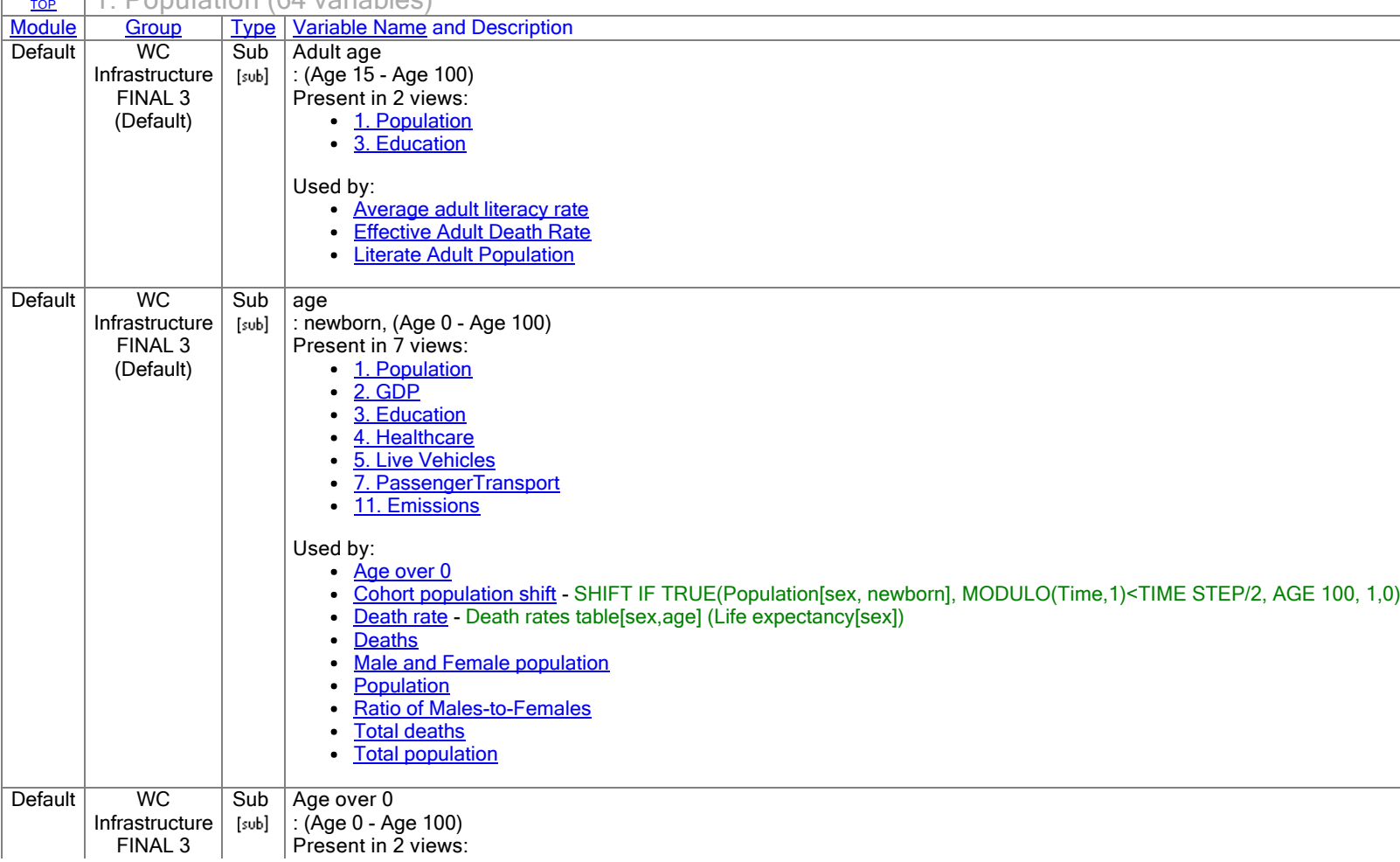




\section{Appendix D}

\section{Model Results}

\section{D.1 Western Cape Road Infrastructure Network Module}

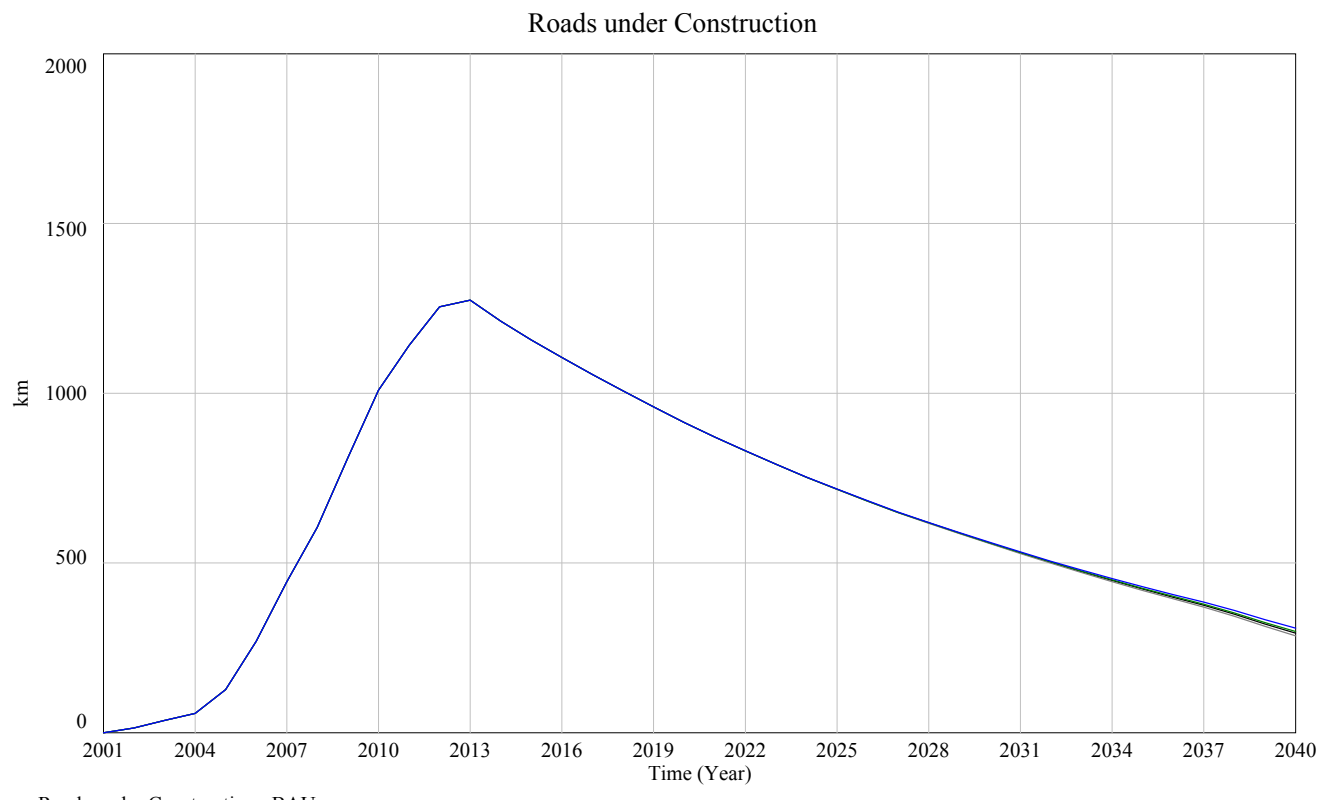

Roads under Construction : BAU

Roads under Construction : GE_RailFreight

Roads under Construction : GE_Pass\&Freight

Roads under Construction : GE_PassTrans

Figure D.1: Western Cape Roads Under Construction 


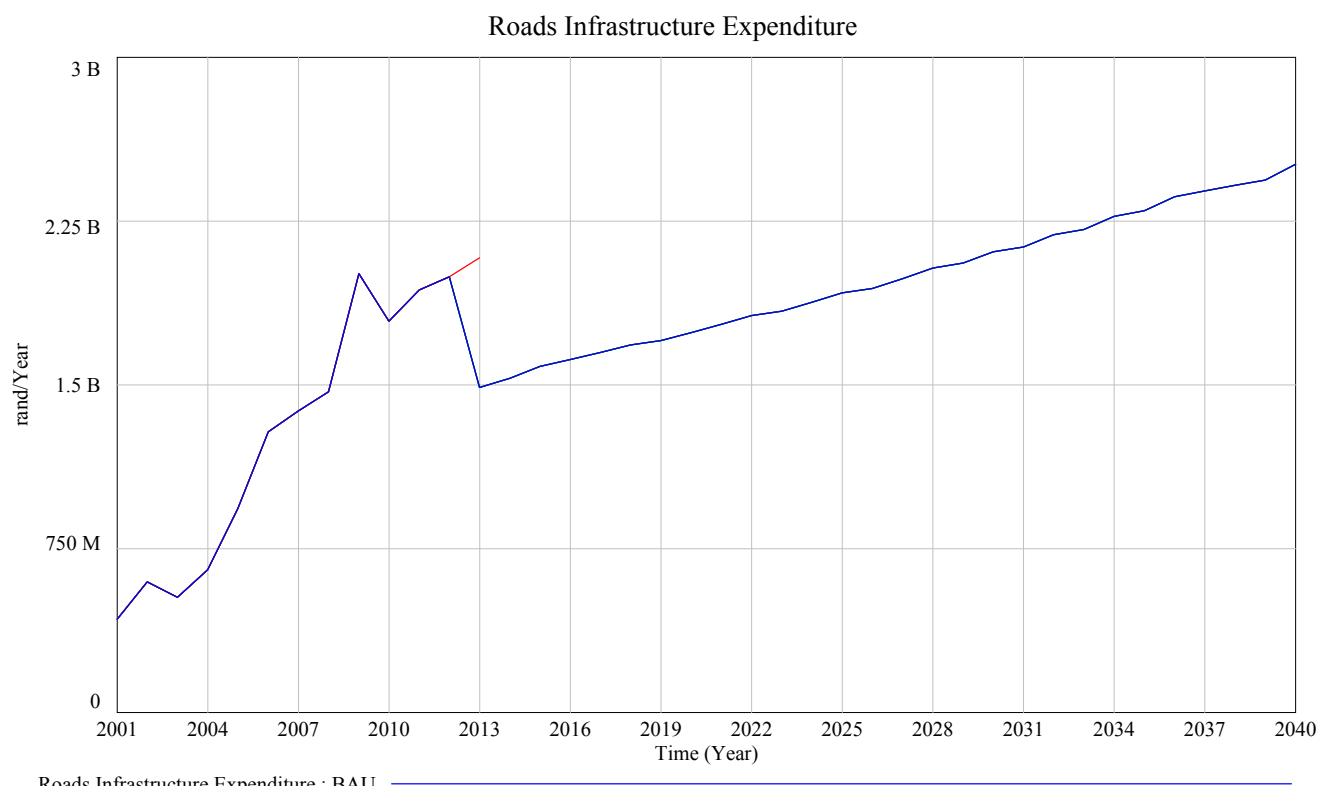

Roads Infrastructure Expenditure : BAU

Roads Infrastructure Expenditure : Dat

Roads Infrastructure Expenditure : GE_RailFreight

Roads Infrastructure Expenditure : GE_Pass\&Freight

Roads Infrastructure Expenditure : GE PassTrans

Figure D.2: Western Cape Road Infrastructure Expenditure

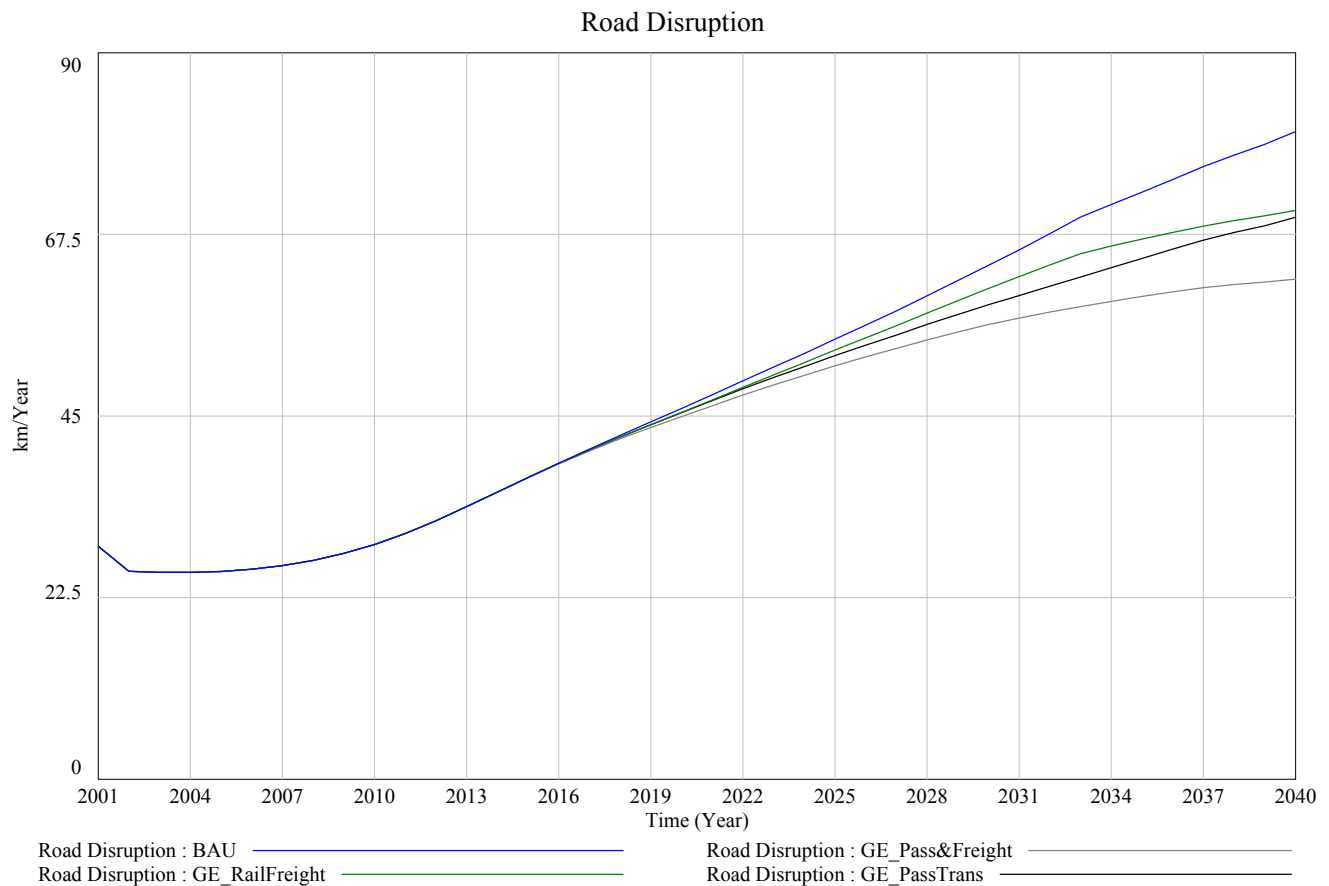

Figure D.3: Western Cape Road Disruption 


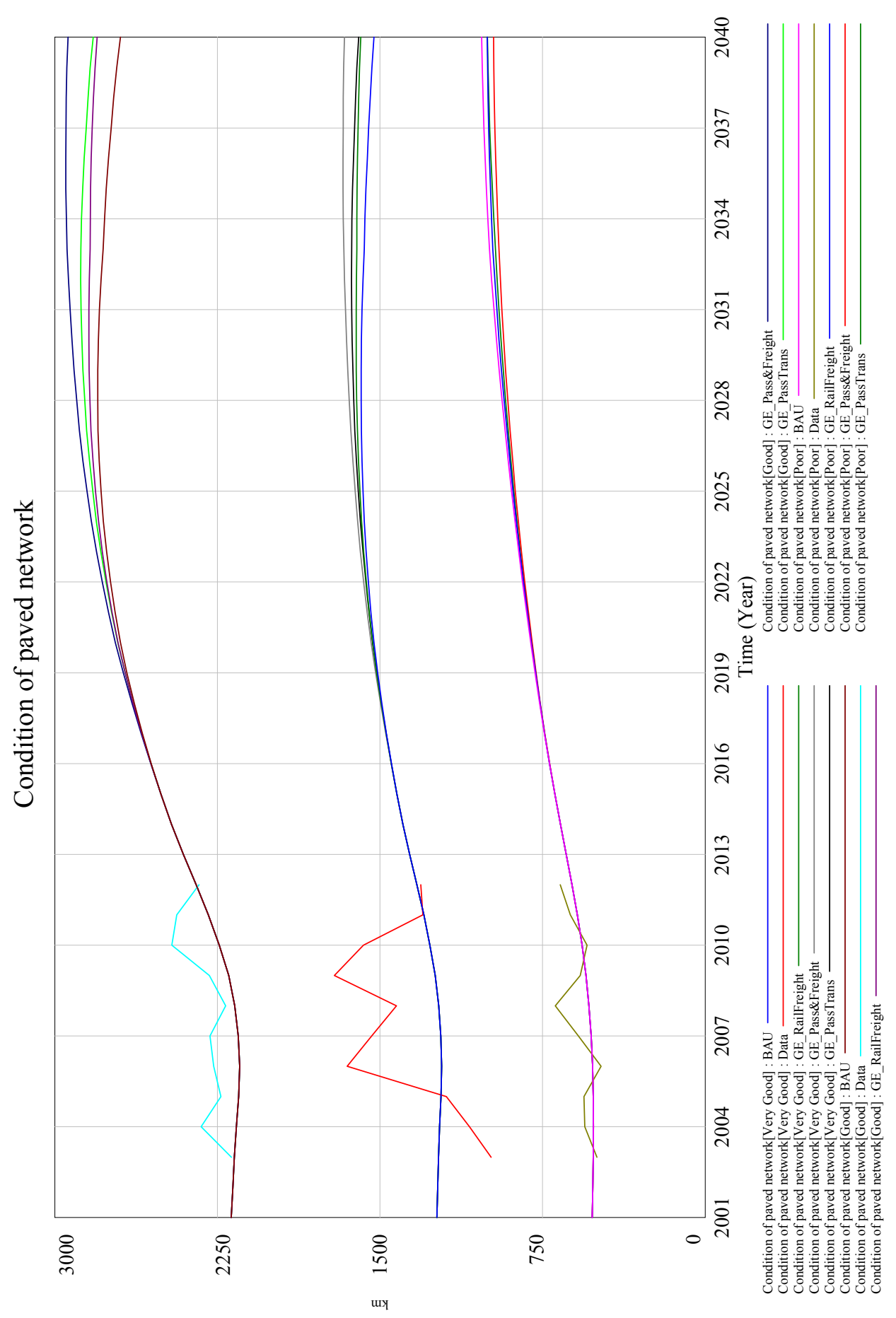

Figure D.4: Western Cape pavement network conditions 


\section{D.2 Live Vehicle Population sub-module}

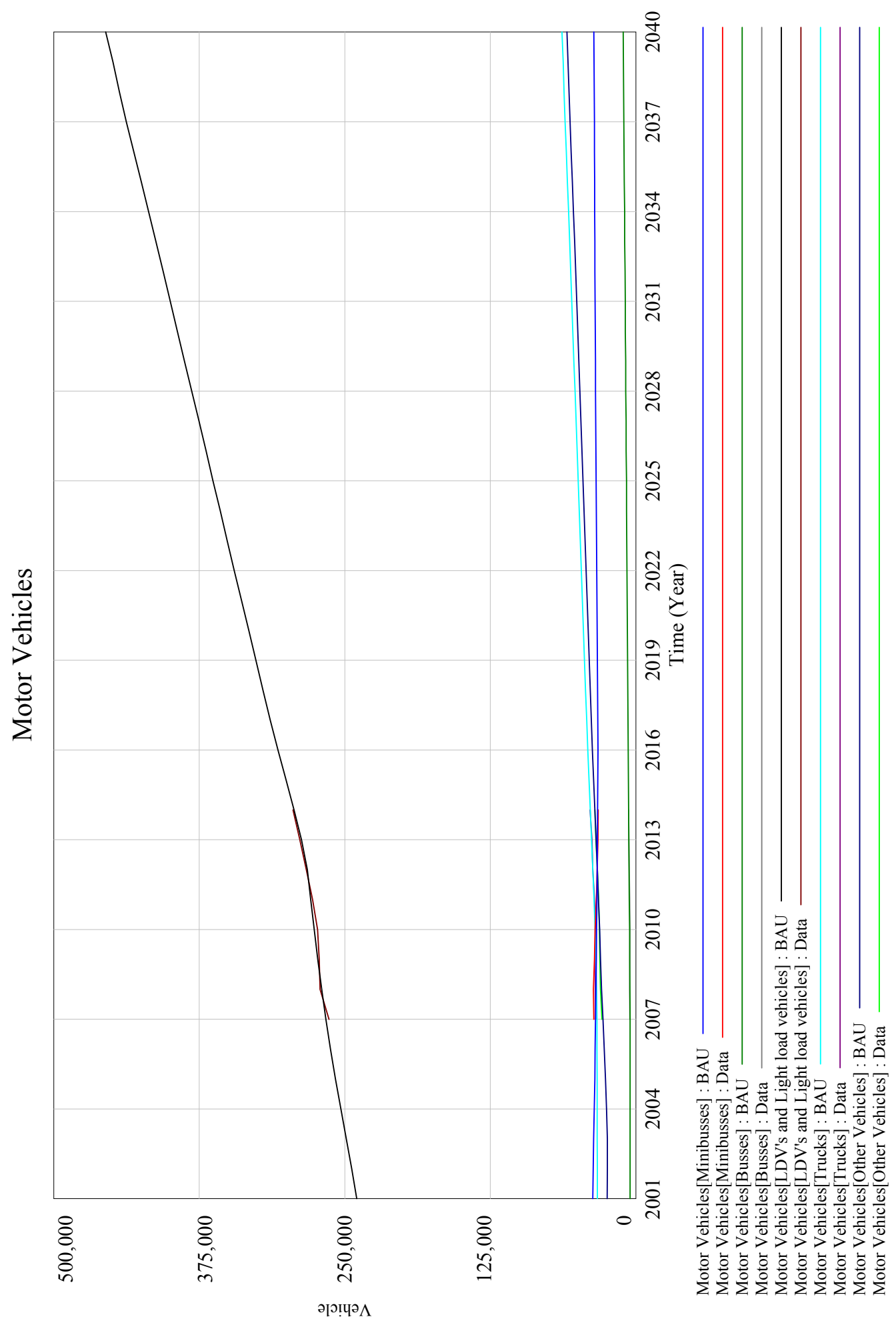

Figure D.5: Live Vehicle population per subscript group excluding motor cars 


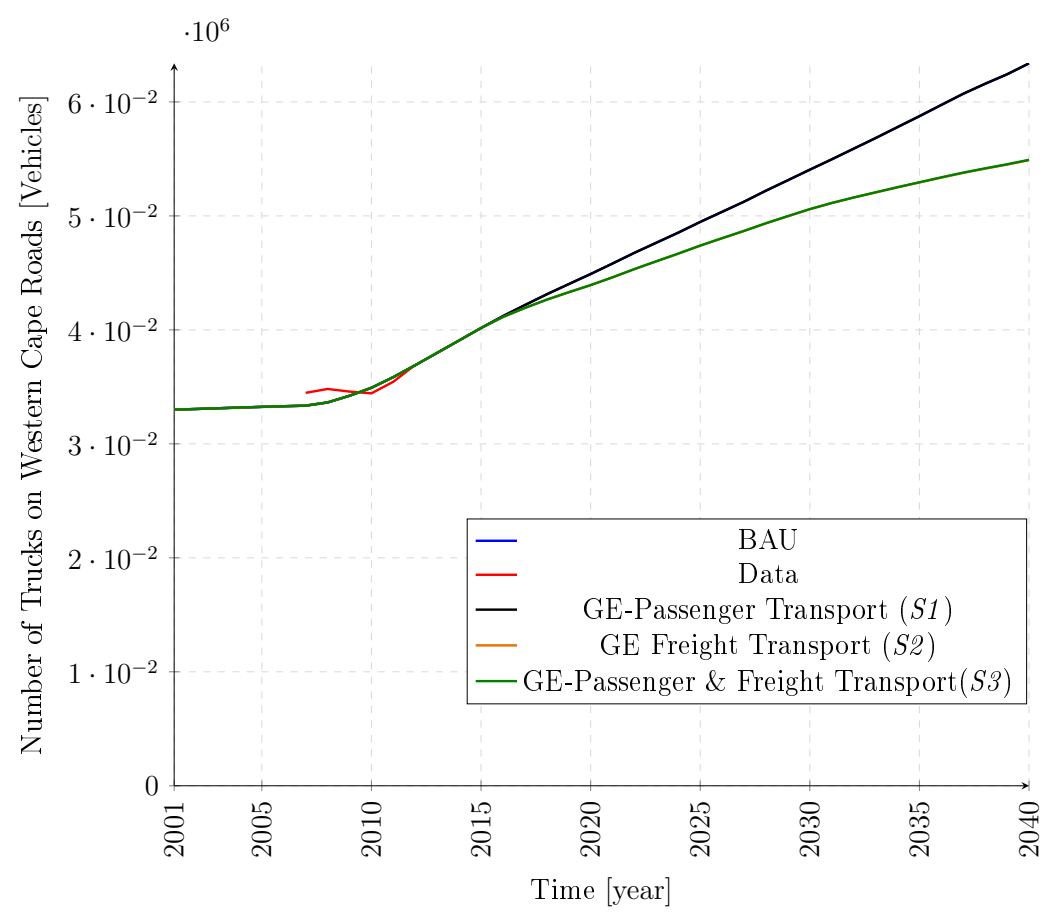

Figure D.6: Total Trucks on Western Cape Roads 


\section{D.3 Cape Metrorail Network and System sub-module}

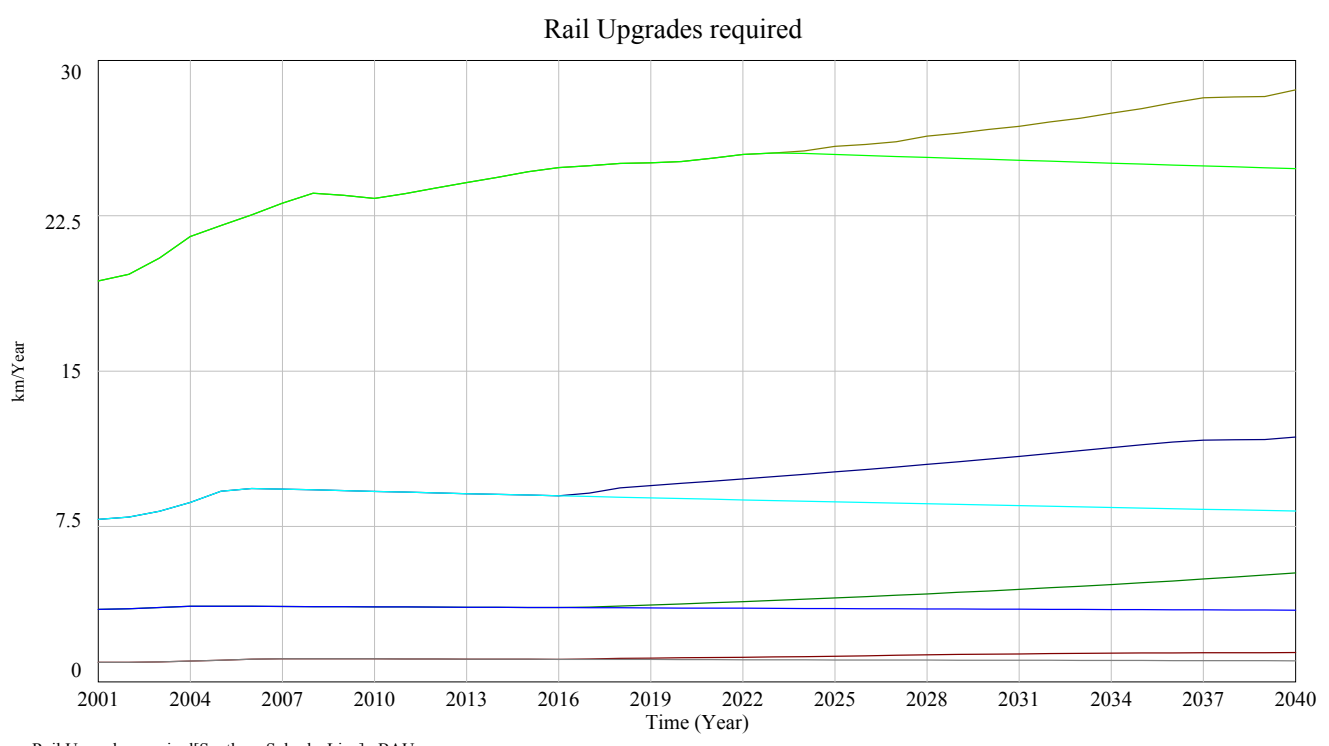

Rail Upgrades required[Southern Suburbs Line] : BAU
Rail Upgrades required[Southern Suburbs Line] : GE PassTrans

Rail Upgrades required Southern Suburbs Line : :GE_PassTrans

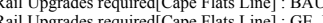

Rail Upgrades required[Central Line] : BAU :

Rail Upgrades required[Central Line] : GE PassTrans

Rail Upgrades required[Northern Line] : GE PassTran

Figure D.7: Cape Metrorail upgrades and maintenance requirements 


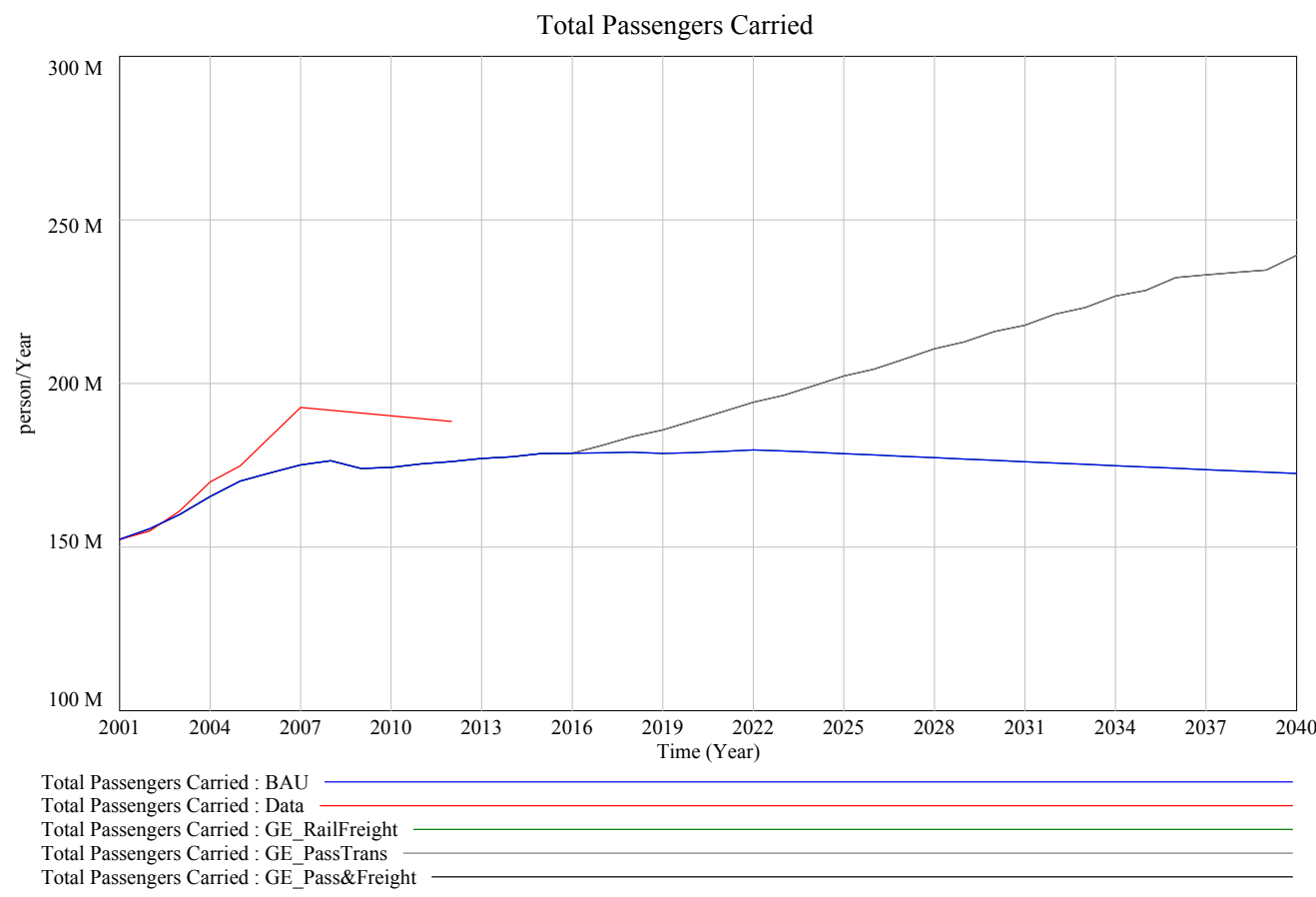

Figure D.8: Cape Metrorail total passengers carried annually

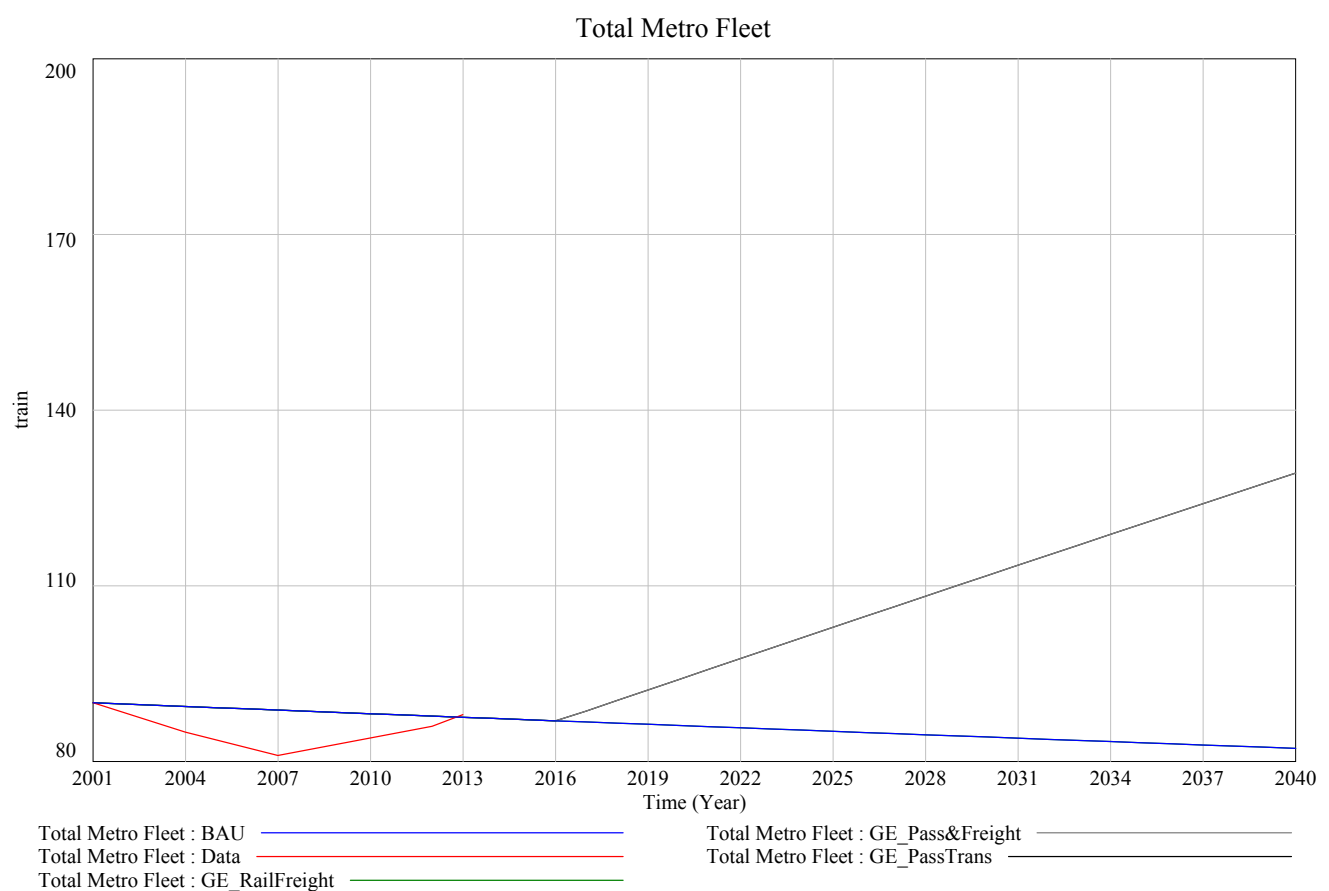

Figure D.9: Cape Metrorail total fleet stock 


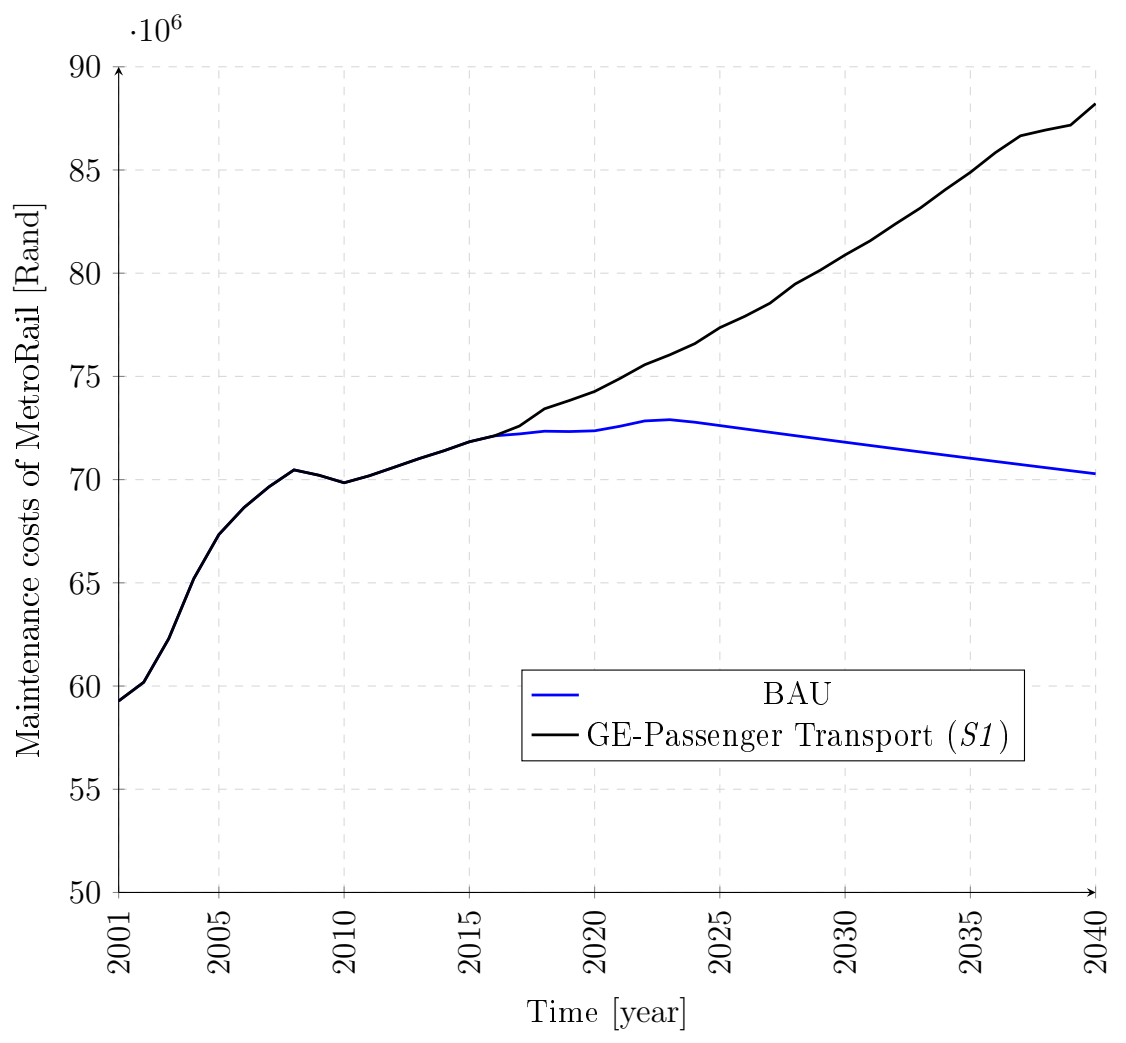

Figure D.10: Cape Metrorail maintenance and renewal costs 


\section{D.4 Western Cape Rail Freight Transport Network sub-module}

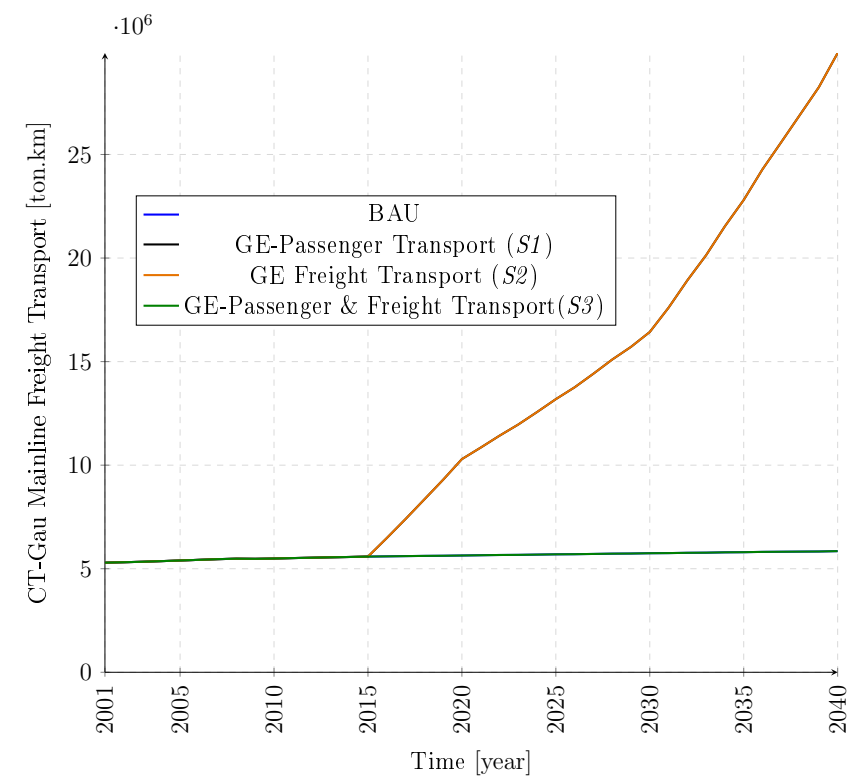

Figure D.11: Cape Town-Gauteng mainline rail Freight Transport

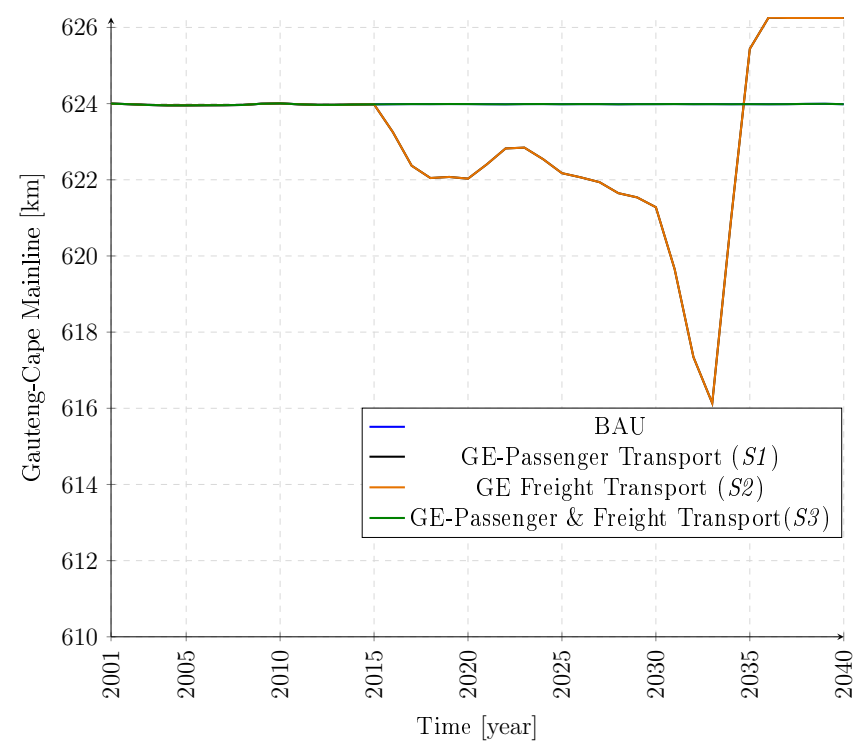

Figure D.12: Cape Town-Gauteng mainline rail network 


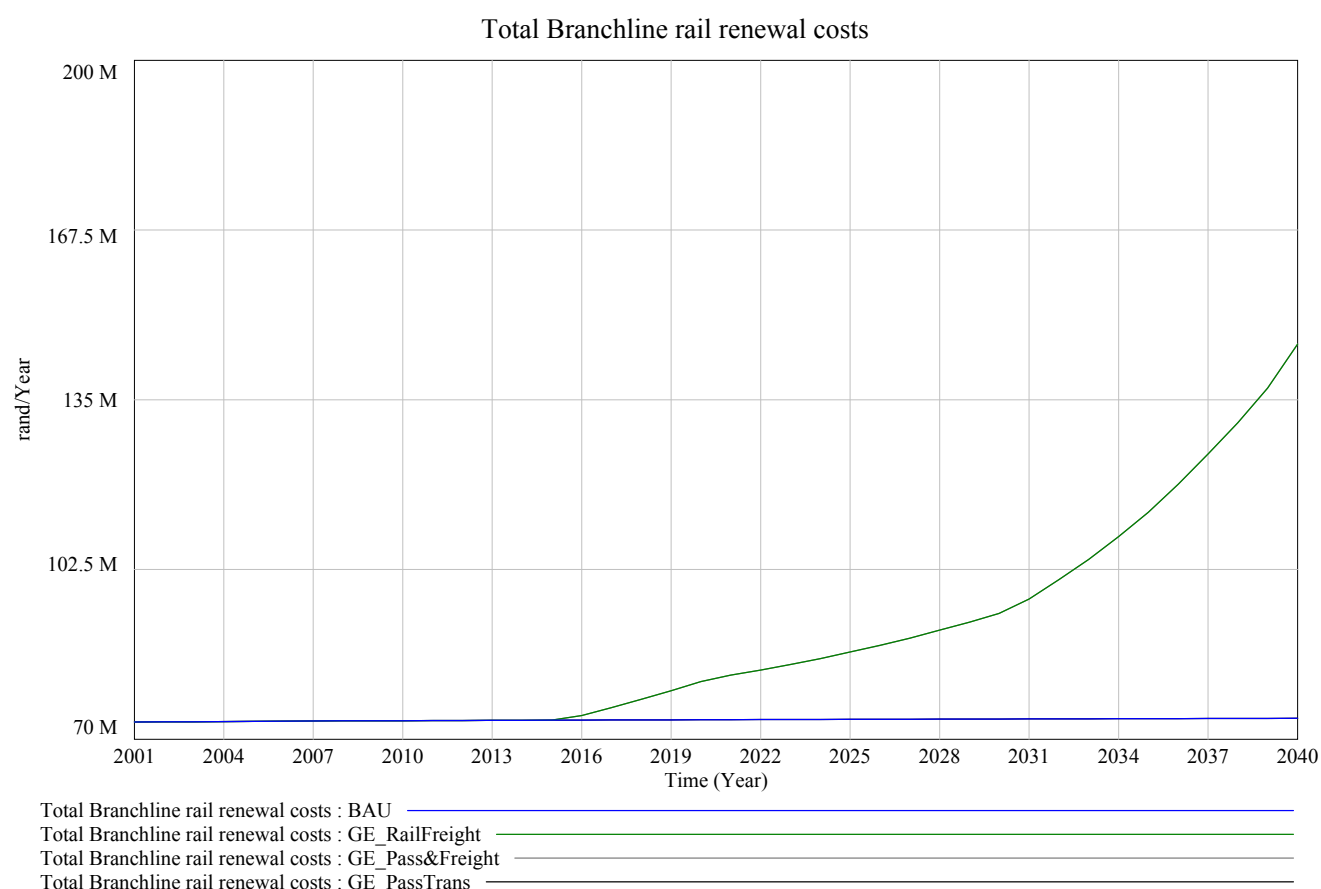

Figure D.13: Western Cape branch-line rail maintenance and renewal costs

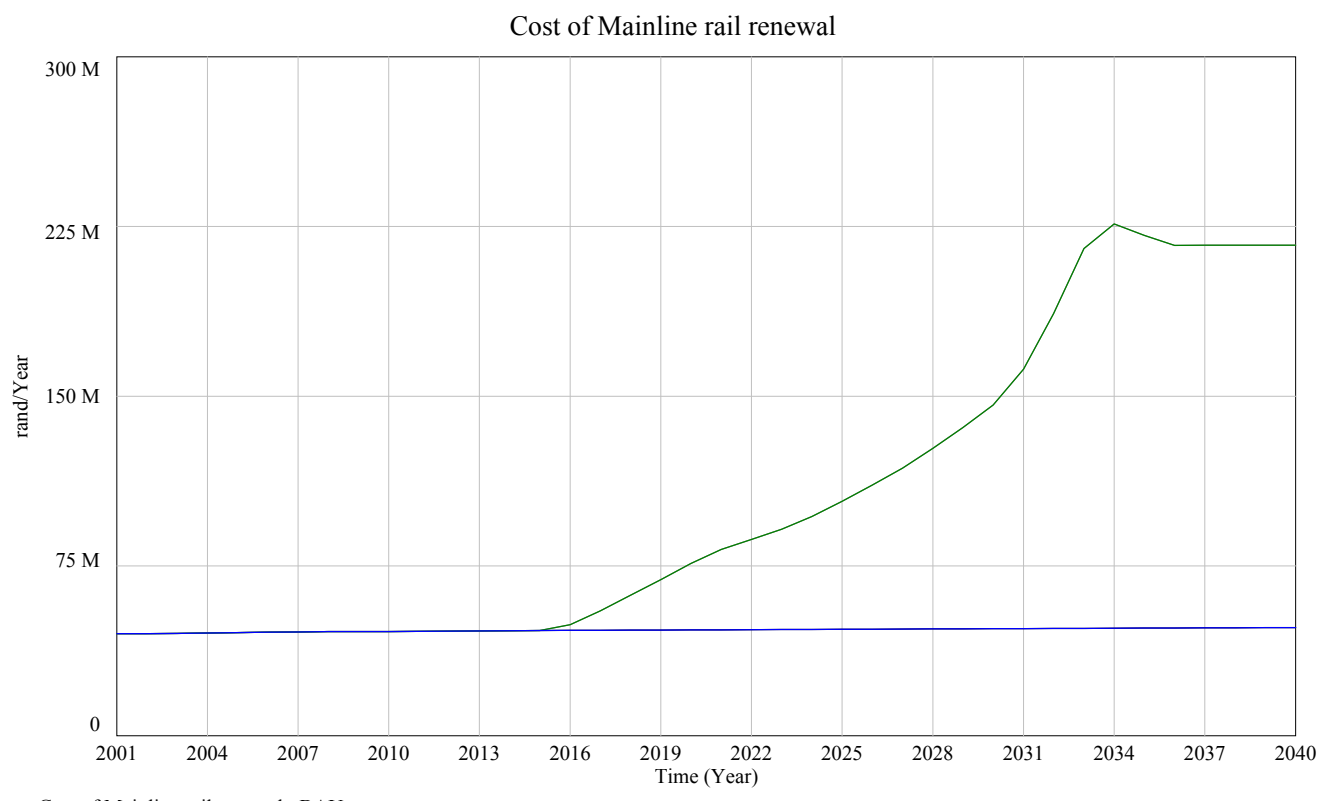

Cost of Mainline rail renewal : BAU

Cost of Mainline rail renewal : GE_RailFreight

Cost of Mainline rail renewal : GE_Pass\&Freight

Cost of Mainline rail renewal : GE PassTrans

Figure D.14: Western Cape main-line rail maintenance and renewal costs 


\section{D.5 Western Cape Freight Transport demand sub-module}

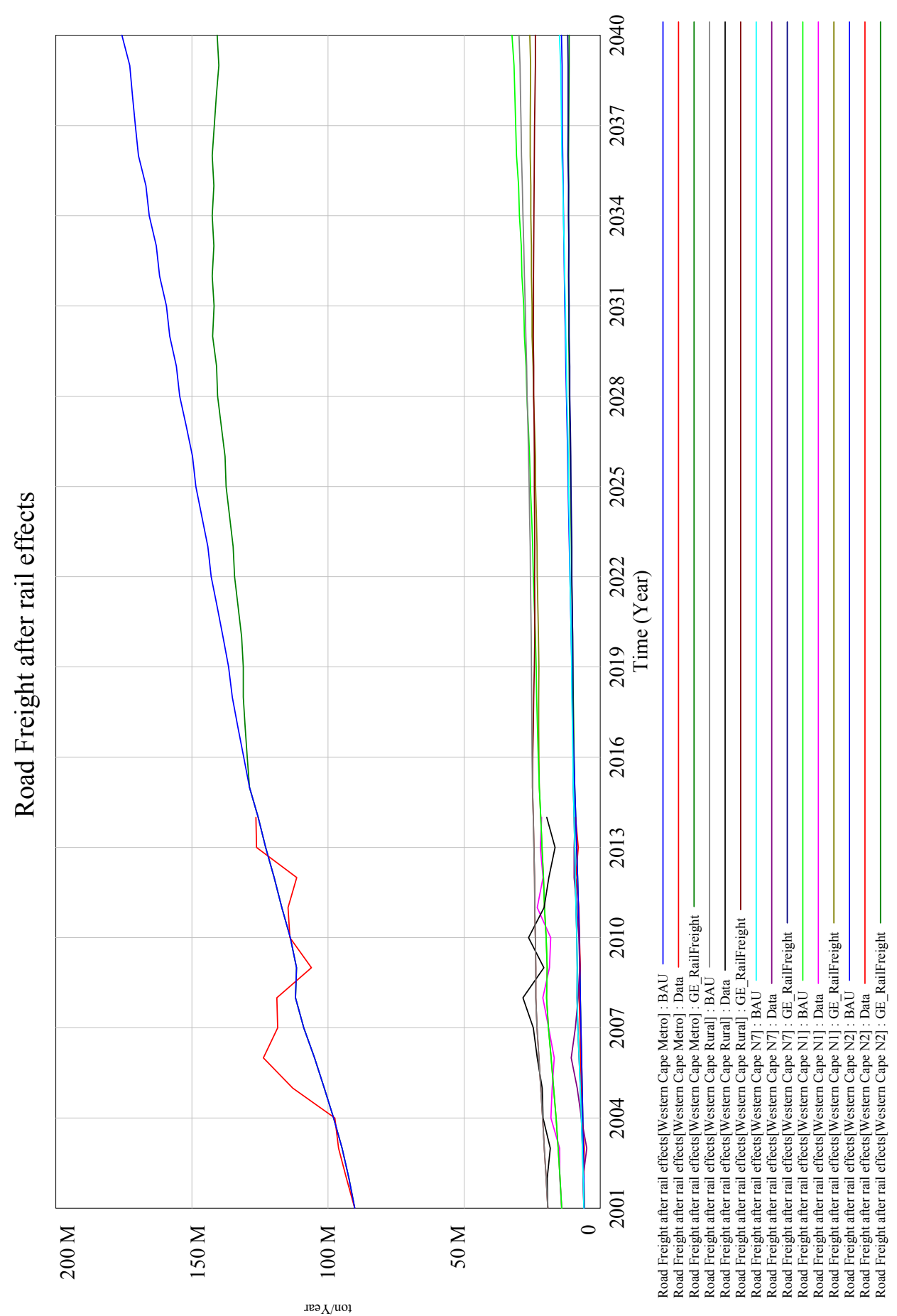

Figure D.15: Western Cape Road Freight Transport along specified corridors 


\section{D.6 Bus Rapid Transit sub-module}

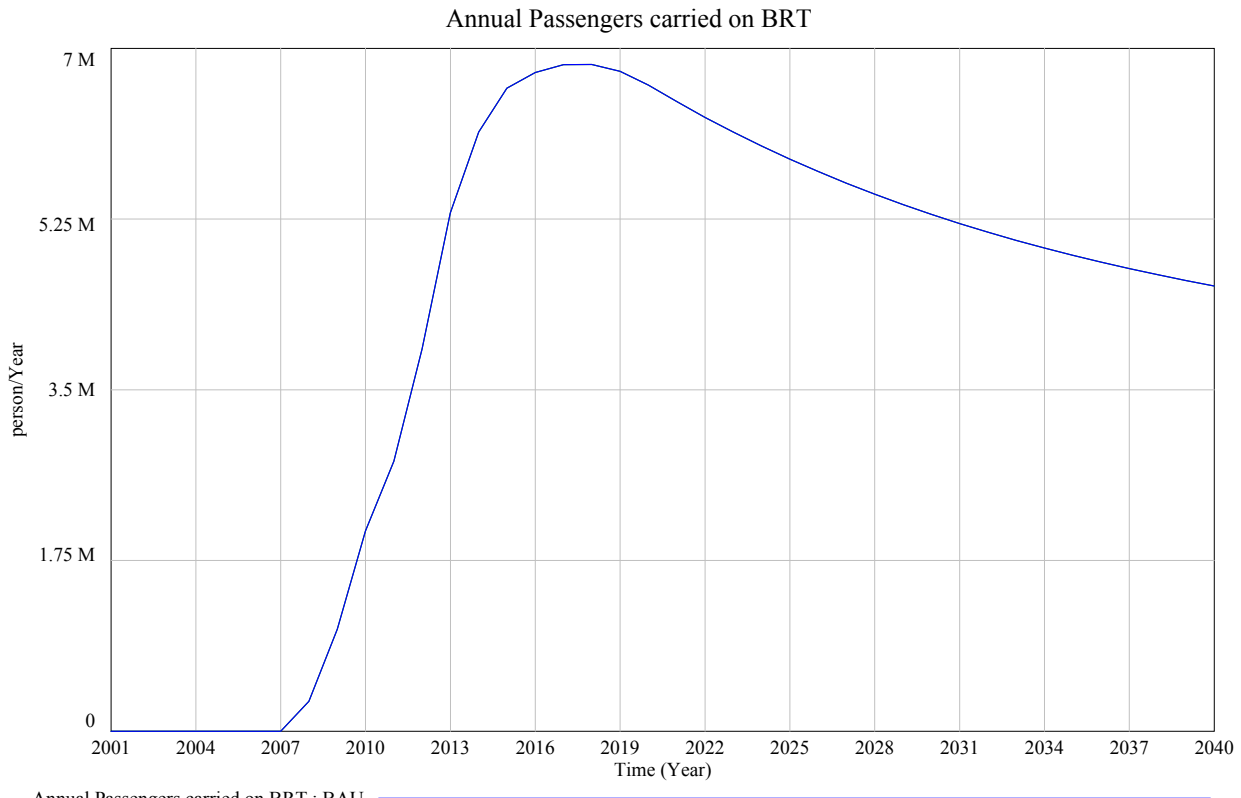

Annual Passengers carried on BRT : BAU RailFreight
Annual Passengers carried on BRT : GE_Raif

Figure D.16: Cape Town BRT annual passengers carried

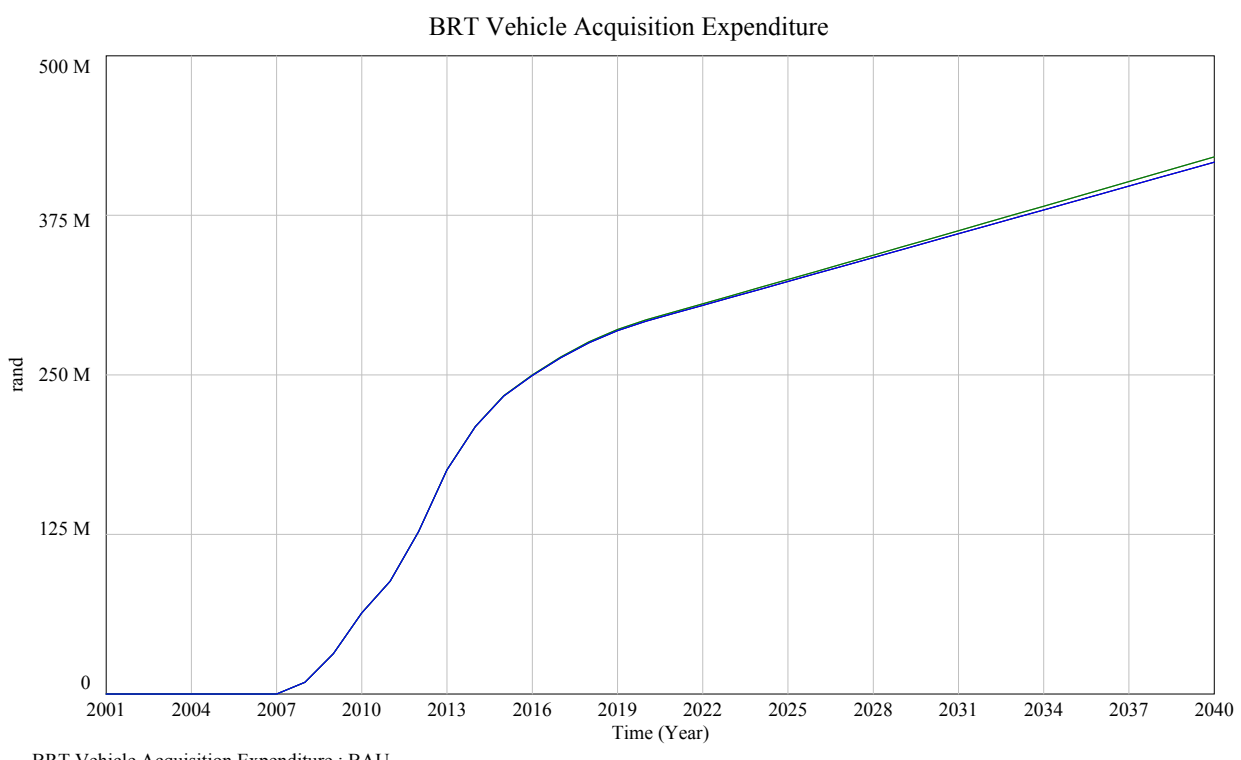

BRT Vehicle Acquisition Expenditure : BAU

BRT Vehicle Acquisition Expenditure : GE_Pass\&Freight

BRT Vehicle Acquisition Expenditure : GE_PassTrans

Figure D.17: Cape Town BRT vehicle acquisition expenditure 


\section{D.7 $\mathrm{CO}_{2}$ emissions from transport for the Western Cape sub-module}

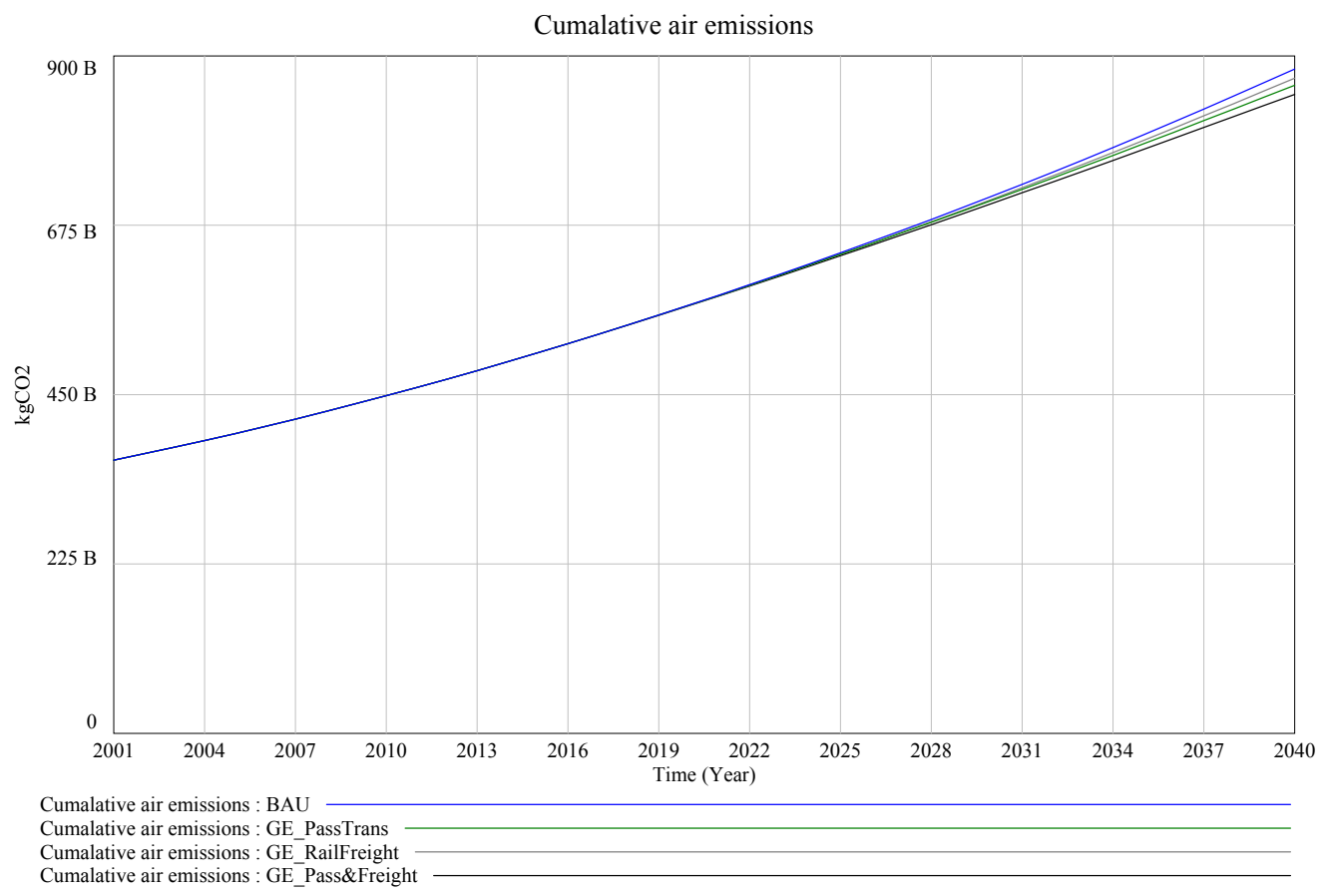

Figure D.18: Cumulative $\mathrm{CO}_{2}$ emissions from the transport sector 


\section{D.8 Passenger Transport in the Western Cape}

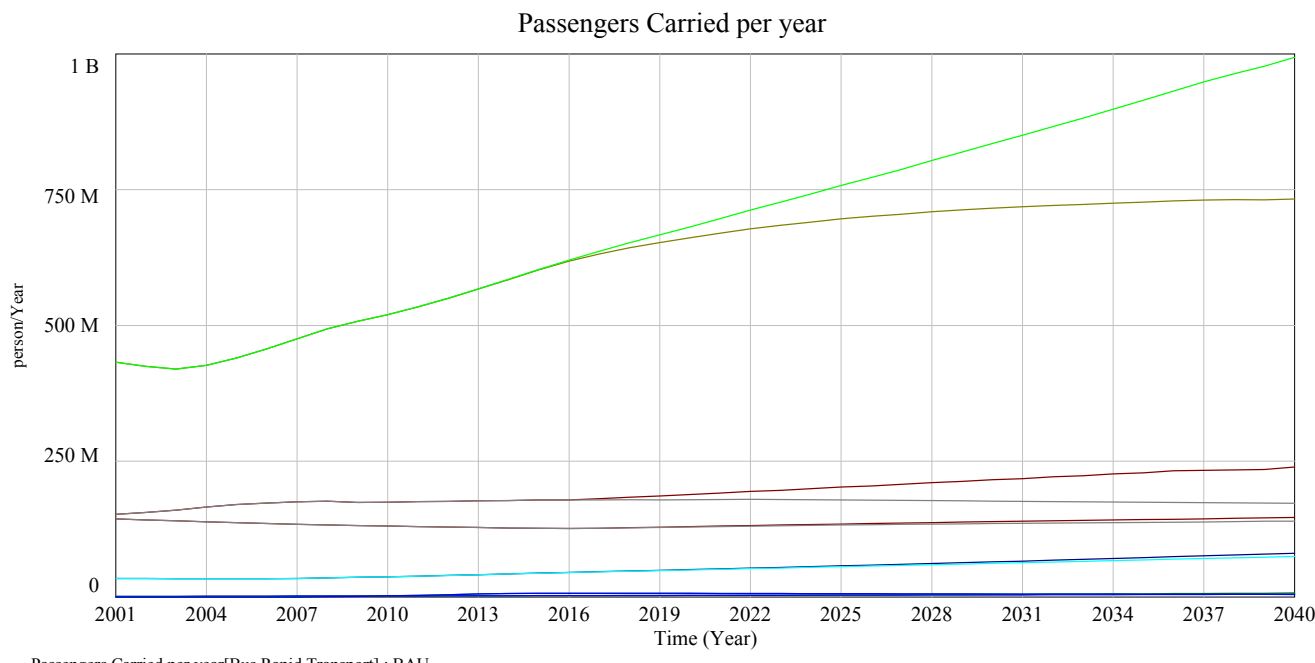

Passengers Carried per year[Bus Rapid Transport] : BAU

Passengers Carried per year[Bus Rapid Transport] : GE_PassTrans

Passengers Carried per year[Minibus taxi] : GE PassTran

Passengers Carried per year[Metered Bus] : BAU

Passengers Carried per year[Metered Bus] : GE PassTran

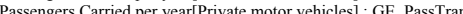

Passengers Carod per

Passengers Carried per year[Metered Taxi] : GE PassTrans

Passengers Carried per year[Rail] : BAU
Passengers Carried per year[Rail] : GE_PassTrans

Figure D.19: Western Cape passenger transport modes 


\section{D.9 Fuel Demand sub-module for the Western Cape}

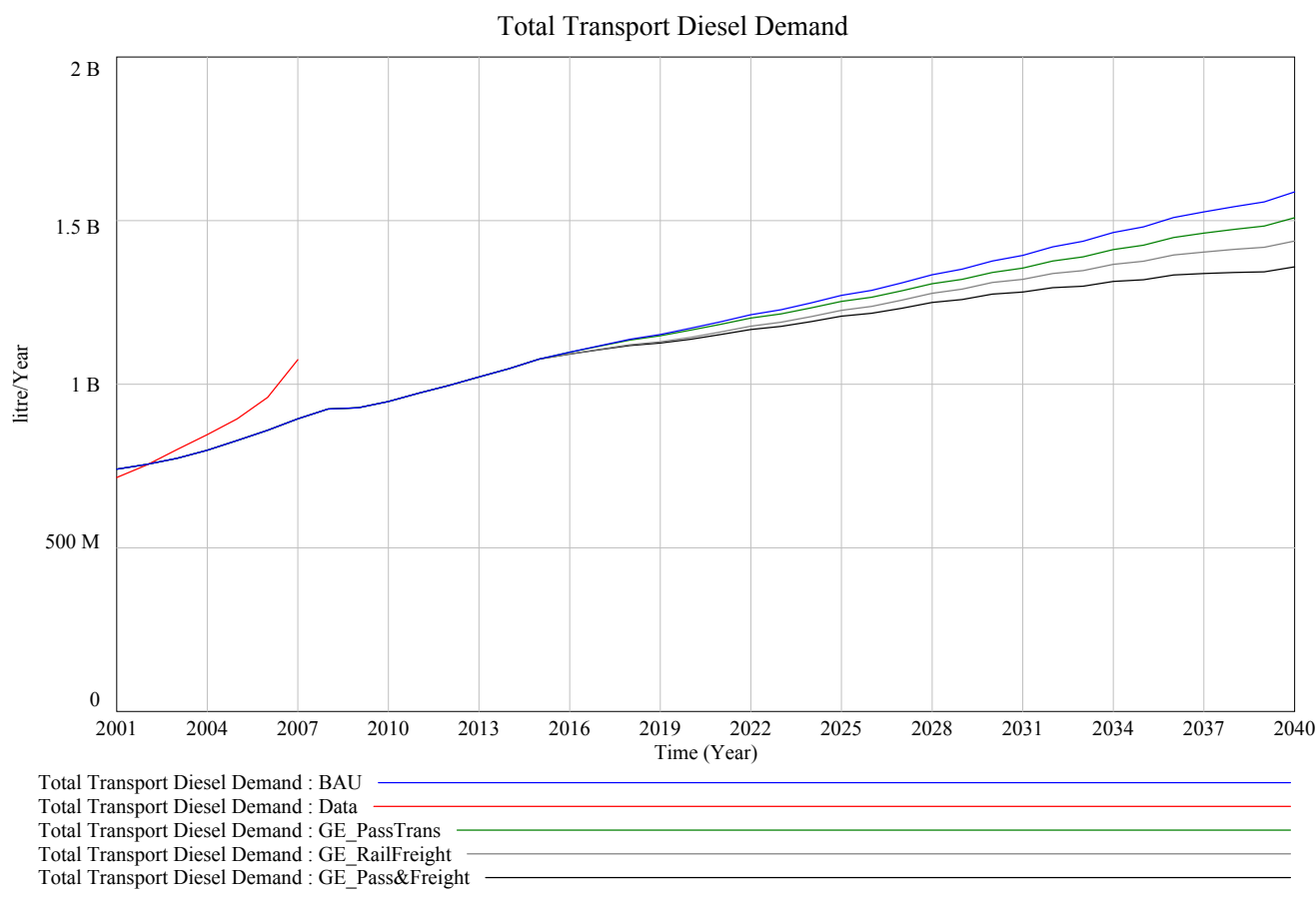

Figure D.20: Western Cape Diesel Demand 


\section{D.10 Total Road Accidents for the Western Cape sub-module}

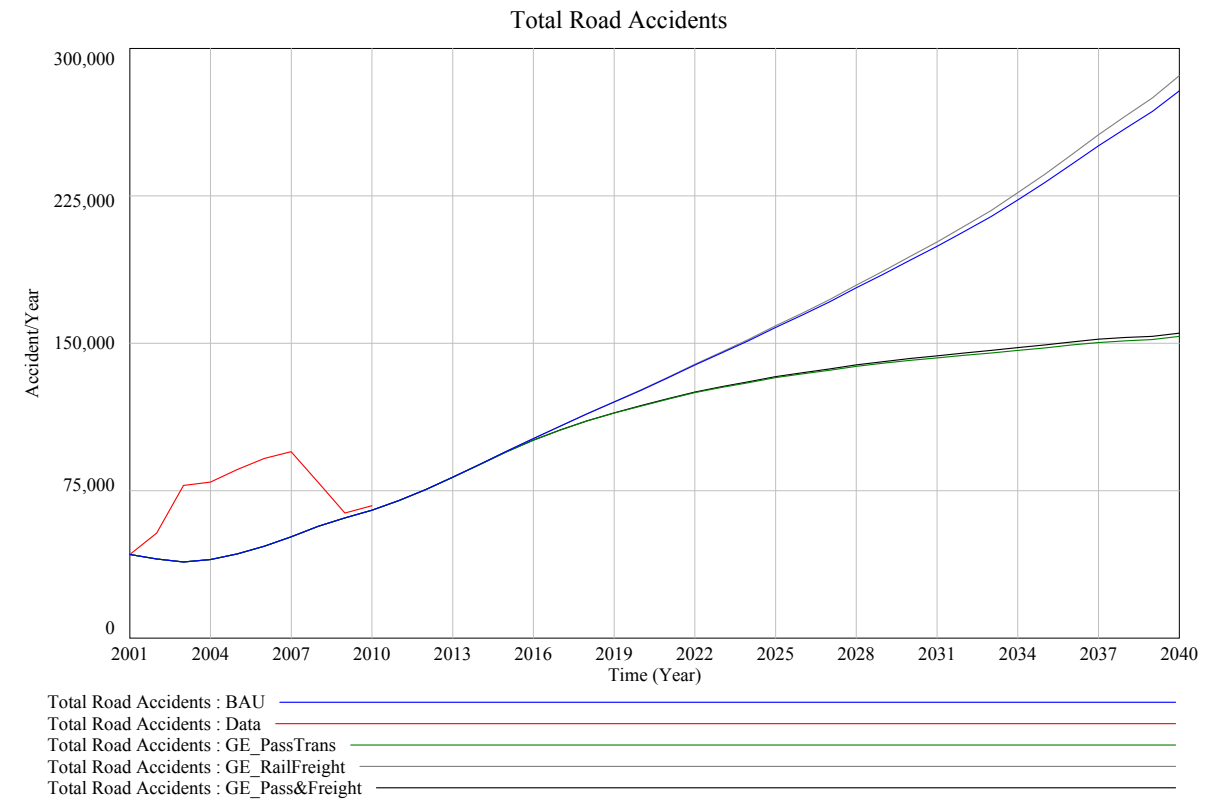

Figure D.21: Total Road Accidents occurring on Western Cape roads

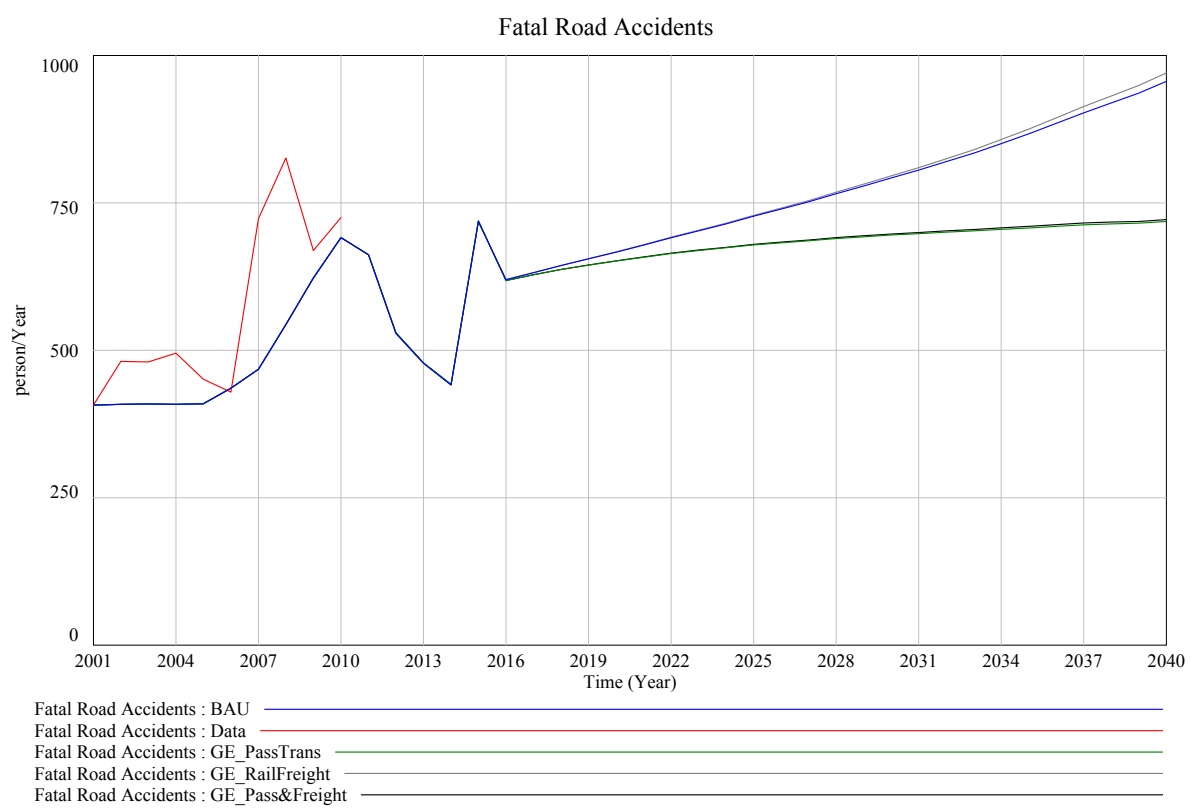

Figure D.22: Fatal Road accidents occurring on Western Cape roads 


\section{D.11 Western Cape Population sub-module}

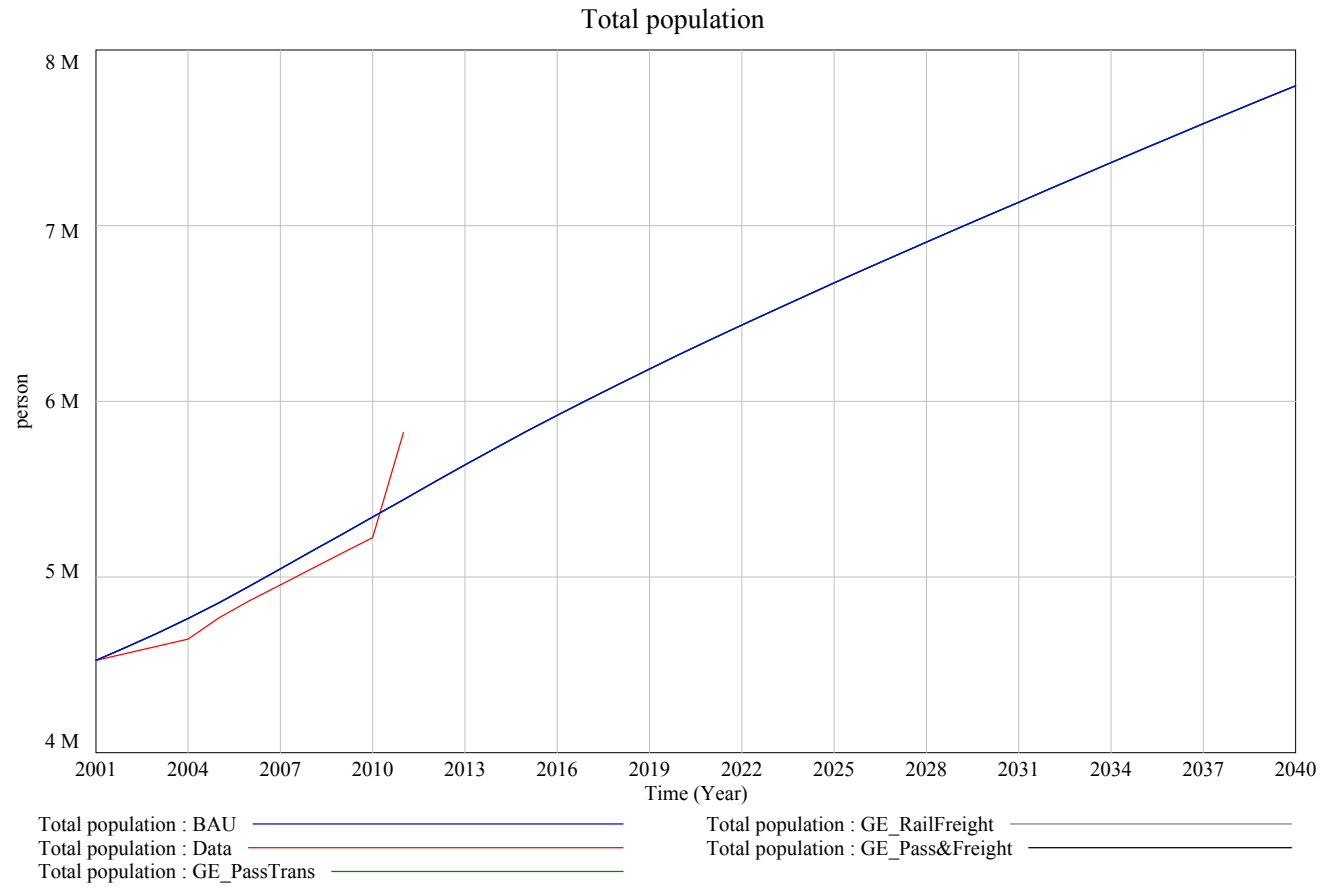

Figure D.23: Western Cape Population 


\section{D.12 GDP sub-module for the Western Cape}

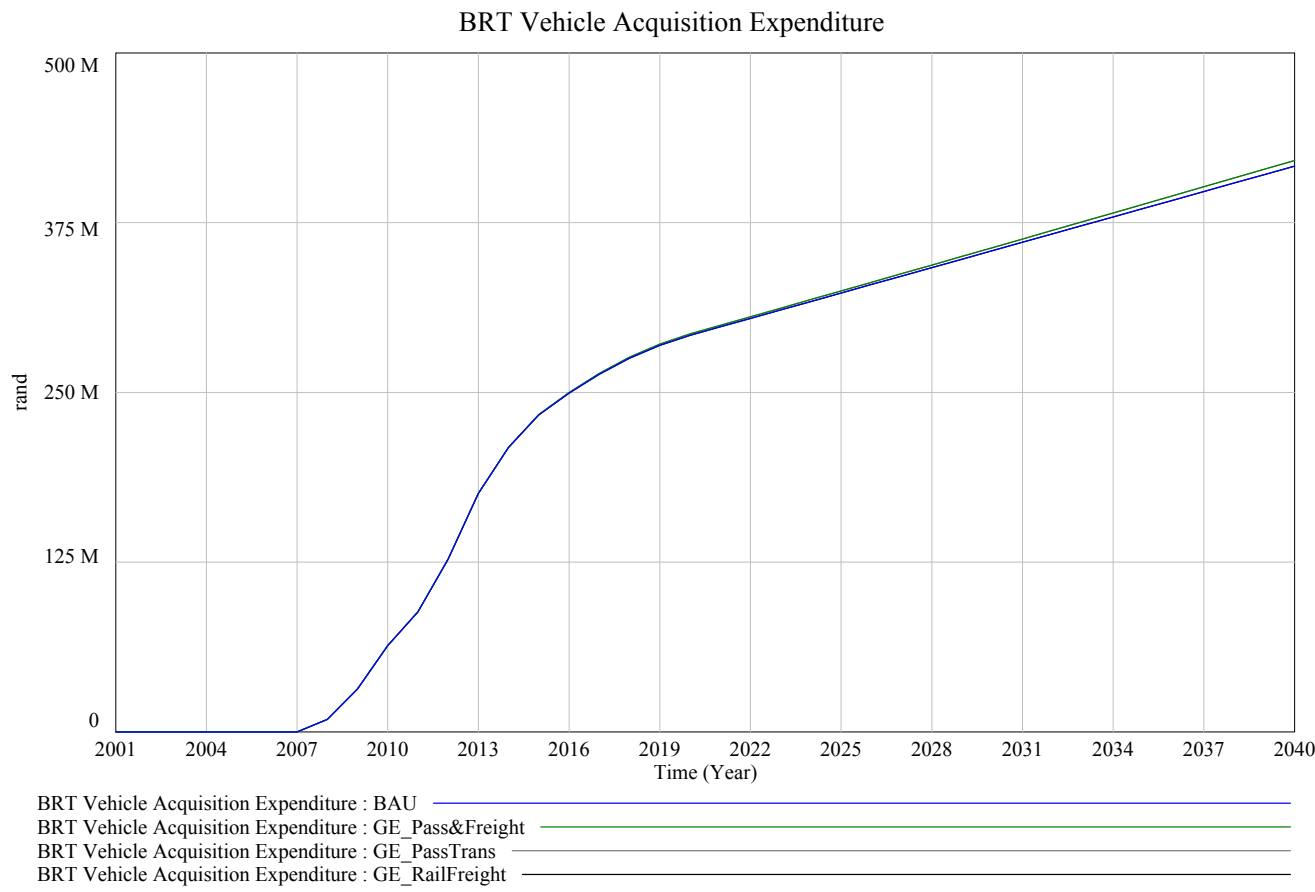

Figure D.24: Western Cape GDP 